
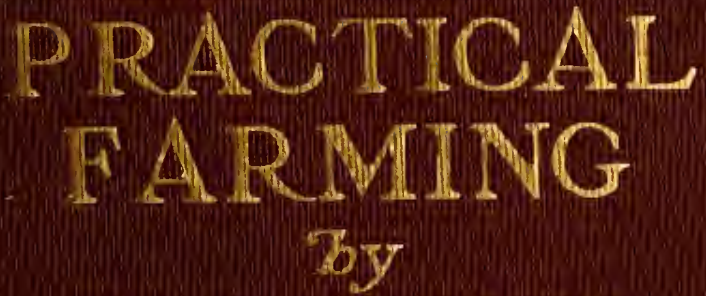

W. F. MASSEY 

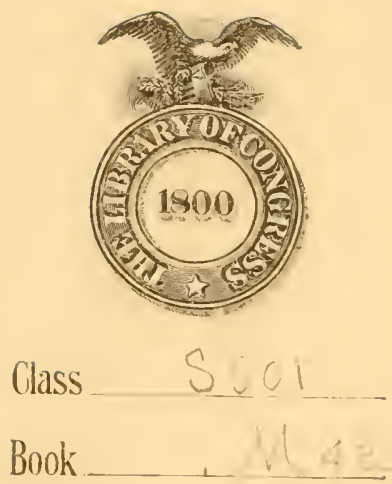

Copyrightit $\mathrm{N}^{\circ}$.

COPYRIGIIT DEPOSIT. 


PRACTICAL FARMING 



\section{PRACTICAL FARMING}

A PLAIN BOOK ON TREATMENT OF THE SOIL AND CROP PRODUCTION; ESPECIALLY DESIGNED FOR THE EVERYDAY USE OF FARMERS AND AGRICULTURAL STUDENTS

W. F. MASSEY

Author of "Crop Growing and Crop Feeding"

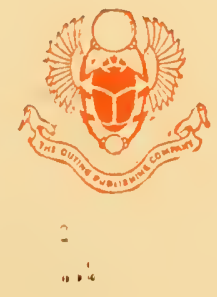

NEW YORK

THE OUTING PUBLISHING COMPANY MCMVII 


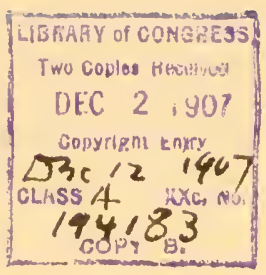

$$
\begin{aligned}
& S 501 \\
& . M 42
\end{aligned}
$$

Copyrighted, 190\%, by

THE OUTING PUBLISHING COMPANY

All rights reserved 


\section{PREFACE}

F late it appears to be the fashion with authors to call their Preface a "Foreword," but I am so old-fashioned that I prefer to call it by the old name, Preface.

You may ask, "Why a new. book on Agriculture?" Simply because in the numerous books for farmers that have appeared of late years I know of none that appeals directly to the man behind the plow in all sections of the country, and tries in the plain language of the farm to explain many of the things which the investigations of scientists have discovered in regard to the treatment of the soil and the production of crops.

To this effort to explain scientific matters in plain language I have drawn in addition from the experience of a long life spent in the practical work of cultivating the soil, and have endeavored to make this a farmers' book on farming, nothing more, nothing less.

Perhaps to keep up with the phraseology of the day, I should call it a treatise on Agronomy. But my oldfashioned notions come in again, and I call it "Practical Farming." Agronomy would sound more scientific, but I have not written the book for scientists, and therefore call it by a name that the plain tiller of the soil will understand.

If he likes it and finds that it is helpful I shall be satisfied. The day when all that pertains to farm life can be 
treated in one small volume is past, and 1 have endeavored to stick to my text and write a book on cropping solely. It has been prepared in the intervals of a very busy life, and I hope it will help the men for whom it is intended.

PHilaneldila, Pa.,

March $5,1907$. 


\section{CONTENTS}

CHAPTER

PREFACE .

I The SOIL.

II The Physical Character of Solls . . . 22

III The Relation of Solls to Moisture and Air. 41

IV The Anatomy and Physiology of Plants 59

$\mathrm{V}$ Plant Food in the Soll. . . . . 79

VI Manures and Commercial Fertilizers . 97

VII LIFE IN THE SOIL • • • • • • II9

VIII Tillage and its Purposes . . . 134

IX The Washing of Solls and Methods of PreventING ThIS LosS . . . . . . . 143

X Crop Rotation-its Purpose and Practice: 148

XI Crops and Cropping . . . . . . 167

XII The Indian Corn Crop . . . . . 172

XIII The Wheat Crop . . . . . 186

XIV The OAts Crop . . . . . . . 198

XV The Cotton Crop . . . . . . . 202

XVI The Товасco Crop . . . . . . 217

XVII The Irish Potato Crop . . . . . 235

XVIII The Hay CROP . . . . . . . 247

XIX How the Legumes Aid Us . . . 268

XX The Grasses . . . . . . . . 274

XXI Commercial Fertilizers for Various Crops . 295 XXIl Useful Tables for Constant Reference • 304 



\section{PRACTICAL FARMING}

\section{CHAPTER I}

THE SOIL

GRICULTURE, or farming, is an art that in-
cludes the character and formation of the soil as
well as its proper tillage to make it productive in the crops needed by mankind. When we look around us and see the great variety of conditions as to soils and climates, and the composition and origin of the cultivated soil, as well as the conformation of the surface and the great variety of plant growth which arises under these varied conditions, we realize that the art of farming is a very complex one.

Its complexity is such that we have to call in the aid of a number of sciences to assist us in understanding agricultural conditions. Geology tells us something of the origin, formation and conformation of soils; chemistry tells us of the elements that enter into their composition; botany teaches us the nature of the plants that make up our crops, and meteorology helps us to understand the conditions of weather and climate, and their influences in modifying land surfaces and in the promotion of plant growth. 
Modern agriculture is largely the child of chemistry, and its future development must always depend to a great extent on the investigations of the chemist. But closely allied to this science is the science that takes in the study of life, and helps us to understand the life of the low forms of plant life that make diseases on our crops, and teaches us how to combat these and the insect enemics that annoy us. The science, then, of biology becomes a very essential aid to the farmer.

Our work is mainly the study of the soil and its treatment in the production of crops.

The science of geology treats of the forThe Geological Origin of Soils mation and growth of the outer crust of the globe. It investigates the composition of the crust, the processes which have contributed to its growth through the long untold ages since the earth was a molten mass, and the elemental influences that have helped to bring the earth into its present form. This science takes into consideration the elevation and depression of the land, the formation of rocks of rarious sorts under and above waters, and the decay and wasting of the rocks that make the foundation of the soils that corer the outer surface.

Geologists have found that the crust of the earth has been formed in successive layers known as strata. It is evident that as these layers have been placed one above another by various causes, the uppermost layer must be the youngest, unless by some cataclysm of nature the rocks have been pressed together and thrust one under the other. This is always evident from the foldings and faults, so called. Where upheavals through rolcanic 
action have thrust rocks from below through the mass above, forming traps or dikes, the nature of the rock itself demonstrates its origin.

\section{Geological}

Formations

If we dig a well we come first to what we call soil. This is darkened in color by the decay of vegetation. Then we find a bed of clay, and below this sand. It is evident that the sand was there first, owing to its superior weight, and that the clay and soil were afterward deposited on top of it. Then, if we find another bed of clay under which is a bed of sand, we can easily determine that there were successive deposits elevating the land. In a similar way geologists have studied the growth of the layers or strata that make up the thousands of feet accumulated on the surface of the original earth crust. If the geologist bores into a bed of sandstone and below that finds a bed of coal, formed from the decay of vegetation, it is evident that this vegetation must have grown on the original surface, and that the sandstone was of later formation. When under the coal he finds a bed of clay loam with the roots of the old forest penetrating, he is strengthened in his belief as to the formation of the coal.

Again he finds a bed of limestone filled with the fossil remains of shellfish and coral-the plainest evidence that living creatures formed these shells and coral before the soil was formed and before trees grew from which the soil was formed, and that the limestone formed from their remains must be older than the coal formation above them. When under this limestone there is found a different rock that further on projects into the surface of the hills, he would argue that this rock, being under the 
limestone, is the oldest, though in the hills it comes to the surface. He would be convinced that in the valley there had been agents at work forming the later accumulation on top of this older rock.

When the earth was a molten mass, glowAgencies at Work in Soil Formation ing with intense heat, the waters that afterward formed the great deep were a dense vapor, lighted only by the glowing globe. Gradually, through long ages, the surface cooled and God said, "Let the waters be gathered together unto one place, and let the dry land appear"; and it was so. The cooling of the surface allowed the condensation of the vapors, and the waters naturally filled the depressions in the surface. Thus seas were formed. The dry land was the hard rock crust crystallized.

Then came the action of the various agencies to which we owe the formation of what we to-day call soil. This condensation opened up the surface of the earth to the light and action of the sun. We must understand that light, sunlight, is one of the phenomena of motion; and that one of its rays travels through space at the rate of I 86,000 miles in a second of time, a rate utterly inconceivable to us. The energy of the sunshine awakes in nature energy of a different sort, resulting in what we call heat. The rays of the sun excite motion in the molecules of the soil and water, causing them to be pushed apart; and by the radiation of heat set the atmosphere in motion, causing wind. Much of the heat formed goes back to the air through this radiation, especially during the nights. In the long nights of the arctic regions more goes back than in the tropics, and differences of climate are largely 
due to this. Even in the temperate regions, when the nights grow much longer than the days, we find that we approach the arctic conditions; and when the days grow longer and the nights are shorter, we approach the conditions of the tropics, where days and nights are even throughout the year.

It is thus clear that the heat produced by

The Agency of Sunshine the action of the sunshine on land and water becomes the great agency in producing plant life on the earth. We must realize that the rays of the sun move through a vast space of intense cold, and that heat is a transformation of the motion made here on earth, and its intensity depends largely on the conformation of the earth itself. Down about the sea level, where the pressure, and consequently the density, of the atmosphere is greatest, the radiation is slower and heat is retained longer, while on the mountain top the lesser atmospheric density permits of a more rapid radiation; so that on the more lofty mountains we have arctic conditions of eternal snow and ice. On the surface of the sea the rays of the sun set up a rapid motion in the molecules of the water, making them warmer until they are changed into a condition of vapor and fly off to form clouds, which distribute the rain on the earth.

We can now see how the disintegrating effect of the heat produced through motion from the sun affected the rocky surface of the earth, and the coming of the clouds from the ocean washed to the lower levels the loosened particles and started the first formation of soil.

Then came the work of the atmosphere itself. At the sea surface the pressure is about fifteen pounds to 
each square inch, and each acre of land bears a pressure of 46,200 tons. The decreased pressure of the air causes a decided change of feeling as we ascend The Work of the Atmosphere from the sea level to the summit of a high mountain, though we hardly realize the pressure at the sea level, and when it is removed do not directly think of this change as causing our new and strange sensation. Pure air is composed of oxygen and nitrogen, two gases mixed together but not chemically combined. The nitrogen exists as a diluent to enable us to breathe the oxygen, for it comprises a much larger percentage than the oxygen-79.05I per cent. of nitrogen to 20.949 per cent. of oxygen. Exactly how deep is the ocean of air, at the bottom of which we live, cannot be known; but it is usually estimated at about forty-five miles. While the air is composed primarily of these two elements, oxygen and nitrogen, it also carries with it other matter useful to the farmer. A small percentage of carbon dioxide, commonly known as carbonic acid, which in large quantities is deadly to animal life, is essential to vegetation. Plants get their carbon from this combination, as will be explained later. The air also contains some nitrogen in combination, in the form of ammonia, as well as the free nitrogen gas and a minute portion of oxidized nitrogen or nitric acid. Still another constituent is that extremely active part of oxygen known as ozone, which is esteemed of great value to animal life. From this air and the matters it contains plants get more than 97 per cent. of their material for building the tissues, and less than 3 per cent. from the soil. But for the air and its constant pressure there would be no heat retained on the 
earth, as we have shown by the case of the high mountain where the decreased pressure allows rapid radiation.

Professor King, in his book on the soil, quotes the work of Professor Langley, who, "after making a long and very careful experimental study of this property of our atmosphere, at the base and summit of Mt. Whitney, in California, reached the conclusion that, had our earth no atmosphere, its surface temperature, even at the equator at noon, would be 200 degrees C. below freezing, or $-328 \mathrm{~F}$." The radiation of heat from the earth is always greater in cloudless weather, and on bright moonlight nights in spring we are apt to have killing frosts, not because of the moon, but because of the clear atmosphere at such times.

\section{Water as a}

One of the most active agents in the transSoil Builder formation of the original rocks into soil is water. We can to-day study its continual work by merely examining the hills and roadsides after a heavy rain and noting the transportation of the soil from higher to lower levels. In connection with water the frost has been one of the most efficient agents in breaking down the rocks. Water getting into the small crevices of the rocks freezes, and by its expansive force breaks off the particles which the rain washes down. In this way every exposed rock is still made to contribute slowly to the soil below.

When life began upon the earth there evidently must have been vegetation of some sort, since vegetation is essential to animal life. We find that even in the oldest rocks now known, rocks that have been transformed by heat, and which hence contain no animal or vegetable 
remains, there is a great store of carbon in the form of graphite or black lead, the material from which our lead pencils are made. Now, as we know of no source from which this carbon could come but from the carbon dioxide in the air, and the only way in which this can become fixed as carbon is through the action of plants, taking the carbon through their leaf-green, it is assumed that there must have been a vast amount of vegetation burned up in the metamorphosis of what are now the oldest rocks visible on the earth. Then in later ages, as the action of the heat, water, and air gave to plants some soluble food, there began a growth of vegetation.

The evidence of geology is that the only part

The First

American

Land of the American continent above the seas in the earlier ages consisted of a strip across the continent in Canada known as the Laurentian formation, from which extended a strip down where the Appalachian system of mountains was formed. All the great interior was occupied by a vast inland sea, extending from what is now the Gulf of Mexico to the arctic regions. There was a slow elevation of this interior, and the inland sea became a series of swampy flats to which the vegetation gradually added by its decay. The remains of this vegetation show that there was a climate of great warmth extending far northward, and intense moisture in the atmosphere. Plants that are now of a very lowly form, such as our mosses and ferns, then grew to an immense, tree-like stature, since plants of that character are better fitted to use large quantities of carbon dioxide than the plants of modern times, and the atmosphere was too full of this poison to animal life to permit their existence in 
the higher forms. The great moss trees were the means used by the Almighty to remove the excess of carbon dioxide from the air, and thus gradually fit it for the use of higher and higher developed animals. Age after age the old moss trees grew and fell, and on their remains other vegetation flourished entirely unlike the trees and plants of to-day. After a while the earth again settled, and the sand and earth covered the great accumulation of vegetable matter and formed the sandstone roof over the coal deposits. The active energy of the sunlight through unnumbered ages was then located in the great coal deposits to await the coming of man for its transformation into active energy by means of the steam engine and other devices. We know that the climate was of a tropical nature at this time by the evidence of the plants that then grew and whose carbonized forms we now find in the coal.

Even in ice-covered Greenland are found the remains of trees similar to the sequoias, or big trees, now known only in California. Later on, the earth in the eastern part of the country was crumpled into mountains, and the coal was pressed and its bituminous matter burned out, till the hard anthracite coal of the Pennsylvania hills was made; while westward, undisturbed by the upheaval, it remained bituminous. The Rocky Mountains of the West were a later upheaval than the Blue Ridge, and in the rocks thousands of feet above the sea level are found the perfectly fossilized remains of fish similar to our herring, showing how great was the upheaval.

With the elevation of the mountains the work of the water at once began. The rains descended and the 
floods came, and nature began washing down the mountains to form the soil of the lower levels. On this soil and in a purer atmosphere, other forms of vegetation appeared, and by their decay added to the mineral soil.

Later on there came a great accumulation The Work of of ice and snow at the North Pole, which
Glaciers gradually extended southward and by its weight so shifted the earth that a great change came in the climate. Plants of warm climates retreated southward. Fossil palm leaves of immense size have been dug up on the elevated Laramie plains, and give evidence of the climate that once prevailed there. As the great ice pack moved south, carrying with it the rocks and vegetation and grinding the rocks over which it passed, it finally made great deposits as its lower edge reached a warmer climate, and left through its whole course the evidence of its passage in the grooves plowed in the solid rocks. The glaciers not only deposited their burden of rocks and soil at their termination, which can now be traced by the range of hills thus formed across the country from southern Pennsylvania westward, but deposited dams in the valleys which caused the formation of lakes in all the sections of the country exposed to the glacial action. Of all the agencies in reducing the mineral elements of the rocks to soil, the glaciers were probably the greatest. But, like all other ages in the growth of the earth, the glacial period came to an end, and the melting ice carried the ground-up soil southward and covered the rocks with the clays of to-day. In the sand and clays in the track of the glaciers the rock bowlders were dropped after being pounded and shaped by their journey. Thus are found in the clays of 
the northern part of the continent transported rocks totally different from the fast rocks of the neighborhood.

With the deposit of the earthy matter which the glaciers had prepared and the restoring warmth of the climate, vegetation again started northward, and through its growth and decay contributed to the formation of what we to-day know as soil, in distinction from the original clay we call subsoil. But the action of the elements still continued to disintegrate the rocks and to transport the particles to lower levels. The limestone was formed from the lime washed into the lakes and from the remains of shellfish and vegetable decay, until by degrees the lake was filled and the deep soil of the limestone valleys was deposited. This soil, not being formed from the disintegration of the rock below, is often more deficient in lime than soils that are formed from the decay of the rocks on which they rest; hence it is often found that soils nominally limestone need applications of lime in cultivation more than some soils on a very different rock formation.

Through all the long ages the work of the

Land

Formations

by Rivers and Rains water has gone on. The rivers, which were immense floods following the glacial age, gradually shrunk in volume as they drained

away the great accumulation of water. The result is seen to-day in all the river valleys where the different heights of the water are shown by the terraces back from the present river bottom lands commonly known as second and third bottoms. But the soil is still being continually washed from the mountains and hills, and the formation of bottom soils along the river is continually going on with every overflow. Great rivers, like 
the Mississippi, carry clear to the sea vast amounts of soil and gradually build up deltas, which are finally elevated into cultivable lands. The Mississippi in times of flood has cut new channels, leaving the old bends as lakes back from the main current. The first effect of a change of location of the land along the river is the formation of a sand bar. On this vegetation grows, and finally a forest of cottonwoods, and above the sand a deep layer of vegetable soil is formed, often to be again undermined by a freak of the current in flood time. In all low bottom lands we commonly find that the water first drops the sand; as the current abates the brick clay in its finely comminuted state is deposited, and on this again the vegetable remains for the cultivated soil. In warm climates the formation of soil where lakes existed goes on rapidly through the accumulation of vegetation. This gradually fills the lake with its decay and deposits its component parts, till finally the lake is soil of great fertility, and the vegetation may have made great mineral deposits from the iron it contains. We find these immense deposits of iron now being utilized in the ancient lake beds of Minnesota, while in the warmer climate of California soils of immense fertility are thus made.

Study the face of a rocky cliff and note The Action what a great accumulation of broken and of Frost

in Soil

Formation pulverized rock forms the sloping talus at its base. All of this came from the action of water and frost on the surface of the cliff, which is constantly forcing off particles, and now and then a big portion of rock. Then a river at the base of this cliff rises and the finer particles are washed along with the cur- 
rent to be deposited elsewhere in the level bottom lands. In every rock quarry a large part of this decomposed rock must be removed to get at the solid rock below, and thus more and more accumulation is made. After every hard winter's frost a fresh accumulation can be found at the base of the cliffs, and the summer rains wash a fresh surface for the winter to act upon. Thus the rivers eat into the cliffs as the frost on the rock aids them. The result is mineral soils for the lower country or deltas at the mouth of the river. Even the summer rains have some disintegrating power on the rocks, for the rain carries with it the great decomposing agent of nature, carbon dioxide. It has formed the calcium carbonate of the low levels, the so-called limestone which was carried there by water. Then when the rain falls on a vegetable soil the water is impregnated with vegetable acids, which act readily on limestone rocks and iron formations. In the great swamps that line our Atlantic coast we find this process of soil-making going on. The vegetable acids dissolve the iron that plants have taken up, and bog iron ore is thus deposited. This was utilized before the great accumulations of iron ore were brought into use by the railroads.

Another force has acted on the land in The Influence the formation of soil. This is the great sea of the Sea on the Land

itself. In far distant ages the sea water was more dense with the carbonate of lime than now, and there were immense accumulations of shellfish which used this lime in the construction of their shells. These grew one generation upon the other, gradually burying the shells below till a deep deposit of limestone was formed from their remains. 
'Then occurred an elevation of that part of the sea bottom where they hat been formed. The great white chalk cliffs of England, for example, and the white nummulite limestone of the lower Mississippi valley, arose from under the sea. Such processes still continue. In the waters of the North Atlantic Ocean myriads of minute animals exist which form a shell of lime carbonate, and their empty shells are forever falling in showers to the sea bottom. The whole of the telegraphic plateatu, as it is called, between Newfoundland and Ireland, has a bottom composed of a deep ooze known to scientists as the Globergerinat $00 \%$, composed of the shells of these minute animals, the flint spicules of sponges and the skeletons of microscopic diatoms. Dredge up some of this mud from the ocean bottom and dry it and you can write with it on a blackboard just as with common chalk.

All the while the forces of the great sea waves are at work in the formation of soil. They eat into the hard cliffs and (lash up at another place the fine particles of sand. At low tide the sand dries and the winds blow it into the great sand clunes that line the coasts covering the marshy land behind them. A forest grows there and after a while other sand dunes are formed, drift inward and bury the forest. Thus a greater elevation of land is made while the sea gradually eats landward and at important points at sea wall becomes necessary to protect human interests. No sooner have the forees of nature clevatel a portion of land above the sea than the waves put in their work of breaking it town.

But the sea is the great agent of another work in the formation of soil. In the more shallow waters along the coast, 
especially in the warmer temperate and tropical regions, the untold millions of coral polyps live and construct great reefs, which are gradually brought to the surface and exposed to the action of the waves. 'The little builders die, but the waves carry the particles of their building landward, and the lagoon behind the reef gradually fills up. The Mangrove trees send their great roots into the water along the lagoon, the shellfish accumulate there, and the decay of the luxuriant vegetation of the tropics soon makes a swamp of a lagoon. But further out again the coral polyps build a reef, and again the process is repeated. In this way, by the constant increase of the coral reefs and the growth of the swamps, a large part of the Florida peninsula has been formed.

As the soils increased on the surface of

How

Vegetation

Prepared the Soil the earth the vegetation increased, till it had taken the greater part of the carbonic acid from the air and left the carbonaceous remains to form what we call soil to-day, and in which we grow crops. The accumulation of vegetable mold is another agency for soil-building and improvement. The roots of trees themselves exert a solvent action on the rocks, and at times in their growth force them apart through the swelling of their roots in the rock fissures. Then other living forms invisible to the naked eye find a home in the vegetable soil, and through their incalculable millions, these so-called bacteria exert a great influence in changing the character and composition of the soil.

Unlike green plants above ground, which throw off oxygen, these bacteria evolve carbonic and other acids 
How Bacteria which are agents of corrosion, dissolving the Work in the soil so that it is carried by the rivers in Ground solution and deposited elsewhere. The work of these invisible plants is of the greatest importance to the tiller of the soil; for it is through their agency that the materials used by other plants are again reduced to their component parts, so that they can once more be used by crops. Thus goes on the constant round of nature, using over and over again the same elements.

Repetition in Nature

The same water that has flowed to the sea is returned by the clouds in rain, and thus keeps up vegetation on the earth and through it the animal life as well. The radiant energy of sunshine acting on the green leaves of plants enables them to get and store away in their tissues the carbon from carbon dioxide. Year after year the tree grows, storing carbon away and locating the energy of the sunshine where it can again be turned into active energy. We cut the tree into firewood and burn it, and get back the radiant energy of the sunshine in the heating of our houses and the driving of our steam engines. In the same manner the coal accumulations are simply the stored-up energy of the sunshine of long past ages, and we get the same radiant energy when we use it for heating or the driving of the locomotive. We burn it, and the carbon dioxide goes back to the air to furnish food for other plants, so that the ceaseless round of nature is kept up. We destroy nothing in this world. What we call destruction is simply the resolving of matter into original and simple states ready to make other combinations and to appear in even more uscful and beautiful forms. The various cur- 
rents in the air keep the materials composing it always stirred up so that the composition is always nearly the same. But for the winds and the natural upward and downward currents of the air there would be an accumulation of carbon dioxide in the lower levels just as we find it deep in wells and mines, causing the choke damp so fatal to animal life.

There are still other lowly soil builders. Subsoiling The late Charles Darwin, the most careful Work of Earthworms and methodical of students, wrote a book on the work of the earthworm. These earthworms are found in all parts of the world, and have in their various genera an enormous range. They are found in the most distant and isolated islands, in far away Iceland, in the West Indies, in the Coral Islands of the Pacific and in the Falkland Islands of the Antarctic Ocean. Their wide distribution, Darwin says, is hard to explain, since they are killed by salt water, and could not have drifted to these islands. But in every place they inhabit they are continually engaged in throwing up little mounds or castings. No one in the country who has observed anything can fail to have observed these castings of the earthworms. In humid climates they are found in the greatest abundance, and always in the more moist localities of drier climates. Every boy who goes fishing knows well that he must look for worms in a moist and fertile piece of ground. An observer in India says that after the water is drawn off from the rice fields the whole soil soon becomes covered with the castings of the worms, and on the lawns they are continually compelled to roll down the castings piled up fully four inches high. Even on the 
high mountains of India earthworms were found, and in Ceylon, Professor King found a worm two feet long and a half inch in diameter. As the worm goes deep in the earth to hibernate during the winter season in the temperate zones and in the dry season of the tropics, the amount of material they bring to the surface has a great influence on the formation and nature of the surface of the soil.

Darwin gives a number of cases where ashes and cinders were spread on the surface and after some years were deeply covered by the earthy matter brought up by the worms from below, till a new soil was formed solely by the worms. At an abandoned limekiln in England several large sandstone pieces were left lying on a hard rubbish of broken bricks and mortar. Thirty-five years later found the stones covered with a deep layer of soil and turf. He had one of the stones removed by men with crowbars, and found that it still rested on the broken bricks and mortar, and showed no signs of having sunk, but the soil and turf had accumulated around it, sloping up to the top in a crater-like form, and the fine vegetable mold around it evidently consisted of the castings of worms, some of which were quite recent. Measuring the rate at which the stone had actually settled, he estimated that it would have taken two hundred and forty-seven years for it to settle so as to bring its surface even with the surface of the earth. From this and other investigations he became satisfied that the accumulation of soil through the ejections of earthworms had a very important influence on the increase of the upper soil. Darwin estimated that the number of earthworms in an acre of land was about 
53,767 , and from their average weight this would mean $35^{6}$ pounds of worms in an acre of land. The weight of single worm castings was found to be over two ounces as an average. This shows well the great amount that can be brought from the subsoil to the surface by this apparently insignificant means.

Thus we see that numerous agencies have Summary of been at work in the formation of the soils Nature's Processes we cultivate. The rain water, with its carbonic acid, disintegrated the rocks; the frost helped, and the water transported the fine materials. The glaciers ground the rocks through unnumbered ages, and their melting carried the muddy flood over all the earth. The growth and decay of vegetation added fertility to it with the materials the trees had gotten from the air; for you will remember that over 97 per cent. of their structure comes from the air and is thus returned to the soil in their decay. Then in some cases the coral polyp has extended the land seaward and enabled the vegetable soil to accumulate, and the little earthworm has industriously burrowed in this soil and deepened the surface soil with material brought from below. Limestone deposits have been heaved up from the bottom of the sea. The rivers have transported soil from place to place, and shrinking left the river flats or bottoms elevated for cultivation.

Restoring a

Even in our own days we can see how Wasted Soil nature restores a wasted soil. Men cultivate a field carelessly in a single crop till they say it is worn out. This has been done particularly in the Southern cotton and tobacco sections. The field is 
turned out as worthless. Then at once nature goes to work to restore what man has wasted. The broomsedge grass covers the old field, and the wind bears the light seed of the old field pine, which starts and grows in the sheltering grass. The pine sends a long tap root down into the subsoil below where the little plow of the devastator went, and year after year pumps up material for growth and takes its great share, too, from the air. Year after year it covers the land with its fallen leaves containing the matters it got from earth and air, and a forest grows up without any help from man. Another man cuts the forest down and utilizes the wood, and finds that he has a piece of virgin soil instead of a worn-out one. This is nature's process of soil-building, and it is the same process that has been going on through all time in the making of the fertile surface soil in which humus or vegetable decay plays so important a part.

We have seen that great accumulations How Lime- that have been made on the surface of the stone and Clays Affect Fertility earth, while largely of a mineral nature, have been the result of the activity of animal life. Chalk is simply one form of what we call limestone; and in all limestones, with the exception of the older limestones, which have been crystallized by heat, we find fossilized animal remains, showing how they were made under either the salt or the fresh water. When these limestones are elevated by the changes of the earth's surface, vegetation starts on them rapidly; and its decay increases what we term soil; and on these limestone deposits we find much of the best type of soils. 
The clays of the different parts of the country are formed from the decomposition to a great extent of the old crystalline rocks of the granite series. They have been spread abroad by the floods of past ages and cover the nakedness of the older rocks, and are gradually transported by the erosive action of the rains and frost to form the foundation for the most productive soil.

Hence we find that long before there was

Preparation of the Earth for Man

a man to till the soil there had been myriads of agencies preparing the earth for his habitation. The atmosphere had been purified of its excess of carbon by its being taken up by the old moss trees and buried in the coal formation for his future use. Even the growing lack of fertility had been provided for by the accumulation of phosphatic rocks in various regions, finally to come into use as man wasted his inheritance by careless cultivation; for the earth on man's advent was a new world growing on the old decay and putting out new forms of tree and animal. Time and time again has the Almighty fulfilled the words of the Psalmist: "Thou takest away their breath, they die, and return again to their dust." "Thou sendest forth thy breath, they are made, and thou renewest the face of the earth."

Phosphorus from the animal bones of past ages is used in the fertilizing of our fields to-day, and thus they are taking on a new life, and we know not how often this has been done in the long ages past, for we have seen that all the materials that enter into our soils to-day and grow up into crops have always existed and will exist till the end of all things, taking on new shapes age after age. 


\section{CHAPTER II}

\section{THE PHYSICAL CHARACTER OF SOILS}

7 HE earthy covering over the rocks, which we call soil, being largely composed of the particles

1 of the rocks themselves, varies greatly in its lexture or physical composition. Since its first deposition this soil has been the great laboratory of nature in which many and great chemical and physical changes have been brought about. And in this great laboratory the work has never ceased. It is still in progress, through agencies which may be classed as physical, chemical, and biological, as we shall see.

There is a wide difference, as the most

The Soil's Capacity for Moisture casual observer may note, in the size of the particles that make up our soils, and this difference in size involves also a great difference in the capacity of different soils for the retention of moisture. In soils that are sufficiently well drained for agricultural purposes the moisture does not exist as standing water; and this is essential since the welfare of all our cultivated plants demands free access of air. It is moist air rather than water which plant roots need, and this moist air is secured by the delicate films of water that surround and adhere to each particle of the soil.

It will be easy, then, to realize that the smaller these particles, each with its delicate film of water, the greater 
total amount of moisture in the soil. Professor King, in his book on the soil, well illustrates this with the example of a marble dipped in water. It will be surrounded by a film of water. A marble one inch in diameter will hold a film of water 3.14I6 square inches in area. Reduce the marble to spheres one-tenth of an inch in diameter and their aggregate areas will be 3 I.4I6 square inches. Reduce the particles to one-hundredth of an inch and it will take a million of them to fill a cubic inch, and they will have a total area of 3I4.I6 square inches. With soil particles only one-thousandth of an inch in diameter, it will take one thousand millions to make a cubic inch; and their aggregate surface must measure 3 14 I.6 square inches -all contained in the inch which, as a whole, had but 3.14I6 square inches of surface.

This illustrates in the plainest possible manner the way in which moisture is held by soils of different physical character. Naturally, in a cultivated soil there is a tendency for the finer particles to settle downward between the coarser particles, if they are of the same specific gravity. Thus we find that in the wide areas that exist in some countries like China, where the soil to a considerable depth has been formed by finer particles blown by the wind, there is a smaller percentage of extremely fine particles than where the soil is sedimentary clay that was carried by water. The more sandy nature of this "loess" soil, so called, makes it far more easy to cultivate than the sedimentary clay which has a far larger percentage of fine particles. Where the clay particles approach the fineness of the five-thousandth of an inch, they are apt to be agglomerated into larger masses and not to hold, each 
individually, a film of water. Still, the fineness of the clay soil makes it far more retentive of moisture than a coarse or even a fine sand. The computations of Professor King are meant to be comparative and not actual to a further extent than he has computed.

Varieties of Soil Texture

The texture of the soil has a great deal to do with the way in which the rain water, laden with the carbonic acid, affects it. A piece of rock may lie on the surface for ages and suffer very little loss in bulk. But if the same rock is pulverized into an impalpable powder and mixed with the soil, its decomposition will be comparatively rapid. This is well illustrated by the case of the phosphatic rock dredged from the rivers of South Carolina, where it has lain for countless centuries slowly wearing and being rounded. But when put into a mill and reduced to the impalpable powder sold on the market under the name of "Floats," it becomes a useful plant food which is readily acted upon by the rains and the combinations of matter in the soil.

Pclouze, a French chemist, found that a flask in which water was kept boiling for five days lost less than two grains in weight; but when he broke off the neck of the flask, reduced it to a fine powder, and boiled it five days, he found that one-third of the weight of the flask had been dissolved by the water. If, then, such an insoluble material as glass can be thus dissolved by the action of hot water, we can begin to realize what is going on in the soil in which the action of the sun's rays has set up heat, and in which the fineness of the soil gives the rain water an opportunity to act. 
Loess, or wind-borne soils, are made up of very fine particles held together by mineral matters, so that in cultivation they approach the nature of the sandy soils. Differences in the physical nature of soils explain the difference in the degree to which air and the roots of plants penetrate them. In a soil of a mellow texture the roots of many plants strike down several feet. The tap root of the alfalfa plant in a mellow subsoil will go straight down, while on a soil the surface of which is sandy but underlain by a very compact clay of great fineness of particles we have found the roots of alfalfa striking this clay and then running horizontally, so that the plants came under the blighting influence of a summer drought.

But a soil too loose in texture becomes a leachy soil. This is the case with deep sands, through which the water, laden it may be with plant food, soon gets beyond the reach of plants, and constant applications of fertilizers are needed to keep up its productiveness. The barrenness of sand hills is largely due to this leaching away of plant food. Hence, in the amelioration of such soils, applications of clay and lime have been found useful in binding the particles and making them less open and leachy. The rotation of crops, and the addition of organic matter in decayed vegetations, also improve the leachy sands, for on account of their extreme fineness the particles of vegetable decay have a greater power to retain moisture than matter in any other form. This black humus or organic decay is of the first importance in agriculture, not only as a carrier of plant food that has contributed to the structure of other plants, but as a mellower of a heavy soil, as a 
compacter of too light soil, and especially as a retainer of moisture for the roots of crops.

The agencies by which combinations are The Chemical formed and broken up are not only chemical Composition of Soils

but biological, as we shall see later; for soil fertility depends to a great extent on life in the soil. A fertile soil is really a living soil, while a barren soil is to a great extent dead. But our present lesson is in regard to the chemistry of the soil.

Chemists have discovered that the soil and air and water are composed either of mixtures or chemical combinations of certain elements. An element is matter reduced to its ultimate form, something in which we can find but the one thing. The great advance in chemical science, however, is still finding new elements, and finding that some substances which have been regarded as elements may yet be divided into two or more elements. Some of the well-defined elements are known as metals, such as iron, potassium, aluminum, calcium, magnesium, sodium, and manganese. Others exist in a gaseous form, such as oxygen, nitrogen, hydrogen, etc.; while still others, though non-metallic, are found in a mincral state, as silicon, carbon, sulphur, chlorine, and phosphorus. The air we breathe is made up of a mixture of oxygen and nitrogen, both free and not combined with each other, the nitrogen being in the air as a diluent to enable us to breathe the oxygen. For in free oxygen alone we should soon burn up. Oxygen exists in the soil as a free gas necessary to the roots of plants. It is also found in combination with nearly all other elements and is the active constituent of the mineral acids. 
Combinations

of Silicon,

Carbon,

Oxygen, and

Hydrogen

The most abundant element in nature is probably silicon. The quartz rocks so plentifully distributed over the earth are composed of silicon and oxygen, making what is called silica, and the breaking down of these rocks makes the sharp quartz sand used in plaster for building. Silica, either in the form of sand more or less fine, or in the forms of pebbles and broken fragments of rock, makes the greater part of the bulk of all the soils, and without a liberal amount the cultivation of soil would be almost impracticable.

Carbon gets into the soil through the decay of vegetation. Vegetation gets it from the air, through the green leaves that possess power to gather carbon from the atmosphere, where it is always present in combination with oxygen. When it combines with oxygen and forms carbon dioxide, or as it is commonly called, carbonic acid, it becomes one of the great decomposing agencies in the soil, and also combines with lime to form the carbonate of lime known as limestone, or with other elements, making other carbonates.

In the soil this carbonic acid plays a very important part as a decomposer of combinations that are insoluble in plain water, and so brings into use for plants potash and other plant foods that exist in the soil. While carbon in its various combinations is plentiful in all fertile soils where humus or vegetable decay abounds, no experiments have proved that plants ever take carbon through their roots from the soil. In building up their structure, in which carbon plays a very important part, they get their supply rather, as we shall explain further on, through 
their green leaves from the carbon dioxide in the air. Hydrogen, when combined with oxygen, makes water, which is of such vital importance to plant and animal life alike. The water that plants take up from the soil by means of their root system furnishes them with the greater part of the oxygen they need and with all the hydrogen; and from combination of it with the carbon taken in by the leaves the plant makes starch, sugar, and woody material for its structure and for storage as future food.

Sulphur occurs in the soil in the form of Occurrence sulphates of iron, lime, and magnesium. of Sulphur, Chlorine, and Phosphorus The sulphates and oxide of iron color our clays and play an important part in the manufacture of the leaf-green of chlorophyil in plants. Iron is the most plentiful of all metals and one of the most essential plant foods, for without iron there would be no green leaves and hence no getting of carbon from the air, and therefore no plant growth. It exists in inexhaustible amount in all cultivable soils, and while of vital importance there is no danger that it will ever become deficient, for the decay of the forest leaves and vegetable matter in general rapidly restores it to the soil.

The element chlorine is found in its most common combination in the chloride of sodium, or common salt. It is also found naturally combined with potash, and thus furnishes one of the readiest means for restoring potash to soils that are deficient in this material. While salt is found in all soil waters and in all plants it is still an unsettled question as to whether or not it is an essential part of plant food. Potash, with which chlorine is often combined, is essential to plant life; but there is no evidence 
that sodium, the base of common salt, is of value to our cultivated crops, though some once imagined that the soda could replace the potash when it is lacking. Most experiments, in fact, go to show that in the absence of potash soda cannot take its place, and that plants will perish for lack of potash even though soda is abundant.

The element phosphorus is never found free in nature, since it burns on exposure to oxygen, and in its most familiar form, the heads of matches, it is used as a means of producing flame. It is found in all fertile soils, and is essential to the life of plants, for without some soluble combination of phosphorus in the soil, no plant can grow. It is removed from the soil by crops, and grazing animals take it rapidly in the formation of their bony structure. Hence, in all of our older cultivated soils it is apt to be more deficient than any other form of plant food. It is a component part of all the old rocks, and their decay and disintegrations have furnished it to the soil. In some sections it is found in immense deposits made up of the fossil remains of the extinct animals of former ages, and these deposits now form the chief source from which we replenish the waste of phosphorus in our cultivated soils.

The fossil phosphatic rock is pulverized and used to some extent in that form as a fertilizer, which slowly becomes available to plants through the action of the carbonic acid in the soil water, or is dissolved in sulphuric acid so that a large part of its phosphorus is made available for mixture with soil water. The ancient animals made their bony system from the lime and phosphorus of the old vegetation, and have left the combination in the 
soil to be used over again in furnishing plants with food. In addition to the fossil phosphorus in the rocks we get phosphorus from the bones of dead animals of the present day, which thus quickly return it to the soil to grow more plants and to feed more animals; for, as we have seen, without phosphorus no plant can grow, and without plants no animals could live on the earth. Thus the mineral kingdom supplies food to the vegetable and the vegetable to the animal, and the succession of life is maintained.

While analysis shows that there is an immense deposit of the various essential plant foods in the soil, it has also been proved in practice that continual cropping depletes some of these faster than others, and that one of the most rapidly used-up elements is phosphorus. While, as we shall see hereafter, we can get nitrogen in abundance without applying any to the land, our older cultivated soils may need application of phosphorus and potassium in the forms of phosphoric acid and potash for the perfection of crops, even when a chemical analysis would show these abundant in the soil. For often they become available too slowly for the demands of modern farming. It has been found, too, that the plants that help us get nitrogen from the air can do this far more effectively when well supplied with phosphorus and potassium. Lime added to the soil plays, as we have seen, an important part in the nitrification of organic matter, and it also assists in bringing into use the insoluble potash in the soil. If carelessly used it may aid in the robbing of the soil. But the use and abuse of lime will be treated in a subsequent lesson. 
Importance of Nitrogen, Aluminum, and Potassium

The larger part of the atmosphere is made up of nitrogen, which, as we have shown, is there to dilute the oxygen so that we can breathe it safely. Nitrogen rapidly leaves the soil by the growth of plants and by leaching away in the soil water, and is also driven back to the air by the combustion of organic matter. In the soil it is most abundant in the vegetable decay of humus that makes soils dark in color. The decay of animal tissues also contributes to this humus and consequently to the store of nitrogen. Nitrogen exists, further, in the soil in combination with lime, potash, and other bases formed through the action of microscopic plant life on organic matter. By this action ammonia, the hydride of nitrogen, is released, which is still further reduced by these various bacterial forms to nitric acid. The nitric acid seeks a base in the soil and forms the nitrates of lime, soda, or potash. Plants with green leaves use nitrogen only when it has become a nitrate, and hence the action of bacteria in reducing the organic matter and carrying its nitrogen to a nitrate is an important work in nature's process and goes far toward separating a living soil which abounds in microscopic life from a dead soil in which these minute forms are starved out by the lack of organic matter.

The metal aluminum is one of the most abundant elements. It is of late becoming more familiar to all in its metallic form, since modern chemistry has devised ways for separating it from its combinations in clay. It is the very foundation of all true clays, which are formed by the decomposition of granite or feldspar; and while 
itself it does not feed plants it is important as clay in increasing the ability of soils to retain moisture and plant food. Clay is essential to bind together the particles of silica and to make clayey loams, which are more retentive than pure sands.

The metal potassium is one of the most important of all the elements that contribute to the growth of plants in the soil. The first material that we can discover that is formed within the tissues of a plant is starch, and from this starch all the long series of substances known as carbohydrates are made, and the woody structure of plants is built up of these by the living matter in the plant cells. But without potassium in a soluble form no plant can make starch, and hence can make no growth. Not that there is any potassium in starch, but it has been well proved that in its absence no starch can be formed. Plants could not use potassium in a metallic form, and it is found in combination with oxygen, making potash. The granitic rocks contain the silicate of potassium in their feldspar and the clays formed from the decomposition of these rocks are rich in potassium, which becomes slowly available to plants as potash through the action of the carbonic acid in the soil waters. It has been found, too, that the carbonate of lime acts on this insoluble potash and sets it free for plants, and lime sulphate also has a similar effect. In New Jersey and other sections of the Atlantic coast there are beds of greensand marls which contain a mineral known as glauconite. This has a very considerable percentage of potash, which becomes slowly available when applied to the soil. Kaolin, the white clayey material from which chinaware is made, also con- 
tains potash. When we burn wood in the fire, especially the harder woods, such as oak and hickory, we find that these plants had a large supply of potash, which is left in the ashes. Wood ashes, therefore, are useful as applications to the soil for restoring potash, lime, and phosphorus in a form very readily available for the use of plants.

We have in a former lesson mentioned the great abundance of limestones, and have said something of their formation in past ages. Carbonic Lime, Sodium, acid, united with the metal calcium, formed etc., as

Productive Factors these limestones, in many of which there is also found a varying percentage of another metallic element, magnesium. Both calcium and magnesium are essential as plant food, and are found abundantly in all the seeds of our cereal grains and of other plants. The carbonates of these elements are found so plentifully in nature that they are practically inexhaustible so far as mere plant food is concerned. But lime, or the carbonate of calcium, in the form of calcined limestone or common quicklime, plays a very important part in the development of the productive capacity of our soils when used in an intelligent way. Of its use and action we will have a lesson further on.

The metal sodium is important as the base of our common salt; but, as we have said, though closely resembling potash it cannot be used as a substitute for that material in a fertilizer mixture. When combined with nitric acid, however, forming the nitrate of soda, it becomes one of the most readily available and important carriers of nitrogen. 
Experience

There has long been a notion, and it is More Reliable than Analysis

still prevalent among those who have not given close study to these things, that a chemical analysis of our soils will at once show us what they need in order to become more productive. But while the chemist can find out the composition of the soil, he cannot determine the availability of the materials of which it is composed, and a soil may show a full composition of all the essential elements of plant food and still be a barren soil so far as plant life is concerned, because the existing plant food is not in available form. It seems that often the physical nature of the soil and its mechanical texture has more to do with its productiveness than the actual amount of plant food it contains.

A study of the soil through the experimental growing of various plants in plots, with the addition of the different plant foods separately and in various combinations, will help the farmer to understand the needs of his soil better than any number of chemical analyses. Chenical analysis shows that there is a very great difference in soils within very limited areas, and it has also been shown that the roots of plants have a selective capacity, and that some take far more of certain elements than others do. Hence the study of the soil must be continued for several years, and with varying plants, in order to arrive at an intelligent understanding of its needs. Of this we will treat more fully when we come to the study of fertilizers.

The common classification of soils as clayey, clay loam, sandy loam, sandy, or peaty, really tells us little in regard to the actual composition of soil, since soils of 
Classification similar appearance and texture vary greatly of Soils

in their chemical composition and productivity. All through the upland country east of the Blue Ridge Mountains there is found a clay loam of a reddish color, which the soil survey made by the Department of Agriculture has called Cecil clay, from the fact that it was first noticed in the northern part of Cecil County, Maryland. But it is well known that this Cecil clay is of greatly varying character within limited areas, being far more mellow and tractable in some places than in others, and it varies also in fertility and productiveness. Therefore a superficial soil survey, depending on the similarity of appearance, is a poor guide to the character of the soil. The productivity of a soil depends very largely on the ease with which the plant food it contains is dissolved in the soil water, and also on the coarseness or fineness of the particles of which it is made up. A clay soil containing a much larger actual amount of plant food may still be less productive than a soil with much smaller store of food, but which from its mechanical nature allows the store to be more easily used by the roots of plants.

In the physical character of soils, the terms light and heavy have reference to the ease or difficulty of culture rather than to the actual weight; for, bulk for bulk, a "light" sandy soil is really heavier than a "heavy" clay soil. A soil will be termed sandy when 35 to 50 per cent. of its material is made up of coarse grit. In a clay soil the extremely fine particles are in the greatest proportion, even making 95 per cent. in the heaviest clay. Between the sandy soils and the clay are numerous gradations, dis- 
tinguished as sandy loams and clayey loams according as the soil particles differ in size and the soil is more or less easy of cultivation. Soils derived mainly from the decay of organic matter form a class by themselves, and are termed peaty, swampy, or humus soils. These soils when well drained are generally found to be abundantly supplied with nitrogen, but are apt to be deficient in the mineral matters, phosphorus and potassium, and produce a rank growth without a corresponding maturity of the grain or fruit.

One of the most important contents of arable soil is what we call humus, the decay of organic matter which makes the surface of the soil darker in

Humus, its Sources and Services color, more mellow in character, and above all, more retentive of moisture. While generally esteemed of the greatest importance, humus is still, in its chemical composition, not so well understood as the mineral soils. Its value does not seem to lie so much in its furnishing plant food, though of course it does this, as in its physiological and mechanical effect. The soils of arid regions, which are generally deficient in humus, are still very productive when only water is applied; and a soil of good mechanical composition will produce fine crops though destitute of humus, if well supplied with soluble plant food.

Humus is formed from matter which once carried life, either animal or vegetable, and which the forces of nature are reducing to such form that the materials can be again used in the building up of plants and the support through them of animal life. It is simply the result of the neverceasing round by which nature uses over and over again 
her old materials, getting again the carbonic acid, water, nitrogen, and the ash elements for the building of new forms. In northern sections, where the snowfall is heavy and the winters long and cold, the vegetable matter in the forest waste is held in place, and its decay being slower than in warmer regions there is always in the virgin soils of the north a greater accumulation of humus than in a southern and warmer region. When we come to the tropics, with their uniform heat in the soil and rapid oxidation as a consequence, the amount of humus is very slight. In the high open woodlands of our own southern country the leaves of the deciduous trees blow into the hollows and low lands and there help to form the fertile bottoms, while the hills retain very little. Hence, for the careful farmer in the red clay hills of the South, it is of far more importance to increase the humus content of his soil than it would be with the deeper humus soils of the North.

Nothing has tended more to the impoverishment and unproductiveness of the southern uplands than the constant cultivation of cotton on them, with only the aid of commercial fertilizers, which return no humus to the soil. The first steps in their improvement must be the restoration of the organic decay that has been burnt out of them in the long clean culture of cotton. These soils have become really dead, because the microscopic life that finds its food in the humus has been starved out. Since the products of the life of the soil-bacteria are of the greatest importance to our cultivated plants, it is evident that the greatest value of the humus lies in its being the home and food of these microscopic forms. Stable manure, while 
containing less plant food, bulk for bulk, and in a far less available form, than commercial fertilizers, has a value which the fertilizers do not possess. It aids in kecping up the supply of humus by the decay of the organic matter it contains, especially through the presence of straw, etc., that has been used in the bedding of animals. The commercial fertilizer exerts no influence in making the soil more retentive of moisture, while the stable manure does this essential work. The nitrogen that is in the organic matter of the humus, when it is reduced to nitrates through the action of the bacteria which are engaged in what we call nitrification, is rapidly washed from the soil in humid regions; and hence it has been shown by analysis that the small amount of humus in the soils of arid regions has a larger percentage of nitrogen than the larger amount of humus in humid regions.

In the soils of arid regions there is, as might be supposed, a larger percentage of soluble plant food than in the soils of humid regions, simply because it has not been washed down by heavy rains. The presence of a larger percentage of lime in the soils of arid regions also has a tendency to flocculate the particles, and to prevent the formation of plastic clays so common in humid sections. Hence, irrigating water applied to soils of an arid region brings about a wonderful productiveness by the solution of the food waiting for water.

In the sections devoid of rainfall, like Peru, and parts of Chili, the nitrogen has accumulated in the form of nitrate of soda, which has become of great commercial importance for the supplying of nitrogen to our cultivated crops in the most rapidly available form. 
Action of Organic Agents in Soils

It has been well said that the chemistry of carbon is the chemistry of life, for its presence in the soil is evidence of living forms having been there and died there. In like manner it has been said that the chemistry of the rocks is the chemistry of silicon, of which rocks are so largely composed, and which in their decay they have furnished in many complex compounds to the soils of the earth. In fact bio-chemistry, the study of chemical changes made in the soil through the action of living forms, is becoming more and more a matter of investigation from which great results are being had and greater are still to be obtained.

We know that the breaking down of organic matter in the soil is the work of microscopic plant life. The ammonia thus released in turn becomes the food of other micro-organisms, which reduce it to nitrites. Then still another form feeds on nitrites and makes nitric acid, which at once unites with some base in the soil, such as lime or potash, and in this form, a nitrate, the nitrogen becomes food for the green-leaved plants. We know, too, that while the green-leaved plants are dependent for their carbon on the carbon dioxide in the air, these microscopic forms, which make no green and cannot thus get carbon from the air, have the power that green-leaved plants do not possess of getting carbon from the carbonate of lime in the soil, and that thus the presence of lime carbonate in the soil aids in the process of nitrification or the change of organic nitrogen into the readily available nitrates. But the soil still offers innumerable problems to the chemist, and many a question is yet to be worked out there in the 
solution of which the small laboratory of the chemist hardly suffices. For nature often contradicts the results that are attained in restricted conditions and in artificial ways.

We have now learned that a certain amount of nitrogen, potassium, phosphorus, magnesium, iron, calcium, and perhaps some minor constituents is essential to plant life, and that these must be in such combination as will render them easily appropriated by the roots of plants. If any one of these elements is entirely lacking in the soil no plant can grow in it. This much has been abundantly proved. Sulphur, which is also an essential in plant life, is gotten from the combinations of the other elements with sulphuric acid, forming the sulphates of lime, ammonia, or potash. Some of these things that are deemed essential are really needed by plants in very small amounts as plant food. Silica is taken into the plant simply because the plant cannot help taking it when dissolved in the soil water, and a large portion of the lime found in the plant tissues is there for the same reason, though part is utilized by the plant to render harmless some products that would be harmful to plant life, like oxalic acid. The lime unites with this and forms crystals of oxalate of lime that are insoluble in the cell sap, and thus the acid is rendered harmless. A soil without iron could form no green matter for the leaves of plants, and without this green matter the plants cannot decompose the carbon dioxide in the air and get their carbon, and hence no growth. But iron is found everywhere in some form, and is so plentiful in nature that no soil is deficient in it. Every green leaf takes up iron and in its decay returns it to the soil, so that it is being used over and over again. 


\section{CHAPTER III}

THE RELATION OF SOILS TO MOISTURE AND AIR

HE roots of plants, if we except the aquatic plants of the swamps and marshes, do not need water

1 in the soil, for standing water in the soil shuts out the air which is essential to the oxidation of plant food, and keeps the soil cold. What we need in the soil is moist air. We have seen in our first lesson that the percentage of moisture in the soil will depend largely on the size of the soil particles, each surrounded by its film of water. A soil that parts with this moisture rapidly by evaporation into the atmosphere will always be a colder soil than one which holds the moisture and evaporates it more slowly. So standing water is harmful, though moisture is necessary. It is essential that the soil be penetrated by air that the oxidation of matter in the soil may take place, and it is necessary that there be a due amount of moisture so that plant food may be dissolved for the roots since, as we shall see, no plant food is taken up until completely dissolved in the soil moisture.

The rise of water in the soil to supply

Supply of Moisture by Capillary Attraction that taken by plant roots and by the evaporation into the air is caused by what is known as capillary attraction. Place a thick towel with one end in a pail of water and the other end resting on the ground and you will see that the water is taken up from the pail and transferred 
over the rim to the ground through the capillarity set up in the fine meshes of the towel. The same capillarity occurs in the soil when left at rest, and in this rising water there is also brought to the surface soil much plant food that otherwise would be out of reach of the roots of crops. It has been shown that when a glass tube of very small diameter is inserted in water the water will rise in the tube above the surface of the surrounding liquid, and also that the smaller the diameter of the tube is the higher the water will rise within it. In like manner very small tubes form in the soil by which water rises in the same manner, and the extreme fineness of these naturally formed tubes greatly increases the power to draw up the water, though in a far more irregular shape than the straight tube of glass. Professor King says that he "found that a very fine sand did lift water through four feet at the rate of .9I pounds per square foot in twenty-four hours, while a clay loam lifted it at the rate of .9 pounds per square foot through the same distance in the same time." By this means water from below is continually being brought within the reach of the plant roots.

Since all plant food must be in a state of solution in the soil before plants can use it, the importance of a supply of water along with an abundant supply of the oxygen of the air in the soil, will be at once apparent. The films of water surrounding every soil particle exert a wonderful influence in the solution of food for the plant roots. Even materials which the chemist finds insoluble in water in the laboratory are slowly attacked by the soil water with its carbonic acid and brought into shape for plants to use. Finely pulverized phosphatic rock when placed in the soil 
and left to the action of these films of water gradually releases its phosphorus to the roots, though the chemist finds that it is soluble only in strong acids. But Nature's laboratory, though working slowly, works all the time and often puts at naught the results of the laboratory of the chemist. Few who have not studied the matter scientifically realize the large amounts of water used in the production of our cultivated crops. For every ton of dry matter in a crop of Indian corn the plants used 309.8 tons of water, and similar amounts are used by other crops. A clover crop uses a great deal larger amount than corn. This water is not only taken as a means for the carrying of plant food, but is itself necessary for the life activities of the plant; for no matter how much food may be present and within the plant its activities must cease if there is not a sufficiency of water present for the living matter to continue its work.

Soils vary greatly in their capacity for the

Retentive

Capacity of Various

Soils retention of moisture. Since the water in the soil is held in films surrounding each grain, it is evident that a coarse-grained soil will hold less moisture than one made up of very fine grains. Then, too, the capacity of the soil for drawing water from below will vary with the fineness of its particles, for we have seen that the finer the capillary tubes in the soil the higher the water will rise from below. This capillarity will also depend on the depth at which the permanent water-table in soil is from the surface. Also, in a finely divided soil the water that falls in rain percolates more slowly downward and moisture is retained longer after a rain than in a coarsely granulated 
soil. This can be readily seen in a deep, sandy soil after a rain. The rain water disappears very quickly, while on a more loamy soil the surface will remain wet for a much longer time and on a compact clay the water may stand for a time on the surface if special means have not been provided for sinking it in the soil by underdrainage. Even in a sandy soil the rate of percolation downward depends largely on the fineness of the sand. There are soils in some sections which are known as pipe-clay soils, which drain very slowly and become very hard in dry weather, when the soil is really not properly a clay but sand of great fineness and has just enough of clay to bind these very fine particles closely together. They are really quicksand soils and are among the most intractable of soils for cultivation since they hold water till evaporation takes place from the surface, making the soil cold and unfavorable to vegetation. When soils of this nature are well stocked with humus or organic decay they are made more porous, and the downward percolation is more rapid. Yet the retention of soil moisture is increased, though it may seem paradoxical, for the hardening of such soils in dry weather is due to the extreme fineness of the particles favoring rapid evaporation from the surface, unless the formation of a crust is stopped by frequent shallow cultivation. Free percolation of water through the soil is essential to the keeping of the aëration of the soil perfect, provided the percolation is not too deep and a more retentive stratum is not far below. But the rapid percolation in a coarsely granulated sandy soil under which there is no retentive subsoil is excessive, and makes what is known as leachy soil in which the plant food is 
rapidly carried downward by the rain water out of the reach of plant roots. In such a soil constant applications of manure and fertilizers are essential to the production of crops and the accumulation in it of organic decay that will tend to make it more retentive of moisture. Then, too, the depth to which the water percolates and the feeble capillarity of a coarse sand makes the rise of water in such soils less than where there is a retentive subsoil near at hand. These sandy soils, however, yield up to plants their water more completely than a clay loam. Professor King reports that he found corn able in a sandy soil to draw down the water content of the soil to 4.I7 per cent., while in a clay soil with a much greater water capacity the corn crop could draw it down only to II.79 per cent.

In all soils there is a point below the surProper Depth face where water is constantly present. This
of Watertable is called the water-table. Where this is too near the surface the soil is rendered cold, and the chief value in tile underdrainage is in lowering this water-table so that the air can penetrate deeper in the soil and there will be a greater depth of soil containing only the capillary moisture that is needed by the roots of plants. Much of the greater productivity of the lowlands or bottom lands is due to the fact that the permanent water-table in the soil is nearer to the surface than on the uplands, and hence the capillarity of the soil can bring moisture to the roots more readily and constantly.

The water-table in good arable soils should always be four feet or more below the surface, and as a matter of fact it is on the uplands generally from ten to fifty feet down. What concerns us mainly in agricultural opera- 
tions is how much moisture can we control and retain in the soil for plants during seasons of drought, for the actual movement of the water in a saturated soil is of importance mainly as a question to be determined in the drainage of land. The rapidity or slowness with which water evaporates from the soil is what concerns the farmer and is largely what determines the productiveness of a certain soil.

The Bureau of Soils of the United States Experiments Department of Agriculture has made some of Moisture experiments to show the rate of evaporation from the different soils. In making the soil surveys in various parts of the country this Bureau gave various names to certain types of soil according to the locality where each peculiar type of soil was seen. "Cecil clay" has been spoken of. In like manner they call the heavy clay soil of the Hagerstown valley in Maryland, "Hagerstown clay." The "Yazoo clay" is named from the soil in the Yazoo river bottoms in Mississippi. These three clay soils the Bureau says are the strongest types of clay soil used for agricultural purposes in this country. After evaporation in tin cans for twenty-five hours the Cecil clay retained seven per cent. of the water it contained at the start, while the Norfolk sand retained but one per cent. In another experiment samples of a number of soils were exposed to the sun and wind for six hours. Sand-hill soil that had ro per cent. of water at first, lost 33 per cent. of its content; and Cecil clay, which contained at first I 7 per cent. of water, lost but I4 per cent. of the amount it contained.

The importance of a loose soil cover as a preventive of evaporation was shown by an experiment with various 
samples. Cecil clay was placed in a tumbler and covered with a layer of dry earth an inch thick. Some light loam from St. Mary's County, Maryland, was treated in the same way, and one glass was left to evaporate without any cover. The total loss from the Cecil clay was somewhat less than half as much as that from St. Mary's loam, showing the marked difference in the resistance offered by the two soils to the passage of watery vapor. The uncovered loam lost three times as much as the covered.

From various experiments it is evident that the percentage of humus in a soil has a marked effect on its capacity for retaining moisture. In general, then, we may assume that evaporation is less rapid from a clay soil than from a loam or sandy soil, and that to retain the moisture brought up by capillarity in any soil it is advisable to keep a layer of loose and dry soil on the surface and to prevent the formation of a crust there which would promote the rapid evaporation. In short, by shallow cultivation during dry weather we can prevent the loss of moisture and hold the capillary moisture where the roots of the plants need it.

Selective Capacity of Plant Roots

There is, however, one point that has been determined by experimenting with water in the solution of plant food in the soil. As is well-known, the food which is taken up by the roots of plants must be in complete solution. But the extent to which this solution is due to the water in the soil is far less than is usually imagined. At the Minnesota experiment station grain grown in pots filled with a very fertile soil, grew finely and matured normally. In other pots sand entirely free from plant food was also planted 
with similar grain. This sand was kept moist with water that was leached through a fertile soil similar to that in the first-named pots, thus getting as much as possible of the soluble plant food in the soil. Another pot of the sand was watered with distilled water. This last pot produced plants to the extent only of the plant food in the seed sown and then died. The pots watered with the soil leachings grew feebly and finally died, showing that the soil leachings alone did not furnish food enough for the plants.

These experiments seem to confirm the opinion that the roots of the plants themselves have a solvent power on matter in the soil which is not directly soluble in the soil water. It also goes far to explain the fact that matter, like pulverized phosphatic rock, which the chemist decides is insoluble in water, when placed in the soil, does feed the crop. While, therefore, the presence of water is essential in the soil, the solution of plant food is not altogether dependent on the water, and experiments made to show that the water-soluble food in all soils is very similar are misleading, since they take no account of the work of the plant roots themselves, which not only take part in the solution but, as we shall see later, have the power to select the foods they particularly need in different percentages in different crops.

Effects of Atmospheric Pressure on Moisture Supply

Movements of water in the soil are often due to the soil air and its expansion and contraction. Springs and small streams will often swell up for the same reason that the mercury falls in the barometer, that is because of lessened air pressure. Changes in the barometer are very commonly accompanied by changes in the 
outflow of water from tile drains. When the air pressure above ground is lessened there is to some extent the same diminution in pressure of the air in the soil, and the water flows more freely from drain or spring, and rises higher in wells. Some years ago late in autumn a correspondent of a city paper wrote to the editor that he noticed that just before a rain storm the water in his spring rose, and he wanted to know the reason. The editor, who we suppose had been taught the old fable that the sap runs up the trees in the spring and runs down in the fall, replied that this was easily explained, for it was the sap running out of the roots of the trees at that season of the year. Inasmuch as nothing of the sort takes place, as we shall see later in our study of plants, a little more information would have taught the editor that it was simply the release of the atmospheric pressure that caused the water to flow into the spring, just as it causes the mercury to flow into the cup of the barometer. It has been found that in Wisconsin during the summer, from July to September, the surface of the ground water and the rate of percolation into tile drains are subject to daily oscillations in level and changes in the rate of flow, owing to the daily expansion and contraction of the air contained in the upper two or three feet of the soil. "The changes of pressure thus developed react on the capillary water in the soil in the zone where the cavities are nearly or quite filled, forcing the water down and out into drainage channels when the air is expanding, but allowing such as has not been permanently lost to return again to its normal level when the pressure becomes less with the cooling and contraction of the soil air." This diurnal rise and fall from the differ- 
ences in the pressure of the heated and cooling air can be easily traced in a shallow well.

We have seen that the capacity of a soil Proportion of to retain moisture varies generally in proRainfall

Retained by Soil portion to the percentage of clay it contains. Few soils do retain in the upper five feet of the soil as much as twenty inches of water, while some authorities claim that for the best results in the crop the water content should be held up to fifty inches or more. While the water-fall of a section may annually amount to this much in inches, the percolation and evaporation very largely reduce the percentage available to the crops. In practical agriculture, then, the conservation of the soil moisture becomes of the greatest importance especially where the annual amount is below the optimum. Even in regions of heavy rainfalls as in our South Atlantic states a large part is carried off by surface washing in the torrential rains of summer, another part evaporates, and still another passes down into the subsoil in the drainage, so that even with fifty inches of annual rainfall it is one of the most difficult of problems to retain for the use of plants as much as one-third of the rainfall. The importance, then, of using every means possible to prevent the loss of water will become apparent to any one. The practical means for accomplishing this will be more fully treated in another lesson.

We have seen that water standing too near the surface is damaging to our cultivated crops since it makes the soil cold and shuts out the oxygen of the air which is so essential to the welfare of the plant roots. We have also noted that the point in the soil where water lies per- 
Drainage and manently is known as the water-table. Mechanical Improvement of Soils

Where this water-table is within a foot or two of the surface any addition from rainfall soon floods the land and destroys crops. Hence the importance of drainage for lands of this character. Open ditches will to some extent lower this watertable and carry off the rainfall. But open ditches to be effective in the drainage of the land need to be quite close together and thus are seriously in the way of cultivation. Their banks also become the nurseries of weeds and bushes and need constant clearing. They occupy too much of the land. Hence the importance of taking the water away in underdrains. Underdrains are not primarily for carrying off the rainfall rapidly but for lowering the permanent water-table in the soil, thus making room for the air and enabling the soil the more rapidly to take up the water that falls in rain. The air, too, warms the soil and lightens its mechanical condition. To accomplish this the drains must of course be placed in the soil deeper than the natural water-table, and the nearer the lines of drains are to each other the more effectually they will lower the water-table, since each drain will draw water only from a certain distance each side of it, and if too far apart the intervening water-table will be very little lowered.

The best material for underdrains is tile Materials and baked like bricks. These are made in short Methods for Draining Lands lengths and of various diameters. Many shapes of tiles have been made, but practical tile drainers have settled down on the round tubular tiles as best. Various other materials have been used and answer very well for a time where tiles may be 
too expensive. One of the simplest forms of underdrains is to cut a ditch of the proper depth and lay in the bottom two pine poles with the bark taken off. These are laid so as to leave a space between them and a larger pole is placed on top so as to form a channel for the water between the first two. The whole are covered with leaves to prevent the earth sifting in and the ditch is then filled. These pole-drains last well and have in some cases done effective work for twenty years. Drains are also made where rocks or stones are plentiful by placing them on the sides of the ditch and covering with other and larger rocks or stones and then with smaller broken parts before filling. These drains when well made are of a very lasting character. Still other drains are made by nailing four narrow boards in the form of a long box and laying these in the ditch. These, too, last well in the ground, for when kept constantly wet the wood, shut from the air, takes a long time to decay. But for permanent drains the earthen tiles are much to be preferred where the expense can be afforded.

Still we have had in use well-made stone underdrains which as near as could be ascertained were laid one hundred years ago and are still effective. The drains should be cut as deep as the fall in the land will allow, for the deeper they are below the surface and the nearer the lines of drains to each other, the more effectively they will lower the water-table.

Special tools are made for digging and shaping the bottom of the ditch and for laying the tiles. We have found that it is always better to cover the tiles at first with fine hay or straw to prevent the earth sifting into the joints of the pipes. 
Ground Plans In cutting ditches for underdrains they and Grading should run in a direct line to a general of Ditches drain or outlet. The grade of the bottom of the ditch must be made perfectly uniform, since any break in the grade will form sags that retain silt and choke the drains. In a piece of low ground bordered by high land and with a stream of water running through, the drainage is simple, as the ditches should run from the base of the hills directly to the stream, inclining somewhat in the direction of the stream to prevent any choking of the outlet. In this case the ground plan of the drains will be like the bones of a fish with the stream representing the backbone. The ditches should be as narrow as they can well be dug so that the tile at the bottom will rest in a solid bed of similar size and shape to the tile used.

The distance between the line of ditches will vary with local conditions. Where the fall is slight and the ditches not very deep, they will need to be nearer together; even where there is a good fall and the ditches are cut deeply they will be better near together, if there are strong spring heads near the higher ground. In fact we have found it an advantage to run a line of large tile around the base of the hill to cut off the springs and then to branch the tiles from this line to the outlet.

The size of the tile used will depend on the amount of water to be carried. Where the wetness of the land is caused by strong springs that break out and overflow it, there will be need of larger tiles to carry off this water than where the wetness is simply due to a general nearness of the water-table to the surface. Where the drains empty into an open ditch or stream the outlet must be protected 
with a facing of stone or bricks to prevent the washing and caving in of the bank. Where a tile drain crosses a springy place with many crawfish holes it is better to place a narrow plank in the bottom of the ditch on which to place the tile, as the burrowing of the crawfish is apt to throw the tiles out of line and choke them. Wherever the fall will allow it, the depth to which the water-table is lowered should be as nearly four feet as practicable. Where it is impracticable to have the drains so deep they should be nearer together. Never connect a lateral tile drain with a main tile at right angles, but always at a more or less acute angle in the direction of the current. The same caution should be used in terminating at an open outlet, where the end should be above the water in the open ditch or stream.

The higher or lower level of the source of the water to be drained determines the width between the drains to some extent. As before shown, the water-table in the soil will always be a little higher midway between the lines of tiles, and when the lines are too far apart the watertable midway between the lines will be practically undisturbed. Where the water in the tiles comes from strong springs on higher land above, the lower levels will become subirrigated from the seepage from the full tiles lower down and a permanent moisture maintained there. If this is not kept too near the surface it will be of advantage to some crops. We once had a piece of land kept moist in this way in which crops of melons and cucumbers throve all through the summer when on drier land they dried up after producing the first crop of fruits. For garden crops like celery this subirrigated land will prove very favorable. 
The advantages of underdrains over open ditches are so many that the matter is hardly debatable. Underdrainage, by lowering the standing water in the soil, admits the air to a greater depth and hence tends to make the soil warmer. It improves the mechanical texture of the soil through this admission of air separating the soil particles. The roots of plants are able to run deeper into the soil by reason of the improved depth of aërated soil and the improved texture. The soil dries earlier in the spring, and hence can be worked at an earlier date, which is of itself advantage enough to pay for the work. The presence of standing water in the soil prevents the release of nitrogen from the organic matter in the soil in the form of nitrates for the use of plants, both by shutting out the air and by preventing the increase of the bacteria which are engaged in the process of the nitrification or change of organic nitrogen to nitrates soluble in the soil water. There is also an acid condition in wet soils that is unfavorable to the growth of plants, and particularly unfavorable to the life of the soil bacteria, the microscopic plants which, as we have seen, are among the most important of the agencies engaged in the production of the higher plants that form our crops.

The immense arid regions of the far West,

IrrigationSurface and Overhead where the rainfall is too light for the production of crops, are made in many sections extremely productive through irrigation from canals conveying the water at a higher level from the upper waters of the streams. The United States Government is now engaged in a vast system of storage lakes in this region so that great areas of the land now in desert by reason of lack of rainfall, will be brought into cultivation. The 
need for irrigation on these lands is generally admitted. But few as yet realize the importance of irrigation in sections where the rainfall is abundant, where it is differently distributed. Our South Atlantic states have an abundant rainfall, which is at times excessive, but at other times they suffer from protracted drought. Cultivators, especially the market gardeners, are beginning to understand that a supply of water available in dry weather often makes all the difference between success and failure of the crops. Instead of running water on the surface in ditches the market gardeners of the South have devised a system of overhead irrigation by means of iron pipes elevated on posts high enough to work horses under. In some cases the water is forced by a steam pump directly through a main pipe of large size, from which lines of perforated pipes of smaller size branch forty feet apart from each other. By this means a general shower is made over the whole plot of land. In one instance we have examined eighteen acres are thus watered. In other cases the water is pumped to an elevated tank and from there distributed by natural flow to the pipes.

Another value has been found in this method of overhead irrigation. This is for the purpose of warding off damage from late spring frosts. The shower is kept up during a frosty night, and the cold water, being always above the frost point, with its latent heat prevents any damage from the frost. In hilly districts where there are running streams and low lands bordering them, irrigation may often be done with economy on a small scale by the natural flow of the stream being turned from above to take a higher level in a ditch along the base of the uplands 
from which it can be taken to water the market gardens on the flats by running the water slowly between the rows of vegetables. With high-priced products like those of the garden it is often, even in humid districts, profitable to provide some means for watering in dry weather. With the introduction of cheap gasoline engines for pumping water to elevated tanks this can often be accomplished even on lands that cannot be watered from streams.

In some sections, especially in Europe, on high-priced lands, the sewage flow from the cities has been utilized in the production of great crops of grass. The sewage flows over the surface and the surplus water is carried off by a system of underdrains. Irrigation for general farm crops in our humid sections is still in the future, but will come with the increase in population and the value of the farming lands. In one large institution of over five hundred inmates, in this country, the sewage is disposed of on a five-acre lot of grass. The sewage is received in a general cesspool from which porous tiles radiate in all directions, and below these are lines of drainage tiles to carry off the surplus water, which flows almost entirely purified by the absorbent power of the soil, into a stream below. The field cuts very heavy crops of grass.

It is probable that the overhead system, imitating a rainfall, will be the one most generally used by market gardeners. One market gardener's farm in North Carolina has now eighteen acres irrigated in this way. The overhead sprinkling pipes can also be used for the distribution of fertilizers dissolved in the supply tanks and can thus be distributed in the most uniform and readily avail- 
able manner. The absorbent power of a good loam soil is such that even when the plant food is in perfect solution the soil will hold on and rob the solution of the plant food so that nothing will escape in the drainage water except the nitrates. 


\section{CHAPTER IV}

\section{THE ANATOMY AND PHYSIOLOGY OF PLANTS}

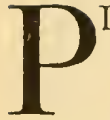

LANTS of all kinds make their growth by multiplication of minute box-like forms called cells. In the lowest forms of plant life the entire plant consists of a single cell containing the living matter known to botanists as protoplasm. This living matter, though itself a formless substance resembling the white of an egg, does all the work of the plant. From material carried by this formless protoplasm it builds the walls of its cell and carries on all the functions of life. As plants develop in complexity we find that the first increase of these cells is in long strings, cell added to cell in straight rows. With little higher organism, as in mosses, they are formed into flat tissues by the union of these rows of cells, making some resemblance to the true leaves of the higher plants. When we come to the ferns we find a greater complexity, certain cells taking on certain work and others making quite different forms. Then in our ordinary forest trees we find a still greater complexity and division of labor between the various cells.

By examining the cross-section of one of our trees we can see with the naked eye a series of rings of growth around a common center. Examining these rings with a microscope we find that the appearance of rings is produced by the decrease in the size of the cells and the thickening of their walls toward the close of the season, the new 
growth of the following season starting with large and thinwalled cells and gradually growing thicker-walled toward the close of the season of growth.

The ring-like appearance gives us the means for counting the age of the tree. Growth is added to the tree in circles of cells something after the manner of building a house by adding brick after brick, only that in the tree the brick-maker and the mason live inside the bricks and from their own substance construct the walls around them. In the first stages of growth, as between the bark and the wood, these cells are all in communication with each other, so that materials can be transported up or down throughout the whole increasing tissue of the cells, and their becoming more woody cuts off each cell to itself, and the living matter in each cell goes on thickening the walls around it till its substance is entirely used up, and in the completed wood there is no life left. It is now heart wood, dead wood, and remains simply as a support to the tree, while the life goes on circling around it and gradually adding more completed wood to the heart. That this heart wood is no longer of use to the tree except as a support is well shown by the fact that the heart may decay and the tree become hollow and the growth still goes on uninterrupted. But cut off the sap wood, and the tree at once dies.

\section{Two Leading Classes of Plants}

There is, however, another class of plants in the stems of which we see none of this ring-like growth, but the whole stem is filled with a multitude of long fibers growing through a softer aggregation of thin-walled cells. We do not find this character of growth in trees till we reach the 
section where palm trees grow, but all of our grasses have some such structure. Indian corn, really a grass, is a good example. Break off a dry stalk of corn and you will find a multitude of the thread-like forms growing up through the soft fundamental tissue. If we make a thin cross-section of a corn stalk and examine it under a microscope we shall see that these threads are really tubular in form and are the means through which each leaf on the corn plant gets the water from the soil. Not that the soil water comes up in these tube-like structures in the same way that water runs through a pipe, for the elongated cells are really filled with air and the water rises by permeating the walls of the cells.

These two classes of plants have been denominated, the first class exogens or outside growers, and the second class endogens or inside growers. While these names are not scientifically accurate they serve very well to distinguish the characters of the plants. The differences in their structure are correlated with other differences, beginning from the structure of the flowers, the germination, and the general habit of the plants. The better distinguishing terms would be to call the first class, the exogens, dicotyledons, because of the fact that in germinating from the seed they always have a pair of seed leaves, while the other class or endogens, are very properly monocotyledons, or one-seed-leaf plants. The seed leaves are termed cotyledons by botanists, and with the prefix, mono, the word means of one, and with $d i$, of two, seed leaves. There is still another class with which we have little to do in agriculture, which make a circle of seed leaves in germinating, and is therefore called poly, or many 
cotyledons. Our pine trees give us an example of this class. But the pines, while differing in their internal structure from many other plants of two or more seed leaves, are still outside growers like the true dicotyledons.

Even our common forest trees, which in the greater part of this country all belong to the dicotyledons, have certain of their cells transformed into the tubular shape for the conveyance of water and afterward for the distribution of the elaborated material for the growth of the tree. Various names are applied to these transformed cells by botanists according to the purpose they serve in the life of the plant. But it is not our purpose here to deal in botanical terms further than is necessary to comprehend the structures that carry on the life-work of plants.

To study the growth of a plant it is best The Study of to begin with the seed. One of the best subjects to select for study is the common garden bean. Take some beans and soak them for a night in water. The next morning you will find that they have swollen. This is the first step toward germination. So long as a seed is kept perfectly dry the living matter in it will remain dormant, and in some seeds it can be kept dormant, but still living, for many years, whilc others lose their vitality in a short time, and some will not even admit of complete drying. But to return to the swollen bean. You will find that it has a protective coat around the whole - a sort of skin. On one side you will find the eye or scar where it was attached to the interior lining of the pod. On one side of this eye you will find a raised lump and on the other side a minute opening through the outer skin. Now place a knife blade carefully 
on the other side of the bean and split it into halves as it naturally divides. Down near the eye you can easily sce a pair of miniature leaves and a short pointed stem, the point being directed straight toward the little opening we noticed on the outside. The bean, having imbibed moisture, is ready to begin active life, for a plentiful supply of moisture is essential to the activity of the living matter in the sced, which performs all the work of the plant, and it must swell from its dormant condition and fill the cells before active life can begin.

Now place in a deep saucer a number of layers of thick blotting paper and wet them well. Lay some of the swollen beans on this wet paper and cover the saucer with a pane of glass, and keep in a warm place. At the same time plant some in wet sand in a box with the eyes of the beans down. Watch those on the paper and in a little while you will see the pointed end of the stem you examine in the split bean protruding through the little opening, and directly the two halves of the bean begin to separate and rise up, and become somewhat green in color. The stem runs along on the damp paper straight ahead and becomes a root, and shortly other roots branch from it, each with a pointed end. Examine these roots with an ordinary magnifying glass and you will see that the end of each rootlet is naked, while just back of it the root is covered with a velvety coating of fine hairs.

The older botanists told us that the extreme tips of the roots of plants were soft and spongy, and they called them spongioles, supposing that it was by them that the plant got food from the soil. We now know better, and know that the means through which the plant takes food from 
the soil dissolved in the soil water, is the mass of fine root hairs just back of the pointed tip, and that instead of being the softest part the tip of the root is really a little older than the part just back of it.

We have seen that the growth in a tree is carried on by the increase in cells circling around it under the bark. The same is true with the roots. The protective cover of bark is carricd to the remotest rootlet, and the cells increase under it at the tip and around it everywhere. The added growth at the tip under the root-cap pushes the root forward in the soil, while the outer part wears away to some extent and is constantly renewed. You will understand at once that this is a wise provision, for if the extreme tip were really the youngest growing point it could never insert itself among the particles of the soil. 'The root hairs, which are the means through which the plant gets food from the soil, dry up and dic off as the root gets older, while new ones are constantly being formed out near the advancing root-cap; so that the roots are always foraging in new soil. This illustrates the error that a multitude of farmers make in putting manure or fertilizers only in the hill for corn. It would do the corn far more good at the critical period of earing if it were in the middle between the rows, where the advancing roots would find it at caring time. In the hill the roots soon pass it and are foraging in poorer soil which fails to sustain the growth started by the manure in the hill, and the corn plants soon show that they are failing. Knowing, too, that the portion of the roots engaged in getting food from the soil is a short part near the tip of the rootlets, we can understand the folly of running a plow decply through 
a corn field and tearing off the roots that were feeding the plants.

But to return to our beans. Note the beans planted in the box of moist sand. The two halves of the bean separate as they come above the soil. They get larger, and green in color, and the little leaves that you saw in embryo in the split bean are developing into large green leaves. Until the plant takes on this green color it is entirely dependent for food on what was stored in the dry bean. The two halves, separating, form the cotyledons or seed leaves, though they never take on the character of true leaves, and it is not necessary they should in the bean because of the rapidity with which the second pair of leaves come out. But the thick cotyledons could remain under ground and feed the plant till the true leaves appear. In fact this is done by the garden pea and the acorn, the cotyledons of which always remain below ground, and the first leaves seen are the true leaves and not seed leaves.

The green color is caused by certain granules in the living matter of the cells taking on a green color. These granules are called chlorophyll grains, and the green color they carry is the most important thing in the life of the higher-developed plants, as we shall see later. The little bean, now having roots, a pair of seed leaves, and a second joint and pair of leaves, is a complete plant, and has all the parts that any plant has, even to the largest tree; for the great tree is but a repetition of these plant units: a node or joint, an internode or space between the joints, and a pair of leaves or one leaf. The bean plant in the sand has these, and the great tree merely has more in number of the same things. 
How Plants

Get Food from the Air

We have said that the green granules in the living matter of the plant cells known as chlorophyll, are one of the most important things in the life of the plant. And the green color is essential to their activity. Let a potato sprout in the dark and you may take the section of the stem and find that the granules are there, but have not taken on the green color. Find two potatoes of exactly the same weight. Let one sprout in darkness and keep the other one from sprouting till the sprouted one has made long white shoots. Then thoroughly dry them both as a chemist would dry them and you will find that the sprouted one has not gained anything in dry matter. There has simply been a transfer of the materials stored in the potato to a different form, and no real growth has been made. Now take two similar potatoes and let one of them sprout in the full light of the sun till there have been developed strong green shoots, then dry both again, and you will find that the potato that has made green sprouts has gained a little in dry matter.

Hence we find that in some way the green color is an important thing in the plant life. By far the larger portion of the structure of all plants comes from the air, over 95 per cent. How then does the plant get the material for growth from the air? In the leaves of every plant, especially on the underside of all leaves, there are numerous openings of microscopic size, on each side of which there is a cell something like a lip, and these two lips constitute really the mouths of the plant, for they are capable of opening and closing just as we can open and close our lips. They open between the loosely arranged cells in 
the interior of the leaf. These cells are full of the green chlorophyll granules. The air, as we have seen, always contains a minute portion of carbon dioxide or carbonic acid gas. When the sun shines, and at no other time, the mouths of the leaf, or the stomata (singular stoma), open, and the air with the carbon dioxide, can penetrate to the interior of the leaf, there coming in contact with the green granules. This green material has the extraordinary power of breaking up the combination of the carbon and oxygen in the carbon dioxide and taking in the carbon. The leaf throws off the oxygen and thus serves to purify the air from the carbon dioxide which, while furnishing food to the plant, is poisonous to animal life. It cannot of course be determined that the plant does throw off the identical oxygen that was combined with the carbon, but it does throw off about the same amount. Getting this carbon, then, from the air, the living matter in the cells of the leaf goes to work to make further combinations with it and the hydrogen, oxygen, and other matters brought from the soil. So it constructs new material for new cell walls, for renewing the waste of living matter, and for the purposes of growth in general.

The materials elaborated in the leaves are sent to every part of the plant where cells are forming and growth is going on. To the remotest tip of the shoots and the farthest rootlet, the materials for growth are sent from the leaves, so that whatever the leaf of a plant is that will be what the plant as a whole is. No mistake is ever made. The leaves of the apple tree manufacture material for apple wood, apple roots, and apple leaves only. The oak and the pine growing side by side with their roots inter- 
laced, never forget that they are oaks and pines, and that each takes food from the soil in a different way and makes a different article in the final result of its work. The soil water, brought 1 p by the roots and distributed to the leaves through the elongated vessels which branch into the leaf and form what we call the veins of the leaf, has food for the plants in a very dilute state. The stomata of the leaves then take on another office, and to some slight extent the whole leaf aids in this. 'This is the evaporation or transpiration of moisture, in the form of invisible vapor, into the air. Thus the plant condenses the watery food, retaining the food and parting with the surplus moisture. Sometimes this evaporation becomes too rapid, and the moisture passes off more rapidly than the roots can supply it from a comparatively dry soil. The result is that the leaves wilt and the stomata in the leaves close, so that the evaporation is checked. 'The wilting of the leaf is Nature's method of checking evaporation. If too long continued of course the plant dies, but under ordinary conditions the plant during a night will have taken up more moisture from the soil and the morning finds it freshened again and ready to resume work.

If you will examine the arrangement of the leaves on a branch of any plant or tree you will find that they are arranged so that each leaf has its own share of exposure to light and air, so that cach leaf has its own opportunity to do its work.

When the leaves take in the carbon dioxide and in this way get carbon by breaking up the combination with the oxygen, the plant goes to work, as we have said, to manufacture the materials needed for growth, and for the sup- 
port of its living matter. 'The first thing we can find that is formed in this way is starch, but it is probable that really some form of sugar for the immediate consumption of the growing plant is first formed, though it cannot be detected. Starch is called a carbohydrate because it consists of carbon, oxygen, and hydrogen. Carbohydrates are used by plants for building purposes and as a storage form for food to be used in subsequent growth. Starch is largely stored up in seeds, but in some seeds is very largely changed into oil, as in the cotton seed and others. When we put a seed in the ground and it imbibes water and begins to germinate, the starch is transformed into a sort of sugar which the growing plant can use, for starch as starch is not digestible by animals or plants.

In the germinating seed there is a sort of ferment formed that changes starch to sugar without itself being in any way changed. We have the same thing called diastase in our saliva, and when we cat starchy food this is mixed with it and changes the starch to a glucoside or sort of sugar, so that it is made digestible. Starch, then, is a storage for food. It is stored in the cells of the plant and when active growth begins it changes into sugar for use. Take a potato that has sprouted, and on cooking it you will find that it has become clammy and has a sweetish taste, owing to this transformation of the starch. In seeds where the food is stored in the form of oil the oil is transformed back to starch and the starch to sugar for the use of the plant till it can develop green leaves and get more material from the air for the manufacture of more starch. From the starch all the long list of substances called carbohydrates is formed; the sugars, oils, acids, and 
woody material for trees. The only part of the plant containing nitrogen is the living matter or protoplasm, which does all the work of the plant. We find, then, in all our food crops these two classes of substances: the nitrogenous or proteid materials and the carbohydrates and fats. Of these and their nature we will treat in another lesson.

'Take a large plant of green Indian corn How Plants

Get Food from the Soil and cut it up and weigh it. Then dry it thoroughly by artificial heat so as to drive off all the water. Weigh it again, and you will find that it has lost a great deal by parting with the water it contained. Now burn it. Burn it thoroughly, as a chemist would in a crucible, till nothing is left but pure white ash. With the exception of the nitrogen and water which has been driven off into the air, this little handful of ashes contains all that the plant took from the soil, and you can realize how small a portion of the bulk of the plant came from the soil. The ashes contain the lime, phosphorus, potassium, and other mineral elements. You have destroyed the stalk of corn as a stalk of corn, but you have not really destroyed anything. You have simply ehanged to another form of energy the energy of position located there by the sunlight acting on the green leaves. Thus in burning coal we get back the radiant energy of the stunlight of long ages ago when the plants that formed the coall-beds grew; and we send back to the air the materials that in the first place came from the air, the carbon dioxide and the water, so that nature can begin to use them over again in the construction of other plants. We can change the form of matter but we can never destroy anything. 
Now, how does the plant get these mineral elements from the soil? In treating of the germination of the bean we have seen that near the pointed root-cap there is a short space covered with velvety hairs. These hairs on the rootlet are the absorbing agents of the plant through which it gets food from the soil. The pointed root-cap we learned is projected through the soil by the increase of cells behind it; and as fast as new root growth is marle there is a new belt of root hairs formed as the old ones dry off, so that the roots are always foraging in fresh soil. Since these root hairs are of extremely minute size, though they have been demonstrated to be tubular, they cannot take in any undissolved matter, and hence the food for the plant must be completely dissolved in the soil water.

There is some evidence, as you saw in an earlier lesson, that the root hairs themselves have a power to hasten the solution of matters in the soil, and they certainly have the power to select from the dissolved plant-food in the soil water the elements they most desire. Thus, one plant will use potash in much larger percentage than another, and another will seek out the phosphorus and nitrogen more largely. No matter how the roots interlace in the forest each tree does its own work and never by any mishap takes on the work of another.

The soil water, laden with the plant food taken in with it, is carried up through the long tubular-shaped cells and the veins of the leaf till it meets the carbon taken in from the air; and then, in the leaf, which is the laboratory of the plant, all the materials that add growth to the plant are formed. The water that rushes up into the trees in the spring is not sap but merely the material 
for the manufacture of the elaborated sap in the leaves. The plant gets from the soil nitrogen, phosphorus, potassium, lime, magnesium, sulphur, and some other minor things. The nitrogen originally comes from the air to the soil, and we have means for getting it back from the air, as we shall see.

Each part of the plant, we have observed, has its particular function. The leaves, with their chlorophyll, take in and decompose the carbon dioxide in the air, appropriate the carbon for starch-making, and return oxygen to the air to purify it for animal life. The roots, with their constantly multiplying areas of root hairs, take the various ash elements and the nitrogen from the soil dissolved in the soil water, and carry the dissolved food up through the conducting bundles of cells to the leaves. 'There the material for construction and for the food of the living matter is formed, and from this claborated material all the increase in the cells of the plant is made, both to tops and roots. It is plain, then, that roots are the product of stems and leaves, and not stems and leaves of roots. It is perfectly possible in most plants to place a cutting under proper conditions, and from food stored in the cells of the cutting to form roots, and in this way to make a new plant that is identical with the plant from which the cutting came. In some plants it is easy, indeed, to make new plants also from cuttings of the roots, for on many roots there occur what are known as adventitious buds. But this fact does not contradict the statement that roots are the product of stems, for the material from which growth is made from a root cutting is the result of materials stored there by the stems and leaves. 
Some green-leaved plants grow immersed in water, and these get their carbon from the air always present in water and in turn they keep the water supplied with oxygen to support aquatic life in animals that live in the water. Put a few fish in a vessel of water, and they soon exhaust the oxygen and are found sucking air at the surface and soon die. But if a few water plants are grown in the vessel where the fish are they remain healthy and thrive. This shows that water always contains some air, and that plants are essential to animal life in water as on land. Without plants there could be no life either on land or in the water, for plants use the minerals which animals cannot use and transform them into shapes that are the food of animals. On the other hand, a large part of the food of animals is excreted and returned to the soil for the use of plants, and the dead bodies of animals return to the earth to feed other plants, thus keeping up the round of nature.

Plants are increased in various ways. How Plants The natural way in which all of our higher Are Perpetuated and Perfected plants are increased is by the seed. In the blossoms of plants the leaves, which on other parts of the plant perform the work of taking in carbon, are transformed into the various organs, each having its special office to perform in perpetuating the life of the plant.

The normal, complete, and perfect flower has four sets of organs. First, at the end of the stem bearing the flower we find what is called the calyx of the flower. This is commonly green, but sometimes colored (botanists do not class green as a color, it being the natural color of plants, and when a part is said to be colored it means 
that it is some color beside green). Inside of this calyx there is a row or rows of colored leaves, known as petals, and these taken together form the corolla of the flower. The calyx, the scparate leaves of which are called sepals, and the corolla take no part in the formation of the seed. They are the protective parts of the flower; and by the color of the corolla bees and other insects are attracted to the flowers and serve to set the seed, as we shall see. Inside the corolla there are a row or rows of still more transformed leaves, commonly slender and hair-like, and on the end of each of these is a closed vessel containing minute cells of living matter. These are called the stamens or male part of the flower, and the vessels at the ends are called anthers. The little cells of living matter contained in these anthers are what is called pollen. As this pollen matures the vessels containing it open in various ways, so that the fine pollen grains are dispersed. In the interior center of the flower is another organ called the pistil. A normal pistil consists of an ovary or seed vessel at the base, a more or less elongated stem called the style, and a space at the top of this which is entirely bare of any skin or covering and for a time is moist, and which is called the stigma. Now, when the pollen in the anthers of the stamens is mature and is dispersed it falls on this moist stigma. At once the little cells begin to grow and penetrate downward through the style of the pistil till they reach the ovary or seed vessel. In this ovary there are certain bodies known as ovules. The living matter of the pollen reaches the living matter in these ovules, and at once a new growth is started and finally the germ of a new plant is forned-a seed-and is 
surrounded by or includes a store of material that can be used by it in germinating when the seed is planted. The seed now formed, with its germ and store of food, parts with its water and ripens into a perfect seed, which is capable of remaining dormant for a longer or shorter period in different plants; and when placed in the soil it imbibes water and the living matter again becomes active, and the food stored in the seed supports the growth until green leaves are formed and new material for growth can be got from the air.

We have described a normal, complete, and perfect flower. A complete flower has all the organs named, but a flower may be perfect for all the purposes of seedmaking when the corolla and calyx are absent, hence the distinction between a perfect and a complete flower. Some species bear flowers on one plant which have only the male organs, and have the pistils or female organs on flowers borne by other plants. Some plants, like our Indian corn, have male flowers or stamens on one part of the plants and the pistils or female flowers on another part.

In Indian corn the anthers with their pollen are the tassel, and the pistils that belong to every grain on the ear are what we call the silks, and the part of the silks that extend beyond the ear are the stigmas which receive the pollen, and this perfects the embryo or germ in the grain of corn. The tassels with the pollen are elevated so that the pollen does not generally fall on the stigmas of the same plant, but is blown to others. But in a corn field this pollen is made in such great quantities that all the pistils usually get a supply, and nature adopts this plan to prevent too 
close breeding. One can easily see that this is so by observing a solitary plant of Indian corn that grows at a distance from any other corn plant. You will find that only a few grains will be formed on the cobs, because only a little of the pollen fell direct on the stigmas of the pistils. You will also see that a plot of yellow corn planted to the windward of a plot of white corn will affect the white corn, and make scattered grains of yellow corn by reason of the wind-borne pollen. In this way corn will often mix a long distance. All of our plants and crops make a great abundance of pollen in order that there may be no lack of seed-making.

All this is Nature's process for the increase of plant life. Man has devised many other methods for the increase of plants. It is found that by crossing in various ways of the pollen of one plant on the pistils of another the plants grown from seed can be made to vary greatly. Hence, in our fruit trees we seldom resort to the seed except for the purpose of getting new varieties. We continue the identical plant by dividing it in various ways. This can be done by making cuttings and rooting them as we have shown, or the cutting may be inserted as a graft or bud on another plant which already has a root, and this serves to sustain the new part that is attached to it and allowed to make the future tree. Or we may bend a branch to the earth and cover it till rooted and then have a new plant identical with that from which it came. Of all these artificial methods of increasing plants we will treat in detail in further lessons. Our farm crops are grown from seeds, and the perfection of the seed is a matter of great importance to the farmer. Every farmer, 
therefore, should understand the methods best adapted to the perfection of the seed he uses for his crops.

Much has been published of late years in Plant-breeding regard to the improvement of the corn crop, Applied to the and great stress has been placed on the
Corn Crop and proper selection of ears for this purpose. But the mere selection of pretty and well-formed ears will do little toward the improvement of the corn crop. In any improvement of our plants used for farm crops we must make a careful study of the whole plant. If we breed corn simply for a pretty ear we may get the pretty ear borne on a very undesirable plant with but a single ear, and that too far from the ground and liable to be blown over. In starting the improvement of Indian corn we must remember what has been said of the way corn is fertilized by the pollen around it. Each silk is a separate pistil, with its separate ovary, the whole of which is transformed by the pollen into a fruit or grain. So, instead of assuming that the ear is the unit to begin with we must know that each grain on the cob may have, and probably has, a distinct male parent or pollen grain, and is therefore entirely different in its inheritance from the grain just beside it. Now, if the pretty and well-formed ear we have selected by the score card has grown where it is surrounded by inferior plants it is easy to see that it will be as apt to reproduce the inferior plants as the one from which it came. Therefore, the farmer who wishes to improve his corn should plant a plot to be grown for seed. He should use corn that has long been grown in his section, for corn from far north or south of any given locality will not do well there till acclimated. He should give this 
plot the best attention in the cultivation. Then, when the plants begin to make tasscls, go through and remove these from the plants that show no ear coming, and from all of an inferior character and of too tall and ungainly stature or too stunted growth, or that are evidently of inferior production. In this way the pollen will be produced only by the best plants in the plot. From the best ears grown in this way select seed for another plot, and use the general product for the field planting. Take the same care every year with the seed plot to get all the plants nearer and nearer to your ideal of a perfect corn plant.

Breed at first for productiveness in ears, and after the trait of bearing two or more ears is well established it will be time enough to go by the score card and select the best ears. I have given these directions for the selection of seed corn as it is one of the important crops and one that yiclds readily to proper selection. You want plants of corn of a sturdy habit, with short joints and broad leaves, for the leaf is the most important organ in the general development of the plant. Similar methods will be of value with all of our crops, whether wheat, cotton, or any other crop; for only from the best formed and best matured seed can the best crop be grown. Of other crops we will have more in detail hereafter. We have used Indian corn to illustrate how plants develop. How the roots of this corn plant should be developed and improved we will discuss more fully when we come to tillage of crops. 


\section{CHAPTER V}

PLANT FOOD IN THE SOIL

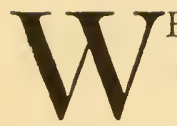

THILE plants get the larger part of their bulk from carbonaceous material constructed from carbon taken out of the air, we have scen that the elements which they get dissolved in the soil water through their roots are of vital importance, for without the water itself the carbon would be useless, and without the nitrogen there could be no protoplasm to continue the life work of the plant. A fertile and productive soil is not only one in which there is a good supply of the elements which the plant gets from the soil, but one in which the mechanical texture is such, and the condition of the plant food is such, that the roots of plants can make use of the food.

Years ago the notion prevailed that all that was necessary to show the farmer how to improve the productiveness of his soil was for the chemist to make an analysis of it and show him what it lacked so that he could add the lacking materials. But experience has shown that this analysis is of little value to the farmer, for the chemist can simply tell him what the soil contains, but cannot tell him whether plants can use these materials or not.

Sometimes certain plant foods, especially potash, which are in an unavailable condition in the soil, may be made available by the use of lime or plaster, which is the sulphate of lime, and many farmers seeing that lime helps 
their soil have jumped to the conclusion that all they have to do to make their soil rich and productive is to keep using lime on it, not realizing that the effect of the lime is to make available the supply of potash that already exists in their soil. Hence, there came about the proverb that "lime enriches the father and impoverishes the son." While this is true when lime is incautiously used, with the idea that it is simply a manure, lime is of great value in improved agriculture, as we shall see later.

Plants cannot grow in any soil which does not contain nitrogen, phosphorus, potassium, calcium, iron, magnesium, sulphur, sodium (for some species), chlorin, and silicon. Most of these exist in inexhaustible amounts in all cultivable soils. Those which are liable to become exhausted or deficient from cultivation are nitrogen, phosphorus, potassium, and sometimes calcium. The crops we grow take these in larger amounts than other elements. If any one of these is in the soil in a smaller percentage than a proper development of the plant requires, the crop will be smaller even though the other elements are in full supply. The soil that has a very small percentage of potassium and phosphorus may have a large supply of nitrogen; and the plants may make a rank growth and yet fail to perfect grain, since the perfection of the grain depends on these elements. In like manner there may be a full supply of these available and yet a deficiency of nitrogen, and the plants will make a feeble growth, and lack the healthy green of flourishing crops. Hence it is necessary that the plant food in the soil shall be as well balanced as it has been found necessary to balance the rations for our domestic animals. 
Then again, a soil may be abundantly supplied with all the elements of plant food in a perfectly available form, but if there is no water to dissolve them for the use of plants the soil will be a barren one, or produce only such plants as are able to exist in desert conditions. The results of irrigating the desert lands of the West show this very plainly. Still again, the soil may possess an abundance of plant food, but the temperature of the soil may be kept too low by the presence of water near the surface, the water, too, shutting out the full supply of air which is essential to plant roots. So the soil will be unproductive except in such plants as prefer these saturated conditions, and the growing of farm crops on such land imperatively demands the drainage of the surplus water. Then, too, as we have said, the physical and mechanical nature of the soil may prevent the prosperity of plant life on it, and means for ameliorating these conditions are usually within the reach of the farmer, as we shall endeavor to show later.

While all the elements named are essential to plant life, some of them exist in all soils so abundantly that there is never any need for using them as additional plant food. Iron, for instance, is the most abundant of all the elements. Our clays are colored with the oxidized iron, and we could hardly make up a mixture of fertilizing materials without at the same time getting some iron in it. The green color of plant leaves caused by the chlorophyll grains, is due to iron, and so long as trees and plants in general make green leaves it is evidence of an abundance of iron. Sulphur is essential, but it is always in combination with other elements in the soil and the fertilizers 
used, and we do not use sulphur as sulphur. (In fact, as we shall try to explain, we do not use any of the elements in the soil as pure elements.) Sodium is essential mainly to marine plants, and is of little use in the plants usually grown as farm crops. There was some years ago an effort made by the salt manufacturers to make the farmers believe that sodium could take the place of potassium. But you have been told that plants will not thrive where there is a deficiency of potash, though there may be a large percentage of sodium. None of our cultivated crops use sodium to any great extent, though the chloride of sodium, common salt, may have some effect in the solution of other matters in the soil, and to some extent may be useful to such crops as cabbage and beets, which in their wild state are natives of the seashore. Lime exists in the soil as the carbonate of calcium, and is largely used by plants to render harmless certain acids, such as oxalic acid, which are formed in the plant. The oxalic acid is located in crystals of the oxalate of lime in certain cells, and this form being insoluble in the cell sap, the acid is rendered harmless to the plant. Lime is also found in all the cell walls. But the supply of lime needed as plant food is usually abundant in all cultivated soils, and it is mainly valuable as a reagent, as will be explained in full.

Nitrogen is a gas which we have shown to be the larger part of the mixture of nitrogen and oxygen which we call air. Hence it must be got into combination with other matters before it can be located in the soil and become available to plants. Considerable quantities of nitrogen are brought to the soil in the rain water in the form of ammonia, which is a hydride of nitrogen. The decay of 
organic matter, or matter that has once formed the bodies of animals or of plants, also brings ammonia to the soil. But it has been found that the roots of ordinary plants do not use ammonia. When the organic matter decays in the soil, however, the decay is caused by certain low forms of plant life known as bacteria, which hasten the decay by their growth and through this decay release the ammonia. Then other forms of these bacteria, which thrive in a soil abounding in organic decay or humus, feed upon the ammonia and the final result is the formation of nitric acid in the soil through their oxidation of the nitrogen. Then this nitric acid at once combines with whatever alkaline base may be present, usually lime or potash, and we have a nitrate which plants can use at once, and which if not used at once is soon washed from the soil by reason of its great solubility. Careful experiments have shown that our green-leaved plants use nitrogen only after it has been brought to the condition of a nitrate, and as this process of reducing organic matter and releasing its ammonia and converting it into nitric acid is carried on by the minute plants in the soil known as bacteria, it is evident that to maintain this useful life in the soil there must be in the soil a due amount of organic decay or humus. The office of nitrogen in the plant seems to be the promotion of vital activity tending to rapid growth. But this growth can be maintained and matured properly only when the nitrogen has associated with it a due percentage of the ash elements which plants get from the soil. Probably the most important of these is phosphorus.

We have shown that we cannot use nitrogen as a pure element in the feeding of plants. In like manner we can- 
The Role of not use phosphorus. Pure phosphorus takes Phosphorus in the Plant fire at once on being exposed to the oxygen of the air. This fact is made use of in the manufacture of our friction matches. Hence we must get our phosphorus in some combination in which it can be used by the roots of plants and can for this purpose be dissolved in the soil water. Phosphoric acid, the oxide of phosphorus, is generally found combined with calcium, forming the phosphate of lime. It is found in this shape in fossil rocks and in the bones of animals in general. As it exists in soil it is one of the most rapidly exhausted forms of plant food. The ripening grain takes phosphorus from the soil. The availability of the phosphorus in the soil depends upon the form in which it exists. In freshly ground bones it is sooner made aviilable than in the pulverized fossil rock, because of the more rapid decay of the fresh bones. But unlike nitrogen, it does not rapidly leach away from the soil in the drainage water, for a good loamy soil or clay soil will hold on to it till some plant calls for it, but in case there is more of the soluble phosphoric acid applied than plants at once use it will revert to a less soluble form and remain to become more slowly arailable.

The exact office which phosphorus performs in the plant is less fully understood than that of other elements. So far as we know it seems to be mainly useful in the transfer of formed materials to points where maturity is needed, as in the ripening of fruits and seeds. There may be great activity in the plant through an abundance of nitrogen, and yet the grain may fail to perfect through the deficiency of phosphorus. 
The Rôle of

Potassium in the Plant

Potassium is a metallic element, and like the other elements cannot be used by plants in its elemental form, but must be had in some combination. We get potassium in the form of the oxide of potassium, or as it is commonly called potash. No plant can thrive in the absence of available potash in the soil. In our clay soils, which are the result of the decomposition of granitic or feldspathic rocks, there is usually a large supply of potash in the form of an anhydrous silicate, which becomes slowly soluble through the action of the lime in the soil and the carbon dioxide in the rain water, and it can be rendered more rapidly available by fresh applications of water-slaked lime, which, as one chemist has said, "pushes out" the potash from its insoluble silicate. While nitrogen rapidly leaches from the soil in the drainage water, there is but a slight loss of potash in this way, for the soil holds the phosphorus and potash much more strongly than it does nitrates, and but the merest trace of these is usually found in the drainage water. Potash is much more slowly used up from the soil by crops than phosphorus is, since in the ripening of grain the potash largely returns to the roots. Still there are crops like potatoes and tobacco which select far more potash than other plants and hence these exhaust the soil supply most rapidly. Potash also exists in nature in the combinations with chlorine, sulphur, and carbon, making the muriate, sulphate, and carbonate of potash. These are all readily soluble forms, and are the forms in which potash is most commonly used in fertilizers. It is also combined with nitrogen in the form of the nitrate of potash, or as it is commonly called, 
saltpeter. Wood asles, especially those from the hard woods, contain a considerable percentage of potash and a large percentage of lime, and are of value as a source of potash. As an ingredient in a fertilizer, potash is of less importance on many soils than phosphoric acid or nitrogen, because of its greater abundance in clay soils and because less of it is removed in the crops than of nitrogen or phosphorus. Nevertheless it is important that a sufticient supply be at hand in the soil in an available form; and sandy or peaty soils are generally deficient in potish. Manufacturers of commercial fertilizers have as a rule given too much prominence to phosphoric acid in their mixtures and too little to potash, especially for use on such crops as largely select potash. In the economy of the plant it has been fully shown that phosphoric acid does not have its full effect unless there is a due supply of potash present, and on the other hand potash will not give the best results in the growth of the plant unless there is also a due percentage of phosphoric acid a vailable. The interdependence of these can be easily understood when we realize that the office of potash in the plant is to favor the formation of starch and that of phosphoric acid is the conveyance of the formed material to points where it is needed in the construction of new cell walls. Starch, which we have seen is the starting point of materials for building, and the storage form of plant food, cannot be abundantly made for phosphoric acid to convey to the grain as plant food, unless sufficient potash be available. Though the combination in which potash is applied to the soil may be perfectly soluble in the soil water, the absorptive power of a good loamy or clay soil is such 
that it will retain the potash from a combination like chloride of potash while the chlorine may be leached away. That is, the absorptive power of the soil is such that it will rob a complete solution of the mineral elements and keep them till some plant roots need them.

Lime exists in rocks and in the shells of marine shellfish as the carbonate of calcium. By burning the rocks or shells we get the oxide, and this, rapidly slaked with water, makes a hydrated lime which is still quite caustic and active, but rapidly returns on exposure to the air to the more insoluble form of the carbonate. Lime is essential to plant life, but while large percentages of lime are found in the ashes of plants a comparatively small percentage is really used as plant food. It is taken in because it abounds in the soil water and is useful for the thickening of the cell walls in woody plants, and is also used by plants to render harmless certain acid that is formed as a sort of excretory or waste matter. This was discussed in Chapter II. Though lime is essential to plant life there are few soils in which it is not abundantly present for this purpose. Nevertheless fresh applications of lime are often very beneficial. Soils through long cultivation are apt to become acid, and many of our crops will not thrive in an acid soil. Lime, then, is useful to correct the acidity of the soil and render it slightly alkaline in its nature. Lime also has a good effect on heavy clay soils, preventing the clay from forming hard masses, by flocculating it into small masses that aggregate loosely together. The use of lime on a sandy soil has been spoken of in Chapter I. While lime to a small extent is plant food, it differs from the other elements which we have mentioned as plant food 
in the fact that it is more a stimulant and reagent in rendering plant food already in the soil available to plants.

In a soil abounding in vegetable decay the work of the bacteria which change the organic nitrogen into nitrates is greatly helped by lime, for these microscopic plants have a power which no green-leaved plant has, in that they can get the carbon they need from the carbonate of lime, while green-leaved plants get it from the air as we have before explained. Lime should never be mixed in fermenting animal manures, as it tends to make the ammonia in the manure more volatile and to drive it off into the air. On the other hand plaster, which is the sulphate of lime, has a tendency to prevent the loss of ammonia by putting it into a less volatile form.

It is supposed by some that the use of the dissolved phosphatic rock or acid phosphate is apt to render the soil acid, by the plants taking up the phosphorus and leaving the sulphuric acid which at once unites with the lime already in the soil, and in this way robs the soil of lime carbonate. In this case lime freshly slaked in water and applicd will restore the lime needed as a carbonate, and will tend to sweeten the soil.

It has been found that a sour condition in the soil is detrimental to the bacterial life needed there, and in this condition clover fails to grow, and the farmer says that his land is "clover sick." This condition always indicates the need of lime. Lime is of great value to the student farmer, but must be used intelligently because it may be of damage to the man who does not study his conditions. 
We will now examine the sources of various plant foods, and will first deal with nitrogen.

Sources of Nitrogen

We have explained that nitrogen exists as a gas in the air, and that to get it in the soil from which our crops must derive it, it must be in some combination, and that the final form in which plants use it is in combination of nitric acid with a base, forming a nitrate of lime, potash, or some other base in the soil. When it is reduced to this available form it is so readily soluble that it washes out of the soil more rapidly than any other form of plant food, and hence must be more frequently renewed in the soil. Then, too, when the vegetable matter in the soil is rapidly oxidized or burnt up by the continuous cultivation of one crop year after year on the same land, as our cotton farmers and the wheat farmers of the Northwest have been doing, there is a serious loss into the air more than through the cropping. Nitrogen, when purchased in any form, is always the most costly of all the plant foods that make up our commercial fertilizers. It is found in all decay of vegetable or animal matter, and is then known as organic nitrogen. A soil abounding in humus or vegetable decay is usually supplied with nitrogen more or less available. One special value of stable manure is in the organic matter which is applied with it, and which, having to pass through the process of nitrification in the soil through the agency of bacteria, makes the more lasting effect of such treatment. We also get nitrogen in an organic form more readily available in the dried blood from the great slaughterhouses. When this is carcfully dried and is of a red color it is far more valuable than that which has heated and has turned to a 
black color. 'The red blood may contain as much as is per cent. of nitrogen. A similar and important source of nitrogen is the dried and pulverized scrap from the fishoil factories, which contains 8 per cent. of nitrogen and nearly as much of phosphoric acid.

Another product from the slaughterhouses is what is known as tankage. All the refuse animal scraps which cannot be utilized as food for men are boiled down and dried and pulverized. Its value depends on the material used, so that tankage varies greatly in the percentage of nitrogen. Some manufacturers of fertilizers have used ground leather scraps, wool and hair waste, and horns as a source of nitrogen. These are of little value in a fertilizer on account of their slow decay.

A great source of nitrogen is cotton-seed meal, which is the by-product in the manufacture of cotton-seed oil. The pomace left after pressing castor-oil beans is also pulverized and used in like manner. Cotton-seed meal will contain from 7 to $S$ per cent. of nitrogen and also some phosphoric acid and potash. The best authorities, however, believe that this meal should not be used as a fertilizer clirect, since its feeding value as a component part of a well-balanced ration for farm animals is greater than its manurial value, while the larger part of the nitrogen can still be recovered in the manure, and thus greater profit will accrue to the farmer than by using it as a direct manure. But all manufacturers of fertilizers use it very largely in their mixtures.

Formerly one of the chicf sources of nitrogen was in the Peruvian guano from the Chincha Islands in Peru. But this cleposit was long since used up, and the Peruvian 
guano of to-day comes from a different set of islands and has a far lower percentage of nitrogen, though a high total of phosphoric acid. One of the greatest sources of nitrogen of late years is the nitrate of soda found in Peru. This, being already in the form of a nitrate, is at once available to plants, and is always to be applied to growing plants and not to dormant ones in winter, since if not used at once by plants it is readily leached by the soil. Another important source of nitrogen is the sulphate of ammonia. This salt when pure contains 2 T.2 per cent. of nitrogen, ammonia being a hydride of nitrogen, and in the ordinary commercial forms it has 20 per cent. of nitrogen. This makes it far richer than nitrate of soda. In the manufacture of boneblack for the sugar refineries by distillation it is obtained, and also from the waste ammoniacal liquor from the gas works. Of late years improved methods of making coke have increased the amount of sulphate of ammonia saved in the process. The sulphate of ammonia becomes more quickly available to plants than the organic nitrogen in animal refuse since in that form the ammonia needs first to be released before the process of nitrification or the forming of nitrates can be accomplished, while the ammonia is ready at once for the work of the bacteria that carry on this process of making nitric acid. But it has been found that on soils that are to any extent acid the application of the sulphate of ammonia is actually poisonous to plants until the acidity is corrected by lime.

We have seen that phosphorus is the element most generally deficient in old cultivated soils, and since we cannot get it from the air as we can nitrogen, as will be 
Sources of Phosphorus

explained later, it must be returned to the soil in the manure, or fertilizers applied. In some cases where farmers find it profitable to feed on the farm food raised elsewhere it may be possible to keep up the supply of phosphorus in the soil without the purchase of phosphates. And right here we are reminded that in many parts of the country the farmers have got into the habit of calling all commercial fertilizers phosphates. Of course, all complete fertilizer mixtures have some phosphate or generally phosphoric acid in them, but the term phosphate is applicable only to the dissolved phosphatic rock known as acid phosphate. The complete mixtures are always called commercial fertilizers. Formerly, almost the entire supply of phosphorus came from the bones of animals. When these bones are ground raw they will usually contain from 20 to 28 per cent. of phosphoric acid and about + per cent. of nitrogen. Since the phosphoric acid is in an insoluble form its becoming available depends largely on the fineness of the material, and if the bones are fresh it is hard to get them very fine on account of the oily matter associated with them. To rid fresh bones of this oily matter they are often steamed. This steaming also takes out most of the nitrogen. Accordingly the stcamed bone is valuable only for its phosphoric acid, though at times a small percentage of nitrogen may remain. But as a source of phosphoric acid the steamed bone is better than the raw.

Tankage, which we have referred to as a source of nitrogen, also contains bone and furnishes a considerable amount of phosphoric acid in variable amounts depending on the character of the material used. 
The fish scrap, which is valued mainly as a source of nitrogen, also has a considcrable percentage of phosphoric acid, and as we have before said, there is a small percentage of phosphoric acid in cotton-seed meal and castor-oil pomace.

Animal charcoal is made from bones. It is used in the refining of sugar, and after this in the manufacture of fertilizers for the percentage of phosphoric acid it contains. It usually contains about 35 per cent. of phosphoric acid, but as its availability in the soil is slow it is used less now than formerly. Bones gathered on the Pampas of South America are burned and made into what is called bone ash, which may contain 35 per cent. of phosphoric acid. But the chief source of phosphorus of late years is the phosphatic rock found in South Carolina, North Carolina, Florida, Tennessec, and others of our Southern States. The rock from different sections varies in its percentage of phosphoric acid, that from Tennessee being generally the richest. In South Carolina it is dug from the deposits on the coast and is also dredged from the rivers. This rock is often ground to an impalpable powder spoken of in our first chapter under the name of "Floats." Chemists formerly attached no value to this because of its insoluble state. But more recent experiments have shown that in the soil it does become gradually available, and its use is increasing because of its greater cheapness as compared with ready dissolved rocks, and also because of the fact that the rock dissolved in sulphuric acid has a tendency to rob the soil of lime carbonate, through the plant taking the phosphorus and releasing the sulphuric acid. This latter at once unites 
with the lime in the soil and makes the sulphate of lime or plaster, and in this way is apt to cause an acidity in the soil which is harmful to the prosperity of the microbes that live with clover, and hence harmful to the growing of clover. The notion that acid phosphate carries free sulphuric acid is generally erroneous, for a well-made phosphate has the acid completely neutralized. There is also a notion which the manufacturers of bone fertilizers have encouraged, that phosphoric acid from bones is better than that from the rocks. Phosphoric acid is always one and the same thing, no matter from what source it comes, and the only difference is in its solubility. That in raw bone is insoluble and also that in the pulverized rock. From bone it will become available more quickly than from pulverized rock, because the bone, if fine, decays more readily, but the most readily available form is in the dissolved rock or acid phosphate.

Phosphorus, in the form of phosphoric acid, does not leach from the soil as the nitrates will, but is held there till called for by plants.

\section{The Sources} of Potash

Potash is the oxide of potassium, a metallic element, and as we have seen, one of the essentials to plant growth. Formerly most of the potash used was derived from the ashes of hard woods, and these are still a valuable source not only of potash but of lime, and to a more limited extent of phosphoric acid. But the supply of ashes is totally insufficient for the needs of modern agriculture, and the discovery of potash salts in the salt mines of Germany was of the greatest importance to the farmer. This potash is found as al chloride in what is commonly called the muriate of 
potash, and is also found as a sulphate and as a carbonate, in all of which forms it is readily used by plants.

One of the most commonly used forms of the crude potash salt is what is known as kainit. Though the potash in kainit is a sulphate of potash it is associated with so large a percentage of chlorine that its action is rather that of a chloride than of a sulphate, and for this reason has been found detrimental to some crops such as tobacco, for which only a pure sulphate should be used. Moreover, the expense of freighting a crude salt like kainit, which has but about 12 per cent. of potash, is so great that it is not now so much used as the manufactured and concentrated form called the muriate of potash or chloride. In this concentrated form there is an average of 50 per cent. of actual potash. A very high grade may contain more than $5 \circ$ per cent.

The high-grade sulphate of potash is also a manufactured article which usually has a little more actual potash than the muriate and in a better form for crops like tobacco, Irish potatoes, and crops in which sugar is an important ingredient. Another refined article is what is known as the double manure salt or sulphate of potash and magnesia. It has not over one-half the amount of potash that is contained in the high-grade sulphate, and the potash costs more in this form. In the same manner as with phosphoric acid, the soil will absorb and retain potash even to a greater extent than it will phosphoric acid, since it is largely left in the roots, while the phosphoric acid is concerned in the ripening of the grain. Still another source of potash, which has come into use of late years, is the waste stems of tobacco and the tobacco dust from 
the smoking-tobacco factories. These contain as much as 8 per cent. of potash and two and a half per cent. of nitrogen and a small percentage of phosphoric acid, and in many places near the factories they can be had at a price that pays well for their use. 


\section{CHAPTER VI}

\section{MANURES AND COMMERCIAL FERTILIZERS}

HE term "manure" is generally understood to mean the manure obtained from domestic ani-

1 mals. But in the consideration of manures we will not use the word in so limited a sense, for there are numerous materials of a manurial nature that are not artificial manufactures like the commercial fertilizers. The muck and peat from swamps, when properly piled and composted with lime and ashes, make a valuable manure, and the sewage from cities is frequently condensed into what is known as sludge, which has a very considerable manurial value. Farmers who are located near the ocean can get a large supply of seaweed which is blown on the beaches in storms, and which has a very good manurial value in itself, but is also valuable when dried as a bedding material for domestic animals and an absorbent of the manure. We have already noted the manurial value of the ashes from hard woods, and it is important that all these should be carefully saved and kept from the weather on every farm. Coal ashes are commonly considered of no value. But we have found that they are quite valuable on heavy clay soils as a means for the improvement of its physical character. They are also very retentive of moisture and help in this way in the soil. The ashes of cotton-seed hulls are among the very 
best sources of potash, but of late years they have been taken up mainly by the manufacturers of fertilizers and are no longer on the general market. In many sections there are deposits of marl of varying character. The greensand marl is of the greatest value, since it contains phosphoric acid and potash. The ordinary shell marl is valuable solely for the carbonate of lime it contains, and like lime in general, it improves the mechanical condition of the soil. Lime in any form is not to be considered as manure, however, but a reagent in bringing about changes in matters already in the soil, making them available.

Barnyard

Since the keeping and feeding of livestock is of vital importance in any system of improved agriculture, the proper saving and applying to the land of the droppings and urine of the stock, so that there shall be as little loss of its plant food as possible, is essential. The need for commercial fertilizers has been largely brought about by the waste of the home manures during past years. And unfortunately this waste is still going on all over the country, while it can be very largely avoided by proper care. Careful experiments have shown that in many cases fully one-half of the manurial value of the barnyard product is lost by improper fermentation and leaching. Professor Voorhees estimates that if but one-tenth part of the present waste of manure were avoided (and a larger percentage is avoidable) the total amount of constituents thus saved would be more than equivalent to the amounts of plant food now purchased in commercial fertilizers.

When manure is thrown out from the stables in loose piles it begins at once to ferment, and its nitrogen flies 
off into the air in the form of the volatile carbonate of ammonia which every one can easily smell escaping from a manure heap. The heat engendered in the fermentation causes a rapid oxidation of the organic materials in the manure, and a loss of what would in the soil be making humus. All over the country we see this practice. The heaps in many places are thrown out under the stable eaves, and there is not only a loss from the fermentation but there is also a great waste through the rain-water falling on the heap and washing out its soluble plant food. We have often seen drains made to carry off this manurewater down hill to some stream that carries it away forever from the farm. Every farmer should understand that the manure from his stock is one of the most valuable assets of the farm, and should use the utmost care in saving and applying it. The sooner the manurial accumulations can be got upon the land where they will feed crops, the better. On many farms it is perfectly possible to haul out the manure and spread it on the land as fast as it is made daily.

On a farm where a good rotation of crops is practiced there can always be found a place at all seasons of the year where the manure can be spread and go to work feeding plant roots instead of wasting in the barnyard. In summer, after the clover is cut, the manure can be profitably spread on the stubble. Or it can be spread between the rows of corn or cotton or any other crop that may be in process of cultivation. During the winter months it can be hauled and spread on the sod that should be ready to go into corn the next spring.

But it is not always practicable to haul out the manure daily since there will come times when it is not practicable 
to haul on the wet land. How, then, shall we care for the manure that must be kept on hand for a time? Wherever it is possible the open barnyard should have a hard bottom. Where rocks are plenty it should be paved or macadamized to prevent the clay from working up under the tread of the cattle into mud. Then the barnyard should be well filled with straw or forest leaves several feet deep all over, so that whatever manure is made in the open yard may have some absorbent at hand. Covered barnyards are often advised, but unless there is extra care given to them the manure therein is apt to be damaged more than in the open yard with plenty of absorbents. In the stable the rule should be to have box stalls kept plentifully bedded. The animals tramping on the manure will prevent fermentation and the manure can safely be left in these box stalls till it is convenient to haul it and spread it on the field. But after loosening it up in the stalls, haul it at once to the fields, for it will at once begin to ferment and lose value if piled. The box stall with abundant bedding is the safest place possible for keeping the manure till hauled out, and the rain will make the decay of what falls in the open yard better than if in a covered yard where it will heat and fire-fang. But as little as is practicable should be left in the open yard.

Years ago, when the writer was carrying on a large stock farm, he had the barnyard macadamized and the manure hauled out daily, so that at all times one could walk in the yard without inconvenience. But the learner may ask, "Does not manure spread upon the surface of land left exposed lose a great deal?" There is little fermentation when thus spread, especially if torn up fine 
and spread evenly with a manure-spreader, a machine that should be on every farm; and it loses mainly only water, while if piled up in the barnyard it loses immensely of that most valuable constituent, the nitrogen. Then, instead of the rain's washing out the plant food to run away from the barnyard, it is washed into the soil and the soil holds it there for the use of the crops. Even in cold climates, where the soil freezes hard, the manure spread in the fall and let lie till spring has given the best results in the crop. At the New Hampshire station an experiment was made of spreading manure on the surface in the fall and letting it lie all winter. On another piece the manure was plowed under at once in the fall. On a third piece the manure was spread in the spring, and then all three pieces were plowed for corn. The best corn was made on the plot where the manure lay on the surface all winter.

Have as little manure as possible, then, in the open yard. Keep what is in the box stalls well tramped down and filled up with straw or leaves, and it can remain there unhurt till it is convenient to haul and spread at once. The urine from the animals is of more value, even, than the droppings, and an abundance of absorbing material is of importance to save this. If the stalls have a hard clay bottom do not put a wooden floor in them. If the soil is sandy and apt to leach, the floor should be made of broken rock grouted well with cement to prevent the loss of the liquid manure. Then, if it cannot leach away, and plenty of absorbents are used, the whole can be saved and make a far more valuable manure than if the liquids leached out. 
The manure from well-fed animals is of far more value than that from ill-fed ones. In fact, cattle that are merely kept alive all winter on straw and corn shucks make a manure that has very little value as compared with that from animals that have been fed a well-balanced ration in which there is an abundance of the nitrogenous or protein foods. You cannot get something out of nothing, and while manure from straw-fed stock may have some valuc it will still be mercly straw and of no more value than the matcrials the stock had to make it of.

While freshly made manure may have little plant food that is at once available as compared with the concentrated and soluble plant food in commercial fertilizers, it has an added value which the fertilizers lack. This is the large amount of organic vegetable matter associated with the manure. This, when buried in the soil, oxidizes slowly and adds the black humus to the soil, and not only releases plant food but has a further important effect in making the soil more retentive of moisture. Hence the longer continued effect of an application of manure over one of readily available fertilizers.

While keeping manures in piles always involves some loss, it is often desirable to partially rot it, especially for garden purposes. This can be best accomplished by piling the manure in broad flat heaps with layers of dry muck or woods-carth, and chopping this down frequently and repiling in the same flat heaps. Then, if convenient to water, sprinkle it well all over, and make a trench around the compost pile to catch the leachings to be returned to the heap. But for the ordinary farm crops it is never economical to go to the heavy labor of composting 
the manure. It is far better to get it out as rapidly as possible, for it requires high-priced crops to pay for the labor of composting and the loss in the process.

The Cornell station found that a ton of manure with the usual straw bedding was worth, when fresh, \$2.30. After it had been exposed to the weather for six months it had lost ninety-eight cents of this value, or 46.6 per cent., nearly all of which would have been saved had it been spread on the land while fresh instead of being left in a loose heap. They also left 4,000 pounds of horse manure in a heap from April to September. Calculating from its content at first of nitrogen, phosphoric acid, and potash, this manure was worth $\$ 2.80$ per ton, while on the $22 \mathrm{~d}$ of September it was found to have lost so much that it was worth but $\$ 1.06$ for what weighed a ton at the start. They also left ro, 000 pounds of cow manure exposed during the same period. At the end of the time the manure that was worth at the start $\$ 2.29$ per ton had left of the ton only $\$ 1.60$ worth of plant food. At the North Carolina station manure in three weeks showed a loss of 2.77 per cent. of its nitrogen. The Massachusetts station found that the leachings from a manure pile caused by rain had in them plant food worth $\$ 2.94$ per ton although the leachings were 93 per cent. water. All the investigations go to show that keeping the manure in the yard can usually be done only at a great loss. When spread on the field these valuable leachings are absorbed by the soil, and as there is little fermentation there is less loss of ammonia there. The only way to keep manure, as we have said, without great loss is to keep it packed under the tread of stock in the stables. When once 
loosened up and the air admitted it should at once go to the field. In covered manure yards, where there are cattle enough to keep the manure trampled down as made, there will be less loss than in an uncovered yard, but manure thrown in heaps in a covered yard will lose more rapidly than in an open one. We have said that the urine of the domestic animals has a far higher manurial value than the solid excrement. Few farmers realize this. Carefully made analyses show that the urine of the horse has plant food in it that makes it worth $\$ 5.37$ per ton, while the solid excrement is worth by the same analyses $\$ 2.23$ per ton. The urine of the cow is worth $\$ 4.37$ per ton, and the solid dropping but $\$ \mathrm{I} .49$ per ton.

It has been estimated from carefully made experiments that the manure of one horse is worth annually, from the market price of the nitrogen, phosphoric acid, and potash it contains, $\$ 24.06$ per year; that of the cow is worth $\$ 32.25$ per year; that of a sheep is worth $\$ 2.29$ per year, and that of a pig $\$ 3.06$ per year. Where a large stock is kept, and half the value of the manure is lost by fermentation and leaching, we can readily see how much the farmer is losing, and why so many farms get poorer instead of richer. The average barnyard manure, as ascertained by a number of investigators, will contain plant food to the value of $\$ 2.20$ per ton. In addition to the waste of manure in yard and stable there is commonly a great waste in its applications when spread by hand, some spots getting an excess in the large lumps while other spots are not covered. It is here that the value of the manure-spreader comes in, giving a more uniform coat and making the manure go much further than if spread 
by hand. As we have pointed out, one of the chief values of farm manure lies in the large amount of vegetable matter carried with it, which keeps up the humus supply in the soil and makes it more mellow and easy to work, and more retentive of moisture for the sustenance of crops in dry weather. The commercial fertilizers have a far larger amount of plant food in a more readily available form, but they do not furnish this organic decay. How we may make the fertilizers take the place of stable manure will be the subject of future treatment.

While lime is essential to the life of plants, Lime and Its most of our cultivated soils have a large sup-
Work in Agriculture ply in them. It has been shown that a good wheat soil which will produce a crop of twenty-five bushels of wheat per acre, will contribute to the grain and straw about seven to eight pounds of lime per acre, while there will probably be in this acre of soil fully two tons of lime. And yet it has been found that application of freshly water-slaked lime on this same soil will increase the wheat crop. We are therefore forced to believe that it is something beside the lime itself which causes the increase, since the crop had already at command a far larger supply than it could possibly use. Careful investigations have shown that, aside from a limited use by plants as food direct, lime has a still greater influence as a reagent in the soil.

Soils having a large amount of humus from the decay of organic matter may get into an acid condition which is unfavorable to the growth of many crops. This acid condition may be brought about also in soils which have not an excess of organic matter, through long continued 
cropping and annual dependence upon commercial fertilizers. But from whatever cause, it is found that this acidity is fatal to the growth of the soil bacteria that carry on the process of transforming organic nitrogen into nitrates. In the one case, while there is an abundance of the organic matter for their use, the acidity of the soil is detrimental to their growth. In the other case, they have simply been starved out by the lack of their food. The acidity in the soil is also fatal to the bacteria that live on the roots of clover and other legumes and enable them to acquire the free nitrogen from the air. In either case, then, lime is the remedy by which the alkalinity of the soil is restored.

Lime promotes the nitrification of organic matter in the soil, not only through its effect in sweetening the soil and making conditions more favorable to the nitrifying bacteria, but also in another way. It is directly helpful to the bacteria; for these microscopic plants, having no green leaves, are not able, like plants with green leaves, to get carbon from the air; but they have the power that no green plant has, to get the carbon needed from a chemical combination. They get carbon from the carbonate of lime in the soil, and in this way their growth and activity is greatly increased. It is found, therefore, that lime has an important bearing on the formation of nitrates in the soil, for the use of crops with green leaves which take nitrogen from the soil only in the form of a nitrate of lime or potash or whatever base may be present in the soil. The bacteria on the legumes get what they need directly from their host plants, and though they are parasitic to this extent they return more 
than they take and make what is called a symbiosis, or living together.

Many of our heavy soils, particularly those in which the clay is the result of the decomposition of granite rocks containing large percentages of feldspar, have in them large amounts of potash in the form of an insoluble silicate. On these soils it has been found that the use of lime has the effect of releasing potash in such a shape that plant roots can get it. In some soils the first use of lime has such a marked effect from this releasing of potash that farmers often jump to the conclusion that all they need to keep their land rich is to continue applying lime as a manure. But you understand by this time that the lime has only helped them to get at what was already in their soil and has depleted instead of enriched it. While the ordinary commercial fertilizers are merely the means for supplying plant food that may be deficient in the soil, lime is therefore to be regarded more as a stimulant. It has also a mechanical effect about which you have already learned.

Lime and ashes, remember, should never be mixed with the farm manures, since the effect will be to form the volatile carbonate of ammonia, which will escape into the air, for wood ashes contain a large percentage of lime. Neither should lime be mixed with phosphatic fertilizers as it will tend to revert the phosphoric acid in them into a less available form or condition. But there is another form of lime that can be used with benefit with the manure. This is the sulphate of lime commonly known as plaster. When this is mixed with the manure it tends to retain the ammonia in a less volatile form. Plaster also has the effect of releasing potash in the same way that lime does. 
Commercial Fertilizers

We often hear men, who have seen the bad results that have come through the injudicious use of commercial fertilizers, say that they are only stimulants, and that they do the soil harm. The fact is that the only real stimulants used are, as we have seen, lime and plaster. The commercial fertilizers consist of the various plant foods that have been found from experience to be most commonly used up and made deficient in our old cultivated soil, in a readily available and concentrated form. They contain when complete fertilizer mixtures, all the plant foods that are contained in animal manures, but in a more concentrated and more readily available form, and hence are more quickly used by crops.

The main difference between the commercial fertilizers and stable manure lies in the fact that the stable manure carries with it a large amount of organic matter that increases the humus content of the soil, and thus renders it more mellow and more retentive of moisture, while the commercial fertilizers only furnish readily available plant food. Therefore, if the use of commercial fertilizers is continued year after year, without any effort to restore and maintain the humus-making matter in the soil, the final result will be the starving out of the nitrifying bacteria and the souring of the soil, while the absence of humus will cause a heavy soil to run together after rains and bake hard and dry out quickly. Under such conditions hilly clay soils are made more inclined to wash. This result can be seen all over the South, where cotton has been grown year after year with simply an annual application of commercial fertilizers in small amount in connection 
with the scratch plowing of the little plow and one mule. Right under the shallow plowing the soil is hard and unbroken, and when the torrential rains that are common in the South come, the shallow broken soil gets into a creamy state, and having no vegetable matter in it to hold it, it runs down hill as the only way it can go, and a gully is soon formed, and the farmers find it necessary to make terraces and banks of various sorts to check the waste, when by a more thorough plowing and deepening of the soil there would be room to hold the water and check the washing, especially if vegetable growth had been turned into the soil. Then they jump to the conclusion that their land is getting poorer because the fertilizers applied in a scanty way are only stimulants, when the fault is in their management of the land and the way in which they use the fertilizers merely to squeeze a little more from the soil to sell away from it. They apply a little fertilizer, generally in the hill or furrow, and the crop at once uses up the little supply of food and then draws further on what was in the soil, and the result is that the soil is left really poorer than before.

I have told you of the various forms of plant food that are essential to plant life and which must be in the soil in order to make plants grow. Some of these, as I have shown, are naturally in such abundance in the soil that there is no need for applying them in fertilizers. But there are three of the elements that are exhausted from the soil in cultivation. These are nitrogen, phosphorus, and potassium. I have also explained that we do not use these as pure elements, but in various combinations; as nitrogen in nitrate of soda, sulphate of ammonia, 
tankage, cotton-seed meal, etc.; phosphorus in phosphate of lime found in rocks and bones; and potassium in the potash salts and ashes in the form of potash. The object of commercial fertilizers is to furnish these things in a concentrated and readily available form. They are naturally associated with other matters, so that in a ton of fertilizer we find only certain percentages of the essential plant foods. Then, in order to make a particularly low-priced article, the manufacturers often add what they call a "filler" of perfectly inert material, so that while an apparently low price is charged, the farmer is really paying full price for all that is of value in the article, and is paying freight on the filler, which is of no value. Hence, in buying fertilizers it is always cheaper to buy a highgrade article than a low-gradc. I know of one instance where a manufacturer of a low-grade fertilizer added to each ton 500 pounds of the burnt oxide of iron which was the result of his manufacture of sulphuric acid that was used in the dissolving of the phosphatic rock. This material was perfectly useless to the farmer if not actually harmful, and one-fourth of the freight on each ton was for this useless material, while he thought he was getting a cheap article. There is always an abundance of filler naturally associated with the materials that must be used in the manufacture of fertilizers, and no filler is needed whatever.

The term "Complete Fertilizer" means that the article has in it a due percentage of nitrogen, phosphoric acid, and potash. Any two of these alone makes an incomplete fertilizer, and, as we shall see, it is often advisable to use an incomplete mixture. Manufacturers of fer- 
tilizers often put the nitrogen in their fertilizers on the sacks as ammonia. This has become customary because the figures look larger, for ammonia is a hydride of nitrogen and is only partly nitrogen, and nitrogen is the essential thing we are after. You can find the actual amount of nitrogen in the article by multiplying the figures on the sack for ammonia by 0.8235 . Thus, if the sack brand says that the mixture contains 3 per cent. of ammonia, this means that it has 2.47 per cent. of nitrogen. In some states the manufacturers of fertilizers print a great deal on their sacks to make farmers think there is more in the goods than there really is. For instance, the two following analyses were recently submitted for our opinion:

\section{FIRST}

Nitrogen .............. to 3 per cent.

Ammonia...............

Soluble Phosphoric Acid. ..... 3 to ro per cent. Insoluble Phosphoric Acid.....7 to 8 per cent. Potash................ 7 to 8 per cent.

\section{SECOND}

Ammonia...........2 to 3 per cent. Soluble Phosphoric Acid....6 to 8 per cent. Insoluble Phosphoric Acid. . 2 to 4 per cent. Equal to Bone Phosphate...4.36 to 8.73 per cent. Potash............. to 3 per cent. Equal to Sulphate of Potash.3.7 to 5.55 per cent.

All this simply means, in the first article, that it probably contained 2 per cent. of nitrogen, 3 per cent. of soluble phosphoric acid, 7 per cent. of insoluble phosphoric acid, and 7 per cent. of potash, for when any sliding scale is printed on the sacks it is always safe to assume that the 
lowest figure is the true one, and the ammonia is put there simply to represent what the nitrogen would be as ammonia, and does not mean that there is both nitrogen and ammonia.

In the second the ammonia is put down, and the phosphoric acid, and "Bone Phosphate" is put there because that amount of phosphoric acid would be contained in the given amount of bone phosphate, and to make the farmer suppose that there is some bone in it, as farmers have an idea that phosphoric acid from bones is better than phosphoric acid from rock when both are the same identical thing. Then "Equal to Sulphate of Potash" simply means that such a percentage of sulphate of potash would contain the potash stated, while the probability is that the potash in the article came from the cheaper muriate of potash.

In some states, notably in North Carolina, the law requires that the manufacturer put on his sacks only the actual percentage of nitrogen, phosphoric acid, and potash that the article contains, only this and nothing more, no sliding scale an $\mathrm{l}$ no "equal to." It is well for the student to understand these things so as to be able to arrive at the exact value of the article submitted to him. Formerly, there was a great deal of fraud practiced in the manufacture of commercial fertilizers, but of late years the laws in most states have been made so strict that there is now little actual swindling in these, and the upright manufacturers are as earnestly in favor of the enforcement of the laws as any one, since they, too, are protected from competition with worthless frauds. What is important for the farmer to know in regard to any complete fertilizer 
mixture is what it contains that is of value as plant food and not what the fancy-brand name may be.

Different crops use nitrogen, phosphoric acid, and potash in different amounts, some selecting nitrogen and phosphoric acid mainly, while others call for a large percentage of potash in proportion to the other ingredients. Hence, while a certain ready-mixed fertilizer may be well suited to one crop it may not be as well suited to another one. Then, too, the soil on one man's farm may be mainly deficient in nitrogen and phosphoric acid, while another farm near by may be especially deficient in potash. Therefore the same fertilizer would not be the best for both, for it will, if it has a sufficient percentage of potash for the latter, make the first man buy what his soil does not particularly need. From these facts there has arisen the practice of home-mixing of fertilizers.

Knowing that what we want is the proper Home-mixing percentage of nitrogen, phosphoric acid, and
of Fertilizers potash for the various soils and crops, one need only buy the nitrogen he needs in the most accessible form, the phosphoric acid in like manner, and the potash also, and he can readily mix these with the aid of a shovel and a sand screen on a barn floor, can do it as well as it can be done in any factory, and can save a great deal of the cost. Nitrogen can usually be had more cheaply in nitrate of soda than in any other form. But in mixing a fertilizer it will not do to use the nitrate of soda alone as a source of nitrate, for it is so readily dissolved that it must be used at once by the plants or is washed away. It is useful in the start, but we must have in addition to the nitrate some organic nitrogen like that contained in cotton- 
seed meal, fish scrap, or tankage, which will become available during the growth of the crop and will thus keep up the feeding of the crop. Phosphoric acid can be gotten most cheaply in acid phosphate or the dissolved phosphatic rock, and potash can be had best and cheapest in the muriate of potash imported from Germany. Knowing, then, the percentage of nitrogen, phosphoric acid, and potash contained in each of the materials, it is easy to make up a complete fertilizer suited to the various crops and soils.

While one's soil neerls can only be ascertained by the man who cultivates it, the chemist, however, can tell you what your soil contains, and you may have a soil that the chemical analysis shows contains large amounts of all the elements of plant food, and yet it may be a very unproductive soil by reason of the unavailability of these things. Actual experiments on the soil itself are necessary to determine what it particularly needs in the way of fertilizers. Professor Voorhees, in his work on Fertilizers, suggests that the farmer stake off ten plots, each onetwenticth of an acre, and gives the following plan:

Plot I. Check. No Fertilizer. . . . . . . . .

Plot II. Nitrate of Soda. . . . . . . . 8 pounds.

Plot III. Superphosphate (Acid Phosphate). I6 pounds.

Plot IV. Muriate of Potash. .......... 8 pounds.

Plot V. Check. No Fertilizer..........

Plot VI. Nitrate of Soda. . . . . . . . . . 20 pounds. Acid Phosphate. ........... 6 pounds.

Plot VII. Nitrate of Soda. ............. 20 pounds. Muriate of Potash.......... 8 pounds.

Plot VIII. Acid Phosphate............. 40 pounds. Muriate of Potash. . ......... 8 pounds.

Plot IX. Nitrate of Soda............ 8 pounds. Muriate of Potash........... 8 pounds. Acid Phosphate. ............ 6 pounds.

Plot X. No liertilizer. . . . . . . . . . . . 
By studying the results on these plots for several years with the same treatment annually, the farmer can come very close to ascertaining the actual needs of his soil, and can determine what he needs especially to buy and what he need not buy. If every farmer studied his soil in this way there would be an enormous saving in the purchase of fertilizers, and he could buy the materials containing what he needs and mix them in the proper proportions better than any manufacturer can do it for him. It will generally be found that phosphoric acid alone, though the soil may need it, will not have its due effect unless there is present naturally in the soil or is added to the fertilizer a due percentage of potash, and it will also be found that on a soil that is deficient in potash the potash applied will not have its due effect unless a due percentage of phosphoric acid is present or is added. These two forms of plant food are so intimately associated in their work that both must be present for the best results. It is found in many soils that potash is present in sufficient amounts, while phosphoric acid is always deficient.

Hence, on such soils it would be purely a waste to apply potash. But on many other soils, especially those of a sandy nature or the black and peaty soils of reclaimed swamps, it is found that both of these materials are deficient and must be supplied.

How the

It has been long noticed by all cultivators Needed Nitro- of the soil that certain kinds of plants, such gen May Be as clover, cow peas, and other members of $\mathrm{Had}$ Free of the botanical family called leguminosæ, or
Cost pod bearers, so called because they form their seeds in pods of various sizes from the minute 
pod of the clover to the large pod of the pea, did in some way add to the fertility of the soil on which they grew. Many supposed that they absorbed ammonia gas from the air through their leaves, for it was found that the content of nitrogen in the crop was greater than could be had from the soil. But in recent years this capacity of the leguminous plants for acquiring nitrogen has been the subject of close and long-continued study by leading biologists of Europe and America, and the process is now better understood. That is, we have found out the organisms which enable the clover and peas to get nitrogen, though the exact way in which they do it is yet a matter for investigation, and there are several theories in regard to it. For the farmer in practice it is enough to know that they do get nitrogen for him. The air is made up of a mixture of oxygen and nitrogen, as we have heretofore seen. The nitrogen is not in chemical combination with the oxygen, but is simply mixed with it to dilute the oxygen so that animals can breathe it. It is therefore termed free nitrogen. It was found that whenever there was an increase of nitrogen in the clover, peas, or other pod plants, there were always a number of little lumps or nodules on their roots, and when the plants had none of these nodules they failed to increase in nitrogen. It was, therefore, assumed that these nodules had something to do with the work, and scientists began to pay special attention to the structure of the nodules. Careful microscopic investigation revealed the fact that these nodules were inhabited by minute living plants of extremely small size. As they differed in form from any bacteria that had before been studied, they were at first termed Bac- 
teriods or forms similar to bacteria. But scientists have now agreed that they are true bacteria, and that they present merely an added form to the many already recognized. They are parasitic on the roots of the legumes; having no green matter in them they cannot get material for growth from the air as grcen plants do, and hence are obliged to live on what green plants have obtained. But though these minute plants draw their sustenance from the clover or other leguminous plants, their parasitism is not harmful, since they are the means of enabling the legumes to get the nitrogen in a combined form which they cannot use as a gas. I have said that the process by which they get the nitrogen into combination is still a matter of study and investigation. The most plausible theory is that these plants are of a nature similar to the yeast plants that cause fermentation in the liquids containing sugar, and that they are really nitric foments which oxidize or bring into chemical combination the free nitrogen of the air with oxygen. Now, when an element is combined with oxygen the result is the formation of an acid, and when nitrogen is oxidized the result is nitric acid. When nitric acid is formed in the soil it does not remain an acid, because the soil contains lime, potash, and other things of an alkaline nature that are bases for the nitric acid, and at once a neutral salt or nitrate is formed, which is at once taken up by the roots of the clover or other legumes and formed into organic nitrogen, which will be finally carried through the nitrifying process in the soil when the clover decays, so that the following crop gets the benefit of it. We have seen that all green plants use nitrogen from the soil only after it has 
got into the form of a nitrate. But when once in this form it is very soluble, and is rapidly leached from the soil. If, therefore, the nitrogen that the bacteria on the roots of legumes gather remains altogether in the soil in the form of a nitrate, it would be lost before the crops of the following season could get it. But being taken up by the roots at once, it is transformed into the living matter of the plant and becomes organic nitrogen, which remains in the soil to decay and become transformed back again the following season through the agency of the soil bacteria which are engaged in the formation of nitrates from organic nitrogen. While it could not be carried over as a nitrate it can be as organic matter, and we can see the great wisdom of the Creator in this process of preservation. But these legume crops, which are in this way enabled to get and leave in the soil for the following crop the combined nitrogen in sufficient amount, are themselves among the greediest consumers of the phosphoric acid and potash in the soil. Hence, we use acid phosphate and potash only on the leguminous crops to increase their growth, and through them to get the needed nitrogen. Since the nitrogen in a complete fertilizer mixture costs about as much as both the other ingredients, we can see the great saving that can be made by using these to get through the agency of clover or peas the needed nitrogen in greater abundance than we could get it in a complete fertilizer, while at the same time we get the organic decay in the soil as well as through the application of stable manure, and can get the most valuable forage for the feeding of stock and the increase of the home-made manures. 


\section{CHAPTER VII}

\section{LIFE IN THE SOIL}

HE casual observer is too apt to look upon the soil as mercly a lifeless mass of matter, from which 1 various chemicals can be dissolved to be taken up as food by the roots of plants. But our microscopes have shown us that a fertile soil, well supplied with humus from decayed organic matter, teems with life, and may well be called a living soil. On the other hand, where long and careless cultivation has been pursued, and the soil has been continually exposed, summer after summer, to the sun (for the sun is one of the most powerful of agents in the destruction of microscopic life in the soil whether it be of a beneficial or harmful nature), and the humus has all been used up, so that the bacterial life has been starved out, the soil really may be termed dead. It has gotten to running together hard, and washes into gullies with heavy rains, and though the chemical analysis may show that there still exists an abundance of plant food in the soil, it is locked up so that the plants cannot get it, and the soil has gotton into such an acid condition, that the life which filled it when new and fresh, can no longer thrive.

The microscopic life in the soil, to which the soil owes much of its fertility, consists mainly of the minute forms which have been given the general name of Bacteria. A 
bacterium is the smallest of known vegetable forms. Many bacteria are barely within the reach of the highest powers of the microscope, and it may be that there are still smaller forms that play an important part in the changes wrought in the soil, but so small as to be undiscoverable. There are many sorts of these bacteria, some being disease-making forms, and others of a beneficial nature. But what we are here concerned with are the forms that exist in the soil and work for the farmer there, and also to arrive at a better understanding of the conditions in the soil necessary for the welfare of these minute plants whose work is always beneficial in agriculture. Many of them vary so little in appearance that some assume that all of them belong to one general species. But whether this is true or not they have become so altered in function that they are as really distinct as though of entirely different species. Certain forms that do certain work in the soil have been isolated and studied; the particular part they play has been definitely determined; and it is evident that a study of these minute forms will help us more toward the understanding of the work that goes on in the soil, than any chemical analysis, which destroys life, can ever do.

When any organic matter, either animal How Bacteria or vegetable, is buried in the soil within
Work in the Soil reach of the atmosphere, the first thing that takes place is what we call decay. This decay, or the breaking down of the original tissues, is carried on in the presence of oxygen and moisture, by millions of these bacteria, whose special work is to reduce the organic matter to its original elements. All organic 
matter contains nitrogen; and the decay carried on by the bacteria releases this as ammonia, which is a hydride of nitrogen. Then at once here are myriads of other forms of these minute plants which find their food in ammonia, and their oxidizing work carries it to the form of a nitrite, but no further. Then other forms take up the work, and the result of their growth and oxidizing influence is nitric acid. When nitric acid is present in the soil it soon seeks a base, for there is always lime or potash or some other base in the soil, and the acid becomes a salt, a nitrate.

Now, it has already been shown that green plants never use nitrogen until it is in the form of a nitrate; and, that when it has gotten into this form, it is readily taken up by the roots of plants, and is so very soluble that if not soon taken up by plants, it is washed from the soil. The absorptive power of a good loamy soil is such that it will take and hold on to phosphorus or potassium and keep it till called for. But not so with the nitrogen, which is soon leached from the soil in the drainage. The ready availability of nitrogen as a nitrate is well shown in the use of the nitrate of soda as a fertilizer, and the speedy effect it has on plants, and also the way in which it is lost from the soil if not used at once.

This process, by which the growth of bacteria in the soil changes the organic nitrogen into nitrates for the use of plants, is called nitrification. And, in order that it shall be carried on in the soil it is necessary that there shall be an abundance of food for the bacteria which do the work. We can see, then, the importance of humus-making material in the soil, and the loss that takes place from 
careless cultivation, through which it is used up, and none returned to keep the work going on. This is one of the most important reasons for the rotation of crops, in which there shall frequently come on the soil crops like clover or peas that will return organic matter to the soil, and thus keep up the work of the nitrifying bacteria, which can thrive only on decaying matter.

But while all organic matter contains

The Agency of Bacterial Nodules on Legumes nitrogen which the plants have gotten from the soil, there is one class of plants which in their decay furnish nitrogen more plentifully, which they have gotten from the air, and which, therefore, is really an addition to the nitrogen of the soil. This class of plants is the one which botanists call the Leguminose, meaning plants that make their seed in legumes or pods. And here again we find the work of these minute plants we call bacteria. But they are bacteria that subsist on living and not on dead matter. It has long been known to farmers that in some way the growing of clover, cow peas and other legume plants, did help the productiveness of the soil. It was long thought that they had the power to get ammonia from the air through their leaves. But carefully conducted experiments soon proved that the leaves of the legumes had no such function. It was deemed reasonable to suppose that when there is ammoniacal gas in the air the leaves might absorb it, but it has never been proven that they do. The study of the legumes was taken up by scientific men and their growth accurately observed. It was soon found that when any legume did acquire more nitrogen than existed in the soil in which it was grown, there were 
always on the roots certain little knots or nodules; and it was also observed that when there were none of these nodules on the roots the legume plants did not increase in nitrogen any more than other plants. It was also found that, when there was a great store of nitrogen in the soil, the plants used this and formed no nodules. It was evident, then, that in some way these nodules were the agents through which the nitrogen was acquired. Then scientists began the study of the nodules, and found that they were caused by parasitic bacteria which find a home on the legume roots, and through their growth cause the change in the tissues of the roots making the nodules. The bacteria draw their nourishment from the legumes in part, and hence are parasitic. But the parasitism has been shown not to be harmful; for the bacteria enable the legume to get from the air more than they take from the plant otherwise; and it thus becomes a sort of symbiosis, or living together, which is mutually beneficial.

In the first study of these bacteria, they were found to have so different a form from any other bacteria that they were called bacteroids, or forms similar to a bacterium. But it is now pretty well determined that they are true bacteria, altered in form by their peculiar work. In fact, it seems that they have been so altered that certain ones live only on certain legumes and on no other, having become specially adapted to certain host plants, so that we have clover bacteria, pea bacteria and bacteria that live on other legumes; though it may be shown yet that any of them in time can accommodate themselves to different hosts.

While any of the legumes may be made to thrive and grow on soil that abounds in abundant plant food, their 
peculiar work of getting nitrogen, which is a free gas in the air, and locating it in the form of organic matter, is always done through the agency of the bacteria that live on their roots, and these do their work best in a soil where there is not an over-abundance of nitrogen, which as one has said, makes them lazy, and interferes with the work of the bacteria. Therefore it has been found that, for the best results with the legumes, the soil must have in it an abundance of these parasitic bacteria. They are apt to be absent from a soil in which the particular legume sown has not before been contained. In such case it has been found necessary to inoculate the soil with the specific bacteria which live on the plant to be grown.

There has been much talk recently about

Methods of Inoculating the Soil the wonderful "discovery" made in the Department of Agriculture, of cultivating the bacteria in nutrient solutions, and drying them for distribution to farmers. There is nothing new in the artificial culture of bacteria in the laboratory, for it has been done for generations. The only new thing about the discovery is the method of distribution. It is well-known that these minute plants can be dried and retain their vitality for a long time; and, when placed in nutrient solutions, they may again become active and increase enormously and rapidly. The new cultures soon became known commercially under the name of "Nitrocultures," and have been sold to farmers at \$2 per culture, which cost perhaps three cents. These bacteria are sent out in dry cotton wool and with them some nutrient materials, for the purpose of making a solution in which the bacteria are placed, and in which they at once thrive. 
These solutions were to be used to sprinkle the seed down, and thus to convey the bacteria to the soil when the seed are sown. Some years ago a similar preparation was sent out from Germany under the name of "Nitragin," which was to be applied to the soil to increase the number of the nitrifying organisms concerned in the formation of nitrates from organic nitrogen. This nitragin was a complete failure, and no better results have so far been obtained from the nitro-cultures for the inoculation of the legumes. The artificially grown bacteria do not seem to adapt themselves readily to the soil conditions, and the nitro-cultures will soon be relegated to the same disuse that has overtaken nitragin.

How, then, shall we bring about the needed inoculation of the soil for the growth of the various legumes? The easiest way is to get some soil from a field where the particular legumes have thriven and made nodules, and scatter this over the soil to be sown. This method has uniformly been successful. It has been found that soil, in which certain more or less related legumes have grown, will inoculate the soil for others. The plant generally known as sweet clover, melilotus alba, which grows as a weed in nearly all parts of the United States, has been found to contain bacteria which will live on the roots of alfalfa. It has also been found that the more nearly related plant, burr clover, medicago denticulata, when sown in the rough burr-like seeds, will carry the bacteria of alfalfa with it; since alfalfa, medicago sativa, is a very near generic relative. Then it has been found that the bacteria, which live on the roots of the garden pea, will also live on the roots of the vetch, and that crimson clover seed sown 
in the chaff, will inoculate the soil for clover of any other species. In fact, the use of inoculated soil is now the general mode of introducing the bacteria to new localities. The Southern cow pea needs no inoculation in the South, where it has been grown for generations, and in a new locality the dust that always goes with the peas, will carry the inoculation.

Conditions

Affecting

Bacterial Life in the Soil

Soil in which there is an abundant supply of organic matter will always contain an abundance of the nitrifying organisms, provided it is well drained and has not gotton into an acid condition. Acidity in the soil is destructive to the nitrifying organisms as well as to the symbiotic ones that live on the roots of legumes; and the failure of clover in many parts of the country is due more to acidity in the soil than to any other cause. The application of phosphoric acid, in the form of dissolved phosphatic rock has been thought to be largely the cause of this acidity. Not from the acid used in the making of the acid phosphate direct, for it is rather a humic acidity; but because, when the phosphate is applied to the soil, the phosphorus is used by plants and the sulphuric acid used in dissolving the rock is set free and at once unites with the lime in the soil, making sulphate of lime, and thus robbing the soil of lime carbonate necessary to preserve its alkalinity. The cure for such a condition is of course lime carbonate. Lime not only sweetens an acid soil and renders it suitable for the bacterial life, but it directly promotes the growth of the bacteria. These minute plants have no green matter, and hence cannot get carbon from the air as green plants do; but it has been found 
that they have the power which no green plant has, to get carbon from chemical combinations, and they can get carbon from lime carbonate. To preserve bacterial life in the soil, then, we need to have the soil in a feebly alkaline state, and hence, when growing the legume crops on the soil frequently in the rotation, we must avoid acid conditions by an occasional application of lime.

\section{Denitrification}

This brings us to the next branch of this investigation. In soils rich in vegetable decay, there is often a serious loss of nitrogen through rapid oxidation and the consequent escape of ammoniacal gas into the atmosphere. The constant exposure of the soil, in the clean cultivation of cotton in the South and in single cropping in any part of the country, without the use of recuperative crops, is one of the greatest causes of this loss. Bulletin 53, of the Minnesota Station, shows how great the loss is in the constant cultivation of wheat year after year there. While a crop of wheat harvested removed but 24.5 pounds per acre, it was found that the actual loss of nitrogen from the soil was I 7 I pounds per acre. But when wheat was grown in a rotation, in which clover was used as a means for the restoration of the organic matter, there was a great gain instead of loss. The same result has been shown in the constant clean cultivation of cotton in the South, as well as in the same practice in many sections in the cultivation of tobacco. These natural losses are easily preventable by a proper rotation of crops.

We have already pointed out the danger of great loss of nitrogen; through the improper handling of the manures of the farm, by leaving them to ferment in piles and 
losing the volatile carbonate of ammonia, or by leaving the manure to leach under the eaves of the barn or on piles in the field. We have also pointed out that there is less loss when the manure is hauled and spread as fast as made. Another loss of nitrogen from the farm is the selling of crops having a high feeding and manurial value, such as legume hay, instead of getting its fecding value and saving its high manurial value, and selling such crops as have a higher market value, but a comparatively small manurial value. There are conditions under which a farmer may sell forage crops profitably by exchanging them for a greater value in manure, but these conditions prevail only in localities near a high-priced market for hay and a plentiful and cheap supply of manure. As a rule, all forage and roughage of the farm should be fed on the land, and the manure carefully saved and returned; for, aside from its value as a carrier of plant food in an available form, it is of equal importance as a means of keeping up the nitrification in the soil and preventing the rapid loss through denitrification. It is really a question whether this last function of farm-yard manure is not fully as important as its use in supplying plant food direct. The importance of constantly replenishing the nitrogen in the soil is shown by the fact that, aside from the constant escape into the air through the too rapid oxidation of organic matter, it rapidly drains from the soil in the drainage water when it has gotten into the soluble form of a nitrate. This loss of nitrogen has been more pronounced in the South than elsewhere, by reason of the practice of leaving the cotton and corn fields bare of regetation in winter, and exposing the soil to the winter 
rains in a section where there is far more rain than freezing in winter. A winter cover-crop becomes of special importance in the South, and is also important anywhere. This cover-crop must be a green winter-growing crop, capable of taking up and holding in the form of organic matter, the nitrates that would otherwise be washed from the soil and lost. We have no figures to show how great this loss is, but it has evidently been one of the most serious causes of the loss of nitrogen in Southern soils, where the oxidation of the organic matter in the soil has been promoted by constant exposure. In the case of the phosphates already in the soil, or applied to it in a soluble form, there is far less danger of loss, since the phosphoric acid, unused at once by plants, reverts in the soil to a less soluble form; and the absorptive character of the soil is such that it will retain its hold on the phosphoric acid and potash, till called for by plant roots; and the loss of phosphates and potash is mainly through the crops carried off, and the young animals raised on the farm and sold; for the making of the bony frame of a growing animal is one of the chief sources of loss of phosphates from the soil.

The fact that nitrogen, as a nitrate, is rapidly washed from the soil shows, too, the importance of having a supply in the form of organic decay; for when we apply nitrogen that is already a nitrate, as in the nitrate of soda, it must be used at once by plant roots; while the organic nitrogen is more slowly coming into use as the plants need it. Hence, the very soluble form of nitrogen in nitrate of soda should never be used except when the plants are in rapid growth, and then, not in excessive amounts. 
Microorganisms as a Manurial Factor

There is also a wide difference in the fertilizing value of the solid and liquid portions of the manure of animals, so far as the nitrogen is concerned. Carefully conducted experiments have shown that, as compared with nitrate of soda, the solid parts of the manure have an effectiveness of but Io per cent.; while the liquid part has an effectiveness of 90 per cent. as compared with the nitrate, which is very nearly equal to that of sulphate of ammonia. The nitrogen of the liquid portion of the manure is very rapidly converted into ammonia, and thus may rapidly escape into the air. It has also been shown that the effectiveness of the nitrogen in the solid materials of the manure is not increased by mixing with them the liquids, but that the conversion of the nitrogen in the urine into ammonia is hastened by the admixture of the solid excrement and straw. The changes in manure are carried on by microscopic organisms, which multiply with inconceivable rapidity, and thus accomplish wonderful results.

These micro-organisms or bacteria are plentiful in the manure as soon as it leaves the animal body, and it is believed that many of them come from the stomachs of the animals along with the excrement. 'The air of the stables always swarms with them, and the latter furnishes myriads; and, since we can detect the smell of ammonia at once, it is evident that they are promptly at work. Some of these bacteria are denominated aërobic, since they require the oxygen of the air in order to live and grow; while others flourish only in the absence of air and are therefore termed anaërobic. Those that require air for 
their work can be controlled by the exclusion of the air. Experiments are recorded which show that they are capable of converting the nitrogen in urine completely into ammonia which escaped into the air in twenty-four hours, when air was freely admitted, while this escape of ammonia was almost entirely prevented by the exclusion of the air, though the nitrogen was still largely converted into ammonia.

The same changes occurred in the solid excrement, but more slowly. This explains the value of keeping manure in box stalls under the feet of animals that pack it down, and thus keep the air excluded. We have heretofore shown that this is one of the best means for preventing loss from the manure. How rapidly these micro-organisms work, is well shown by the rapidity with which this packed manure heats and loses nitrogen when thrown out in heaps and exposed to the air. Maerker, an eminent German investigator, has found that the nitrogen, in deep, stall-fed sheep manure, compared favorably with that of sulphate of ammonia and nitrate of soda; while ordinary barnyard manure, which contained denitrifying organisms from previous bad treatment, either did not give good results, or actually lowered the yield.

Kainit has been found to be effective in checking the formation of ammonia and superphosphate in preventing its escape; and they also add valuable constituents to the manure heap. While caustic lime will, if applied to fermenting manure, drive off the ammonia, it has been found that lime, applied to perfectly fresh manure, will not cause this loss, and that the loss will be very small. But so quickly does the work of the organisms begin, that, while 
it will prevent denitrification in perfectly fresh manure, it is practically impossible to use it effectively because of the rapid fermentation. Lime is also not advised, because it tends to convert the available nitrogen of the manure into insoluble and less available forms, though it will destroy the denitrifying organisms. When the organic matter is in the soil, the application of lime, as we have before shown, will hasten its nitrification. The microorganisms that denitrify manures can be destroyed by the bi-sulphide of carbon, but this is too expensive an article to be devoted to this purpose.

A recent official publication says: "One point, which has been clearly brought out by recent investigation is that the addition of straw may very decidedly reduce the fertilizing value of the manure, the injurious effect being the greater the larger the amount of straw used. This is explained by the fact that straw contains organisms which convert the available nitrogen in manures, and, in the soil, into forms which the plant cannot utilize." All this we regard as pure nonsense. Of course, when a large amount of straw is used the actual excrement bears a smaller proportion to the whole; but the value of the straw is in its humus-making nature and the nitrogen will, without doubt, eventually be brought into use in the soil. Reducing manures to their immediately available plant food value is no way to measure their permanent effectiveness.

Summary

We would sum up briefly the whole matter of nitrification and the retention of nitrogen, for the use of plants, as the work of micro-organisms in the soil, and in the manures. Those in the soil are engaged actively in the change of organic matter into 
nitrates; some, in the manures before application, are to be guarded against as denitrifying agents; and that an abundance of vegetable matter mixed in farm manures is of final benefit to the soil through the furnishing of food for the beneficial organisms that bring about its decay and the liberation of its nitrogen in the readily available form of nitrates. It is also true that the more rapidly manure is spread on the soil after being made, the better for the crops, and the more it will aid in keeping up bacterial life in the soil. Therefore, do not be afraid of straw or leaves or any bedding material, except sawdust and shavings which, through their acidity and slowness of decay may, to some extent, be harmful. But, as a rule, get with the manure all the good vegetable matter you can, and get it out on the land, where leaching will meet plant roots ready to absorb it. 


\section{CHAPTER VIII}

TILLAGE AND ITS PURPOSES

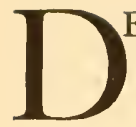

EEP breaking of the soil is necessary for the full devclopment and extension of the roots of plants in the soil. Those who have never investigated the great extension of the roots of our cultivated plants can hardly realize how widcly they ramble under favorable conditions, or how great the nced is for this extension, if the best results are to be had in the crop.

Deep breaking admits the air to the roots, and air, with its oxygen, is essential to plant growth in the soil. Unless the soil is permeated by the oxygen there can be no activity in the roots of plants. Anything that shuts out the air from the soil checks plant growth.

Standing water in the soil shuts out air

Moisture Needed for Growth and prevents the growth of our upland plants, but moisture adhering to every soil particle is necessary. Few realize the great amount of water that our growing crops take from the soil. Professor King, in his work on the soil, shows that an acre of corn, planted three feet eight inches apart each way and with four stalks in a hill, will withdraw from the soil in thirtcen days 244 tons of water, and that, too, from a soil so dry that no amount of pressure could squecze out a drop of water from it. Hence a very wide extension of the roots is needed to do this work so 
rapidly, since the only part of the roots engaged in the absorption of food from the soil is the narrow zone of root hairs just back of the advancing tip of each rootlet.

In a well-developed corn field, which has been properly plowed and properly tilled afterward, the whole soil is a complete net work of branching rootlets, each with its penetrating root cap and its zone of root hairs. The roots from opposite rows meet and cross each other till hardly an inch of soil is left unoccupied. This also means that an extreme fining of the surface soil is needed, for as the plants develop the roots tend more and more to seek the upper layers of the soil and demand a very permeable material for their minutely divided rootlets, which cannot penetrate hard lumps.

The fining of the surface soil also favors Retention of the rootlets by retaining the needed moisture Moisture Favored by he Fining of the Surface right where they are rambling. A surface of loosely aggregated clods exposes too much surface to the air, and dries out rapidly, while the finely pulverized soil acts as a blanket over the soil to check the evaporation of the moisture arising from below by capillary attraction, and to hold it near the surface where the roots can get it.

While deep breaking is advantageous in enabling the oxygen to penetrate the soil, the subsequent tillage should always be shallow. As we have shown, the roots, as the crop approaches maturity, tend more and more to branch near the surface, and deep cultivation not only damages the crop by the breaking of the roots, but it turns the soil up to dry out rapidly instead of keeping the shallow blanket of fine soil to act as a check to evaporation. Both 
of these evils occur when the farmer uses a plow in the final cultivation of the corn crop to throw up a ridge of earth to the rows of corn, which is not only not needed there, but, by being removed from the middle of the rows where the roots are feeding, the soil is dried out, and even the roots which the plow failed to cut are destroyed by the drying of the soil.

Conditions

Needed in the soil in order that any plant may thrive or Soil for Plant any seed germinate. These are, first, the Growth

There are three conditions needed in the presence of moisture in due amount but not in excess; second, the presence of the oxygen of the air, and third, the presence of the proper temperature suited to the plants cultivated. If any one of these is entirely lacking no plant can grow, and a deficiency of any one leads to a feeble growth.

Another reason for shallow cultivation of the soil is the fact that it makes the soil warmer. It has been found that a soil cultivated but one and a half inches deep was much warmer than when it was cultivated three inches deep. This was the case even to a depth of three feet. Hence, the keeping of the shallow blanket of fine soil on the surface enables us to retain heat as well as moisture. Since the roots of our upland plants penetrate deeply into the soil, it is necessary that the air shall penetrate deeply. And there is another important reason for the deep loosening of the soil. The presence of oxygen is not only essential to the activity of the plant roots, but the bacteria which are engaged in the process of releasing nitrogen from organic matter in the soil, and transforming it into nitrates so that green leaved plants can use it, thrive only in the 
presence of abundant supplies of oxygen. Shut out the oxygen and these bacteria cannot live, but other forms that are engaged in denitrifying the soil in which they live, thrive only in the absence of oxygen, and then get in their harmful work.

Tillage

Promotes

Nitrification

These bacteria which carry on the work in the soil called nitrification, are among the most important aids to the farmer. The organic decay or humus in the soil contains nitrogen. But our cultivated plants, as we have shown heretofore, cannot use nitrogen until it is in the very soluble form of a nitrate. The nitrifying bacteria in the presence of oxygen and a proper temperature take the ammonia of the organic matter and transform it into nitrites, and then another form feeds on these nitrites, adding more oxygen till nitric acid is the result. Then when nitric acid is present in the soil it at once combines with whatever base may be at hand, either lime or potash usually, and a nitrate is formed which plant roots can use. Hence, one of the most important objects in tillage is to promote the growth of these nitrifying organisms through an abundant supply of oxygen, and at the same time prevent the growth of the denitrifying organisms that thrive only where oxygen is lacking.

Fining the

The complete pulverization of very reSoil Promotes fractory minerals, thus enabling the water the Solution and carbon dioxide to act upon every parof Plant

Food ticle, will dissolve from them matters otherwise insoluble. Feldspar, for instance, is rich in potash, but is very insoluble. But it has been found that when it is finely pulverized and digested a week 
in water, from one third of I per cent. to I per cent. was dissolved in the water. This means that if there was an acre a foot deep of this finely pulverized material, ro,000 pounds of plant food otherwise unavailable would become soluble in a week.

What this would mean can be better understood when we reflect that in applying fifteen tons of stable manure to an acre we furnish only I $5 \circ$ pounds of potash and I 40 pounds of phosphoric acid. The more we grind the soil, then, the more it will yield up to us its store of plant food.

Water passes more readily from a coarse to a fine layer of soil. Hence, there is an added advantage in the fining of the surface soil, while allowing the deeply broken soil below to remain undisturbed to bring up moisture from below to keep the supply good near the surface.

To sum up then: pulverization of the soil not only favors the root development and the penetration of the air into the soil, but it improves the moisture and other physical conditions, promotes weathering and disintegration, and thus releases plant food, and also supplies favorable conditions for the growth of the nitrifying organisms for which oxygen is needed, and discourages the growth of the denitrifying organisms which do not thrive in presence of oxygen.

Weed destruction, or what is better, weed

Weed

Destruction

Merely an

Incident of Tillage prevention, is rather an incident in tillage than an object. Proper tillage, sufficiently frequent, will certainly prevent the growth of weeds. Weed-killing should never have to be done in a cultivated crop. The primary object of tillage is to produce the conditions in the 
soil most favorable to the growth of the crops cultivated, and if this is properly done there can be no weed growth provided the cultivation is done as rapidly and frequently as it should be. Of course there may come times when for frequent rains, the weed growth will get the start of the cultivator, and heavier tillage will be needed to destroy the growth, but these occasions will always be the exception with the careful and methodical farmer.

For the breaking of the ground the plow

The

Implements for Tillage in some form is always needed. The evolution of the modern plow has been one of the greatest in agricultural implements. In general form it may be said that all turning plows are alike in having point, share, land-side and moldboard. But all these differ in some-respects in form with different makers, and they vary also a great deal in their ease of draft. For general turning of sod land, the modern sulky plow on which the plowman rides, is the best development of the turning plow.

Formerly, and still in some parts of the country, much use was made of the shovel plow, which simply tears up the ground without turning the furrows. A modification of the shovel plow is the bull-tongue still used to some extent in the South. It is the cause of much of the waste of the Southern hillsides which were scratched with it while the clay below was left hard, and when the deluges of rain that are common in the South come, the shallow loose surface gets into a creamy state and must run down hill and cause a gully to start, all of which could have been prevented by deeper plowing.

In recent years the disk plow has been invented and 
put on the market in various forms. In this plow the turning is done by a rolling disk of steel set diagonally to the line of draft. As yet there is no prospect that this style of plow will entirely supersede the moldboard plow, since it has not yet been adapted to the turning of a sod nor the plowing of land that is quite soft. But where the soil is too dry and hard for the moldboard plow to be used at all, the disk, with a strong team, will break it since, unlike the moldboard plow it has no tendency to jump out of the furrow. So, at present it seems that the main use of the disk plow is to enable the farmer to plow when he otherwise could not do so because of dry weather.

Modern farm implement makers are getting more and more to providing all tillage implements with seats so that the workman can ride, and thus relieve the farmer of a great deal of the hardest work on the farm, following the plow and cultivator. The two-horse cultivators are a great advance on the old single-horse cultivator, not only because the operator can ride, but because one man can do the work that required two men with the one-horse cultivator, and thus a great saving of labor is made, and the work is better done.

The disk principle has also been introduced into the riding cultivator, and for many purposes that disks are an advantage, as they pull out no sod or trash that may be in the ground. But cultivators with small shovel teeth are still the favorites with most farmers. The fact that shallow and level cultivation is an advantage in the retention of moisture in the soil and as a preventive of damage to the roots, has led to the implement termed the weeder, similar in general form to a hay rake but with flattened 
teeth. This implement takes a wide space of soil and during the earlier stages of the crop can be used to great advantage since its small teeth can work right up to and among the growing plants and thus keep down the young starting weeds. By taking care to have corn rows run very straight, the weeder can be used through the whole cultivation of the crop by taking out the teeth that strike two rows and thus enabling the operator to cultivate the whole of one row and the halves of the others at once passing, and by thus rapidly going over the ground the work can be repeated more frequently, and when rains are frequent advantage can be taken of the short intervals to keep the forming crust broken until the corn gets so tall that the final cultivation must be done with the single cultivator.

Harrows and Harrowing

No matter what sort of a plow is used the preparation of a proper seed bed demands that the upper surface of the soil be made fine. For this purpose we use a harrow. Harrows are made in a legion of forms, every one of which has some advantages for special work. Most of the older forms of harrows depended for the pulverization of the soil on an array of projecting spikes in a heavy $\mathrm{V}$-shaped frame. In the further development of the spike harrow the teeth were made of steel instead of iron and of a smaller size, and the frame is so contrived that the teeth can be made to slant backward making what is known as the smoothing harrow, an implement of much value for the final smoothing of the surface or the breaking of a forming crust before the plants are above the ground, or for covering grass and clover seed.

The various forms in which the spike harrow has been 
fashioned are almost innumerable, but of late years the attention of inventors has been toward other forms not dependent on straight spikes for their work. One of the best of the modern harrows is the spring-tooth harrow, in which the teeth are curved steel springs with pointed teeth. These do excellent work in ground where there is no sod or rough matter turned under, as they tear and cultivate the soil very thoroughly.

Then came the harrow known as the Acme, which consists of a long row of small moldboards attached to a common bar, which merely turn and pulverize the surface without dragging anything out. This is an excellent implement for fining the surface over a buried sod.

But for deeper cutting the disk principle was adapted to the harrow, and the disk harrow came into use. The deep cutting of the disks gave them an advantage, while they, too, have no tendency to pull out buried trash. Finally a modification of the disk came into use, known as the cutaway, from the fact that the outer perimeter of the disks are cut into teeth. This form cuts still deeper than the disk and both are the last development of soilpreparing implements. 


\section{CHAPTER IX}

THE WASHING OF SOILS AND METHODS OF PREVENTING THIS LOSS

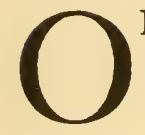

NE of the chief sources of loss in hilly soils, especially the hill lands of the South, is the washing of the surface soil during heavy rains. The upland soils of the South, owing to their peculiar composition, and the fimprudent practice of keeping them in clean culture in cotton year after year, aided by the shallow plowing which has been the rule, have been wasted and washed into gullies until in some places the land is utterly irreclaimable. Efforts bave been made to check this washing by running a system of horizontal banks with narrow ditches above them to carry off the water slowly. While this for a time checks the downward rush of the water the result finally is that the hillside ditches gradually become gullies. In North Carolina a better system has been adopted to a great extent. They make broad banks around the contour of the hills with plow and horse scoop and give these a very slight fall, with a broad leveled space on the upper side to cause the water to spread out and move slowly down the slope. The broad banks are cultivated just as the rest of the land, and not allowed to grow up in grass and weeds like the old hillside ditch banks. 
But even these are not always effective, for at times there will come a flood of rain large enough to swell up and overflow the banks and the result is a worse wash than if there was no bank there, because of the gathered head of water. The real cure for the trouble can only be made by a total abandonment of the methods of culture which are responsible for the washing, the shallow plowing and the constant working of the land in clean hoed crops. When these hills were first cleared from the forest the land did not wash because it was full of humus and the fibrous matter from tree roots. But year after year only a few inches of the loose surface soil were stirred, the humus was used up, and the soil became more compact and inclined to run together and bake, and when the shallowplowed surface got filled with water and was reduced to a creamy condition, while the clay below remained perfectly hard, it naturally ran down the hill carrying off all the plowed surface and leaving the hard red clay exposed to the action of the rain and the frosts of winter, and every rain took off all that the frost had heaved up, and a gall and gully were formed.

It has been seen that the so-called terracing

How Shall

We Prevent this Washing of the Southern hills has been but a partial remedy, and that in spite of the banks the soil continues to wash; it is evident that the only real cure is to return the land to the conditions that existed when it was freshly cleared, and to plow the land so deeply that it will retain a great deal more water without running. Crop rotation, then, in which the legumes come frequently on the land as a means for the restoration of the humus, accompanied by deep plowing and subsoil- 
ing, will do more to check washing, not only in the Southern uplands, but in hill soils anywhere than terracing. The Southern farmers have long since learned that it will not do to plow straight furrows up hill and down, but in many sections further North, where the soil does not tend to wash so badly as the Southern soils, this practice of straight furrows on hill lands is working serious damage. In the South the furrows invariably follow the contour of the hills, and it would be wise for farmers in all hill lands to adopt this plan, not only because of its lessening the tendency to wash, but because it is easier for the team than to plow straight up a hill.

The red clay soils of the Southern uplands show hardly a trace of difference in color between the surface soil and the subsoil, and in fact the red clay of these uplands is all of uniform character all the way down to the fast rock, and will all become good arable soil if exposed to the action of the air and frost. In the improvement of these hills that have been only scratched over for a century or more the turning must be gradual and not too much of the unused soil exposed at once. But this does not prevent at once a deep loosening of the soil, for below where any good plow should run the subsoil can be loosened by a subsoil plow following in the same furrow. With the soil loosened to a depth of fifteen to eighteen inches it will take a complete cloudburst to start the soil to running down hill, and when to this deep breaking we add the burying of the roots of peas or clover we still further check the tendency to wash. Then, if in every hoed crop like cotton or corn there is sown some crop as a winter cover, crimson clover or rye, so that there will be a cover of green 
vegetation on the surface all winter to prevent the leaching away of plant food and the winter washing of a bare soil, and furnishing also vegetable matter to turn under in the spring, we increase the fibrous material in the soil and still further check the tendency to wash. The one-horse plow and the clean and constant cultivation in cotton have been the cause of the bad gullies in the Southern hills, and the puny attempts to dam back the water have done little good. So long as the continuous cultivation of the land is practiced and the one-horse plow is the means for breaking the land for crops, the washing wiil never be checked, no matter how elaborate the terracing may be made.

Deep breaking, subsoiling and rotative cropping, with a cover crop always on the land in winter, will do far more to check the washing of the Southern hills than all the terraces that were ever constructed. Then, when the land is in clean crop, the common practice has been not only to break the land on the contour of the hill, but the rows are laid off in the same way, which is all right so far. But the practice followed in the cultivation of the crop has of itself led to a great deal of the washing. Instead of working the soil shallowly after the planting of the crop, and keeping it as level as possible, the practice has been to hill up the soil to the rows of cotton or corn, and when the rains descend the furrows thus formed soon get filled. The upper ones overflow and those further down the hill continue to gather head and overflow till a torrent is formed rushing down and a gully starts. If the crops had been worked shallowly and level there would have been no hollows to gather a head of water, but it would have been spread out and largely sunk in the soil, and if 
deep plowing had been practiced there would never be any great gathering of water on the surface to rush down in one torrent. Then, added to the deep breaking and the proper rotation and cover crops we need the shallow and level cultivation to prevent a head of water gathering. We need the shallow cultivation, too, to preserve the moisture in the soil by checking the evaporation at the surface and not turning up the moist soil below to be dried out.

But there is another sort of washing that is going on in all parts of the country where there are hills and running streams. The banks of the streams have been completely cleared and cultivated to the margin, and when the freshets come the banks cave in and the soil is washed away to choke the rivers. After every rain storm one can see the result of this washing in the soil-burdened waters that go flowing to the great rivers and choking the harbors. This has been the result of the clearing of the lowlands right to the borders of the streams instead of leaving a bordering of small trees and shrubs to bind the banks. Streams in every part of the country are thus wasting the soil, most of which could be prevented by setting willow cuttings along the banks, and keeping the tops cut back annually to prevent too tall a growth to shade adjoining crops. 


\section{CHAPTER $\mathrm{X}$}

CROP ROTATION-ITS PURPOSE AND PRACTICE

T' $\mathrm{T}$ has been found that where the same crop is grown on the land year after year, no matter how well sup1 plied with fertilizers, the yield cannot be kept up profitably, and often the soil refuses to produce that crop at all.

No crop is ever entirely removed from the soil. The roots at least remain there to decay, and it seems that plants soon get tired of feeding on their own decay. Some have supposed that there are deleterious excreta thrown off by the growing roots of plants, and that these are poisonous to that particular plant while not so to plants of a different character. But no true excretory process has ever yet been discovered in plant life, though it is believed that the roots do exhale carbon dioxide in the soil. But this would only tend to render the insoluble plant food in the soil more available, and would not be at all poisonous to plants.

In the experiments at Rothamsted, England, conducted by Lawes and Gilbert, they cultivated Irish potatoes on a piece of land continuously for a long scrics of years until it finally refused to produce any potatoes. But when it was sown to barley it made a crop of seventy-five bushels per acre. The cause of this probably was that plants select plant food from the soil differently. Irish potatoes call I 48 
for a large percentage of potash, and in the scries of years they had been grown on the land they had so reduced the content of potash in it that potatoes could no longer be made, but there was still enough left to make a fine crop of barley, the food requirements of which are very different.

In our native forests we find that there is usually a very great diversity of plants, and a great difference in their root development. The pine tree sends a deep tap root into the soil and gets food below where the spreading roots of the oak feed, and it takes food of a different composition from the oak, and the leaves of all the trees fall and decay and furnish each with what it wants, so that in the forest there is really a rotation of crops going on all the time.

We have seen that humus, or organic de-

Economical Advantages of a Rotation of Crops cay, is a very important constituent in a fertile soil. Long clean cultivation of the land in a hoed crop exposes the soil to the sun in summer and the winter rains till the humus is used up and the plant food is leached away from the soil. This can readily be seen in the cotton belt of the South, where this continuous clean cultivation has been the rule for many years until the land refuses to give a fair crop and only makes a moderate one by the use of commercial fertilizers.

This has been the result of an impression that cotton was the only crop it paid the farmers to grow, and that they could buy corn and hay cheaper than they could grow it. But they overlooked the fact that the crops that should properly form their rotation would, if properly arranged, tend continually to increase the productiveness of the land in cotton. 
It has been well said that sand and clity form but the skeleton of a soil, and that humus, or organic decay, is its life. A rotation, then, in which crops of clover or peas are grown, tends through these, and their feeding to live stock, to restore to the soil the humus which long clean culture has used up. If the humus furnished no plant food it would increase the capacity of the soil to produce the money crop through the improvement it makes in the physical condition of the soil, making it more mellow and more easily cultivated, less liable to crust and bake hard, and also retaining water better. But the humus also does furnish plant food through the agency of the bacteria that find their home in it and transform the nitrogen contained in the organic matter into nitrates that plants can feed upon.

While, directly, the auxilliary crops may not return as much cash as the cotton crop, their indirect effect on the cotton crop will well warrant the rotation. The same is true of any other money crop grown in this country. The wheat lands of the Northwest have deteriorated from their former productiveness, while the old lands in Maryland and other parts of the winter wheat growing sections have, through a proper rotation of crop, greatly increased in the production of wheat, till in some sections where formerly they made ten to fifteen bushels per acre, the thoughtful and progressive farmers now average forty bushels per acre.

In the South there are also a few farmers who have realized the value of a proper rotation of crops, and have grown legumes for forage and the improvement of their soil, who produce two bales of cotton per acre, while the 
general average of the cotton belt is about 200 pounds of lint per acre with the general all-cotton practice.

The adoption of a systematic rotation of crops in the South and the use of the cow peas for the feeding of stock, would open up a profitable industry in the stock feeding, and would result in the making of larger supplies of homemade manure to relieve the farmer from the constant purchase of commercial fertilizers. Then, too, the getting of the fibrous matter from the pea roots and the humus from the manure, accompanied by deeper plowing and level cultivation, would check the great tendency of the Southern uplands to wash into gullies, for the clean culture of generations, with the shallow plowing of the one-horse plow, has been the means for great waste in this way, as we have shown in the preceding chapter. The adoption of a short rotation and the growing of the legume crops would enable the Southern hill farmer to dispense with the expensive terracing now found necessary to check the washing of his lands.

What

Of course, no hard and fast rules can be

Rotation is laid down that will apply to every farmer's Best for the conditions. But the following have been Cotton Farmer found admirably adapted to the needs of the upland cotton farmer. Beginning with corn on the land, he should sow peas among the corn, at last cultivation of the crop. The corn should be cut and cured in shocks, and if the peas have made a rank growth they can be mown for hay, and the surface then finely chopped up with a cutaway harrow to prepare the land between the shock rows for wheat or winter oats, and after the shocks have been removed the spaces they occu- 
pied may be sown to oats later. Cut these oats and immediately after harvest break the land well and sow cow peas broadcast for a hay crop to be cut as soon as the first pods begin to turn yellow. Then crimson clover seed should be sown on the pea stubble as a winter cover. This clover can be turned in the spring and the land prepared for cotton, using on the cotton only the mineral fertilizers, acid phosphate and potash, for the clover and peas preceding will give all the nitrogen needed, and fully half the cost of the fertilizer will thus be saved. At the last working of this cotton sow the crimson clover seed again at the rate of fifteen pounds per acre among the cotton. Now, during the winter haul out and spread with a manurespreader on this clover all the home-made manure from the feeding of the pea forage and the corn fodder, and when the clover blooms in the spring turn it under deeply for corn again. Cultivate this corn level and shallow, and repeat the sowing of peas among it and then repeat the general rotation. Following this method a few years will soon show a great increase, not only in the cotton crop but in the corn and small grain crops as well. One young farmer whom we had induced to adopt this rotation for cotton, wrote to me enthusiastically that he had found that cotton was not the only crop that would bring him money, for he had made seventy-five bushels of winter oats per acre and then had made two tons per acre of cow pea hay on the same land the same season, and that the hay was salable at $\$ 20$ per ton, so that the crop of oats and hay were worth a great deal more than a crop of cotton; that the oats and the feeding of stock gave him cash at different seasons so that he was able to run his cotton 


\section{Crop Rotation-Its Purpose and Practice 153}

crop for cash and hold it if the price did not suit him. Systematic rotation of crops and the fecding of stock are needed more in the Southern cotton belt than anywhere else, for there is no moncy crop in the country that offers a better prospect for profitable culture than cotton with good farming, while there is none that keeps the farm and farmer poorer than the all-cotton practice, with commercial fertilizers bought on credit and paid for out of the cotton crop.

In the wheat-growing sections of central Crop Rotations and southern Pennsylvania especially, the for the Winter old practice in wheat growing-a practice Wheat Sections of the which is still common in many of the less Middle States progressive sections-has been to break an old sod for the corn crop, and the following spring to seed the corn stubble to oats. The oats stubble after harvest is plowed and prepared for wheat, with which the land is secded down to timothy, and in spring has some clover sced sown on it. The grass is mown for a number of years and then pastured and finally broken again for corn.

This involves a long rotation, an enormous amount of fencing, and a depletion of the soil before the rotation is renewed by the breaking of the sod, which has been allowed to remain till no longer profitable for hay or pasture. Gradually the best farmers are discovering that a shorter rotation and more frequent use of clover or cow peas is far better for the development of the production of the sale crops. In this shorter rotation the oats crop is abandoned as a commercial crop and only grown for the supply of feed for the farm horses, as we will note. 
A Modern

In the neighborbood of the larger cities, Short Rotation where there is constant demand for timothy for a Wheat Farm hay at good prices, the temptation has always been to allow the land to lie in grass so long as a moderatcly fair crop of hay can be made from it. But it is far better to get two to three tons per acre of hay in one year than to get a ton or half a ton for several years. There is no reason why a farmer, who is situated near a good hay market, should not sell hay as well as any other crop grown, provided he takes other means for keeping up the humus-making material in his soil. Whether the rotation shall be a three-year or a four-year one will depend on the conditions and environment of the farmer. If his main object is to get large crops of wheat and corn, and to use up all the roughage of the farm in feeding stock, the three-ycar rotation and the entire abandonment of timothy will be best. It is hard to rid farmers in the Middle States of the notion that no matter how short the rotation is they must sow some timothy seed when they sow clover. The fact is that only clover is needed in such a rotation. Various circumstances are gradually forcing the Eastern farmer into ncw methods and shorter rotation of crops. The increasing scarcity of timber, and the consequent cost of fencing is destined to bring about a change which will be of great benefit to the farms. This change is the entire abandonment of pasturing the cultivated fields, and hence the abandonment of fences that pasturing makes necessary. The modern grain farm should always have an area set apart as a permanent pasture, on which care is taken to maintain the sod in good order and free from 
weeds by annually top-dressing it liberally with commercial fertilizers, and an occasional going over with the hay rake to scatter the droppings of the animals.

This permanent pasture will be the only part of the farm needing a fence, since in most states they no longer pass laws about what sort of a fence is a lawful one to keep other people's stock off your land, but have gone back to the sensible common-law doctrine that every one is responsible for his stock and not for that of other people, and that hence he is obliged to fence his cattle in, but not to fence other people's cattlc out. This change has come about largely from the recognition of the fact that every farmer owns the fee simple to one-half the highway in front of his farm, and that he has only dedicated this to the public as a means for travel, but still owns whatever grows on the land, and hence owns the pasturage, which the public has no right to use and compel him to fence their straying cattle out. This abandonment of fences over large sections will gradually become the rule everywhere, and with it must come a great improvement of the cattle and live stock in general, and a more rapid improvement of the land through the abandonment of pasturing on the fields devoted to crops.

Having the permanent pasture, the laying An Improving off of an ordinary farm is usually easy, es-
Three-year Rotation pecially when we intend to run the whole in but three general divisions. It may not always be practicable to make each section or field of exactly the same size, but it is desirable that they shall be as nearly equal as the character of the land will permit.

We will assume that we have a field in sod, another, 
which was in corn the year before, will be in wheat, and a third from which wheat was taken last year, will have a stand of clover to be cut for hay. Starting then, in the spring we will plow that sod deeply after having applied to it all the manure that can be saved from the stock fed during the winter, and hauled on the sod whenever it was fit during the winter and spring, always remembering that manure kept on hand is always losing value, and the least loss is when it is spread on the field. If the land had been long in sod it would have been better to have plowed it the fall before, and to have run a subsoil plow after the turning plow to deeply loosen the land, and then to have sown rye as a winter cover and to catch the fleeting nitrates that form even in the winter. But starting in the spring, all we can do is to give the sod a deep breaking and thorough preparation for the corn crop. But having deeply plowed the land and turned down the sod, the subsequent cultivation of the corn crop should be as shallow and level as possible. From Pennsylvania southward it is a good practice to sow some of the Southern cow peas among the corn at the last working, and later, as these ripen and the leaves are falling, to sow seed of crimson clover among them, letting all remain as a winter cover if the corn is to be followed by oats in spring and the rotation made longer. But in the three-year rotation we are beginning we will cut the corn as soon as well glazed and will shock it in rows as wide apart as practicable. Then, if the peas have made a heavy growth they may be mown for hay, but if not very heavy they can be chopped up with the cutaway harrow and the surface made for and seeded to wheat. Now, as this wheat will have ready for it a 
good deal of nitrogen from the decay of the sod and the manure applied to the corn, and also from the growth of the peas, it will not be wise to apply a complete commercial fertilizer, that is, one containing nitrogen, since the tendency of an excess of nitrogen is to make too rank a growth of straw, and consequently a risk of lodging and failure of the crop. But the perfection of the grain crop demands that there shall be an abundance of available phosphoric acid and potash present. Therefore, it will always be found profitable to apply about 400 pounds per acre of acid phosphate and muriate of potash mixed in proportion of six parts of the first to one of the latter material.

The soil having become well settled from the spring plowing and cultivation of the corn, it will be far better for the wheat that only the surface shall be chopped fine with the cutaway, since a well-settled soil is needed for the wheat. The fertilizer will of course be harrowed in the preparation of the land. The corn and stover are gotten off during the late fall and winter, and in spring the shock rows can be sown to oats, and the whole land seeded with clover, using the medium red clover as the best for general purposes. After the wheat harvest, and as soon as the ever-present rag weeds start, run the mower over the stubble to cut them off and give the young clover a chance to develop.

The following spring, before any growth is apparent in the clover, spread on it twenty bushels per acre of freshly water-slaked lime, and run the smoothing harrow over to spread it evenly and to mix it with the soil.

The clover should be cut twice during the summer, the 
second crop containing the seed, and if your land is clean of weeds you can keep it so better by sowing clover seed of your own growth than by buying it and getting other people's weeds. This completes the rotation, and you now have a clover sod on which to haul and spread manure as fast as made until spring, when it should again be turned for corn and the rotation repeated. By practicing this rotation, lands that formerly made ten bushels of wheat and forty bushels of corn per acre now make forty bushels of wheat and seventy-five bushels of corn per acre.

In sections where the crop of Irish potaHow this Rotation May Be Varied toes may be made a profitable part of the farm cropping, a part or even half the sod land devoted to corn may be used for the potato crop. If this is practiced, it will be better, on the part used for the potatoes, not to apply the barnyard manure, which is apt to encourage the scab, but to give the potatoes a liberal dressing of acid phosphate and muriate of potash, mixed as suggested for the wheat crop, but in at least double the amount and mainly in the furrows before planting, since the potato does not spread its roots widely like the corn. This potato crop will put the land in the best possible condition for the wheat crop following, and in the next round of the rotation the part of the clover sod that was last plowed for potatoes should be used for corn, and in this way both corn and potatoes will come on the land but once in six years, and the manurial needs of each will be best served.

The idea in the above suggestions is to so arrange the rotation that the wheat, which will be the main sale crop, will have the best chance. Corn, being a gross feeder, 
can better be used to consume to some extent the food supplied by the turned-under sod with its coarse manure, and the cultivation of the corn and potatoes will put the plant food in the soil in the best possible condition for the wheat, aided by the mineral fertilizer applied, and the soil also will be in the best mechanical condition for seeding the wheat crop without replowing, so that if the land is well broken for the corn or the corn and potato crops there will be but the one breaking in three years, and a great deal of labor will be saved while the crops will be benefited.

I do not mean those sections of the MidWhere Clover dle and Northern States where clover for-
Does Not Thrive Well merly throve, and where it has now become difficult to get a stand, but the more Southern sections of the wheat-growing area in which clover has seldom been a success through the long summers. Here a similar rotation can be practiced with crimson or the annual winter-growing clover, and cow peas used as the legume crops for the making of hay and the improvement of the soil in nitrogen. Assuming that we start with a growth of crimson clover sown the fall before and on which the farm manure has been spread during the winter and spring, we will plow the whole growth under when the clover is in bloom, and prepare the land for corn, sowing peas among the corn at last working as before. These peas are to be mown for hay and the land prepared for wheat or winter oats, and at once, after harvest, the land is again well plowed and cow peas again sown, using not less than one bushel of seed per acre broadcast. When the peas have reached a proper state of maturity, as shown 
by the pods turning yellow for ripening, and the stubble well disked and again seeded to fall grain, which the following summer is again followed by peas for hay, and the stubble disked and seeded to crimson clover, on which the farm manure is to be again spread during the winter and turned under for corn again in the spring.

In this rotation we have an abundance of forage crops for feeding and making manure, and if each pea crop is dressed with 300 to 400 pounds per acre of the phosphoric acid and potash mixture heretofore advised for wheat, the forage will be greatly increased, and the means for stock fecding also, so that a large amount of manure can be raised on the balanced ration of the pea hay combined with the corn stover either used dry or as ensilage. In the three-year rotation there will be two wheat crops, one after corn and another after peas, which will usually be the best one, and there will always be a green manure crop for the corn. It will be seen that in these rotations there is no purchase of artificial nitrogen, and in any grain or cotton farming the peas and clover will furnish all the nitrogen needed, and will thus make a great saving in the purchase of fertilizers.

The need of an improving rotation of

A Rotation for an Upland Cotton Farm crops is greater perhaps in the cotton belt than in any other section of the country. The practice of planting cotton year after year on the same land, and depending on complete commercial fertilizers only for the making of a crop, has resulted disastrously all over the Southern uplands. The soil, deprived of humus and plowed very shallowly with one-mule plows, has washed into gullies, and with the shal- 


\section{Crop Rotation-Its Purpose and Practice 161}

low plowing the terrace banks erected to stop the washing have been generally ineffective when extra rainfalls occur, since they often fill and cause a heavier washing by the accumulated head of water in them. Terracing is only a partial preventive to the washing, and the only real and permanent preventive to the tendency of the land to wash is deep breaking and a restoration of the vegetable matter which the long clean culture in cotton has used up.

In no section of the country will decp subsoiling work greater benefit than on the red clay hills of the Southern cotton country. The summer rains come in great floods and cloudbursts, and the soil being plowed but three or four inches deep, with a hard clay subsoil right below, the shallow plowed surface gets into a creamy state and must run down hill, since there is nowhere else for it to go. But if the land is plowed more deeply and the subsoil plow follows in the same furrow so as to loosen the whole surface to a depth of $\mathrm{I}_{2}$ to $\mathrm{I}_{5}$ inches, it will take an enormous rainfall to move the mass. And more than this, the deeply broken mass will retain the water that would otherwise be washed down hill, and by shallow and level cultivation can be retained in the soil to carry the crops through the long droughts that are about as common as the floods of rain. Deep plowing and shallow and level culture to form no furrows to gather a head of water, will be far more effectual in preventing washing and gully formation on the Southern uplands than any terraces that can be contrived with the shallow plowing that has been the rulc. When these lands were first cleared from the forest they did not wash, because they were full of humus and fibrous vegetable matter. They were mellow and 
easily cultivated, and were retentive of moisture. But year after year the soil was exposed to the sun in the cleanest of cultivation which the crop of cotton demands, till the vegetable decay was used up and the soil began to crust and bake, became harder to cultivate till the plow became a necessity for working the hard soil.

The remedy is to restore the new-ground conditions through getting back the wasted humus by a systematic use of a short rotation aided by the growing of forage crops and the feeding of live stock. It is hard to get the Southern farmers to realize that the subsidiary crops used in a rotation can of themselves be a source of profit while increasing the capacity of the land for the production of the staple money crop. They have so long been accustomed to look to the cotton for all the money they want and imagining that they cannot afford to grow other crops needed for the stock, that there has been in many sections an entire abandonment of cattle-feeding, and no animals are kept but the mules that cultivate the crop, and the cotton is expected to pay for all, to buy the mules themselves, pay for hay and grain to feed them with, pay the fertilizer manufacturer a long price for credit on the fertilizers used, while the farmer, with all depending on the single crop is at the mercy of the whole. For generations the Southern farmers were taught that their money crop was not adapted to rotative farming as practiced by good farmers in other sections, and they have gone on in the blind faith that cotton was the only thing that could be made to pay in the South.

But a change is gradually coming, and here and there farmers who are studying and endeavoring to improve, 
are showing the value of a rotation of crops that is designed for the improvement of the soil for the money crop. When one farmer at least, to our knowledge, has succeeded in an average seasor in producing two bales of lint-cotton per acre in a section where the average crop is less than a fourth of a bale, and has done it with less use of the commercial fertilizers than his neighbors who make the smaller crops, it must finally dawn on the Southern cotton grower that his crop, as much as any other crop, is adapted to a diversified farming system.

It is important in devising a rotation for a cotton farm to consider the situation and the soil. In the upper or Piedmont country, the land of the red clay hills, wheat should be the small-grain crop mainly, though a portion of the small-grain area can well be used for the production of fall-sown oats, which are often very productive. In the more level and sandy sections nearer the coast, the true cotton soils, the small-grain crop should be oats entirely, since in these lands the winter oats will soon develop into great productiveness, while the sandy lands are not well suited to wheat. Enthusiastic but inexperienced advisers of Southern farmers in the Southern press often tell the farmers that they should grow everything they need that can be produced in the climate. The effort to do this would not be systematic farming, but merely a heterogeneous collection of many things. What is needed in the development of a cotton farm is a system of few crops all tending to develop the capacity of the land for the production of cotton, while of themselves yielding the farmer a profit. The rotation would vary hardly at all whether in the rolling upper country or on the coastal 
plain except that on the level coastal plain there will not be the same need for the deep subsoiling that is needed on the hard red clay of the hills, except where there is a hard clay subsoil in reach of the plow. While wheat may be the better small-grain crop for the hills and winter oats in the plain, the crops may vary to this extent, but the preparation and cultivation of the soil will be identical.

While every farmer must in every section

A Successful Cotton

Rotation

be the judge of what is best for his particular needs, and suggestions for rotations of crops must be largely suggestive, so no one can lay down hard and fast rules for the adoption of every one, we have known the following rotation to be adopted with great success in the South.

Starting with a cotton crop, which has been fertilized in the usual manner with a complete fertilizer of rather low grade in the furrow, we will add to this a good dressing of a high grade commercial fertilizer in the middles between the rows of cotton, for the cotton plant, like the corn plant, sends its roots far and wide. We will plant that cotton flat, harrowing down the beds after putting in the fertilizer. The first cultivation will be with a smoothing harrow before the cotton comes up, so as to break any crust that may have formed. Then, after the cotton is up we will work it both ways with the weeder, and thus completely keep a crust from forming around the plants to make them "sore shinned" in the wind while young and tender. Of course, the weeder will tear out some plants, but not near as many as will have to come out in chopping and will save a great part of the chopping.

Then all the subsequent cultivation will be done with a 


\section{Crop Rotation-Its Purpose and Practice 165}

fourteen-tooth cultivator, running as shallow as possible, or with a two-horse riding cultivator with small teeth and arranged so that the operator may shift the teeth from side to side and regulate the depth with hand levers. This is a far better implement and a greater labor saver than the ordinary one-horse cultivator, and is as far ahead of that as the one-horse cultivator is ahead of the cotton sweep, so largely used in the South.

The growing scarcity of labor in the South will compel the use of labor-saving implements, and as one man riding with two horses can do far more work than two men with two horses worked singly, the lack of the men will of itself soon compel the use of the labor-saver.

At the last working of the cotton we will sow, while the soil is freshly stirred, fifteen pounds per acre of crimson clover seed to act as a winter cover on the land. Now, during the winter we will get out on this clover all the manurial accumulation and spread it broadcast, preferably with a manure-spreader in order to make it go as far as possible and as evenly as possible. When the clover is in bloom we will plow all under for the corn crop, and this, too, we will cultivate shallowly and level like the cotton, after breaking the soil very deeply and thoroughly. Among the corn we will sow at the last working cow peas, and work them in. We will cut and shock the corn for curing as soon as well glazed, and will mow the peas and put the stubble in order for the fall crop of oats, on which we will apply a dressing of acid phosphate and potash mixed six parts of the first to one part of the last named, and use about 300 pounds per acre, well harrowed in in the preparation of the soil. These oats can either be grown as a grain 
crop or harvested as hay. But in either event the land should be replowed as soon as possible after harvest, and one bushel of cow peas sown per acre, using on them the same application advised for the oats. Cut the peas for hay as soon as properly matured, and sow crimson clover again on the pea stubble without any preparation. A little rye sown at the same time will not be amiss, as there may be a poor stand of clover in the first practicing of this rotation, but which will improve as the soil gets inoculated with the bacteria that live on the clover. These legumes will give you all the nitrogen now needed by the cotton, and we can now start with only the broadcast application of the phosphoric acid and potash, planting our cotton flat and working it always as shallow and as level as possible. With each round of this rotation you will find the crops of cotton, corn and oats improving in yield if you feed all the corn fodder and the pea hay. With the amount of forage produced the cotton farmer with such a rotation should soon be able to raise enough manure to cover his entire corn planting, and this with the peas and clover following the oats crop will make the farmer annually more and more independent of the fertilizer factory. Following this rotation several years, one farmer made a crop of seventy-five bushels of oats per acre and made two tons per acre of pea vine hay after the oats were cut on the same land the same season, and he found that this double crop was of far more commercial value per acre than the cotton crop which he had been taught to consider the only money crop in the South. 


\section{CHAPTER XI}

\section{CROPS AND CROPPING}

T $\mathrm{N}$ the succeeding chapters I propose to take up the practical method of cultivating the various American

1 farm crops. I hope to give somewhat in detail the best methods adopted in the various sections where these crops are grown. Of course, any series of instructions for any crop cannot be made hard and fast rules for every condition. It is assumed that the reader will be able to take the suggestions and adapt them to his own conditions.

Many of these crops are grown in different climates and on a great variety of soils. While the soil on a farm may not be the ideal one for a certain crop, it will be found that no farmer can afford to entirely ignore the crop that for various reasons has become the chief money crop of the section.

Many Northern farmers in changing to a location in the South, see the wasted condition of a great deal of the soil in the tobacco and the cotton regions, and at once jump to the conclusion that the culture of cotton or tobacco has been ruinous to the soil, and they conclude that if they are to restore the fertility of the soil they have located upon they must ignore these crops.

But long experience has shown that in some sections the soil is well adapted to the cultivation of some of the 
different types of tobacco, while over a large part of the Southern States the cotton crop is the natural money crop, a crop in which that section has the advantage of all the rest of the world. Hence, it would be a mistake for any one going to a new section to assume that the farming there is entirely wrong, and that he should abandon the crops that he considers responsible for the depleted condition of the soil. Such a notion is superficial. It is not the fault of the tobacco or of the cotton that the lands have become unproductive, but it is the result of longpracticed and erroneous methods of cultivating these crops. The true policy, therefore, for a comer into a new district is to accept what nature and long experience has established as the money crop of the section, and then undertake to grow it better by improved methods of farming.

While in the greater part of the cotton belt, for instance, the practice of depending on the one crop, and cultivating the land year after year in cotton, has reduced the productivity of the soil to a very low ebb, there is no more profitable money crop grown on the farms of America than the cotton crop when used in an improving rotation designed for the restoration of the wasted humus that long clean cultivation has burnt out of the land.

Another error that farmers make is moving southward or eastward from the fertile lands of the West, as many are now doing. This is to charge the waste to the use of commercial fertilizers and declaring that these are only stimulants. Commercial fertilizers have been very wastefully and injudiciously used in the South, especially by the cotton farmers. But we must not jump to the conclusion 
that the use of commercial fertilizers is a mistake. The all-cotton man dribbles a little in the furrow for the crop, all of which is at once taken up by the crop, and a further draft is made on the store of plant food in the soil. The result is that the land grows poorer instead of better.

At a farmers' institute in a Southern State, a chemist stated in our hearing that the only purpose of the commercial fertilizers is to make crops, and that they cannot be used for the permanent improvement of the soil. I combated this statement at once. This is what the cotton farmers have always practiced and have grown poor in doing it. My idea is that the true purpose of the commercial fertilizers when properly used, is to start the improvement of the land through a proper rotation of crops and the growing of the legumes. Some have imbibed the error that a good rotation of crops is in itself a method of improvement, when in fact a rotation is designed to get more out of the land by increasing its humus contents and thus rendering available much that would otherwise not be gotten from the soil.

As we have shown, a short rotation in which the legume crops come in frequently on the land as a means for getting the use of the free nitrogen of the air and also of increasing the humus-making material in the soil, demands that we keep up the supply in the soil of the mineral matters, phosphoric acid and potash, for, while the legumes will get us the nitrogen and combine it in organic matter to be brought into use for the succeeding crops, they are, at the same time, the most greedy consumers of the mineral elements.

Therefore, while an injudicious use of commercial fer- 
tilizers combined with continuous clean culture of one crop, has resulted in wasted fields, and a great waste of money for what the farmer in a good rotation can get without buying, the proper and liberal use of the mineral forms of plant food is the most rapid and profitable method for improving the condition of the soil.

We have often urged that in any ordinary grain or cotton farming the farmer who farms right will never need to buy any nitrogen in any form, for the legumes will give him plenty for the succeeding crop and will give him also forage, which, fed to stock, will enable him to make more manure at home and thus have less and less need for a complete fertilizer. But all of our older cultivated soil has become deficient, from the carrying off of crops, in phosphoric acid and potash, especially in phosphoric acid. There is no way in which we can get these back to the soil from the air as we can the nitrogen, and hence, they must be restored in some artificial way.

In recent years there has been a great deal said and written about a little farm near Philadelphia where Doctor Detrich made the soil so fertile that he supported thirty cows, so far as hay and roughage was concerned, on less than fifteen acres of land, and the soil became so fertile that he not only did this but had hay to sell. Doctor Detrich boasted that he used no commercial fertilizer.

But he bought liberally of grain for the cows. This grain was grown on some one else's land, and the Doctor was simply transferring the fertility of other people's land to his own. He had a near market for dairy products at a good price and, therefore, could afford to do this.

But there are few general farmers who can afford to buy 
the fertility of other people's land in this way, and these must get what their land needs in some other way. The most ready way is through the use of commercial fertilizers.

There has been so much experimentation with commercial fertilizers on various crops by the experiment stations all over the country that farmers in many sections have imbibed the notion that for every crop grown they need a specially adapted fertilizer mixture.

In the discussion of the various crops we will endeavor to show what we consider the proper use of these fertilizers in the growth of the money crops through their use more directly on the crops that feed the stock, feed the land, and increase the humus of the soil. In order to treat more fully of the crops that do these things we will follow the chapters on the leading farm crops with one especially devoted to the various legume crops that are so important in the improvement of the soil, for, as we have often stated, in our opinion the farmer of the future must be a legume farmer, and must depend more and more on this class of plants for feeding his stock and feeding his soil. 


\section{CHAPTER XII}

\section{THE INDIAN CORN CROP}

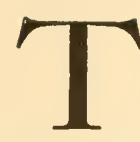

1 HIS is the great cereal crop of the United States. Wheat may rank higher as an export crop direct, America, and while not so largely exported as grain, the results of feeding it to cattle and hogs make the export of beef, pork, etc., a very important item. Owing to the wide range of climate to which Indian corn has become adapted it has become the most important forage and feed crop of America, thriving, in its numerous varieties from Maine to Texas. Through the central Western States we have what is called the great corn belt, where, owing to the virgin fertility of the soil, its cultivation on a large scale has made these states the great stock, dairy and pork producing sections of the country.

But corn is naturally a plant of the tropics, and the longer seasons of the cotton belt make this section peculiarly adapted to the cultivation of the crop since there is never any risk from early frosts catching it as there is in a large part of what is called the corn belt. But in the South, the exclusive devotion of the farmers to the cotton crop has led to careless cultivation of corn, and in many sections to a dependence on the West for all the corn needed. Added to this, the careless selection of seed, which has allowed the plant to attain the natural devel- 
opment of stalk common to warmer climates, so that the general notion has arisen that corn in the South must be planted very wide apart to give it air, and with a single stalk in a hill five to six feet apart each way, a large crop is out of the question, especially since the tall corn has long since, through this same careless selection of the biggest ears in the crib, gotten to produce but a single ear on a stalk.

Much has been written of late years in Good Seed Selection Important in all Sections regard to the selection of the seed of the Indian corn plant. Methods of selection should, however, be adapted to some extent to the conditions of soil and climate where the crop is to be grown. In the more Northern sections it is important that the crop ripen early so as to avoid danger from the early frosts in the fall. Hence, the Northern planter needs to select in the first place corn that has been produced in his climate, for there is no crop grown that is so much influenced by being transferred far north or south of the section where the crop is to be produced. On the more Northern limit of corn culture the long-eared, eight-rowed, flint corns are essential to success, while coming into more southerly climates the dent corn in numerous varieties takes the place of the flint, and in the fertile lands of the southern river bottoms the horse-tooth or gourd-seed corns find a congenial home, and if any of these are transferred northward or southward they take some time to become acclimated to new climatic conditions.

Therefore, in the improvement of our seed corn we should avoid sending off north or south of our locality 
for seed, but should take at the start the corn that has been long cultivated in that particular section, and through careful selection, year after year, breed it to the ideal of what we consider the plant should be.

The great fault in what has been called corn breeding of late years has been the taking of the ear as an individual unit for the starting point. The ear of corn is a great aggregation of individual fruits borne on a common receptacle, the cob. Every fruit or grain is the result of the impregnation of a separate pistillate or female flower by the male element or pollen. The so-called silks constitute the pistils or female part of the flower, and each pistil is attached to an ovary in which are certain ovules that are transformed into seed or grain when the pistil is impregnated by the pollen. This pollen, or male element, is produced in what is called the tassel. Those who have noticed a solitary corn plant growing at a distance from any other corn plant have doubtless observed that it seldom produces well-filled ears, because little of the fine dust-like pollen falls directly on the protruding pistils, or silks, but is blown away from it, and the silks that receive no pollen fail to develop grain.

But where a large number of corn plants are growing together the vast abundance of pollen blown about in all directions in apparently wasteful abundance is pretty certain to reach all the silks, and the result is a full ear or ears on each. We see, then, that the plant that produced the grain is seldom the one that furnishes the pollen for the perfection of the grain, but that the pollen from the thousands of stalks around constitutes the male parent of the grains on the ear. It is, therefore, perfectly possible that 
each fruit or grain on the general receptacle may have had a different male parent, and from its male parent may inherit very different tendencies.

And right here is where the popular score-card selection fails. The student is instructed to select ears of a particular shape, grains of a particular shape, and cob of a certain character, all making up what is considered an ideal ear. But there is no certainty that these ideal ears will reproduce similar ones, since, as we have said, every grain on the ear may have inherited different tendencies from its male parent. The essential thing, therefore, in the effort to improve the corn plant, is to start with the true unit of improvement, the grain, and to regard each grain as an individual, and endeavor to make the environment such that all the grains of the ears will inherit the same or similar tendencies.

What the farmer should want in any breeding of seed is the increase of his crop per acre. He wants bushels of corn per acre rather than pretty ears and fewer bushels, and mere selection by score card will never advance him much. Then, too, in the breeding of any plant the paying of attention to one feature of the plant is not true breeding. It is like some of the fads that stock breeders have at times been carried away with, such as breeding animals to a particular color without regard to the qualities that make them valuable for either dairy or beef purposes. The breeder often got the color but with inferior traits for the purpose for which he is raising stock.

So, also, in breeding grain. If we take the ear of corn as the sole object of our attention, we may succeed in getting a very uniformly fine ear but on a plant illy adapted 
to our needs. In the South it will be long-legged and single-eared, and in the North may have characteristics that make the plant undesirable and unproductive in bushels per acre. What we need at the start is a proper ideal of what, in our particular section, should be the ideal corn plant. In the North, earliness is of prime importance. 'Then we want prolificacy, and a stout, shortjointed plant that bears its ears as near midway the stalk as possible. Selecting by a score card in the barn will never tell us anything about the plant on which the ear was borne. It will never tell us what sort of plants surrounded it and furnished to the pistils the pollen needed for the perfection of the grain, and this sort of selection tends to decreased productiveness since the pretty ear selection will eventually result in the production of a single ear on a plant.

Heredity is one of the strongest forces in nature, and the constant and long-continued selection toward a wellconsidered ideal plant will gradually establish a hereditary tendency to come true to seed, as the saying is. That is, we establish a family or strain of common ancestry and common inherited tendencies.

Then, of course, it follows that the proper selection of corn for seed must be made in the field by close attention to the character of the whole plant during the entire season of growth. If we wish our pretty ear to become fixed in its tendencies to reproduce such ears, we must see that the plant does not get pollen from plants that produce inferior ears. If we want to increase the number of ears on the plant, and so increase the yield of the crop per acre, we must see that the plants that have the pro- 
lific tendency are the ones to furnish the pollen for the whole.

In short, we must select the plants that come nearest to the ideal we have formed of what we want in a corn plant, and then must see that it has all disturbing tendencies removed from it. We must not allow the ears on a prolific plant to be set by pollen from a plant that produces a single ear or none. In the corn crop of this country it has been estimated that ro per cent. of the stalks in every field make no ear. But these barren stalks will produce pollen, and this pollen will impregnate the pistils of the plants all around it, and thus the tendency to produce barren stalks is perpetuated. And selection by score card tells us nothing about this, and it may be, and often is the case, that grain on an inferior nubbin may be better seed than the grain on a large and handsome ear, simply because of better male parents.

Plant, from the best seed obtainable, How Shall We which has been produced in the same local-
Select Our Seed Corn ity, a separate patch for seed. Plant as usual for a crop, and give the patch the best possible cultivation. 'Then, having formed in mind the ideal corn plant you desire, watch the growth during the season. When the plants show signs of making tassels and silks, go through the patch row by row, and pull out the tassels from all stalks that show no signs of ears and from all inferior and weakly stalks, so that the pollen for the impregnation of the silks will all be borne on plants that come nearest to the ideal you have formed. You want plants that are stout, leafy, and short jointed, and which bear the ears, two or more, at a convenient distance 
from the ground. In short, the ears should be nearly half-way between the tassel and the ground.

From this patch select the best ears, taking those especially good, and from the most productive plants, for the seed patch the next year, and use the remainder for the general crop. By persevering in this way, year after year, you will establish a heredity so that your corn will come annually nearer and nearer to a fixed type. When the hereditary tendency to produce prolific plants, and few or no barren ones has been fixed, it will be time enough to look after the particular style of ear you may prefer. Of course, in selecting seed for a northern locality, you must pay attention to the earliness of the plants and select with that in mind. But from Virginia, southward, there is no necessity for particular earliness, and that may be left out of the calculation since the climate is adapted to the full ripening of any variety, and the earliest are not always the best for the South.

Indian corn is the grossest feeder of all The Place in the crops grown on the farm, and hence is the Rotation for the Corn Crop the one best adapted to use the rough manure of the farm to get it into the best condition for the following crops of small grain. Hence, in a rotation where wheat is the money crop, and the rotation is a short one, the corn should come on the clover sod from which the hay was cut the year before. This clover sod furnishes a ready place for the regular hauling of the home-made manure as fast as it accumulates. The manure should be gotten out and spread, preferably with the manure-spreader, all during the fall and winter. No loss of any amount need be feared from 
letting the manure lie on the surface during the winter, for it will lose far less there than if kept in the barnyard, and the absorptive power of the soil will hold on to its valuable constituerts. In the spring the sod and manure are to be turned under deeply, the land thoroughly prepared with the harrow and planted. The planting will depend largely on local conditions. On level land it is the common practice in the Middle and Northern States to plant in hills about three and a half to four feet apart each way, so that the cultivation may be in both directions, leaving two or three stalks in the hill, and with the more dwarf-growing flint corns sometimes four stalks in the hill.

In the South, and particularly in the Southern hill lands, where there is danger of washing, all rows for cultivation must run on the contour of the hills, and hence corn is always planted in continuous rows with a single stalk in each place. On the level lands of the cotton coast belt, the tall growth of corn has led to planting it very thinly - one stalk in a hill, five to six feet apart each way. No effort is made to breed the natural tall growth of the corn down to a more moderate stature, and the general opinion is that the wide planting is necessary there. But where there has been attention given to the proper breeding of the plants, corn can be planted much closer, and a more prolific strain established. Plants that produce but a single ear in single hills six feet apart cannot produce a large crop no matter how fertile the land, and therefore it is of especial importance to attend to the breeding of the corn in the South. We have found that on the hill lands of the South corn properly bred can be planted in rows less than four feet apart and fifteen inches in the rows, 
and produce maximum crops tried by the scale of any section.

But whatever the method used in planting, the after cultivation shoukl always be level and shallow, except in low flat lands that need drainatge, where it may be necessary to plant on ridges and to kecp the middles clear to assist in the drainage. But these lands are exceptional. The first cultivation of the corn crop) should be made before the grain germinates, and the best implement is the smootlying harrow to merely break the crust and allow the grain to germinate easily and uniformly. Then follow with the weeder, going both ways. $\Lambda$ plant here and there may be (lamagerl by the weeder, but there is nothing that will help) the young corn plants to start off ahead of the weeds so well. After the corn gets six or eight inches high the twohorse riding cultivator, which enables the operator to cultivate both sides of a row at once, is the implement to use. The final cultivation, after the corn gets tall and shows signs of tasselling, is the small tooth one-horse cultivator or the spring tooth single harrow. Cultivated in this way there will be no furrows to catch a head of water to start a wash rlown hill, and the shallow cultivation will retain the moisture in the soil, especially if the cultivation is kept up in (lry weather and a loose blanket of soil is kept on the surface. Worked in this way the roots are unharmed and the moisture kept right where they seek it.

The common practice, especially in the Middle and Southern States, is to throw a furrow to the rows with a turning plow as the "laying-by" cultivation. This tears the feeding roots off and gives a serious check to the corn, and at the same time turns up the soil to dry out and thus 
still further injures the crop. Many farmers think that this earthing up helps the stalks to withstand the wind better, when in fact it weakens them. Corn plants on a level surface throw out strong brace roots, which are nature's means for holding it erect. If these are covered they are made soft and weak, and the effort is made to throw out others above the ground, which do not find a good foothold on the sloping ridge, and the corn blows down worse for the hilling.

Uses of the Corn Crop

We have dwelt so fully upon the cultivation and improvement of the corn crop because it is the greatest of all forage crops not only in this country, but the greatest crop for the feeding of live stock that can be found in any country. It has placed this country in the van in the production of beef and pork for the markets of the world. Hence the uses that the American farmer can make of the crop and the most economical and profitable uses are important matters for study. While corn is of course used largely as human food, the object of the present work is to point out its most profitable use in the feeding of our domestic animals.

In too many sections there is a great waste of valuable food in the corn crop. This is especially the case in what is called the great corn belt of the Central West. There it is common to gather only the grain and then turn cattle into the ficld to glean the fodder that, standing in the frost, has become practically worthless. The cattle strip the stalks of the leaves and leave the remainder. And this is not the only mischief. The cattle ranging over the soft and wet ground puddle and pouch the soil, and do serious injury to it in the future cultivation. 
Then, too, the land is left bare all winter, and loses fertility in the winter rains, when it should have a green winter cover crop to catch the fleeting plant food and hold it to be returned to the soil in the spring.

Carefully made experiments have shown that the stalks, leaves and husks of the corn have a feeding value equal to the grain. Hence, in this way for using the crop nearly half of its feeding value is sacrificed. Of course, in a large part of the corn belt the sale of the matured grain is an important matter, and few feed to stock all that they grow, though in most cases this could be done with profit. But even where the grain is largely sold the fodder can be saved in a way that will make it far more valuable as stock food. Letting the stalks stand till the grain is mature enough to gather and store, leaves the stover of very little real value.

But if the corn is cut while the fodder is still good and untouched by frost, that is, as soon as the ears are well glazed, and is cured in shocks, the fodder is of far more value for feeding. Modern machinery has greatly lessened the labor of cutting and shocking the corn. We now have machines that cut and bind and shock the corn. Then, when it is cured, we have the huskers and shredders that separate the corn from the stover and tear up the whole stalk and leaves into such a shape that not only is a far larger portion eaten, but the waste part is in such a shape that it makes a more valuable bedding material and absorbent for the manure liquids.

The clearing of the land from the stalks leaves it in shape for the sowing of small grain that should follow, and even where it is the practice to follow the corn crop 
with oats in the spring, the sowing of a winter cover crop even of rye, is an important matter to prevent loss of fertility in the winter and to add humus in the plowing in spring for the oats crop, and the shredded fodder can be stacked and kept in perfect condition, and will make a far better feed than the cattle could get by ranging the stalk fields in winter when they should be comfortably housed and regularly fed.

The Silo

But the most important and valuable invention in connection with the corn crop in recent years has been the invention of the silo, into which the green corn is cut and preserved in a succulent state for feeding in winter and for tiding over a drought in summer when the grasses fail in the pastures. For the man whose interest is in live stock, either as a beef feeder or as a dairyman, the silo is indispensable. Through its use he can make his farm carry profitably far more stock than he could profitably feed on the dry food.

A silo is merely a building made as nearly air tight as is practicable at bottom and sides and freely ventilated above, into which the corn is cut by machinery made for the purpose into half-inch pieces when it is in the green or roasting ear state. The fermentation that ensues drives out the air and the green feed is preserved in a succulent state closely resembling the green forage of the pastures. The Evolution

In the first introduction of the silo in this of the Silo country, and the development of the ensilaging practice, it was common to make the silo under ground by excavating and walling up a great pit. It was also the practice to plant the corn very thickly in the rows, literally sowing it in furrows. This resulted in 
a very immature product with few ears and little grain. Then, when this immature corn was put into the silo it made a very sour silage, and many formed a prejudice against the whole practice from this quality of the product. It was also thought important that the cut corn be packed very tightly as the silo was filled, and when the filling was completed a board cover was placed over the top and tons of rock or bags of sand were piled on it to still further compact the mass.

The result was a slow fermentation and a very sour article of feed, and though cattle soon got fond of it the odor was not pleasant and the milk was apt to absorb some of it, so that the companies engaged in making condensed milk refused to take the product from cows fed on silage.

Another difficulty was found in the use of the underground pits. This wals the labor and cost of hoisting out the feed, and the large amount of spoiled silage from the constant condensation on the cold cement walls, and in the corners where it was hard to exclude the air. In 1886 , after thinking seriously over the defects in the then common practice, 1 came to the conclusion that we were making a mistake in the tight board cover and the weighting of it with rocks. I had also come to the conclusion that corn planted so that it would make good ears would be more valuable as ensilage. Therefore, that season, for the first time, I had well-matured corn and cut it in the silo in the state a little too hard for roasting ears but still quite green. After filling the silo I covered it with a foot of cut straw to catch the mold that always gathers near the top. The result was the best and sweetest ensilage I had ever 
made up to that time. But I still found that in my underground pits I had a great deal of spoiled silage next the walls and in the corners. Added to this was the great labor of hoisting the material out for feeding.

About this time came the experiments in overground silos, and we were all soon using the wooden silos above the ground. These did better than the underground ones, but still the square corners were a trouble. We cut these off and made octagon silos, which were better. Then followed the practice of making doors all the way down on one side, fitting tight with the pressure from within and being taken out, one by one, as the material reached a lower level. These doors made the loading and unloading easy.

Finally, since the octagon seemed so much better, some bright man developed the notion to make the silo after the manner of the water tanks of the railroads, only that the sides should be perpendicular. Hence, of late years the evolution of the silo has been in the direction of improving on the circular stave type, which has become the universal style, though some large silo users are now constructing them in the cylindrical shape, but of reinforced cement or concrete construction. But where the making of good ensilage is the main object the wooden stave silo is the best ever invented, for the concrete construction has some of the faults of the old underground silo in the cold cement walls causing a great deal of condensation and resulting in more spoiled ensilage than in the wooden ones. 


\section{CHAPTER XIII}

THE WHEAT CROP

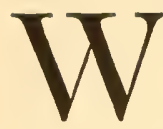

THEAT is the chief grain exported from the United States, both as grain and as manufactured flour. Two classes of wheat are produced in this country in general, the winter and the spring varieties, and in recent years there has grown up a third class in the semi-arid West, the Durum or Macaroni wheat. Under the former methods of manufacture all the finest flour was made from the white winter wheats of the Middle and Upper Southern States. But for many years past the improved methods of making flour by the roller process have shown that the finest flour is made from the hard grained spring wheat of the Northwestern States.

While winter wheat is sown in the fall months and the spring wheat is sown in the spring, the methods of cultivation and the preparation of the soil for the crop are identical. Therefore, we will treat mainly of the winter wheat and its place in an improving rotation. Formerly it was thought important for the best results that wheat should be sown on a clover sod plowed early in summer and kept harrowed or cultivated during the remainder of the season till seeding time. But of late years this summer fallowing practice has been largely abandoned, since the decreased price of the product has made it necessary that more economical methods should be adopted, so that I 86 
now the wheat crop usually follows a summer hoed crop, either corn or tobacco.

In some sections of the country, especially in the central states, farmers still adhere to the practice of following the corn crop with oats in the spring, and then to prepare the oats stubble for wheat. But the best farmers are rapidly learning that this following of two small grain crops in succession is not the best for the land, and while good crops are important, the progressive farmer should never lose sight of the maintenance of the fertility of his soil and its increase in productiveness. 'Therefore, the most advanced farmers have found that where wheat is the money crop, a short rotation, in which the legumes, mainly red clover, come in frequently, is the best not only for the land but for the gradual increase in the yield of the wheat crop.

In any system of farming, the crop on Various Rotations for Wheat which the farmer mainly relies for income, the money crop of the farm, should have that position in the farm rotation that tends to increase the yield of the crop while maintaining and increasing the fertility of the soil.

In the more northern part of the winter wheat region the main crop of Irish potatocs shares with Indian corn in importance as a hoed crop, and the cultivation of either of these makes the best of a summer fallow for the wheat that is to follow both.

Adopting a three-year rotation, the practice would be to take a clover sod for the corn and potatoes. On that part to be devoted to the corn crop all the manurial accumulation of the farm should be spread during the fall and 
winter, and the more rapidly it is gotten out and spread after being made, the better, since any way of keeping manure in barn or barnyard will result in far more loss than spreading it on the field.

On that part to be devoted to the Irish potato crop it will be better to use commercial fertilizers liberally, since the use of barnyard manure directly on the potato crop tends to encourage the growth of the scab fungus. If this course is adopted, when the field comes around again in corn and potatoes, the part planted in corn should be used then for potatoes and that in potatoes for corn. In this way each of these crops will come on the land but once in six years, and the land will be alternately manured from the barnyard and with fertilizers.

The sod for potatoes and corn is turned deeply in the spring, and the cultivation of both should then be as we have indicated for the corn crop, shallow and level and rapid. The deep breaking is an important matter both for the corn and for the crop of wheat that is to follow the hoed crops. The corn is, of course, to be cut and shocked for curing, and may be shredded and husked or used in the silo as the farmer thinks best in his particular conditions.

Neither the corn land nor the potato land should be replowed after the crops are off, but the soil should be left settled from the deep spring plowing, and only the surface made fine by repeated harrowing with the cutaway or disk harrow. The more complete this fining and tramping of the surface is made the better the chance for the wheat. This is especially true if the autumn weather is dry, as it is apt to be, for the establishment of a fine dust- 
blanket over the surface will tend to keep the moisture in and will promote the germination of the grain.

Of course, in that part where the corn has been grown there will be wide spaces where the corn shocks stand in rows which cannot be sown to wheat. But these spaces can be utilized in spring, after the shocks have been removed, for getting the farm supply of oats for feeding, and on most farms where wheat is the money crop, the oats crop is only of importance as feed for the farm horses and is seldom an important sale crop.

Time for

The date for sowing the winter wheat Sowing Wheat crop will vary with the climate of the locality. What would be early sowing in one part of the winter wheat belt would be late sowing in another. Too early sowing must be avoided because of the danger that the crop will be attacked by the Hessian fly in the fall. Hence, we have always advised that the first appearance of a hoar frost should be the signal for wheat sowing, as after that there will be little danger from the fall fly, and there will still be time enough for the crop to get strong enough to pass the winter in safety. This rule would make the sowing from early September on the northern limit of the winter wheat belt to November on the southern side.

Sowing the Clover Crop

From Pennsylvania, southward, we would always sow red clover seed in the fall at wheat seeding. In the northern part of this section it may at times fail from a hard winter following, but in that case there is always another chance to sow in the spring, as most farmers now do. In the northern part of the winter wheat belt, the clover is best sown in early 
spring when the soil freezes at night and thaws the next morning, so that the seed will be covered by the thawing. But further South this spring sowing is fully as risky as the fall sowing. There, a warm spell may ensue and the clover seed will germinate, and then a return of cold when it is in a very tender state, may destroy it entirely, as I have had happen in my own experience in Virginia.

Therefore, in the more southern sections, if the fall seeding should fail, the spring sowing should not be made till freezing is past. Then a light smoothing harrow run over the wheat will prepare the soil for the seed, and the spring rains will soon cover it.

Of the general complaint in all the winter wheat sections of the failure of clover in late years, we will speak more fully in the discussion of the clover crop itself.

After getting a good stand of clover it can be mown for hay one season or left for two seasons, as the conditions of the farmer seem best. If mown but one season it will be better for the crops of wheat and corn, and the rotation will then be three years, clover, potatoes and corn, and then wheat and oats.

From Virginia, southward, red clover is a Wheat in the very uncertain crop, and there the cow pea
South with Cotton will be the best legume. In the true cotton belt, the level sandy soils of the Atlantic coast and Gulf regions, wheat is of minor importance, and there the winter oats will largely take the place of wheat in the rotation. But in the upper or Piedmont sections of the cotton belt wheat can be profitably grown in a good rotation with cotton. There, too, the wheat should follow the corn crop among which cow peas have 
been sown at last working, and are thoroughly chopped up with the disk harrow in preparing for wheat. After the wheat, on which an application of acid phosphate has been made, the land is well broken and sown to cow peas at the rate of one and a half bushels per acre. These are to be cut for hay, and crimson clover sown at once on the stubble. The clover is turned under in spring for cotton, planted on the level and worked level and shallow, and at last working of the cotton, crimson clover seed are again sown to be plowed under in spring for corn, after all the manurial accumulations of the farm have been spread on the clover during the winter. This will give a three-year rotation that will soon result in heavy crops of wheat and heavy crops of cotton, and the forage grown from the peas and corn will enable the Southern farmer to feed more stock and make more manure at home, and so get gradually independent of the fertilizer factory except for phosphoric acid and potash.

Rotative cropping and the feeding of live stock are the great needs of the South, and system like this will soon develop the fact that in all the Piedmont region of the South the crop of wheat and pea vine hay the same season will be worth more really than the cotton crop. But of the cotton crop in general we will treat in a separate chapter.

The Spring Wheat Crop

Single cropping in any region and with any crop will finally result in soil exhaustion and poverty to the farmer. It has had this result in the cotton country, and many tobacco sections of the South, and it is rapidly having this effect in the spring wheat sections of the Northwest. While in the old soils of the winter wheat section of the East the farmers in 
some sections have, through a good rotation of crops and a wise use of the cheaper forms of commercial fertilizers, got their lands up to the production of forty or more bushels of wheat per acre, the lands of the fertile plains of the Northwest in Minnesota and the Dakotas have fallen in production to about fifteen bushels per acre, simply through the continual growing of wheat on the same land. The Minnesota Experiment Station has shown that a good rotation is as important in the production of spring wheat as in that of the winter wheat, and it is evident that the days of the great bonanza wheat farms must soon be passed and the farmers must go to farming instead of merely sowing wheat. There the crop of Irish potatoes will be a very important one as a preceding crop to wheat, and the rotation should be one long enough to establish a sod for turning for this crop and for corn of the earlier flint sorts that can be grown there.

Seeding to grass with the wheat, the spring wheat farmer should mow the land two seasons, feed the hay and fodder and probably the corn, too, and return the manure to the land for the corn crop, and the following spring back to wheat again. But the thoughtful student farmer must devise a rotation that suits his particular needs, and in this section the flax crop may be of interest and must be provided for. In fact, no iron-clad rules can be laid down for any section, and what we are advising here in regard to farm rotations are mercly suggestive and for farmers to study out for themselves.

The requirements of the wheat crop for food in the soil will be the same, no matter where the crop is grown or whether it is winter or spring wheat. On the virgin 
Fertilizers for soils of the prairies of the Dakotas the the Wheat

Crop

wheat growers have hardly realized the fact that they are rapidly approaching the time when they will be confronted with the same need for fertilizing the soil that the Eastern wheat growers have found.

In fact, the investigations of the experiment stations in that section of the country have shown that the productive capacity of the soil has already been greatly decreased by the practice of growing wheat continuously, and already the winter wheat growers in the Middle States have, through better systems of farming, increased the production of wheat on their old lands to more than double the crop that the Dakotas average.

But in the older states there has been one bad effect from the work of the experiment stations. These stations have studied so much the manurial requirements of the soil and the crops grown, and have devised so many formulas for the mixing of artificial fertilizers suited to various crops, that farmers, especially in the Southern States, have come to the conclusion that for every crop planted they must have a specially devised formula of a fertilizer. They have treated commercial fertilizers simply as a means for increasing the immediate crop to which they are applied, instead of showing how the productiveness of the soil may be maintained and increased through a proper use of some of the forms of concentrated plant food known as commercial fertilizers, and the farmer be saved from buying what he does not need to buy.

We have for many years been trying to impress upon the wheat farmers and the cotton farmers the fact that where the farm is worked in a short rotation, and legume 
crops are brought in frequently on the land, fed to stock and the manure carefully saved and returned to the soil, the farmer never needs to buy nitrogen or ammonia in any form, since the legume crops will give all the nitrogen the succeeding crop of small grain needs, and that, if then, the small grain crop is liberally supplied with phosphoric acid and potash, these will be the only fertilizers needed, and these will be needed only on the one small-grain crop that is the money crop, or on the cotton in the cotton farm.

In fact, it will often be found that if these forms of plant food are given to the preceding legume crop the result on the following crop will often be better than if they had been applied to the crop itself, while the increased yield of the legume crop will not only give an increased amount of feed for stock and the making of manure, but will result in an increased amount of nitrogen fixing by that crop.

Since the nitrogen in any complete fertilizer mixture usually costs as much as all the rest, it will be seen that double the amount of phosphoric acid and potash can be bought without any increase of expense, while the result in the improvement of the soil will be far greater than where the farmer depends on a complete fertilizer merely to produce a crop to sell off the land.

In the southern part of the winter wheat belt the wheat should be preceded by a crop of cow peas. If these are sown among corn, and wheat follows the corn it will be well to chop the whole growth in with the cutaway harrow so as to leave the vegetable matter on the surface as much as possible. Then, assuming that the previous corn crop was planted on crimson clover manured in winter and turned under in the spring, there will be an amount of 
nitrogen in the soil that will call for a liberal application of phosphoric acid and potash to balance the plant food ration, since without this there might be such an excess of nitrogen as to cause the straw to be heavy and weak and hence the crop will fall and lodge. Under these conditions we would use for the wheat an application of 400 pounds per acre of acid phosphate and twenty-five pounds of muriate of potash.

If the wheat is grown in the cotton belt, where the chief money crop is cotton, it will be well to lengthen the rotation somewhat, and to put winter oats after the corn, and at once, after these are harvested, to break the land and sow cow peas at rate of one bushel per acre, to be made into hay for stock feeding, and then prepare the pea stubble with the cutaway for wheat. And this crop of wheat will be helped more if the same fertilizer is used on the peas and not directly on the wheat, and the farm will benefit more through the increased crop of forage. Then in the same manner this wheat should be followed by peas for hay, and the peas by crimson clover in the fall to be turned under in spring for the cotton crop, among which at last working the crimson clover is again sown, and all the farm manure spread on it during the winter to be turned for corn again, and the rotation repeated.

Farming in this way the cotton farmer would need to buy only the cheaper forms of plant food in acid phosphate and potash, and could at the same cost of a complete fertilizer give each of the pea crops a liberal dressing and then let the peas make the wheat and the cotton, too, and that they will do it well has been shown in the ex- 
perience of those who have been induced to try a rotation for cotton.

In the great wheat-growing sections of the Middle States red clover will be the crop that is manured and turned for corn, and the wheat should follow the corn, the land being prepared with the cutaway and not replowed and the same fertilizer mixture applied to the wheat. Then instead of fifteen to twenty bushels of wheat per acre, the farmer would soon find that forty bushels can easily be made in a favorable season.

This would eliminate the oats crop preceding wheat which is a common practice in Pennsylvania. Two smallgrain crops succeeding each other will never result in large crops of wheat, and where the wheat is the money crop the oats crop should be eliminated or confined to the shock rows where the corn stood at wheat seeding time, where enough oats for the use of the farm can be produced.

What we are trying to show to the student is that the great deficiency of most of our old soils is in phosphoric acid especially and in most of them in potash, too, and that if these are liberally supplied and the legume crops used as they should be, the fertility of the soil can be increased and the crops increased without buying nitrogen in any form, and that through the growing of these legume crops, and the making of liberal supplies of forage the farmer will not need to buy any artificial fertilizer for his corn or other hoed crops.

In fact, it has been shown in our own experiments and in those made at experiment stations in various states, that a complete commercial mixture of fertilizers never 
pays a profit on the corn crop. The application will, of course, increase the crop, but where a comparison is made with a plot left without the fertilizer it will be found that the increase has not paid the cost of the fertilizer used.

The corn crop is the one in all of our rotations that can make the most profitable use of the sod and the homemade manure, and with these the corn crop makes the best of all summer fallows for wheat. 


\section{CHAPTER XIV}

THE OATS CROP

S a market crop in most sections of the country the
oats crop is of minor importance. In the Middle
and Northern States and the Pacific Northwest oats are always a spring-sown crop, while in the South, from central Virginia, southward, fall-sown varieties are the only oats that make a crop that will come up to the market standard in weight. Spring oats, even in the southern parts of the Middle States seldom reach the perfection that they do further north.

The varieties of oats used for fall sowing in the South are few in number. The two varieties, the Texas Red Rust Proof and the Virginia Gray Winter Turf oats, being almost exclusively the varieties used. These are far more hardy than the spring oats sown in the North, and even for spring sowing in the South these hardy sorts are better than the northern spring oats.

The fall oats are better suited to the sandy coast lands of the cotton belt of the South than wheat is, and in these sections they should take the place of wheat in the rotation, while in the Piedmont country of the cotton belt they can be used as we have before suggested, as a crop to follow corn and to be followed by peas for a preparation for wheat.

As a rule, the winter oats are sown too late all over the South. Early September is the time for sowing fall oats, I 98 
and by this time in all parts of the South the corn crop should have been cut and shocked and the land ready to be prepared with the cutaway to chop up the pea vines that should have been sown in the corn at last working.

Oats need more nitrogen than the wheat

Manurial Needs of the Oats Crop crop, but sown after a manured crop of corn in which peas have been sown, there will be no more need for buying nitrogen than there will be for the wheat crop, and in fact after a manured corn crop, oats that are to be followed by peas, and the peas fertilized with the application of 400 pounds of acid phosphate and twenty-five pounds of muriate of potash per acre as a preparation for wheat, will not need any fertilizer at all.

Grown in this way, the oats have produced in the South crops of fifty to seventy-five bushels per acre, and when followed by a fertilized crop of peas they make, with the crop of pea hay, a very valuable money crop to help out the cotton crop and to enable the cotton farmer to get on a cash basis.

In mentioning the varieties of winter oats we should have said that recently there has been introduced a variety known as the Appler oats which has been found more productive than the old varieties grown. It would be easy, however, for the progressive farmer to improve any variety by simply using the fanning mill effectively to blow out all light grain and to use only the heavier oats as seed. Spring Sown

The varieties of oats sown in spring are Oats almost innumerable, and we will not attempt to detail the series. Every year the enterprising seedsmen bring out new sorts that are claimed 
to be great advances on the older ones. But, as we have said in regard to the winter oats, the progressive farmer may take any good variety and greatly improve it for his own use by thoroughly eliminating the light grain and sowing only the heavy and plum oats.

Oats are usually the first grain crop sown, and it is important that they should be sown early, for later sown oats are apt to suffer from the advancing heat of the summer. But in their anxiety to get oats in carly, many farmers do serious damage to their land by plowing it when too wet. The land is then cloddy for the whole season and when, as is common in some sections, the wheat crop follows on the oats stubble, it is impossible to get the land into that fine and well-compacted condition that the wheat crop demands. Better be a little late than plow wet soil. If the preceding crop of corn was well prepared and properly cultivated, there will be no need for replowing it in the spring for the oats crop. In fact, it will be far better to use the cutaway harrow only, but to use it thoroughly till the surface is fine. This can be done more rapidly than by replowing, so that the farmer need not rush into wet land for the crop. Then sow two bushels per acre with the grain drill, a disk drill working much better on the corn stubble than a hoe drill.

Oats and Canada Peas for Storage

Over a large portion of the Middle States the crop of Canada peas and oats can well take the place of the Southern cow pea as a forage crop. By sowning two bushels of oats and one of peas the oats will sustain the pea vines, and the whole crop cut when the oats are passing out of the milky stage will make a valuable feed and one that is be- 
coming more and more appreciated in the North. The Canada peas, however, are very uncertain south of central Pennsylvania, and on the southern tier of counties in that State the Southern cow pea will be a better forage crop. Through its intelligent use the soil may be restored to a condition in which clover will thrive, which is a desirable end to attain, since in all parts of the country there is a growing difficulty in getting clover to thrive. On the crop of Canada peas and oats the fertilizer mixture advised heretofore of acid phosphate and potash will be found profitable in increasing the yield of forage and in getting a better preparation for the wheat crop that follows in many sections. 


\section{CHAPTER XV}

THE COTTON CROP

7 HE cotton crop is the chief of all the export crops from the United States. It is the one crop that

1 keeps the balance of exchange in favor of this country, and is the one crop in the world of which we have the practical monopoly. Other countries have tried in vain to produce cotton on a scale sufficient to compete with this country. And yet there is no crop grown in this country the cultivation of which has felt the march of improvement so little as the cotton crop. Its continuous cultivation on the same land, year after year, by the aid of commercial fertilizers has led to the exhaustion of the soil over large areas, the washing of the clean cultivated lands into hideous gullies, and the hopeless ruin of thousands of acres of fertile uplands in the South.

It was long assumed that while a rotation of crops was all right for the grain-growing sections North and West, the cotton crop was the one crop that would not fit into a systematic rotation. The fact is that there is no crop grown that so readily responds to a good rotation of crops, and none with which good systematic farming will give better returns to the cultivator. With the system at present used in most parts of the cotton belt the crop is grown at too large an expenditure of human labor and too 
little of improved machinery that would replace the costly human labor with that of the horse or mule.

As an example of the present method, we recently saw in a cotton field six men, each with a single mule and a plow, going through the rows cultivating the crop. Each man had to go twice in a row. Three men each with two mules on a riding cultivator would complete the cultivation of a row with one passing through, and hence three men would have done, and done better, twice as much work as the six were doing.

The cotton crop needs to-day to be brought into the modern methods of cultivation, and it could thus be grown at less than half the cost that its cultivation demands in the present method.

The improving farmer in the cotton belt

Rotation

Suited to the Cotton Crop must be, like the improving farmer in the grain belt, a legume farmer, only that the legumes he uses will differ to some extent from those used in the North. All over the cotton belt the great forage legume and soil improver is the cow pea. In the best cotton-growing sections, the coastal plain of the South Atlantic and Gulf States, red clover, the great legume of the Middle and Northern States does not flourish, and the cow pea becomes the clover of the South. With it the Southern cotton grower can do all for his soil that the farmer of the North can do with clover, and can do it in one-fourth or less time.

The great lack of Southern soils is humus or organic decay. The long and clean cultivation of cotton has almost cleaned the older soils of this important part of a fertile soil, and its restoration is the most important 
part of the work of the improving farmer in the cotton belt.

Another great lack is the almost entire neglect of livestock husbandry. The entire devotion to cotton, and the lack of forage crops, made it impracticable to feed stock to any extent, and the first care of the improving farmer should be to cure this defect in the farming of the cotton belt. Live-stock husbandry necessarily involves the cultivation of forage crops, and the forage crop best suited to the feeding of stock is the crop also best suited to the improvement of the soil, the cow pea. Therefore, any system of farming in the cotton belt that ignores the growing of forage crops and the feeding of live stock is a vicious and unprofitable system.

The devotion to the single crop of cotton has developed the credit system to an extent unknown in the North. The farmer depends on the cotton for everything else, for food for his stock and his family, and even for the mules that cultivate the crop, and getting all these on credit, depending on the coming crop, he pays exorbitant prices for all that he gets, and this vicious system of credit still further increases the cost of the crop that is already costly because of the laborious methods of cultivation.

The system of rotation that should be used on a cotton farm will depend to some extent on the section in which the grower lives. A rotation that is best suited to the needs of the crop on the level sandy soils of the coastal plain, and the methods of fertilization there, will differ to some extent from those best suited to the rolling uplands of the Piedmont country, the red clay soils of the South. 
Cotton Should Years ago many of the more thoughtful Always Follow farmers in the South came to the conclua Legume Crop sion that the cultivation of cotton, year after year, on the same land was injurious, and they adopted the plan of what they termed "resting" the land. That is, they allowed the field on alternate years to lie fallow and grow up in weeds and grass. Of course, this was better than cultivating it continuously, for it did restore some organic matter to the soil. But the reason given, that the soil gets tired and needs rest was the fundamental error.

The soil is a great chemical laboratory in which constant changes and new combinations are going on. Crops get tired of continually living on their own decay and food elements needed by the crop become deficient, and must be supplied in some way. The most expensive way to supply them is through the purchase on credit prices of the complete commercial fertilizers. The cheapest way is to supply the most costly element, the nitrogen, through the agency of the crop that will enable the farmer to feed stock and make manure, and through having money coming in at different seasons of the year, to get on a cash basis.

The rotation then that is best suited to the level sandy soils of the coastal plain should be one that contains the auxilliary crops not only best suited to the soil and climate, but best suited to increase the productiveness of the soil in the staple crop. We will suggest one that has worked well in that part of the cotton belt.

For this section of the cotton belt, where, as a rule, the soil and climate are not well suited to wheat, the best 
Cotton

Rotation on the South

Atlantic Coast Plain

rotation is a three-ycar one. Beginning with the corn crop, which should be cultivalted flat and shallow, as we have shown in treating of this crop, just before the last cultivation sow one bushel of cow peas per acre among the corn and work them in with the list cultivation. As soon as the corn is well glazed, and while the fodder is still good, cut it and shock for curing. 'Then, if the peas are heavy, mow them for hay, and clisk the land well and sow a bushel and a half of winter oats per acre with a disk drill. As soon as the corn shocks can be removed from the rows where they stand for curing, prepare and sow the shock rows also.

When the oats are harvested remove them from the land and store or stack for threshing, and break the land well and harrow in 300 pounds of acid phosphate and fifty pounds of the muriate of potash per acre, and sow one bushel to one and a half of cow peas per acre. When these are well podded and the pods turning yellow, mow them and cure for hay, and on the stubble sow in September fifteen pounds of crimson clover seed per acre without any further preparation of the land.

During the winter get out and spread, preferably with a manure-spreader, all the home-made manure on this clover, and by the first of April there will be a fine growth and usually in bloom. Turn this all under decply and prepare the land for cotton perfectly level. Having two legume crops preceding it, the cotton will not need any nitrogenous manure, especially if much manure is applied. But it will fruit all the better with an application of 400 pounds of acid phosphate and twenty-five pounds of 
muriate of potash per acre, all spread broadcast and harrowed in before planting the cotton. In this way the land will all be uniformly fertilized alike, and as the cotton roots run far and wide they will always find fresh food.

Instead of the old style of putting fertilizer The Cultiva- in furrows and then bedding on it, and planttion of the Cotton Crop ing on the elevated bed, the modern cotton cultivation demands perfectly level preparation and planting on the level, to be followed by shallow and level cultivation as advised for the corn crop. The distance between the rows will vary with the fertility of the soil. Ordinarily, on thin sandy soils the practice has been to make the rows three feet apart and then chop out to about a foot. But on highly improved land, where the plant grows larger, it will be necessary to give it more room, and it will be found that four feet between the rows and two feet in the row is none too far apart.

The first cultivation should be with the weeder, running lightly crosswise the rows to break any crust that may form before the plants appear, and at the same time to destroy the weeds that are germinating. 'Then, when the plants are well above ground, go over crosswise again with the weeder. This, of course, will tear up many plants, but no more than should come out in any event, and the crust about the young plants will be completely broken, so that they will not be chafed by the wind and made "sore shinned" as often happens with the old method of cultivation. Now, start the two-horse riding cultivator which works both sides of a row at one passing, and has small shovels that merely stir the soil without throwing a furrow of any size. All subsequent cultivation should 
be done with this implement, and a large part of the human labor that has usually been applied to the crop will be saved. We have frequently seen six men, each with a mule and plow, working in a cotton field, and each one going twice in a row. Three men, each with a pair of mules and a riding cultivator would do twice as much work in the same time as the six do in the old style way. There is nothing that the cotton growers need to learn more than the economy of human labor and the use of improved implements and horse power.

At the last cultivation of the cotton, and while the land is still freshly stirred, sow fifteen pounds per acre of crimson clover among the cotton as a winter cover for the land and a preparation for the corn crop. Then, after a couple of rounds of the rotation, and the soil getting into better heart, instead of applying the home-made manure in the winter preceding the cotton crop, apply it on this seeding of clover that is to be turned for corn, for a continued application of manure in connection with two legume crops will tend to make the cotton grow too rank, and as it is termed make too much "wced." But the corn crop can use to better advantage the coarse manure of the barnyard, and in the cultivation of the corn crop it will get so assimilated with the soil that it will give a far better chance to the oats crop that follows.

Therefore, finally, the rotation will be corn with peas among it, oats followed by peas after harvest and these by crimson clover, cotton, with crimson clover sown among it, on which all the manure is to be spread in preparation for corn, and the clover turned under in bloom for the corn crop, and the rotation repeated. 
If all the cotton farmers in the sandy soils of the coast section were working their land in this way, and were feeding all the pea hay and corn fodder, crops of two bales of cotton per acre would soon be common.

In all the red clay uplands of the South,

Rotation for Cotton in the Piedmont Uplands wheat should have a place in the cotton rotation, since in these lands, when well improved, as large wheat crops can be produced as in any part of the country. Then, too, in these lands the rotation should be somewhat longer than in the level lands of the coast plain, so that clean hoed crops do not so often come on the hill lands that are inclined to wash.

The hill lands of the South, as well as the coast lands, should always have a winter-growing crop on them, and should never be left bare in winter, since there is always some formation of soluble nitrates, which, in the absence of a growing crop will be washed out by the winter rains and lost. With a green winter cover crop, even if it is only rye, these nitrates will be taken up and can be restored to the soil by plowing under the cover crop in preparation for a spring planted crop, thus saving possible loss and adding humus-making material to the soil.

In fact, in any rotation that may be devised, this restoration of the humus-making material should never be lost sight of, for, as we have heretofore seen, it is the great lack of the Southern upland soils. What the red clay hills need also is deep plowing and subsoiling to prevent the tendency to wash into gullies by furnishing a deeper bed of loose soil to retain the water. Deep breaking, and level and shallow cultivation of the hoed crops 
will do far more to prevent the washing of the red clay hills than all the terrace banks that were ever constructed.

The constant addition of humus-making material will also have a great influence in preventing the washing. These uplands did not wash when newly cleared from the forest, and only became liable to destructive washing after the humus had been worn out and the soil baked and ran together after a rain.

Of course, all plowing on these hills should be on the level contour of the hill, but every effort should be made to avoid the making of deep furrows to catch water and form a head to break over and start a gully. The ridging up of the crops of cotton and corn in the last cultivation of a season has been responsible for a great many of the gullies that now damage the Southern hills. These furrows between the rows soon fill with water in a heavy rain, and one after another breaks over adding more and more volume, till a torrent rushes down the hill and a gully is started. If the plow is rigidly kept out of the cotton crop, and level and shallow cultivation is adopted, the water will be spread out and will be more largely retained as is needed instead of running off and making gullies and leaving the land dryer in the drought.

While a good rotation is important, the proper cultivation of the cotton crop is equally important when the future well-being of the land is considered. The best rotation will avail little if the cultivation of the hoed crops is bad and the land is allowed to lose its fertility by washing in winter and summer also.

The following rotation will be found a good one for the upland sections: Corn, with peas sown among it; winter 
oats, followed by peas after harvest and stubble prepared for wheat; peas to follow wheat and mown for hay, and crimson clover sown on the stubble, and then the clover turned for cotton among which at last working the crimson clover is again sown, and then back to corn. This will make a four-year rotation in which the legumes come in every year.

Beginning with corn, properly bred for closer planting, on a clover sod that has received during the fall and winter all the manure made from feeding the pea hay and corn stover, we will sow just before the last level cultivation, one bushel of cow peas per acre. The corn will be cut and shocked to cure and the stover shredded for feeding. The corn stubble and peas will be thoroughly chopped up with the cutaway harrow, and oats sown in open furrows as a winter protection, and after the shocks of corn are removed the shock rows also sown in oats. The oats can be allowed to ripen and be harvested as grain or can be cut green and used as hay, and the land at once plowed thoroughly and a liberal amount of the mixture of acid phosphate and muriate of potash mixed five parts of the first to one of the latter, well harrowed in and one to one and a half bushels of peas sown.

These are to be harvested and cured for hay in September or October, and the pea stubble at once disked thoroughly and made as fine as possible without replowing, and wheat sown after the first white frost, using five to six pecks per acre, gradually reducing the amount of seed as the soil increases in fertility.

Following this crop of wheat, plow and prepare the land again for peas and harrow in 300 pounds per acre of the 
phosphate and potash mixture. These peas are also to be saved for hay, and crimson clover seed at rate of fifteen pounds per acre sown on the stubble in September or October.

This clover is to be turned under in the spring and the land prepared as we have suggested for cotton. At the last working of the cotton, and while the soil is still fresh, sow again the same amount of crimson clover seed.

On this clover haul out and spread with a manurespreader, all the manurial accumulations during the fall and winter and up to the time for turning the clover for corn. Then plant corn and repeat the rotation. It is easy to see that by this rotation we are constantly adding some humus-making material in the pea stubble and clover turned under, and also in the manure applied.

It will be noted that we advise the use of commercial fertilizers only on the peas, and only the mineral elements phosphorus and potassium, since on the success of the pea crop the future improvement of the soil largely depends. With the constant succession of peas and clover, aided by the manure that is made from feeding the peas and corn stover, no nitrogenous fertilizers will be needed to be bought.

But the cotton farmer has another source of nitrogen in the seed produced by the cotton crop. He should not sell the seed off the land entirely, but if near an oil mill should exchange the seed for a fair proportion of meal and hulls. The meal, fed in moderate quantity to balance the ration fed to the cattle will greatly improve the character of the manure made, and all that cannot be used in this way should be returned to the soil to aid the manure in the 
production of the corn crop. If the peas that follow the wheat are heavily fertilized with acid phosphate and potash the cotton that follows them can be produced without direct fertilizer application, though in the earlier rounds of the rotation it will pay for a time to use some acid phosphate and potash on the cotton also, if spread broadcast. But, finally, if stock enough are kept to consume all the roughage, such as pea hay, cotton-seed hulls, and corn stover, it will be found that it is only necessary to fertilize the peas.

Then, as the humus increases in the soil, and it becomes more retentive of moisture, it will be found that the phosphate and potash can be used more liberally, since the moisture will dissolve it and the peas will get it. Then it will soon be found that the peas will grow too rankly among the corn and they may there be omitted so that the land can be more easily prepared for the oats crop in the fall. The clover and manure turned under for the corn will abundantly feed the oats, and the fertilized crop of peas following the oats will restore any loss of nitrogen that has taken place, so that the wheat will have an abundance of plant food.

Following this practice rigidly, lands that now make less than a quarter of a bale per acre can easily be brought up to the production of two bales per acre on one-fourth the land, or fully as much if not more cotton than is now made on the whole area, while the increasing crops of oats and wheat will become equally profitable with the cotton, and the stock fed on the abundance of food will bring in cash at a time when cash is badly needed for the cotton crop season, and will thus, through putting the farmer on 
a cash basis, enable him to grow cotton for one-fourth the cost under the old practice of all cotton and a gambling in complete fertilizers bought on credit.

The varieties of cotton that have been

Varieties of Cotton produced are almost innumerable. The ease with which the cotton plant yields to proper selection of seed has led to a great many varieties being put into commerce before their character was well fixed, and the result has been that most of the improved varieties have been short lived, and while still planted by the original names, they have, through careless selection of seed, been allowed to degenerate into something very different from the variety originally sent out by the first improver.

Like the corn crop, the selection of cotton seed has been most careless, while intelligent selection will speedily increase the crop as much as the improvement of the soil will. On the northern limit of the cotton belt, just as on the northern limit of the corn belt, earliness in the crop is of prime importance. Earliness has also become an important matter in the far South, where the cotton boll weevil has become a menace to the cotton growers. There, the cotton must be early to get a crop ahead of the time that the weevil is destructive, and on the northern limit earliness is important in order to get as large a proportion of the crop matured before frost as possible.

Therefore, in the improvement of cotton, earliness is very important, since there is a demand for seed from the weevil sections for the seed produced in the northern sections of the cotton belt. Hence, every cotton farmer should be a seed breeder, and instead of buying seed of 
this, that, or the other variety, let him take the best seed at hand and go to work to develop a plant that is suited to his conditions.

There are two general classes of the upland short staple cotton, the large and the small bolled. It has been found that bolls of extra size are almost invariably associated with lateness in the crop, and while the crop may be larger in a very favorable season its lateness is a drawback. What is especially needed in the upper South, and the weevil-infected sections of the lower South, is a cotton plant of a compact habit, bearing bolls about two inches apart on the stems, and hence a very short-jointed variety. Bearing bolls in pairs or twins may increase the yield, but is usually accompanied by very short staple, and the increase in length of staple is one desirable character to introduce.

The Department of Agriculture at Washington has for years had expert plant breeders at work on the cotton crop, and it would be well for intelligent breeders to get some of the Department's improved seed to start with. Then plant a seed patch, and keep ever in mind through the season the ideal cotton plant you wish to produce, and from the patch eliminate all inferior plants and select seed only from the plants that come nearest to your ideal both in habit and earliness.

Then, instead of taking this cotton to the general ginnery have a small hand gin for the seed crop and you will then be sure to get no mixture. Plant your crop with the selected seed, and also plant another seed patch, always looking toward the ideal plant and saving seed only from the earliest ripening bolls, throwing all the rest into the general crop. 
By following this practice, year after year, the farmer will soon have a variety suited to his conditions, and not only this, but he will have a demand for the seed, for the men who will take the proper care in the selection of seed of any plant are always in the minority and the majority of growers will always be looking for improved varieties rather than improving them themselves.

We therefore do not give a list of the varieties on the market though so far as we have observed the variety known as the King cotton has generally proved to be an early and good variety. In addition to the selection of the ideal plant it is well to select especially for the seed patch the longest stapled bolls every year. 


\section{CHAPTER XVI}

THE TOBACCO CROP

HERE is no crop grown which varies so much in character and quality in various soils and under

1 various climatic conditions as tobacco. This fact has become so well known that growers have found that in their sections only certain kinds can be grown, and hence they have adhered to the kinds that are best produced in their soil and climate. Therefore, in the treatment of the culture of tobacco we will take up the different sorts that are produced in this country separately.

Producing

It has become the almost universal practhe Plants tice with tobacco growers in all parts of the country to prepare their beds for the growing of the plants by selecting a piece of land near the forest that is purely virgin soil, and that is sheltered from the colder winds. A sunny southern exposure is preferred so that the plants may be brought forward as early as practicable. The soil should be one that is well darkened by an abundance of humus or vegetable decay, the dark color of which renders it more absorbent of heat and also retentive of moisture. All growth is cleared from the land and the roots grubbed out. Brush and fire wood are then piled over the spot and fired long enough to burn the upper layer of the soil to a reddish-brown color, and to entirely destroy the seeds of grass and weeds that may be in it. 
The soil is then deeply dug and made perfectly fine, working the ashes well into the general mass. Beds of convenient wilth are then marked out and a fertilizer high in nitrogen and potash is intimately mixed with the soil.

A heaping tablespoonful of seed is well mixed with plaster to enable the sower to distribute it more evenly, and that amount of seed will sow roo square yards of bed. Boards are set on edge around the beds and cotton cloth stretched over as a protection.

The burning is done at any time in the latter part of the winter and seed are sown in late February or early March in the central part of the country and even as early as late January in the South. The sowing should be done with great care so as not to get the seed too thick and have the plants grow up crowded.

The above method is that generally pracA Better Way ticed, but in our own experience and in the to Grow the Plants experience of many who have recently been led to try it, it has been found that the use of glass hot-bed sashes and regular frames pays well in the production of better plants and greater safety from the changes of the spring weather. In this way, the soil is burned over in the same way as described, and a portable frame is set on the beds that is about six feet wide so as to accommodate the sashes which are three feet by six feet. The use of cloth is not only less of a protection to the plants than the glass, but it results in getting the plants drawn up slender by reason of the shade, while under the glass sashes the plants have the full sunshine, and can be easily exposed to the weather in bright days or when warm rains occur, by sliding the 
sashes down. The full exposure to the light results in stout and stocky plants that live far better when transplanted than the weakly and slender plants that are often the result of keeping the cloth over the beds too closely.

Another advantage in the sash-covered frames is that the sowing need not be done so early, for with the aid of the glass the plants can be brought on as soon as it is safe to set them out by sowing the seed the middle of March or even later.

The same care should be taken in the sowing of the seed not to get them too thick so that the plants will be crowded. Our practice has been to sow in rows crosswise the frames about six inches apart, making very shallow furrows for the purpose, and beating the soil down smooth with the back of a shovel. In the rows it can soon be seen whether the plants are coming too thickly, and they can be thinnerl at an early stage of growth as soon as a fair stand is secured. We usually thinned to about two or three inches apart and always had fine stocky plants at an earlier date than those who used the old method.

\section{Fertilizers}

for Tobacco

After long and careful experimentation we have found that the chief manurial neerls of the tobacco crop are for nitrogen and potash, and phosphoric acid in smaller percentage than manufacturers of fertilizers usually use. The source from which the fertilizing elements are secured is also of more importance to tobacco than any other crop grown. While the crop demands a liberal amount of potash to be available in the soil its quality is very much impaired if the potash is applied in the form of a muriate or chloride. Hence, in compounding a fertilizer for tobacco the potash 
should always be in the form of a high-grade sulphate. While the potash in the crude form of kainit is a sulphate it is associated with such a large percentage of salt that it acts as a chloride. Hence, only the high-grade sulphate that is comparatively free from chlorides should be used in the preparation of a tobacco fertilizer.

Of course, the amount of a fertilizer to be used will depend very largely on the fertility of the soil, but the proportions of the materials will be the same in any event. We have seen a formula proposed for tobacco growers which contains 8 per cent. of phosphoric acid, 2 per cent. of ammonia, and Io per cent. of potash. This is a badly constructed formula, for while the percentage of potash is all right the percentages of phosphoric acid and ammonia are wrong. Two per cent. of ammonia would be a very small percentage of nitrogen, since ammonia is a hydride of nitrogen. The nitrogen should appear as nitrogen and not as ammonia, for we want the actual amount of nitrogen rather than that of ammonia to be stated. Then the percentage of phosphoric acid is too high. The effect of an excess of phosphoric acid in a tobacco fertilizer will be shown in what the growers call a "bony" leaf. The plant needs nitrogen to some extent in the immediately available form of a nitrate to start it off early, and the greater part in the form of organic nitrogen to keep up the growth by becoming available during the growth of the crop.

The following formula is the result of long and patiently investigated experiments, and in practice in the bright cigarette types of tobacco, has proved to produce the highest priced tobacco of the season: 
Acid Phosphate ................900 pounds

Nitrate of Soda. ............... roo pounds

Dried Blood...................600 pounds

High Grade Sulphate of Potash. ......400 pounds

This will make a ton of 2,000 pounds. On the best light soil of the bright tobacco belt in North Carolina this formula has been used with great success at the rate of 700 pounds per acre. The same formula, used to this amount in the dark and moist soil of the coast plain section of North Carolina resulted in too rank and heavy a growth. Therefore, as we have said, the amount of the fertilizer to be applied will depend on the natural fertility of the soil.

In the strong soils of Lancaster County, Pennsylvania, for instance, 700 pounds of this mixture would be entirely necdless, while the proportions of the ingredients will be all right for the best quality of their seed tobacco if used in smaller amount.

Soils for

Tobacco

Freshly cleared land in any section or for any kind of tobacco is to be preferred to old manured soils. This simply means that humus is favorable to the production of fine crops. With a proper rotation of crops on the old soils and the use of legumes therein the new ground conditions can be brought about in the oldest soils. In the bright tobacco sections of North Carolina there is a prejudice among the tobacco growers against the use of clover and cow peas in a rotation for tobacco, the growers claiming that the legumes injure the peculiar color and quality of their leaf. This has usually been brought about by neglecting to observe the influence of the legume crop on the soil. The nitrogen 
content has been largely increased. Then, following this increase, the grower uses as large a percentage of nitrogen as he did without it and finds that his tobacco grows too rank and late. Following a crop of peas or clover, the bright tobacco grower will need far less of the organic nitrogen in the form of dried blood, since the legume will furnish that, and he simply needs the nitrate, with the same proportions of the mineral elements as before. In the bright yellow tobacco sections in North and South Carolina it has been found that this type of tobacco can only be grown successfully on a gray and somewhat sandy soil. A red clay soil changes the character of the leaf and darkens the color, and the tobacco either becomes a mahogany, well suited for making plug tobacco, or a still darker shipping tobacco.

In fact, there is no crop grown in this country the character of which is so controlled by the soil conditions as tobacco. Therefore, the different types of tobacco are being grown in the soils and sections that have been found by experience to be best suited to them. In the strong mellow loam soil of southern Pennsylvania a fairly good quality of cigar leaf is grown. In Ohio the tobacco known as the Zimmer Spanish is grown and used as filler for cigars. On the limestone soils of Kentucky the White Burley has become the sole type grown, and is mainly shipped abroad as is also the tobacco of the greater part of Virginia and Maryland, though in a limited section of Virginia a very fine black wrapper tobacco is grown and used for the making of what is known as Navy Plug.

In Connecticut the seed leaf tobacco has become famous as cigar wrappers and until the introduction of the 
Sumatra tobacco was the chief source of the wrappers for domestic cigars. Of late there have been some experiments made in growing the Sumatra tobacco in Connecticut under shelters of cotton cloth. But thus far they have not been very successful. In Florida the culture of the Sumatra under cloth has been more successful, and a very good quality of cigar wrappers is produced. And in Texas in a limited section it is believed that the tobacco of Cuba can be grown to the same quality and character as in Cuba itself.

For this class of tobacco a strong friable

Preparation Heavy Shipping Tobacco of the Soil for

clay loam is best suited. The best preparation for the crop is to grow a crop of clover or cow peas on the land the previous season. Turn this late in the fall and sow rye on the land, to be in its turn plowed down in the early spring after having served its purpose as a winter cover to prevent loss of nitrates from the soil. If stable manure is to be had, give the land a good dressing during the winter on the rye to be turned under with it. Otherwise use the fertilizer formula already given, at rate of 500 to 700 pounds per acre, broadcast. The fall plowing is useful, not only for the decay of the vegetable matter plowed under, but also for the destruction of the cut worms that are apt to infest a clover sod. The rye is to be turned under as carly in March as is practicable, and the land put into fine tilth with the cutaway harrow and the smoothing harrow.

Potash being a very important thing in the feeding of the crop of tobacco, all the accumulation of wood ashes can be profitably added to the land in the final preparation. A part of the fertilizer can profitably be reserved 
for use in the hills at planting time. One hundred and fifty pounds will be sufficient for this purpose.

Planting the

The common practice is to check the land Crop out each way with a small plow and at the intersections to apply the fertilizer kept for the hills and on it to make with the hoe a broad flat hill, mixing the fertilizer well with the soil. If the land is newly cleared there will be need of a smaller amount of fertilizer broadcast, but with this class of tobacco heavy fertilization will always pay well, as well as on the thinner soils devoted to the yellow cigarette leaf. The plants are set in the dark tobacco districts about the first week in May, taking advantage of the moisture in the ground after a rain, but never when the land is mucky from too heavy a rain. In that case wait till the surplus water has had time to soak in or evaporate. One hand can drop plants for two setting them, and the implement used is the ordinary dibble. Machines have recently come into use that enable two rows to be set at once by planters sitting on the machine, the machine watering them as set. For large plantations these planting machines are great savers of labor.

The modern practice of shallow and flat culture is as well adapted to the tobacco crop as to any other, though

The Cultivation of the Crop the majority of the growers still adhere to the plow and hoe hilling. As soon as the plants are established from the transplanting, run the weeder through to loosen the surface and to destroy any weeds just germinating. All subsequent cultivation can be best done with a small tooth two-horse riding cultivator going in both directions. In 
this way very little if any hoe work will be needed, and in these days of labor scarcity on the farm it is important that tobacco growers should learn the greater economy of horse labor over that of the human hand. Rapid cultivation to break the forming crust after every rain is important, and the two-horse cultivator will enable the grower to do this more rapidly and economically than by the old method with plow and hoe. But never work the soil when land or plants are wet. After the crop develops to a size that prevents the use of the cultivator, hand hoeing must be resorted too, for there is no crop that demands the weeds to be eradicated more completely than tobacco.

Topping the Crop

A few leaves next the ground are "primed" off, as it is called, and the ten to a dozen leaves above are left and the bud at the top of the stem is pinched out. It is not absolutely necessary to prime off the lower leaves, but the practice arose from the necessity of getting a clear stem for hilling, and hilling not being necessary it matters very little whether the lower leaves are pulled or not so long as enough are left above them. Pinch the bud at the leaf that hangs directly over the second one next the ground. The topping is done to throw all the growth into the leaves and to save the growth that would be used in the development of the bud and flowers.

After topping, the plants being checked in their upward growth, will start the buds in the axils of the leaves. If Worming and these were allowed to grow it would diminish Suckering

the growth of the leaves on which the crop depends. Therefore, suckering, or the removal of the shoots that appear in the leaf axils before they 
attain more than an inch or two in length is a very important matter, and must be attended to all through the growth of the crop to maturity. The quality of the leaf depends very largely on the assiduity of the grower in the removal of the suckers.

But the most important matter in the growth of tobacco is the fight against the worms, the larvæ of the hornblower moth. This is one of the largest of our moths, being almost as large as the ruby-throat humming bird. It has a long proboscis that is kept rolled up like a watch spring when not in use, but when in use it enables this moth to reach down in the corolla of a deep flower, like that of the tobacco plant, to get nectar.

This moth lays its eggs on the tobacco leaves, where they hatch into a green caterpillar which at once begins life and growth by eating the leaves, and if let alone will to a great extent destroy the value of the whole crop. Three broods of this insect are hatched during the summer, though it is commonly supposed there are but two. Formerly, tobacco growers in their fight against the pest depended on hand picking, running turkeys in the tobacco field and on poisoning the moths with cobalt and sweetened water placed in the corolla of the flower of the Jimson weed, or in a painted imitation flower of the same.

In recent years, however, it has become the common practice to spray the plants with Paris green mixed in water, one-fourth of a pound of the poison being used to a barrel of water and applied with a spraying pump and nozzle. This is all right for the early brood of caterpillars, but for the later brood we are of the opinion that the poison should not be used, as there may some of it 
remain on the matured leaf and be dangerous. Therefore, we would depend on hand picking and the turkeys for the late brood.

The bright tobacco section was formerly The Bright confined to a few counties in the northern Yellow Tobacco of North Carolina part of North Carolina. But in recent years it has been found that the sandy soils of the coast plain of that State and the upper Pine Belt of South Carolina are equally adapted to this kind of tobacco. A light sandy soil of a gray color is preferred for this class of tobacco, which is used both for cigarettes and for making light-colored plug tobacco for chewing.

While it is generally admitted that a new soil abounding in humus is the ideal tobacco soil, there is a great prejudice among the growers of the gold leaf tobacco against improving the humus content of their soils through the use of legume crops such as clover and the cow pea. Many growers declare that they cannot grow tobacco of fine quality after peas or clover. The main reason has been that they forget that the peas and clover have largely increased the nitrogen in the soil, and they use the same kind of fertilizer high in nitrogen that they have been accustomed to use on thinner soil. The result is that the tobacco grows too rankly and late and is of a coarser character. But a good rotation of crops and the improvement of the soil by the use of the legumes is fully as important to the growers of the gold leaf tobacco as it is to those who grow the dark shipping leaf and the White Burley. But after the turning under of a large growth of cow peas or a sod of clover, some other crop should come 
in between it and the tobacco crop in order that the vegetable matter shall be more completely decomposed and in the condition of the natural humus of the new ground that they find so useful.

The tobacco now known as the White

The White

Burley

Tobacco
Burley originated from a selection from the Red Burley, made in Ohio about I864. It is now produced in larger quantity than any other variety of tobacco grown in this country. Its culture is largely confined to the State of Kentucky, though still grown to a great extent in Ohio, the area of cultivation lying on both sides of the Ohio River, and including twenty-four counties in Kentucky, three in Ohio, and parts of other counties in Kentucky. In brief, it is a Blue Grass country tobacco, and is strictly a limestone land tobacco. Even there the quality varies greatly, the north slopes of the hills producing a heavier crop but inferior in quality to the lighter soils and south exposure, while the alluvial bottoms make a coarse and "bony" leaf. It is now used very largely as a material for plug tobacco, having almost entirely taken the place of the Virginia tobacco formerly used for this purpose.

In the culture of White Burley the growers have largely abandoned the practice of making hills for the plants, but set the plants on the side of the furrow made in marking out the land, and then throw earth enough to them as they start to grow to make the soil level. Thereafter level culture is practiced. In fact there is now little hilling up of tobacco except among the growers of the gold leaf in the South, who still stick to the practice. 
The Black

Tobacco of the

Virginia

Mountains

In the mountains of the Blue Ridge in Virginia, especially in the county of Nelson, there is a limited culture of a very dark wrapper tobacco that is used for Navy Plug.

The growers there have a blood-red soil of granitic origin and have adopted a three-year rotation for their tobacco, using no manure or fertilizer whatever, but depending on clover to make the crop. The tobacco is followed by wheat on which clover is sown. The clover stands one year and is then all turned under for tobacco the following season. No crop but wheat, other than tobacco, is sold or used from the land devoted to tobacco. This turning under every third year of the entire clover crop results, of course, in a soil abounding in humus, and the crops of wheat and tobacco are, as a consequence, very fine. But while the soil is rich in mineral matters, especially in potash, from the decomposition of the feldspathic rocks, this practice is rapidly robbing it of the phosphorus content, and ere long it will be necessary to supply this especially for the wheat crop. So far, the practice has resulted well, but the growers should stand ready to supply any lack of phosphoric acid and with this addition they have a very profitable rotation for the black wrappers.

Under the names of Seed Leaf, Broad Leaf and other names, tobacco is grown in the valley of the Connecticut

Seed Leaf

Tobacco and Housatonic Rivers for cigar wrappers. The soil in these valleys makes a fine thin wrapper of a mild flavor that is much used to wrap cigars having a Havana filler. Experiments have of late been made in Connecticut to grow the Su- 
matra tobacco under cotton cloth covers, and though so far the culture has not been profitable the growers still have faith in making it so. But the culture of this leaf has become so common and profitable in Florida that it is probable that the Sumatra wrappers in this country will be largely grown there. But many smokers still prefer the Connecticut Seed Leaf and the Broad Leaf wrappers to the Sumatra. One manufacturer told us that his brands of cigars cannot be made with the Sumatra leaf.

In Ohio a variety known as Zimmer Spanish has come into use for mixing with Havana as a filler in the cheaper grades of cigars to which it imparts a sweetriess that is favored by many smokers.

The methods of harvesting and curing Harvesting and Curing Tobacco tobacco vary greatly in the different districts. In the bright tobacco of the South Atlantic coast section, and in the White Burley section, tobacco is not cut off at the ground as is done in Pennsylvania and Connecticut and the North generally, but the leaves are pulled separately as they mature and are then strung on short sticks for curing by heat in flued barns. At the beginning of the harvest four or five of the lower and riper leaves are pulled in the morning after the dew is off. Some growers string them on the curing sticks in the field, while others load in wagons and haul to the curing barns where women and girls do the stringing with cotton twine and needles, or by using a peculiar turn of the twine around each midrib. The barns are commonly built of logs, and are much taller than broad. The sticks on which the tobacco leaves are strung are arranged on cross beams from the top of the house downward, closely, 
till the barn is full. Sheet iron flues connected with a brick furnace-sometimes two-run around the house The furnace is fed from the outside, and as soon as the barn is filled the fire is started, and the curer stays by it night and day till the curing is completed, watching the thermometer and the tobacco continually. This flue curing is not practiced in the White Burley section but is confined to the Gold Leaf region, though the harvesting in both sections is similar. The degree of heat and the variations in temperature are governed by the experience of the operator and vary with the kind and condition of the tobacco in the house. No attempt to describe the process can by any means make a skillful curer. Practical experience under a skilled curer is the only way to learn flue-curing. Gathering the leaves instead of cutting the whole plant has the advantage that the tobacco is all of a uniform maturity, and the different grades and qualities are more easily kept separate and much time is saved in the grading and assorting for market. Then the crop is cured more safely and in a shorter time, and less barn room is needed, as barn after barn can be refilled as the crop matures and is cured. The stringing on the curing sticks requires some skill, for the leaves must hang face to face or back to back, since if strung back to face they will enfold in curing and be damaged. In the Gold Leaf district a crop of 900 pounds per acre is a fairly good one, while in the tobacco section of Pennsylvania and Connecticut 2000 pounds are often grown, but until recent years the Gold Leaf brought the highest price in the country, the farmers of late years complaining of the monopoly of the American Tobacco Company. 
Harvesting and Curing the Seed Leaf Tobacco

The curing houses used by the Connecticut and Pennsylvania tobacco growers are very different from the rude log houses used in the South for flue curing. The curing being entirely air curing a proper regard must be had to ventilation in the tobacco barn. This is the most important matter in air curing. Prolonged dry weather is dreaded by the tobacco growers after the crop is in the house, for a proper degree of moisture is essential. That is, there must be an alternate dampness and drying to prevent too rapid a curing by prolonged dry weather. On the other hand, too much moisture induces mold, while a proper amount is necessary for the complete coloring of the leaf. The tobacco house is made with a series of shutters that can be closed or opened, as needed. These shutters extend from the ground to the eaves on the sides of the house. When there is an excess of moisture in the outside air these shutters can be tightly closed. Some use horizontal shutters on each tier of plants and prefer them to the old style of upright shutters. An abundance of air is given when the tobacco is first housed for several weeks, care being taken to close when too windy and dry, and opening at night to admit the moist night air. Other growers keep the ventilators open night and day for two weeks after the tobacco has been housed, claiming that the moisture of the night air will thus regularly neutralize the effect of the dry day air. This method of curing requires about twelve weeks. After all signs of green have disappeared from stalks and leaves the crop is taken down when the weather is so moist that the leaves will be soft enough to handle. 
The leaves are then stripped off and packed in boxes lined with paper, under which cords are passed at intervals. These boxes are a foot deep and wide and three feet long. The tobacco is packed on the paper lining with the butts of the leaves to the ends of the box and lapping in the middle. The paper is then folded over the top and the strings are tied across loosely. The bundle thus formed is then lifted out and packed in piles with other bundles made in the same way.

The packers buy the tobacco in this shape from the growers, the price being determined by the percentage of good wrappers in the bundles. The packers sort the leaves into first and second class wrappers, binders and fillers. In sorting, the leaves are tied into hands of sixteen leaves each. These are packed in bulk with the butts out and the leaves lapping within on platforms arranged for a circulation of air beneath. The bulks are four feet wide and as long as desired. The tobacco in bulking should be quite moist, and the bulks are made about four feet high. It is then covered with blankets and weighted down. After remaining in bulk for a short time it is ready for boxing. The boxes will average about twenty-eight inches wide by three and a half feet long for wrappers, and shorter for other grades. The tobacco is placed lengthwise in these boxes and enough of pressure is applied to make the boxes run from 325 to 375 pounds. Loose head boards are used in the ends of the boxes to keep the butt an inch from the ends of the box. Pack when in medium "case," that is medium state of moisture. Lap the tops well and never put any tobacco crosswise the box. The boxes are nailed up and placed on their sides 
and left to ferment and sweat. This begins in June and is carried on for several months, and the tobacco often reaches a temperature of $\mathrm{I}_{50} \mathrm{O}$ degrees or more. This sweating process is necessary to ripen and bring out the full flavor of the tobacco. If kept over to the second year it will again ferment and improve in quality. When the sweating is completed the end of the box can be opened and the samples drawn from different parts to get a fair sample of the contents for sale.

The harvesting and curing of tobacco, it will be now seen, varies greatly according to the different characters of the crop and the purposes to which it is to be applied. The bright yellow gold leaf of the South is very rapidly cured and bulked by the growers, sorted by them and put on the market by the time the crop of the seed leaf is being cut. Hence, the proper curing of the different kinds of tobacco is an art that can only be learned by the handling of each kind under the instruction of an expert and on the spot.

While a man can, by reading and study, become expert in the growing of tobacco, no amount of mere reading and study will make an expert curer. He must learn this from doing it. 


\section{CHAPTER XVII}

\section{THE IRISH POTATO CROP}

T $\mathrm{N}$ nearly every section of the country the crop of Irish potatoes has become one of the leading farm 1 crops, and the production of early potatoes for the northern markets has developed into one of the leading interests with the southern market gardeners.

Hence, the main or late crop of potatoes comes into the regular crop rotation in the Middle and Northern States, while the early crop is interesting mainly to the truckers or market gardeners in the South. Therefore, in any improving farm crop rotation in the North the potato crop can be made one of the leading sources of income along with the corn crop. Of the potato crop thus considered we will treat later in this chapter.

In the South, especially in the South The Early Atlantic Coast States, from the southern Potato Crop in
the South section of Maryland southward to Florida, the production of the early potato crop in succession as the season moves northward, has become of vast importance and the selection of seed and the varieties best adapted to their use are matters The Seed Potatoes for the South of vital interest to thousands of growers.

In the first development of the culture of the early potato crop in the South it was thought essential that seed potatoes for their planting should be grown in the North, and for years there was a 
discussion as to the respective merits of the potatoes grown in New York State and those grown in New England. Each had its favorites among the growers, and every winter the southern-bound steamers were loaded iwith seed potatoes to be planted in the South.

But about twenty-five years ago some of the Norfolk growers got to experimenting with the planting of seed late in summer from the crop of the same year, and gradually it was found that good crops for the winter use could be grown in this way. The first idea in the production of this crop was to obtain potatoes for winter use that would keep in that climate, since it had been found impracticable to keep the early grown crop. Finally, some one tried these late grown potatoes for planting the early crop of the following year, and it was found that they possessed advantages over the potatoes brought from the North.

They are dug in early December, and can in that climate be easily kept over winter in heaps covered deeply with earth, and as they are planted from January to March, according to the latitude, they have had no chance to sprout and become weakened. The northern potatoes, dug in the fall and kept in cellars, sprout more or less in winter and have the sprouts rubbed off. This sprouting is a deterioration of the food material stored in the potato, and as the potato is simply a mass of starchy matter stored around a bunch of shoots, the rubbing off of the sprouts takes off the terminal bud of the shoot, which is always the strongest grower. Then, when these potatoes are planted the growth comes from lateral and weaker buds, usually making a bunch of shoots rather than one strong one from the terminal bud. 
On the other hand the late second crop potatoes in the South that is dug late in the fall or early winter, keeps without any sprouting, and when it grows it is with the strong growth of the terminal bud, and with an undiminished supply of food for the plant. It is hence found that the growth of these potatoes is much stronger and more robust and can stand untoward spring conditions better than the plants from the northern seed. In fact, it has been found that a spring frost that will cut to the ground the shoots of the northern seed potatoes will but slightly scorch the home-grown ones, owing to their stronger development. Since these facts have been proven there has been a great increase in the production of the second crop, and now few growers ever plant the northern-grown seed potatoes at all.

Some years ago, when I, the writer, was Horticulturist of the North Carolina Agricultural Experiment Station, I made arrangement for a co-operative test of seed potatoes in connection with the Cornell, N. Y., and the Maine stations. They were to send me some of their early seed potatoes to plant, and from these I was to grow a second late crop the same season and send to them for planting the following year, while they were to send me more of the same stock sent the previous year, to plant alongside of my late crop from their seed of the year before.

The experiment went as far as the second year. I planted my seed and alongside planted more of their northern seed. The difference was apparent as soon as the tops developed. The northern potatoes made a bunch of shoots, while mine made a sturdy single shoot from the terminal bud and no others grew. The growth of mine 
was so superior to theirs that I took a photograph of two adjoining rows to show it. Then at digging time I piled up and photographed the crop from fifteen hills of each, and the difference in the yield was very apparent, in fact, the potatoes in the crop from the northern seed would have been graded as cullings in the other lot.

The experiment proved so much that my northern friends sent no more seed potatoes.

In eastern North Carolina the early crop

How the

Second Crop

Potatoes are

Grown in the

South of Irish potatoes is ready for market early in June, when not fully matured. Those intended for the late crop are let fully mature. They are then dug and cut in two pieces, since it has been found that they sprout more readily when cut. But they are simply cut in half and not into the usual pieces for the spring planting. The cut potatoes are then placed in little winrows in furrow and either covered with earth or with a thick layer of pine leaves. There they remain till August, and then, as they show signs of sprouting, they are planted in deep furrows but covered very lightly till the green leaves appear, after which the soil is worked to them gradually till level, and all subsequent cultivation should be perfectly level and shallow in order to retain the moisture needed at that season. The crop grows until frost cuts the tops and is then dug and stored for the winter. This is usually about the first week in December. Planting is done in February in eastern North Carolina and earlier in Florida and the states south of North Carolina.

The second crop potatoes are, as we have said, placed in heaps and covered with soil. This keeps them looking 
Early

Bermudas

perfectly fresh, and during the winter, when the potatoes from Bermuda make their

appearance in the markets, the growers who have a surplus of these potatoes have found that they can take them up and barrel them fresh in double-head barrels and ship them to New York, where they are sold as New Bermuda potatoes. The only fraud is that they did not grow in Bermuda, for they are really better than the true Bermudas. The red skin Bliss is the potato used for this purpose, as the Bermudas are red skinned.

The great crop of early Irish potatoes in Planting and the South has been brought about largely Growing the Early Crop in the South by the increase in the manufacture and quality of commercial fertilizers. And yet, while it is known that the earliest and cleanest crop can be grown by the use of these it is also well known that it is important for the crop that the soil be well supplied with humus. This is especially important as a means for preserving the moisture in the soil so essential to the perfection of the potato crop. The best soils for the crop are the sandy soils common to the coast country of the South Atlantic States, and the getting into these soils, where deficient, a full supply of organic matter to decay and form humus is an important matter. In some parts of this section there are large areas of soils reclaimed from the peaty swamps where there is a superabundance of this vegetable decay, and the lack is mainly for the mineral elements phosphorus and potassium. But on the lighter soils it has been found essential to grow the previous season a legume crop to furnish not only the organic matter but the nitrogen largely that is needed for 
the potato crop. Hence, a crop of cow peas sown after some carly crops of the previous scason and left to die on the soil is one of the best preparations for the potato crop, since it not only furnishes the humus-making material but saves the purchase of part of the nitrogen, which is essential to the early production of this crop, much more so than with the main crop grown in the North.

Having such a crop to turn under, the grower prepares his land as soon as possible after New Year's. The question with these growers is not how little of the commercial fertilizer they can use but how large an application they can make pay. One of the largest growers uses from $I, \infty 00$ to $I, 500$ pounds per acre of the following mixture to make a ton:

Acid Phosphate................ 900 pounds

Fish Scrap.................600 pounds

Nitrate of Soda................. roo pounds

Muriate of Potash..............400 pounds

Part of this is well mixed in the soil in the furrows by the planting machine and part of it is spread broadcast. The crop is always planted with a machine that opens the furrows, places and covers the fertilizer and opens again and plants the potatoes. The furrows are about three feet wide and the sets are planted about fifteen inches apart.

The cultivation is done entirely with the cultivator, after a first harrowing to level the soil before the potatoes appear, till the final cultivation, which is done with a small plow throwing a furrow to each side of the row, since it has been found that the early crop is benefited by this, as the sun warms the ridge in the early season better than 
on flat land. The crop is dug also by machincry. Shipping is done in barrels covered with burlaps, and the crop is well culled in the ficld and only first-class potatoes shipped unless the price is so high that it pays to ship culls separately.

Some use the cullings for planting the second crop, but the best growers use only the best potatocs for this purpose as they fear a deterioration of the seed otherwise.

Since the advent of cold storage it has Cold Storage Seed Potatoes been found that the second crop seed can be kept till June and then planted in the South to make a perfectly matured crop better for table use than the usual second crop of the same season. For this crop a sod of clover is a good preparation turned under early in the season to decay before the planting of the crop. This crop should be planted in deep furrows and cultivated in the same way as the second crop from seed of the same season. It needs liberal fertilization, but not necessarily as heavy as for the early crop, since the turned-under sod will furnish a large part of the food needed, and will also help to keep the moisture needed in the soil. Flat culture and no hilling should be the rule, as the crop is grown during the hottest part of the summer. This crop will mature completely and be far better for table use than the second growth of the same season.

The Irish potato crop may very well come

The Main

Crop of

Potatoes in the North into the improving farm rotation in the Middle and Northern States, for the wheat crop follows well after both corn and potatoes. Where a farmer is practicing a good short rotation of crops the best plan is to make the potato crop occupy a part of the field with the corn crop. 
The corn crop following a turned-under clover sod will occupy not only the best position in the rotation for the corn, but the same turned-under clover sod is the best possible preparation for the potato crop. In this case the farm manure should be applied to the part of the sod devoted to corn, and commercial fertilizers should be used on the potato crop to avoid the danger of encouraging the growth of the scab fungus with the manure. Then, in the next round of the rotation the half of the field that was in corn the last time should be put in potatoes, so that each part may have the humus-making effect of the stable manure.

Corn and potatoes both will come off in time to prepare the land for the wheat crop, so that there is no gap or lengthening of the rotation to introduce the potato crop. With the late crop of potatoes planted on the turned-under sod, which will furnish nearly enough of nitrogen, as the nitrification of the organic matter will be going on all during the summer, there will be less need for heavy applications of commercial fertilizer than on the Early potato crop of the southern trucker. Especially will there be less need for the nitrogen these growers use so freely to force an early crop.

The preparation of the soil should be of course of the most thorough character, and where grown on a large scale the use of an effective potato planter will be essential. With one of these modern implements the fertilizer can be applied in the row with the machine ahead of the dropping of the potatoes, and the whole operation of planting can be done in the most rapid manner. 
There are numerous fertilizer mixtures sold as special potato fertilizers which differ very little in their composition from the specials made by the same manufacturers for other crops. The chief manurial demands of the Irish potato crop are for phosphoric acid and potash, and with a clover sod plowed under the grower will have nearly or quite enough nitrogen for the crop. But it may be well to use for starting the crop a small percentage of the readily a vailable nitrate of soda to nourish the growth till the organic nitrogen comes into use with the warm weather. We would, therefore, with such a crop prepare a mixture somewhat after the following:

Acid Phosphate............... 500 pounds

Nitrate of Soda.............. roo pounds

Sulphate of Potash. .......... 400 pounds

We name the sulphate of potash here instead of the muriate used in the production of the early southern crop, because in that crop the mealy quality of the potatoes is of less importance than it is with the crop that is to be kept for winter use, and the muriate is generally a little cheaper.

But where high quality for winter table use is to be desired, the sulphate should always be used, as experiments have repeatedly shown that a far drier and more starchy potato is produced through the use of the sulphate than of the muriate. The early crop from the South is mainly consumed in an immature state as "new potatoes," and such are not expected to have the dry and starchy character demanded in the winter supply of fully matured tubers. 
Keeping

Potatoes in

Winter

In the Middle and Northern States the general place for storing potatoes is in the cellar. In the cellar of a dwelling, where the heating is done by the modern furnace, there will be no proper place for potatoes, since total darkness and a cool atmosphere are essential. The potato cellar should be either under the barn or some other outbuilding, or a structure to itself. It should be totally dark and at the same time have means for ventilation. Few realize that the temperature at which water freezes will do no harm to potatoes. In fact, they will keep a great deal better where a temperature just above thirty-two degrees is maintained. The cellar should be provided with slatted shelves so that the potatoes may be placed not over two feet in depth. After they are first stored there will always be some sweating of the tubers, and while the weather is mild there should be free ventilation without admitting light. Where it is practicable it is well to admit air to the cellar through underground terra-cotta pipes, and to have a ventilator overhead also. After the first sweating process is over it will be found that there is some slight rotting and the potatoes should be overhauled and all decayed ones removed. Plaster or air-slaked lime scattered among them at this time will be an advantage.

After this during all nights when the outer temperature is about, at, or slightly above freezing, keep all the underground and overhead ventilators open, but close up at once as the sun rises in the morning, always excluding light and day time air. By following this practice you will find that the temperature of the cellar will always 
remain cool even into the warm weather of the spring, and there will be little tendency to sprout.

There are two forms of fungus disease Diseases and that affect the potato crop so far as the tops Insects that Affect the Potato are concerned, and another form that affects the tubers only. For the first two diseases, the early and late blight, spraying with a good fungicide is essential to the success of the crop.

The foliage of the potato is also subject to the attacks of the Colorado potato beetle, and if preventive means are not used, this insect in most parts of the country will totally destroy the crop in some seasons. The fungus disease that affects the tubers only, the scab, demands special treatment of the tubers before planting, of which later.

The most generally used preventive of the blights is the mixture known as the Bordeaux mixture. There are several formulas for making this, but the one we have most generally used for the potato crop is as follows: Dissolve five pounds of copper sulphate in a cask with twenty-five gallons of water. In another cask slake five pounds of fresh lime as for whitewash, and after slaking add water enough to make this twenty-five gallons. Strain these slowly into a third cask, stirring all the time. The mixture is then ready for use. The spraying is done with a spraying pump, of which there are numerous kinds, large and small. One of the best is a cask with a pump on a four-wheeled wagon with four nozzles arranged to spray four rows at once. Where the crop is grown on a smaller scale the spraying can be done with a knapsack-sprayer carried on the shoulders of the operator. 
The spraying should begin as soon as the tops of the potatoes are a few inches high and should be repeated every second week. As the beetles appear add to the fifty gallons of the Bordeaux mixture one-fourth of a pound of Paris green or a pound of arsenate of soda, the latter the better. It is well to use this as soon as the mature beetles are seen, for while they do not eat much, they do eat, and the more of these that are killed the fewer eggs will be laid and the fewer of the ravenous larva we will have to destroy.

For the prevention of the scab, which spoils the appearance of the tubers, we should always have the acid effect of the turned-under and fermenting sod. We should avoid land on which potatoes have grown scabby, and if we are obliged to plant scabby potatoes we should treat them before planting with a fungicide. For this purpose the best is to make a solution of formaldehyde, commonly sold under the commercial name of Formalin. One pound or pint of this in thirty gallons of water will answer. Put the potatoes in a sack and suspend them in a cask containing the solution and let them soak for an hour, and then spread out and dry them. The solution is good so long as enough remains, but it is better to add to it a freshly-made solution of the same strength. The same solution can be profitably used for soaking seed wheat and oats to prevent the smut and rust. 


\section{CHAPTER XVIII}

\section{THE HAY CROP}

HERE has long been a notion that the man who sells hay is certain to reduce the fertility of his soil, and doubtless hay making and selling has been practiced and still is practiced by many farmers with this result. But there is no reason why a farmer who practices the proper rotation of crops, and is situated near a good hay market, should not make hay his money crop profitably for himself and his land.

But in many sections near the large cities the practice is to run the land, year after year, in timothy until it will no longer make a paying crop, and then plow for corn. This practice is certain to reduce the fertility of the soil, especially where such farmers are making milk for the city in addition to selling hay.

At a farmers' institute in one of the best counties adjacent to the city of Philadelphia, we noticed that the farmers were mowing their lands for years before turning back to hoed crops. I urged that they should adopt a shorter rotation and grow more clover. But they told us that it was no use, as they could not grow clover as they once did. The reason was perfectly plain. They had run their land in timothy till it was deficient in the mineral matters that clover needs and had gotten it into an acid 
condition in which the bacteria which enable the clover to get nitrogen from the air, could not thrive.

I urged that it was not the part of a good farmer to give up without investigating the causes that made it difficult to grow clover where it once throve well, and told them that they not only needed a shorter rotation but lime to restore the alkalinity of their soil associated with the mineral plant foods that they had been selling off their farms in hay and milk.

Heavy crops of hay, like heavy crops of other things, pay better than poor crops, and the only way to make hay growing profitable is to keep up the fertility of the soil, and right there is where the commercial fertilizers come in most profitably if they are used not merely for the production of crops direct but in the growing of those crops that feed the land and the stock at same time.

A farm where hay is one of the money Rotation for a Hay Farm crops will of necessity be a farm where the small grain crop is of importance, and wheat can well be associated with hay as a market crop.

On such a farm I would devote the entire corn crop to the making of silage for feeding on the farm, and I would not be tempted by a high price for straw to sell the wheat straw, but would consider it one of the important materials for increasing the manure and the humus in the soil, for no matter what is the sale crop the keeping up of the humus-making material in the soil is essential to success. And no matter how important the sale of hay may be it is equally important that some form of live stock industry should be carried on. 
Fertilizers will prove a great help, but fertilizers do not furnish any humus-making material, and hence it is essential that some feeding be done. Where hay is a profitable crop in the immediate vicinity of a large city, beef or dairy products will also be profitable, and butter making will be found to be clear of the drain on the land that milk selling is, since it leaves the mineral matters to be returned to the soil through the feeding of the skim milk.

On a farm so situated the farmer who is to some extent a dairyman, can afford to buy grain to balance up the silage ration, and should have an abundance of straw for bedding and manure making.

Starting then with a sod to be plowed for corn, on which all the manurial accumulation has been spread in the best manner with a manure-spreader, for we assume that no progressive farmer will in this day be without this essential machine for saving labor and getting the best results from his manure, we will turn the sod deeply and plant and cultivate the corn crop shallow and level, and cutting the entire crop from the land for the silo we will have a stubble that can be put into the best condition for the wheat crop by the thorough use of the cutaway harrow, for at that season the deep rebreaking with the plow will be a disadvantage to the wheat crop. But the cutaway must be used in both directions frequently enough to put the few inches of the surface into the best possible tilth.

With this wheat we would seed timothy, after having worked into the soil in the preparation or in the drilling of the wheat, about 400 pounds per acre of acid phosphate 
and twenty-five pounds of muriate of potash. I would seed liberally, for there is a great waste in thin seeding of any grass or clover. Use not less than ten pounds of seed per acre. The following spring sow clover at same rate.

After the wheat is harvested, and the rag weeds start, run the mower over the field to stop the weed growth. But start out with the determination that no pasturing whatever is to be done on the cultivated fields, but have a standing pasture for the stock, and on no account ever pasture a stubble that has been set in grass and clover.

The following spring, before growth starts, apply a light dressing of lime, say 800 to 1,000 pounds per acre, and run a smoothing harrow over to completely spread it. The hay that season will be largely a clover mixture of course. The second growth may be mown for feeding on the farm or left on the land.

The next spring give the grass a dressing of a highgrade fertilizer strong in ammonia, or topdress with nitrate of soda alone after growth starts, at rate of roo pounds per acre, and it will show well in the hay crop. The next winter get out on the sod all the home-made manure again, but do not lime till the next round of the rotation. Do not be tempted to run the sod longer for hay. You will get far better crops by practicing a short rotation and making but one clear hay crop annually and another mixed crop.

Then, by feeding the entire corn crop on the farm in the shape of ensilage, and balancing it with bought grain and making a gilt-edged butter, you will be annually increasing the productivity of the land and will soon be 
getting hay crops that will be the envy of your neighbors who run their land to exhaustion in hay.

For the dairyman or stock feeder who is

Making Hay from Legumes only not especially interested in the sale of hay, the various legume plants offer a hay far superior for his use to the usual grass hays. Not only are they far superior as hay, but the growing of these plants should be the main reliance of the general farmer for the nitrogen he needs for the succeeding crops. And while for the hay market the legumes are not so well adapted as the grasses, there is a growing interest in them in the markets, and those who keep family cows in villages and towns are more disposed to seek these in preference to the grass hays as better suited to the feeding of cows.

\section{Red Clover}

The chief of all the legume crops over a very large part of the country, especially in the Middle and Northern States, is red clover, trifolium pratense. What is known as the medium red clover is the kind most generally used. As we have noted heretofore there has been in all sections of the country where clover formerly thrived, an increasing complaint of the failure to get a good stand, or a failure after a stand has been secured to get the crop to survive the first summer. We hear from various parts of the country of what is called clover-sick land. In some sections of the Middle South, especially in Tennessee, trouble has been had with a fungus disease that affects the plant seriously. But as a rule the failure of clover is due to one or both of two causes, the exhaustion or rather the deficiency in the soil of the plant foods that clover especially needs, phosphoric acid and potash, or soil acidity that prevents the success of the 
bacteria that live on clover roots and enable the plant to get and combine the free nitrogen from the air. In many of the older sections both of these causes exist.

The practice of running land in grass for hay year after year with no help from manure or fertilizers till the hay crop fails, not only exhausts the plant food of the soil but brings it into an acid condition. Liming will restore the alkalinity of the soil, and then the use of fertilizers carrying phosphoric acid and potash will restore the plant food needed by the clover crop.

There has long been a notion that the continued use of phosphatic rock dissolved in sulphuric acid has been the cause of the acidity of soils. This acidity can hardly be charged to the acid phosphate direct, for no manufacturer intentionally leaves any free acid in his product, since that would prevent its drilling freely. But that it has been indirectly the cause has been well shown by experiments at the Ohio Experiment Station which seemed to show that the result of the continued use of acid phosphate had this effect though the crops taking up the soluble phosphoric acid and leaving free sulphuric acid in the soil, which is at once combined with the lime in the soil, and thus forms sulphate of lime and robs the soil of the lime carbonate needed to maintain the alkalinity. The same station found that when a liberal application of complete fertilizer was made, preceded by lining the soil, a fine growth of clover was had on soil where it had been failing.

It is evident, then, that the waly to get back to successful clover-growing is to restore the alkalinity of the soil through the use of lime and then to supply the phosphoric acid and potash that the plant especially needs. 


\section{Making Hay} of Clover

A great deal has been written in regard to the proper method of making hay from the clover crop. The common practice of farmers has been to cut clover for hay when a large part of the blossom heads have ripened and turned brown. This usually results in a very dusty hay largely unfit for feeling horses, because of the dried hairs of the ripe blooms.

A far better hay, and one that is fit for any animal, can be made by mowing the crop at an earlier stage. 'The common practice has been followed mainly because the hay dries more readily. But when properly managed a far better hay can be made from clover when the crop is just in general bloom and none or few heads have browned.

Clover and all hay from legumes should be cured mainly in the cock and barn, and exposed as little to the sun spread out on the ground as can be avoided. One of the most important implements in hay making in general and especially in making legume hay, is the tedder, an implement for tossing up the green cut hay so that it wilts more rapidly. We have always used the following methorl with success. Start the mowers as soon as the dew is fairly off on a bright sunny day, and mow till noon only. Start the tedder right after the mower and keep it going all the morning tossing the hay up lightly. In the afternoon rake the hay into winrows. Next morning turn these winrows over and let lie to dry off till afternoon. Then put the hay into as tall and narrow cocks as will stand well.

Hay caps made of squares of twilled cotton cloth are uscful to protect the cocks from a change of weather and should always be at hand. These are made four feet 
square, or three by four, with eyelets in the corners through which sticks can be stuck to prevent the wind from blowing them off. But during all bright sunshine the cocks should remain uncovered. As soon as you can take a handful of the hay and give it a hard twist and can see no sap run to the twist, the hay is ready to go into the barn. It is important to get it there before the leaves get crisp, as in that case they will be shattered off and they are the best part of the hay. Put it into the barn then while still limp and let it settle in the mow by its own weight and without any tramping that can be avoided. Once in the barn, let it strictly alone, for if it begins to heat, as it will, and you stir it, you will let in the spores of mold that are always in the air and will have some moldy hay. Let it alone and it will cure bright and sweet and you will not have dusty hay if the crop was mown at the right stage, when just in full bloom. Clover hay should always be stored under cover, as it damages badly in stacks.

Alsike or

Swedish

Clover

This clover has been assumed to be a cross between red and white clover, but there is no direct evidence of this. It has seemed to thrive better than red clover in some sections, but is better adapted to northern than Southern conditions and will thrive on land too wet and sour for red clover. It has been found to be a dangerous crop for horses and mules to pasture on, as it produces sores on the animals that give a great deal of trouble. It does not make the heavy growth for hay that red clover does, but is probably a good crop for soil improvement where red clover fails from lack of drainage in the land. As a hay crop it is of minor importance. 
Crimson

Clover

This plant has received a variety of names in various parts of the country, such as Scarlet clover, Italian clover, German clover and Annual clover. It is strictly an annual plant, sown in late summer or fall and matures in early spring from April to late May according to climate. Crimson clover is mainly of value as a soil improver, since it can be turned under in the spring in time for the planting of a hoed crop of corn or tobacco or cotton. It is harder to cure as hay than any of the clovers, and if the blossoms are allowed to get brown the hay will be dangerous food for horses on account of the hair balls that form in the animal's intestines. It can be made into hay if cut as soon as in full bloom, but it requires frequent turning in the cocks till cured sufficiently to store. The feeding value of the hay is higher than that of red clover since it has a larger percentage of protein.

In the Middle States crimson clover is very commonly sown among corn at last working, and progressive farmers in the South sow it among cotton. Both give the soil a good winter cover, which is especially important in the South to prevent the wasting of fertility from the bare and unfrozen ground. Farmers who think about their business are gradually coming to understand the value of a green crop on the land in winter that would otherwise be left bare after a hoed crop. Southern farms have lost as much through the wasting of the bare land in the cotton fields in winter as from the cropping.

Crimson clover is not certainly hardy much north of central Pennsylvania as a rule, and hence cannot be used as a regular crop in the more northern sections. In the 
South it can be sown with success as late as November from southern North Carolina southward, but in the Middle States it should be sown in July or August.

In 1889 when the author assumed a chair

The Southern Cow Pea

in the North Carolina College of Agriculture and Mechanic Arts, after having had experience with the growing of the cow pea in Virginia, he was surprised to note that the farmers there had not realized what this crop could do for them as a regular part of the rotation for the improvement of the soil and the feeding of cattle. He began to lecture on the value of the cow pea at farmers' institutes and in articles prepared for the agricultural press. The result of his efforts surprised him, for not only in the South but in the Middle and Northern States farmers began to inquire about the cow pea, and to-day there are hundreds of acres grown where one was seventeen years ago.

But there have been many who from the name pea have concluded that the plant is a pea such as they have been accustomed to, and we have received hundreds of letters asking about sowing them with oats as is done with the Canada pea. It should be understood, however, that the southern cow pea is not a true pea, but more of a bean, and is a tender tropical plant that thrives only in hot weather. Therefore it could not be associated with oats for hay since if sown when the oats should be sown the seed would perish in the cold soil, and if the oats were sown at the time suitable to the cow pea they would be a failure. Cow peas should never be sown till the soil is warm. In the South they can be sown from May to August, and in the Middle States not till the soil is warm in June. 
On the sandy soils of the South Atlantic States, where red clover does not thrive, the cow pea is really the "clover of the South." The southern farmer can do with it all that can be done with red clover and can do it in onefourth the time that clover needs. It is a common practice in this part of the South to sow the peas among the corn just before the last working and then cultivate them in, thus adding a fine humus-making crop after the corn among which crimson clover can be sown as the leaves fall from the peas and make a good winter cover.

As a hay crop in the South the value of the cow pea can hardly be overestimated, since it will make a fair crop on the poorest of land, and on good soil will make from two to three tons of hay per acre, and hay of far higher feeding value than red clover hay. There has long been a notion that the hay is very hard to cure, but in a long experience in the making of hay from the cow pea we have demonstrated that when properly done, the curing is easier than that of red clover. In the curing of the hay we adopt the same method we have described for red clover hay, with the exception that it is left in the field a little longer in the cocks, but still is put in the barn in a limp condition.

The proper stage in which to cut the crop is just when the pods begin to turn yellow. If cut sooner, the hay is harder to cure, and if left till the pods ripen the leaves will fall off, and as these are the best part of the hay they should be preserved.

Recently a different mode has been adopted in some parts of the South. Stakes six feet tall are planted over the field after the mower and the green pea vines are at once raked and shocked around these stakes in a tall 
narrow shock, and are left there to cure, and not touched till completely cured. The only difficulty about this method is that the greater part of the leaves are lost and much of the outer part of the shocks is blackened by the weather. While the peas will stand exposure to rains better than clover will, it is always better to make a bright and well cured hay and to save the leaves entirely, which can only be done by the completion of the curing in the barn.

North of the Southern tier of counties in Pennsylvania it is doubtful if the cow pea can be relied upon as a hay crop. But even much further north the cow pea will come in very usefully to the dairyman as a means for tiding over a dry period as a pasture crop when grass is burnt uip, for the cow pea, as we have said, is a hot weather plant and will thrive under conditions that make the grass worthless. Being one of the legume family, it has the same capacity for getting nitrogen from the air that other legumes have. When sown on land where the crop has not before been grown the first sowing may not be very successful, as the soil will not be supplied with the bacteria. But these are carried on the seeds to some extent and if the same land is sown the following season it will be found that the inoculation has been made and the crop will succeed. We have accounts from farmers as far north as Ashtabula County, Ohio, and in Wisconsin, who have found this to be the case, and on light and warm soils they have found the pea a very useful green manure plant, even where the seed fails to mature.

The varieties of the cow pea are almost innumerable, as the plant is one of the most variable in its character. The varieties are usually distinguished by the color of 
Varieties of the seeds. But the variation is not in this the Cow Pea characteristic only, for they vary greatly in habit and in the length of time needed to mature the crop, some maturing in sixty days, while others need 100 or more days of warm weather. It will easily be seen then that in the more northern sections only those of early maturity are suited. But from North Carolina southward all the varieties mature perfectly. Among the earliest, which usually mature in sixty days are Warren's Extra Early, New Era and the Large White Black-eye. Of these, two crops can be ripened on the same land in one season in the South, and in almost any section of the North where the farms are not too elevated and the nights cold, any of these can be matured. But these are bush varieties like the bean and do not make the heaviest crops of hay, but are valuable for summer pasture and for soil improvement.

Next in earliness is the variety known as Whip-poor-will. This will mature in about seventy-five days, and it, too, is a bush variety and one of the most productive of seed. Next come the black peas. Of these there is quite a group; all with jet black seed varying only in the size of the peas. The one most commonly used is the large black, which is commonly grown in Virginia. It is a strong running variety and will climb to the top of corn among which it is planted, and sown alone it makes a heavy crop of hay that is apt to be badly tangled and hard to mow. It requires Ioo days of warm weather to mature perfectly. The clay pea, so-called from the clay color of the seed has the same habit and season as the large black and can be classed with it. 
The strongest runner of all the cow pea family is the variety long called the "Unknown" in the South. Recently it has been named Wonderful. Though this is the most rank runner of all the varieties, and makes vines ten to fifteen feet long, its early habit is to grow very ereet and then to run all over the tops of the plants. This makes it easier to mow than the black or clay, as the mower gets under it easily.

But the Wonderful is a very late pea and not adapted to conditions north of east central North Carolina, as in southern Pennsylvania it would not more than get in bloom before frost. But for pasture and soil improvement it will be useful on account of the wonderful mass of vines it makes.

These are only a few of the leading varieties, and I might fill a volume with a description of all the sorts that have been produced in the South. Botanically the cow pea is still something of a puzzle to the botanist. It has been called by various names, but it is now generally conceded to be Vigna catiang, and from the investigations we made a number of years ago we are satisfied that the species is represented by the one known as the White Black-eye, and that from this variety the others have been derived. The White Black-eye is largely grown in the South as a table vegetable, taking the place of beans in the North, and when one gets accustomed to it he becomes an ardent lover of the food.

The Velvet

The Velvet Bean, Mucuna utilis, has atBean tracted great interest of late years as a forage crop for the South. It is the rankest climber of all the legume family. In southern Georgia I once saw 
a plant that had climbed to the top of a tall windmill derrick. The Velvet bean makes a wonderful mass of forage, and is cured in the same way as the cow pea. But it is a plant that requires a long season and is of little use north of the lower Cape Fear river section of North Carolina. From that section south it is a very valuable haymaking crop. We have planted them eight feet apart each way and had them cover the ground waist deep, and though the mass was so great, we found that in the immature state the vines were in that they cured more readily than the cow peas. For the extreme South there is hardly any hay crop that will make a greater yield, and the hay has a high feeding value. The yield of hay and seed both are heavy and few seed are needed to plant the ground sufficiently. But for the larger part of the country, the Velvet bean has no value whatever.

This is another of the legume family that

The Beggar Weed has a value only in the far South, in southern

Georgia and Florida. It is a rank growing species of the common tick seed and is botanically Desmodium tortuosum. It is an annual plant growing from six to ten feet high, and at the Louisiana station is said to have made four to six tons of hay per acre. Experiments made with it as far north as North Carolina and Virginia do not show that it has much value that far north, and that the cow pea is far better in those sections. But on the sandy soils of Florida it flourishes finely, and has, doubtless, a great value there. The family of Desmodium has gotten the name Beggar Weed from the fact that they grow on the poorest soils.

Medicago denticulata, commonly known as Burr clover 
Burr Clover from the burr-like nature of the seeds, is an annual plant belonging to the same family of legumes as alfalfa. It has been found valuable as a soil improver in the South, but is not perfectly hardy northward and hence, as it must be sown in the fall, it is not adapted to northern conditions. It has little value as a forage plant, but as a nitrogen fixing plant it is not excelled by any of the legume family. It has another advantage in the fact that its burr-like seeds carry with them the bacteria for the inoculation of the soil, and as this form of bacterium is the same as that which lives on alfalfa the burr clover forms a ready means for the inoculation of the soil for alfalfa.

Alfalfa

No plant in the legume family has attracted more attention of late years than Alfalfa, which is sometimes called Lucerne. Botanically it is Medicago sativa, and is a perennial plant sending down long tap roots into the soil and hence demands a permeable subsoil.

It is useless to endeavor to grow alfalfa on a poor soil, or one that is in an acid condition and not well drained. A mellow, clayey loam either naturally or artificially well drained suits the crop. While alfalfa, like other legumes can get nitrogen from the air, it is always an advantage to give it some nitrogenous manure or fertilizer at the start. For this purpose there is nothing better than good stable manure. But, like all the legumes, its chief requirements are for phosphoric acid and potash, and if good and repeated crops are expected, the soil must be kept replenished with these, for in the taking off of crop after crop of hay, as is done with alfalfa, the mineral elements in the soil are very rapidly removed. 
When alfalfa is sown in the spring the best growers have found that a nurse crop like barley is of advantage in keeping down the weeds. But the experience of most growers has resulted in finding that the best success is had from late summer or early fall sowing. A good preparation for the crop is the growing during the early part of the summer a crop of cow peas on which a good application of acid phosphate and potash has been made, for no matter how fertile the loam may be, any increase in humusmaking material will be a help. The heavy shading of the peas keeps down the weeds and the peas can be mown for hay, or in the South turned under after mature and dry. But this would make the sowing too late in the northern sections, and it would be better to pasture the peas down before plowing for the alfalfa.

From the middle of August to middle of September is the best time for sowing according to latitude. Care must be taken to get good and clean seed, for there is a great deal of seed sold that has seeds of dodder mixed with it, and dodder is a parasitic plant that is destructive to alfalfa. Better get a sample of the seed offered and send it to your experiment station for inspection, and thus be sure of getting clean seed.

Never sow less than twenty-five pounds of seed per acre, and thirty pounds will be none too many. It has been found that as the soil gets inoculated a smaller amount of seed will do, but in the first start it is better to use seed liberally. In sowing in late summer or fall, it is better not to use a nurse crop, but to sow alfalfa seed alone.

If a good stand is had in the fall, we have found it a 
very useful practice to apply in the early spring before growth starts, about twenty bushels per acre of freshly water-slaked lime, and then run a smoothing harrow over to completely spread it among the plants. Alfalfa, like most legumes, is greatly benefited by an application of lime occasionally.

After sowing the seed, run a weeder over the land to cover them about an inch, but do not roll the land unless it is very dry. In the preparation of the land, a good application of commercial fertilizer will give the plants a start that will greatly promote the chances of a good stand.

The first mowing should be made as soon as a few blossoms show here and there. If you wait till in full bloom, the second growth will be lighter, for blossoming is a weakening process to the plant. The crops can be mown twice and perhaps three times the first year, and thereafter, if the fertility of the soil is kept up by annual top-dressings, you can mow it three to four times a season.

Rake and cock the hay as advised for clover, and store it while still somewhat limp, for if too dry you will lose the leaves, which as one grower says, are equal to wheat bran for feeding. Being a perennial plant, alfalfa will last many years if the soil is well fed. After three or four years it is a good practice to disk the crop over in spring, thus. splitting some of the crowns and loosening the soii and greatly benefiting the growth. Several new varieties of alfalfa have been introduced, but are still in the experimental stage.

The Soja Bean

The Soja or Soy Bean is a leguminous plant that has been introduced from Japan, and in some of its many varieties has found favor with 
farmers in various parts of the country. It can be grown further north than the southern cow pea as a hay-making crop, and is more easily cured into hay than that plant is. The plant has been cultivated as human food in China and Japan, for hundreds of years, but has been introduced into this country in the last twenty-five years.

In this country the crop is valued only as stock feed. The crop in some of the earlier varieties can be grown as far north as northern Ohio. The seed can be planted in drills and cultivated, or can be sown broadcast for hay making. The broadcast sowing makes the finest hay, as those grown in rows make so much hard and indigestible stalk. For hay the crop should be mown when the pods are fairly formed, and before they mature, since after that the stems get very woody. If grown in rows for the seed, the crop will have to be cut by hand, as the seed pods grow so close to the ground that the mower will leave them uncut. The crop will also make good silage and when planted alternately in hills with corn for silage, the feed will be greatly improved by the presence of the soys. The crop has a high protein content and makes a very valuable feed as forage, and the ripe seed are nearly as rich as cotton seed, having 34 per cent. of protein.

In Kansas they made fifteen to twenty bushels per acre of seed. The variety known as the medium early yellow is the best for the Middle States, and the tall yellow for the South. The seed should not be planted till the ground is warm in late May or early June. The growth is larger in some than in other varieties according to height of the plants, and of the tall growing varieties, eight tons of green forage have been made, which would 
give I.I tons of digestible matter, of which one-sixth will be protein. Even as high as thirteen tons of green forage have been reported.

\section{Hairy or} Sand Vetch

\section{Hairy Vetch (Vicia villosa) belongs to} that class of legumes that have been known as "tares." The plant is perfectly hardy in any part of the country. It is an annua sown in late summer or fall and mown in the spring. If the seed are allowed to ripen before mowing, the plant will reseed the land and come again in the fall, and if in a wheat-growing section, it maty become a pest in the wheat crop, the tares that the enemy sowed in the man's wheat field as stated in the Bible.

When sown for hay, the vetch should always have some tall growing grain like wheat or rye sown with it to support the plants, which otherwise will sprawl on the ground and get damaged. Sown with wheat at rate of one bushel of wheat and a peck of retch in September, a fine hay crop can be made by mowing when the wheat is just passing into the dough stage. In the Middle and Southern States, the mowing can be done in time to put the land in corn, and the corn crop will be helped by the nitrogen-gathering capacity of the retch.

But where wheat is one of the staple crops it will be well to aroid the vetch. We once grew a crop of wheat and vetch hay that made nearly two tons per acre, and immediately followed it with cow peas and made as much more hay per acre and then got the land in alfalfa the same fall. This was in North Carolina where the season is long enough to make such a practice successful. 
Like all other legume crops the vetch is greatly helped by a liberal application of acid phosphate and potash.

We have treated thus briefly of the leading The Place of the Legumes legume crops that are of value as soil improvers and forage crops largely to show that through the use of these in a good rotation one can grow forage and improve his land for the production of the grass hay crops for the market, and by practicing a reasonably short rotation can through their use keep the grass improving annually.

The legumes will furnish all the nitrogen needed and by using the mineral plant foods in acid phosphate and potash liberally, their growth, and consequently, their power to get the nitrogen, will be greatly increased. We would advise those best adapted to the making of good forage for the feeding value is far in advance of their mere value as manure direct, and we have no sympathy with the so-called green manure idea. It is poor farm economy to bury a valuable food crop as manure when by feeding it and carefully saving the droppings and applying them to the soil we can recover more than 80 per cent. of the manurial value of the crops, while getting a profit from the feeding value.

Properly cultivated and the legume used as soil improvers and forage, one can easily make a money crop from grass hay without impoverishing his soil; in fact, can make it more productive. Feed the legume crops with commercial fertilizers liberally, and through their use keep up the humus content of the soil and the farm is certain to improve, no matter what the sale crop may be. 


\section{CHAPTER XIX}

HOIV THE LEGUMES AID US

HE great family of plants known to botanists under the name of Leguminose comprises

1 herbs, shrubs and large trees, and it has long been known that these plants do in some way help the fertility of the soil.

For years it was contended that the herbaceous legumes like clover and cow peas absorbed ammoniacal gases from the air and in this way added nitrogen to the soil. But long conducted experiments tended to show that there is no such absorption of ammonia from the air, though the late Doctor Gray once said that he could not see why plants should not absorb gaseous ammonia in the air, but that there was no proof that they did so.

But the studies of biologists finally demonstrated that the acquisition of combined nitrogen in the plants of this family was the result of the growth on their roots of certain microscopic plants known as bacteria. These bacteria are truly parasitic on the roots and by their presence cause an abnormal swelling on the roots forming small knots or nodules in which the bacteria live.

It has never been proven that there are distinct species of these bacteria on the roots of different legumes, but by long association with certain species of legumes many of 
them have acquired characters that make it necessary that that particular legume shall be their home and they do not readily live on other species, though in some nearly allied species the bacteria will transfer from one species to another as it has been found that the bacteria that live on the roots of the Medicago denticulata will also live on Medicago sativa, or alfalfa, and that the form that lives on the roots of Melilotus alba will also thrive on the alfalfa roots. The bacteria that affect the vetches will also be transferred from the garden pea, and all the true clovers seem to be the home of a distinct form common to all of them.

A great deal has been written of late years in regard to the artificial culture of the various forms of bacteria that

\section{Artificial}

Inoculation

are parasitic on the roots of the different species of legumes. It was thought for a time that these laboratory cultures could be used in the inoculation of the seed or the soil for the various legume plants with success. The Department of Agriculture in Washington undertook the work of preparing the cultures and distributing them to the farmers in all parts of the country. Placed in sterilized raw cotton, and with nutrient materials for promoting their growth after being received by the farmers, many thousands of cultures were distributed.

But unfortunately, it was found that the bacteria on the cotton were very short lived, and there were more failures than successes. Hence the use of the artificial cultures has been generally abandoned, it being found more practicable to use the soil from a field that has already been inoculated by long cultivation of the particular legume 
desired. Then, too, it has been found that many of the legumes carry on their sceds the bacteria that live on their roots, and that the mere sowing of the sced will after a time fully inoculate the soil.

This has been found truc in the case of crimson clover. When this clover was first sown in the far South, it was found that it did not succeed and growers jumped to the conclusion that it could not be grown far South. But those who again sowed on the same land found that the previous sowing, though a failure as a crop, had inoculated the soil so that the crop succeeded. The same is true of the Southern cow pea. Sown in the north it rarely does wcll the first summer, but if the same land is sown again the following season the crop is a success.

Then, too, it has been found that the burr-like seeds of Medicago denticulata, or burr clover, as it is called, will carry the bacteria that live not only on its roots, but also on the roots of alfalfa, and the soil can be inoculated for alfalfa by scattering the soil from a spot where Melilotus alba or sweet clover has been growing as a weed. This weed is abundant in most parts of the country, and especially on waste vacant land about the cities. But the great value of the legumes, aside from their capacity to get for us the free nitrogen from the air and combine it in the organic matter for future crops, lies in the accumulation and increase of the humus-making material in the soil. As we have heretofore remarked, sand and clay are the mere dead skeleton of a soil, humus is its life.

In much of the farming of the past, especially in the single cropping of the cotton country, the anrual clean cultivation and exposure of the soil to the sun has burnt 
up and wasted the humus, and the soil is literally dead, because the bacterial life that abounds in humus has been starved out. The soil bakes after a rain and renders the germination of seed difficult. It dries out rapidly and gets so dry in long spells of drought that the plant food in the soil cannot be dissolved and the crops are starved.

When the land was newly cleared from the forest, there was none of these things to perplex the cultivator. It was full of the dark vegetable decay, was mellow to cultivate, did not bake nor wash, and retained the moisture during dry spells. But with the wearing out of this dark vegetable decay by constant clean cultivation, all these difficulties come in and in any system of improvement we must make an effort to get back to the former new-ground conditions.

For this purpose the legumes are the most efficient aid we can have. It would be easy to keep up these conditions if all farmers had an abundance of barnyard and stable manure for their hoed crops annually, for aside from their fertilizing value the droppings of our domestic animals are always associated with a large amount of vegetable matter used in the bedding, which is good humus-making material.

But few farmers have enough of this, and here the legumes, aided by applications of phosphoric acid and potash, come in as a cheap substitute for the vegetable matter in the manure. Not that we would under all conditions advise the use of the whole legume crops as manure for we have more than once said that it is not good farm economy to bury a valuable food crop in the soil, but that it should be used to increase the amount of 
the home-made manure, and give us its feeding value before we return it to the soil.

But even when the crop is saved for forage there will always be a very considerable amount of the humusmaking material left in the roots as well as a goodly part of the nitrogen which the roots have assimilated. Then, too, it is not good economy to plow down a green crop, even if it is not wanted for food, for so long as the crop grows it is doing the work of nitrogen fixing in the soil, and if we cut this short by plowing under the whole crop at midsummer, we lose what the plant would have done for us the remainder of the season.

In the South and in a sandy soil, there is still another reason why no green crop should be plowed under in hot weather. The fermentation of the green mass will often so sour the soil that the growth of subsequent crops is injured instead of being benefited by the turning under of the green crop, and a liming is necessary to restore the alkalinity of the soil.

The legume crop is the place where the commercial fertilizers will pay the farmer best. If the legumes are liberally fed with phosphoric acid and potash, there will not only be a greater growth of forage but the increased activity of the plants will result in a much greater activity in the nitrogen-fixing bacteria on the roots, and the following crop will be more benefited than if the fertilizer had been applied directly to the grain or cotton crop.

Whatever may be the exact way in which the legume crops get the nitrogen from the air, there is evidence that some of it is fixed in the soil, and is of use to crops immediately associated with the legume. Corn, with crimson 
clover or cow peas sown among it is not only not injured by the associated crop, but is actually helped, unless the season is so extremely dry that moisture is taken from it too fast.

The peculiar value of the legumes as forage and haymaking crops lies in the fact that they have far larger amounts of protein than the more carbonaceous grasses, and hence make a more complete ration for stock, and this higher feeding value is gotten from plants that also feed the soil in the most costly and one of the most important elements of plant food, and through their culture the farmer is enabled to increase his crops of the haymaking grasses.

Hence it is becoming more and more evident that the farmer of the future must be a legume farmer. If he finds that clover fails where he formerly grew it well, he must understand that it is usually his own fault, and should at once study the reasons for the failure. In most cases he will find that it is the result of an acidity in his soil or from the deficiency of plant food or the lack of humus that allows the soil to dry out in summer so that the clover dies. He can cure the acidity with applications of lime; he can restore the mineral plant foods that may be lacking and through the use of some of the legume plants that he can grow, he can restore the humus and get his land back to the production of good crops of red clover. And no matter how many of the other legumes he may find useful as catch crops, and in certain places, by far the larger part of the country from Virginia northward, should depend on red clover as the standard legume crop, just as the country south of that should depend on the cow pea. 


\section{CHAPTER XX}

\section{THE GRASSES}

7 HE great grass family includes not only the crops usually known to farmers as grass, but also our

1 cereal crops, for Indian corn, wheat, rye, etc., are all included in the grass family. But here we propose to treat only of those that are commonly used as forage and hay-making crops.

Grass is Nature's great soil cover, her means for accumulating humus soil where forests are lacking. The great prairies of the West owe their fertility to the grasses that have grown and decayed century after century, while the herbage has protected the soil from the sun and thus promoted the bacterial life that is constantly engaged in the preparation of more food for the crop.

The farmer has broken the old sod and found a soil of great fertility, and at once jumped to the conclusion that it was incxhaustible, and has gone on to crop this virgin soil year after year, selling off the great deposit in his bank till in many cases he finds that his balance is getting short. Constant corn growing in the corn belt and constant wheat growing on the fertile plains of the Dakotas has the same result in gradually diminishing crops that it has in the cotton lands of the South.

The improving farmer finds that he must imitate Nature to some extent and grow more legumes and more grass. We have shown how the legumes may aid in the production 
of better grass crops as well as othcr crops on the farm. The Southern farmers have neglected the grasses under the impression that their climate is not adapted to grass simply because they cannot grow the great hay grass of the North, timothy. But there is no part of the country where unaided Nature produces a greater varicty of grasses than in the Southern States.

Many years ago the late Edmund Ruffin, one of the most thoughtful and observant farmers of Virginia, wrote a book giving a description of the coastal plain of Eastern North Carolina. In that book, Mr. Ruffin said that in his opinion Eastern North Carolina was destined to be the greatest stock section of the Atlantic coast, because of the wonderful profusion of native grasses. This was over half a century ago, and from that time down to the present the farmers there have been battling with grass for growing cotton continuously, while the grass still comes in as soon as the cotton is left off, and would have made the country richer if the grass had had the first place instead of cotton.

In any scction of the country one must study the adaptability of his soil and climate to grasses, for there are few that succeed equally well in all parts of the country. Near all the larger cities of the Middle and Northern and Central Western States, where the interest of the farmers is in selling hay in the city markets, there is no grass in this country that has or probably ever will take the place of Timothy.

Timothy

In all the sections named, Timothy (Phleum pratense) is the great hay grass. Not because it makes the best hay, for in our opinion there are 
grasses that make better hay, but because the market demands it and the market knows it and does not know other hay to any extent. And to-day thousands of tons of baled timothy hay are shipped to the southern cities from the central west, while the farmers right around there are wasting their land in cotton where they could produce better hay for their home market and get higher prices for it than in any other part of the country.

Timothy is a grass for a cool climate and a moist clay soil. It is a shallow rooting grass, and soon burns out in a hot climate and warm soil. It is not a good pasture grass, not because animals are not fond of it, for they are, but because of its shallow rooting it is soon destroyed by pasturing. But on suitable soils and in a suitable climate there is no grass that gives heavier crops. While good crops can be grown on strong upland loam soil, the grass does not last so long there as on the moist low lands like river bottoms, which are more naturally adapted to meadows. Timothy, from its shallow rooting character and little sod-making, is more exhaustive on the soil than grasses that make a larger root and return more humusmaking material to the soil. One of its advantages is that it will wait on the farmer, for while many other grasses get worthless soon after flowering, timothy still has some value when near maturity, though, of course, makes better hay cut at an earlier stage.

The common practice is to associate it with clover. This of course helps the land, but the timothy being a late grass, is not in shape for mowing till after the clover has long passed its best stage. Some of the earlier grasses are far better to sow with clover if the clover hay is valued. 
Timothy lacks bottom foliage and should always have some late-growing low grass like red top associated with it to help out the crop.

But timothy, with all its faults has such a hold on the farmers and the markets that it will probably remain the standard hay grass of a large part of the country. But where the hay is to be fed on the farm and is not the money crop of the farm, we would grow legumes and grasses that go better along with clover.

Orchard

Orchard Grass (Dactylis glomerata) has Grass become in many parts of the country a popular meadow and pasture grass. It is one of the grasses that seems to be equally at home north and south. It is better adapted to high land than timothy is. It is a strong rooting grass and withstands drought better than timothy, and from its strong rooting nature is a far better pasture grass. Its name, orchard grass, comes from the fact that it thrives well in the shade of trees. Orchard grass is one of the carliest grasses, and gives a bitc in the pasture earlier in spring than any other grass except perhaps, the meadow foxtail. After the first mowing in spring, it gives a stronger aftermath than most other grasses, and if this is left on the land the strong tussocks that this grass makes, keep the under part green in winter and affords a great deal of grazing cven in the most severe weather, particularly in the South. The faults of this grass are its habit of growing in bunches or tussocks and not covering the ground densely. Though it grows tall and shows a large crop apparently the harvest is apt to be lighter than the appearance owing to this scattering habit. It is a very early grass, and to make good hay it must be 
mown as soon as the blossom heads appear, for if left later the hay deteriorates rapidly in quality. Since the season for the hay harvest with this grass comes so early it is apt to be a time when rains are frequent, and a farmer with a large area in orchard grass will often have a great deal of difficulty in saving the crop in the best condition. Its habit of growing in tussocks can be remedied by mixing it with other grasses, and for hay making we would never sow orehard grass alone. For pasture purposes we have always mixed it with red top and blue grass, using ten pounds of the orchard grass, five pounds of the red top, and ten pounds of the Kentucky blue grass per acre, since heavy seeding is the most economical way to get a dense sod. On strong clay soil, and especially on a limestone soil, the pasture will finally be mainly of the blue grass, and as the blue grass is slower in germination and spreading, the orchard grass shelters it and favors its increase, while the quick germination of the red top gives some pasturage before the others are ready when the red top on high land gradually passes out.

Being an early grass, the orchard grass associates better with red clover than timothy does, since both are ready for the mower at the same time. Orchard grass will thrive, too, on land of a clayey nature that is too thin for timothy, and from its strong rooting nature, it makes a greater mass of vegetable matter to turn under than timothy does. Its chief value, we think, is in the formation of permanent pastures.

Red Top

Red Top (Agrostis vulgaris) seems particularly adapted to low land in the Southern States, and while it grows well on uplands, it is not so 
permanent in its character there as on moist low lands. This grass has a number of common names in various parts of the country. In Pennsylvania it is generally known as herds grass, while in some other sections that name is applied to timothy. It is also known as fine top and bent grass. Dairymen in many sections consider it indispensable in giving a fine flavor to the butter. Being a late grass, it associates well with timothy, and as both thrive on moist low land, it is a good practice to sow some red top with timothy to give that grass a more leafy bottom.

Red top makes fine hay, but not a heavy crop. It is the easiest hay to cure of all the grasses. In very hot and dry weather, we have mown red top in the morning, tedded it thoroughly, and put it in the stack the same evening. This is an advantage in showery weather. It makes a far heavier crop on bottom lands in the South than it does in the Middle and Northern States, and should have more attention from the Southern farmers.

Bermuda

Grass

This is the finest of all grasses for the South. Botanically it is Cynodon dactylon, and is found in warm climates all over the world. Owing to the difficulty of eradicating it when it gets into cultivated grounds it has long been regarded as a pest by the cotton growers. But since it seeds very sparingly, it is easy to keep it in bounds and to use it on a cotton farm as a permanent pasture. It is entirely a hot weather grass, and browns with the first frosts, but when used as a pasture it can be mixed with the Texas blue grass (Poa arachnifera), which is a winter growing grass and has the same running habit as the Bermuda. With 
this mixture a summer and winter pasture can easily be maintained in the South. This grass will not stand the winters north of Virginia, and on its northern limit it assumes the character of a pest to wheat growers, and does not have the value that it has in the South. From central Georgia south it attains great value as a meadow grass, as it can be mown several times during the summer. Owing to the scarcity of seed, Bermuda grass is commonly grown from cuttings of the running stems, commonly called roots in the South. The land is well prepared in the spring, and the stems are run through a feed cutter set to cut rather long. Furrows are marked out and the cuttings scattered along these and covered with a small plow and then rolled. These furrows should be about two feet apart, and the grass will spread over the entire surface the first summer.

As a pasture grass the Bermuda has the great advantage that it will grow on the most sandy soil, and is perfectly indifferent to the hot sun and drought. In fact it will not grow in the shade at all, and hence is not adapted to shady places. But it furnishes the best of pasture when other grasses are burnt up and worthless, and it is adapted to every kind of soil. On a sandy soil it is not hard to eradicate it if necessary, as it can be plowed off entirely from such a soil in great sheets and raked up and hauled off. But from a strong clay soil its eradication is a difficult matter. In fact on such a soil, the pasture is greatly improved by a spring plowing, harrowing, and rolling to cure the hide-bound condition that it may get into.

The great value of this grass in the South is gradually being understood, and if it were more used, the South 
could become as great a pasture country as the blue grass region of Kentucky, for in summer it is far better pasturage than blue grass anywhere. It has been found of great value in Oklahoma and the experiment station there advises its use as a pasture grass. But this is probably as far north as it will have any value as compared with other grasses. But no part of the whole country has a finer pasture grass than the South has in Bermuda.

\section{The Blue}

Grasses

The botanical genus Poa includes a number of species that are known as blue grasses. The best known of these is the Kentucky blue grass (Poa pratensis). This is essentially a grass for limestone soils, and thrives on these soils as it does on no other, though with an occasional application of lime it can be kept in good condition on any good clay soil. It has acquired its common name from the way it has taken possession of the rich limestone soils of central Kentucky, and while it thrives on similar soils in various other states, its great home is in Kentucky and part of Tennessee, and to the fine pasturage it gives there is largely due the fame that Kentucky has acquired in the raising of fine horses. Its fine hairlike roots penetrate deeply into the soil, and enable this grass to recover after it has been browned by a long drought, and though apparently brown and dead, it at once starts into growth with the coming of rain.

Kentucky blue grass is the best grass for lawns from the close and ever-green sod it makes, and it is the favorite grass for this purpose in all parts of the country where there is a good clay soil. It will not thrive on the sandy soils of the South, and in fact there needs some shade from 
the sun even on clay soil. Sown on a southern lawn the ever-present Bermuda soon drives it to the shade places under the trees which the Bermuda avoids.

Canada

This grass (Poa compressa) is also known Blue Grass as Virginia blue grass. It has a great deal of the habit of the Bermuda grass, creeping by surface and underground stems. It will grow on thinner soil than the Kentucky blue grass will, and will also thrive on sandy soils. In many parts of Virginia it has become a great pest to wheat growers. It has value as a pasture grass and as a sod-forming grass to prevent the washing of steep hills, but where the Kentucky blue grass thrives it has little value. On thin hill lands it can be profitably used as a sheep pasture, and will make a permanent pasture on lands too thin and poor for other grasses, and it thrives in all parts of the country north and south.

Texas

Blue Grass

Quite an interest has of late been taken in this grass in the South as a winter-growing grass. It is botanically Poa arachnifera. Its specific name comes from the spider-web-like hairs attached to the seeds, which make them difficult to sow. It has the same creeping habit as the Bermuda, and is valuable as a mixture with that grass, since, while it burns badly in summer it grows green in winter when the Bermuda is brown. In fact one man in North Carolina said to me that he found that the colder the weather the greener the grass grew. Whether it will ever be of any value North is yet to be demonstrated, but the general opinion is that it is best adapted to southern conditions and a mild winter climate. This grass is a native of western Louisiana and eastern Texas, and it is claimed that it 
will be all and more for Texas than Kentucky blue grass is for Kentucky. It is of stronger growth than Kentucky blue grass, and one writer says that he has seen it grow ten inches in ten days, and that the coldest weather does not nip it. It almost disappears during the summer except in shady places, but starts with the first fall rains and cool weather, and will furnish green food all winter in all parts of the South.

With Texas blue grass and Bermuda there is no reason why the South should not become a great grazing country, for both grow on all sorts of soil from sand to heavy clay. Owing to the difficulty in sowing the seed it will probably be better to plant cuttings of the running stems as in the case of Bermuda. These can be had by planting bunches of the seed in squares a foot apart in a sort of nursery ground, and from the growth of these to get cuttings the following fall, for while the Bermuda should be planted in spring the Texas blue grass should be planted in the fall. The cuttings can be planted in rows in the fall and other rows made in the spring between them for planting the Bermuda cuttings, and in one season of winter and summer they will take possession of the whole land.

This is another of the Poas, or blue grasses. Fowl Meadow It is often called foul meadow grass, but the generally used name is that we have given, and is supposed to be derived from the wild fowl having introduced it in a meadow in Dedham, Mass. It is a common grass in the Northern States, and is botanically Poa serotina. Its chief value is from its adaptability to low and wet soils. It makes a fine soft hay and a very nutritious feed. From its growing in low lands it makes 
an excellent mixture with red top on such lands. There are others of the Poa genus of grasses, but the foregoing include all that are of much value to the farmer.

There is no grass about which there has Johnson Grass been so great a diversity of opinion than the grass generally known as Johnson or Means grass. It is closely allied to the sorghums and was long known as Sorghum halapense, but of late years it has been assigned to the genus Andropogon, and is Andropogon halapense. It is a tall growing perennial grass that sends strong underground stems in every direction and also makes seed of large size freely, which are scattered by the birds and the overflow of streams so that when the plant once gets established in small amount in a section it rapidly spreads in every direction and becomes a serious pest to the hoed crops.

Johnson grass is not hardy north of central Virginia, and becomes of greater value as we go southward. Of its value as a forage crop, there can be but one opinion in a soil and climate that suits it, for it makes a nutritious hay, though rather coarse, and can be mown three times or more in a season. Its aggressive nature is the one fault against it. In some sections of Mississippi and Alabama, where at first it was considered a curse, the general opinion now seems to be that it has been a blessing to the country in compelling the farmers who formerly devoted their sole attention to cotton to go into stock raising.

By a thorough plowing and raking of the stems out and a careful preparation of the soil, a crop of cotton can be grown and the grass comes back at once after the cotton 
is off. The only thing that can subdue it is hard pasturing. I have seen pastures in Mississippi where the whole country was covered with Johnson grass in which there was nothing left but Bermuda grass, the pasturing having driven the Johnson grass out completely. But in sections where Johnson grass has not yet appeared, I would not advise its introduction, since there are grasses that are of value in the South which can be kept within bounds, while the Johnson grass cannot be restrained from taking the whole farm. Where it has become established the only thing for the farmer is to make the best use of the abundant forage it affords.

I was struck at the Mississippi Agricultural College with the fact that alfalfa seemed to hold its own among the Johnson grass. I was shown there a plot of alfalfa with Johnson grass towering above it, but at the time of my visit in July, they informed me that the plot had been cut three times and was about ready for the fourth cutting, and that the presence of the Johnson grass enabled them to cure the hay more readily and that the mixture made a very valuable hay. With alfalfa flourishing in spite of the Johnson grass, that section certainly has a forage crop that should make stock raising a very successful pursuit, and stock raising is the greatest need of the Southern farms. In many cases the entire farms have been abandoned to the grass and the owners are devoting their whole attention to cattle and very profitably too. Therefore, while I would not advise the introduction of this grass into a grain or cotton section, I am ready to admit its great value as a forage crop, but I would prefer to grow what I wanted and not be compelled to grow a crop that pushes itself everywhere. 
Paspalum

Dilatatum

The genus $P$ aspalum includes some grasses of value and one or two that are mercly pests. This variety, called the hairy Paspalum is a native of this country from Virginia southward. It grows from two to five feet high and promises to be a valuable grass both for hay and pasture in the South. Tramping by cattle seems to improve it and it makes a tough and enduring sod and has become greatly valued in Texas. It is best increased by the rlinning stems as the seed has a low germinating power. As a pasture grass for the South I consider it far inferior to Bermuda, but it will make a heavier hay crop on moist land, where it is best suited.

This has sometimes been called Louisiana grass, and is found in all the Gulf States, and has crept north as far as central North Carolina in small amount.

Paspalum Platycaule

It has also been called carpet grass from its close matting character. It grows best on low moist land, but is also said to stand droughty conditions fully as well as Bermuda. It scems to be a valuable pasture grass in the sandy soils of Florida and the Gulf Coast, but northward the Bermuda will be a great deal better.

This is an annual grass commonly known as crab grass and fall grass, and in all the northern parts of the country Panicum Sanguihale is esteemed a pest, especially in its persistent habit of getting on the lawns in the late summer and crowding out the perennial grasses. But in the South it attains a great value as a hay crop. On the heavily fertilized land of the market gardens in the South Atlantic States, the crab grass comes 
in after the early vegetable crops have been shipped and often makes a crop of two tons of hay per acre without any sowing. This grass is never cultivated, but always appears after the crops have been cultivated in the South, and is then found of value, and the hay, if cut at the proper stage, is equal to the best timothy hay. It is a common practice on the truck farms in the South after the crop of string beans has been shipped, to plow the vines under and smooth the ground and then let the crab grass have possession for the fall hay crop.

\section{Panicum}

Crus Galli

This is a coarse annual grass that delights in rich moist land and is sometimes used as a hay crop, and makes a nutritive hay that stock are fond of. Efforts have been made by some seedsmen to boom a variety of this grass under the name of "Billion-dollar" grass. But for the Northern States there are many grasses that are far better for the farmer that are of a permanent and perennial character. This annual grass may have some value in the South.

There are a number of other Panicums that may have value in particular sections, but as a class they have not a high forage-making value. In the high mountain section of North Carolina, a perennial Panicum, Panicum clandestinum has acquired a local reputation under the name of fodder grass. It is a hardy but coarse-growing grass, and where it succeds better grass can be grown.

\section{Hungarian} Grass

Setaria Italica, commonly known as Hungarian grass or German millet, is a native of Asia, which has been extensively introduced in all the countries of Europe and America. It is an annual grass of strong growth on fertile soil. It varies 
greatly in character, though all the varieties belong to one species. Recently a variety has been introduced from Japan that has been found to make heavier crops than the older sort, and we have had seed heads sent us from Korea that were as large as a large ear of corn. It is likely that these Asiatic varieties will generally supersede the older varieties. It makes a heavy crop of hay, but if the hay is to be fed to horses, it should be cut as soon as in bloom, for if the seed are allowed to ripen the hay will be dangerous to horses because of the indigestible nature of the seed. The hay, too, is of less value if the seed ripen. This rank-growing grass has been boomed Pennesetum in this country at various times as a forage
Spicatum

plant under the names of pearl millet, cattail millet, and Egyptian millet, and of late an effort has been made to push the seed on the market under the old obsolete botanical name of Pencillaria. It makes an immense growth or green forage on rich and moist land, but as a hay crop has not a great value, being hard to cure and making a very heavy draft on the fertility of the soil. For the average farmer the annual legumes, like cow peas and soja beans, are far superior to any of the millets. Sorghum

Sorghum vulgare includes not only the saccharine sorghums from which syrup is made, but a great many others not of a saccharine nature and known variously as Millo maize, Kaffir corn, Dourra, and broom corn. The variety known as Kaffir corn is now largely grown in the Western States both for forage and for seed. The seed has a feeding value similar to that of Indian corn, and the whole sorghum family have a capacity for resisting droughty conditions better than 
most other cereals of the grass family. Hence the Kaffir corn has attained a great popularity in the semi-arid West. Broom corn is the only member of the sorghum family that is grown for commercial purposes other than feed, and even with this the seed have a feeding value.

Of late years the saccharine sorghums have been largely used as forage plants both for sowing broadcast for hay or for planting for maturity and harvesting for cured stover like Indian corn. All domestic animals are fond of the sweet sorghums, and they should be more largely grown for feeding. Cultivated to maturity, the stalks can be shocked and will retain their succulent character for feeding during the winter, though they will not cure dry like corn stalks. But keeping well in the shocks they can be fed during the winter with good results. For this purpose the crop should be planted in rows just as though grown for syrup making, and should be cut at the same stage of ripeness. The stalks can be cut by machinery and fed with very good results to any animals. Hogs are fond of sorghum and thrive on it either mature or in the field sown broadcast.

The genus Festuca contains a number of valuable species of grasses for hay making. One of the best species is The Fescues Festuca elatior, known as tall meadow fescue, Randall grass, and tall fescue. It is a European grass that has long been cultivated in this country. It is a strong-growing perennial grass growing two to four feet high, and is much relished by cattle green and dry. A smaller growing variety has been called Festuca pratensis, but it is merely a variety of this species. It is as early as orchard grass and associates 
very well with it, but it thrives on low moist lands better than orchard grass does and is at its best on such soils. It is a very valuable grass both for pasture and hay, and thrives exccllently on limestone soils to which it seems to be especially adapted. Festuca ovina, sheep fescue, is a dense low-growing tufted grass that succeeds on thin hilly soils, and has been found well adapted to sheep pastures. It is also uscful as a mixture in lawn grasses, but is of no value as a hay grass.

\section{Bromus}

The Brome grasses include the Bromus secalinus which is commonly called chess or cheat, and by many farmers it is imagined that wheat and oats when killed down by frost will turn to cheat. But the fact is that the cheat is a distinct grass of a very hardy nature and the seeds germinate and grow when the cereal is destroyed and the farmer seeing green plants there thinks it is the grain till it heads out in its true character.

There are some of the family that have acquired a reputation as valuable grasses. One of these is Bromus unioloides, known as rescue grass. This is a wintergrowing grass in the South, and has some value there, but none northward.

Bromus inermis, or smooth brome grass has of late years been found to be a valuable grass for pasture in the semiarid sections of the West. It stands drought and forms a dense sod. In the more humid sections of the East it has not been found of much value.

Lolium

The Loliums, or rye grasses, are hay plants of much value. Lolium perenne or Italian rye grass. Hardly in our climates deserves the name of perennial, as it is usually of short duration. But sown 
early in the fall alone, it will make a good hay crop the following summer, but does not last much longer. The true perennial rye grass, or English rye grass, is far more persistent than the Italian, and is truly perennial; but is inclined, like orchard grass, to grow in tussocks.

Lolium temulentum, or spiked darnel, is a worthlessgrass that has a reputation for being poisonous to stock, and should be eradicated. In some sections of the country, this has the name of cheat, and is the plant that some imagine the cereals to turn into.

\section{Agropyrum}

Agropyrum glaucum is the blue joint or blue stem of the western prairies where it is highly valued as a component of the prairie hay. It has the same creeping and spreading habit of the Agropyrum repens, or couch grass of the East. This last has always been esteemed a pest and a weed, but it has value as a hay grass, though, from its aggressive habit like the Johnson grass of the South, it should be treated as a weed and not allowed to take possession of the land to the exclusion of better grasses.

Commonly known as wild oats. This grass is very common in California, and it has been thought by many Avena fatua to be a degenerate form of the cultivated oats. It makes good forage when cut at the right stage, but may become a pest in grain fields. It is hardly worthy of cultivation, but may be saved where it grows naturally.

We have given merely a sketch of the leading grasses that come within the notice of cultivators in various parts of the country. Some of these have a value in limited 
localities or on special soils, and among them the farmer can find those best suited to his use, for hay making.

For the making of permanent pastures no

Permanent

Pastures one grass is usually best, except in sections

like the blue grass region of Kentucky, where that grass takes possession almost to the exclusion of others. But in all parts of the country there is a growing impression among the best farmers that it is not wise to pasture the cultivated lands, and that for the best results in cropping, the farm should have a piece of land set apart to be kept perpetualyy in grass. For such a pasture a mixture of grasses and very liberal seeding should be used, for the establishment of a dense sod at once is an important matter.

For the South, as we have suggested, there is no better mixture than Bermuda and Texas blue grass. But north of lower Virginia, these grasses have not the value that they have further south. Then the mixture that will be best will depend very largely on the character of the soil. At times the farmer wishes to devote to pasture a piece of low land liable to be at times orerflowed. In such case we would suggest a mixture of ten pounds of tall meadow fescue, five pounds of red top, and five pounds of forl meadow grass per acre.

On high and thinner soils and not on limestone land we would suggest a mirture of ten pounds of orchard grass, five pounds of red top, ten pounds of Canada blue grass, and five pounds of white clover per acre. On strong limestone clay loan we would make the mixture ten pounds of orchard grass, five pounds of red top, and ten pounds of Kentucky blue grass per acre. 
As a rule farmers usually find it a matter of economy to sow grass seed with some cereal crop, either wheat or Nurse Crops rye, in the fall or oats in the spring. But where immediate effect is wanted, as in the case of sowing a permanent pasture, we would prefer to sow the grass and clover alone. When grass seed are sown with a cereal crop we would, of course, add some red clover in the spring as a means for benefiting the land, and making a better hay for horned cattle.

Where grass seed are sown alone, they are better sown in the autumn than in the spring, and the soil should have the most thorough preparation. After sowing, if the soil is quite dry, a smoothing harrow should be run over the seeding and then rolled, but the rolling should be omitted if the soil is moist, and on hilly land that is inclined to wash, we would never use the roller, for there will always be left unpressed spots that will gather the water and wash in rain storms.

Permanent pastures are too often neglected and weeds and briars allowed to grow. The mowing machine is a useful implement for keeping the pasture in order by keeping all wild growth cut off before seed are formed. Then too, the fertility of the soil must be kept up, for, especially when young animals are pastured, they rapidly exhaust the phosphates in the soil. It will be found profitable to give the pasture an annual dressing of 300 pounds of raw bone meal and twenty-five pounds of muriate of potash per acre, and to scatter the droppings with the drag harrow from time to time. In this way the product of grass can be kept up and even greatly increased.

In some parts of the country the broom sedge soon makes 
its appearance in permanent pastures. When young, this grass makes fairly good pasturage, but it soon gets wiry and worthless. It is a grass that can abide acid conditions in the soil better than other grasses, and if the pasture has an occasional liming at the rate of twenty bushels of slaked lime per acre, say once in five years, there will seldom be any appearance of broom sedge. In fact an occasional liming is important to any grass and especially to the blue grasses. 


\section{CHAPTER XXI}

COMMERCIAL FERTILIZERS FOR VARIOUS CROPS

TORMULAS for the making of fertilizing mixtures for farm crops must in the nature of things be merely suggestive, since soils vary so much in their composition and needs, and crops also vary in their manurial requirements.

The student-farmer will study his soil or soils, for often the soils are very different in the different fields of the same farm. The chemist can give little aid in this matter, though he can find out what the composition of your soil is, but cannot tell you anything in regard to the availability to crops of the materials the soil contains.

The American farmers are wasting a great deal of money in the purchase of commercial fertilizers which they could save by a more careful study of the needs of their farms, and by using the legume crops for the getting of nitrogen that costs so much in a complete fertilizer. We believe that the day is rapidly approaching when the American farmers will abandon for any of the usual farm crops the purchase of complete fertilizers, or those containing the three important ingredients, nitrogen, phosphoric acid, and potash, and will by short rotations get through the legume crops all the nitrogen they need, aided by the home-made manures made from the feeding of the legume forage, and will devote themselves in an intelligent 
way to the preservation of the mineral matters of their soils by the use of the cheaper mixtures of phosphoric acid and potash, and to a study of their soils to ascertain whether they need to buy even both of these.

Any farmer can ascertain approximately the needs of his soil by laying out a series of plots, reserving one on which no fertilizer is to be applied, then on another applying phosphoric acid alone, on another potash alone, on another some form of nitrogen alone. Then on other plots make combinations of nitrogen and potash, nitrogen and phosphoric acid, potash and phosphoric acid, and then a combination of all three. Then by noting the results carefully for several seasons he can come very close to what the land especially needs and what he need not buy. We knew one wheat grower in Maryland who did this, and years ago came to the conclusion that phosphoric acid was the only thing needed on his land. He therefore adopted a short rotation of crops with clover on the land frequently, and in a few years found that his wheat crop increased from fifteen bushels per acre to an average of forty bushels year after year, while he used only plain dissolved South Carolina rock phosphate on his wheat, and got through the clover all the nitrogen he needed.

There are some crops like the Irish potato which, when grown as an early market crop demand special fertilization. Tobacco, too, is another crop on which we cannot afford to omit a complete fertilizer. But for the ordinary grain crops of the farm I feel sure that the man who farms right, and works his land in a short rotation with legume crops coming in frequently on the land, need never buy an ounce of nitrogen in any form. 
In one of the bulletins of the Ohio Experiment Station, we find the following statement in regard to their experiments in the maintenance of fertility and the use of fertilizers. "While, therefore, these experiments demonstrate the possibility of producing a regular and certain increase in the yield of cereal crops by the use of a complete chemical fertilizer, yet they show that if such fertilizers are to be used in Ohio in the production of cereal crops with any prospect of profit and as a part of a regular system of agriculture, that system must provide for the accumulation in the soil of the largest possible quantity of organic nitrogen, through the culture, in short rotations, of plants which have the power of obtaining nitrogen from sources inaccessible to the cereals." And in another of their bulletins the same station added later: "At the present prices of cereal crops and of fertilizing materials respectively the profitable production of corn, wheat, and oats upon chemical or commercial fertilizers is a hopeless undertaking, unless these crops be grown in a systematic rotation with clover or a similar nitrogen-storing crop; and the poorer the soil in natural fertility the smaller the probability of profitable crop production by means of artificial fertilizers."

Hence, as we have uniformly insisted, the true use of the commercial fertilizers is to increase the production of the humus-making and nitrogen-storing legume crops, and if these are neglected the dependence of the farmer on commercial fertilizers will hardly be profitable.

Many of the experiment stations have spent years in the study of the manurial needs of the various crops, and have devised formulas for mixing the fertilizers for each. 
This has caused many farmers to imagine that for every crop planted or sown they must have a specially devised fertilizer mixture, and they have gotten the idea from what many station directors have said that the only use for the commercial fertilizers is for the increase of the particular crop to which they are applied, without any regard to the effect on the future productiveness of the land.

It is against this notion that I have fought unceasingly for many years. This plan of using fertilizers merely to get a little more to sell off the land through their direct influence, has brought poverty to thousands of acres, and has made thousands of farmers poor.

While investigations may show what are the special food needs of certain crops, they do not mean that we can always profitably supply those needs direct by the application of artificial fertilizers only, nor do they show that the application of the needed plant food on a poor soil that is deficient in humus will produce the result desired. In fact, as the experiments at the Ohio Station show plainly, such application can never prove profitable. While on the potato crop it will pay to use a complete fertilizer in a liberal manner, even there it will depend largely for its results on the presence or absence of humus-making matter in the soil, and will have a far better effect if a clover sod is turned for the potatoes. We give some of the formulas advised by the experiment stations for the potato crop, while those for grain crops are, we suppose, intended for use where there has been no legume crop preceding.

The following formulas have been suggested by the Rhode Island Station for the home mixing of fertilizers for the potato crop: 


\section{Commercial Fertilizers for Various Crops 299}

Pounds

Acid phosphate............850

Nitrate of Soda ................. 50

Muriate of Potash ............... 300

Cotton-seed Meal ...............
Per Cent.

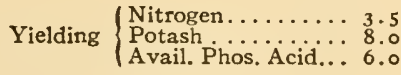

The stations found that a higher quality of potatoes could be made by the following, in which high-grade sulphate of potash is used instead of the muriate:

High Grade Sulohate Pounds

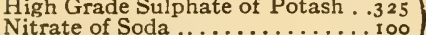
Sulphate of Ammonia ........... roo Dissolved Bone-black ..........750 Cotton-seed Meal ...........725
Per Cent. Yielding $\left\{\begin{array}{l}\text { Nitrogen ......... } \\ \text { Potash } . .0 \\ \text { Avail. Phos. Acid... }\end{array}\right.$

Or for equally good quality of tubers the following:

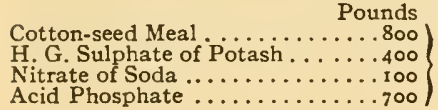

Per Cent.

Yielding $\left\{\begin{array}{l}\text { Nitrogen........ } \\ \text { Potash } \ldots .4 \\ \text { Avail. Phos. Acid... } 5.2\end{array}\right.$

Which we consider an improvement. In all fertilizers for the potato crop especially on the light soil that is best for that crop the main needs are for phosphoric acid and potash, when a clover sod has been plowed for the potato crop. In that case the nitrogen may be omitted except a little readily available nitrate of soda to give the crop an early start. But in no case would we make the percentage of potash lower than ro per cent. of the whole. Gardeners will find this last formula well suited to all vegetable crops.

But as we have more than once urged, with our grain crops, if a good short rotation of crops is used and clover or other legume comes in frequently on the land the only artificial fertilizers we would use are phosphates and potash. 


\section{SOME GENERAL CONCLUSIONS ABOUT FERTILIZERS}

The mixtures on the market known as commercial fertilizers are of use in furnishing in a concentrated form the three elements that are most generally deficient in old cultivated soils, nitrogen, phosphorus, and potassium. These are furnished in combination with other matters, since the pure elements cannot be used.

The notion that some have formed that the commercial fertilizers are merely stimulants, has arisen from the injudicious way in which they have been used merely to get a little more sale crop from the soil by adding a dribble of the fertilizer, which is all taken up by the crop and the soil further drawn upon so that the soil is left poorer than before. Where liberally used to increase the growth of the renovating and nitrogen-storing crops of the legume nature, these fertilizers can be used for the increase of the fertility of the soil.

Lime and plaster, the sulphate of lime, are more in the nature of stimulants, since they serve to unlock plant food already in the soil so that plants can use them, and they bring about changes in the mechanical texture of the soil, and are active in the promotion of the nitrification of organic matter in the soil, and thus enable the plants to get the nitrogen in an available form. Their office in the soil is as reagents rather than fertilizers.

An application of fertilizers to every crop grown may show an apparent profit, but an accurate account with the crops will show that such a course is wasteful and expensive, and that the true use of the commercial fertilizers is to keep up the store of phosphoric acid and potash in 
the soil so that the legumes will do the rest, and if these are well supplied with these mineral fertilizers, there will be little need for other fertilizing beyond what can be done by the feeding of the legumes and the application of the manure thus made.

Farming continuously with one clean cultivated crop year after year, no matter how liberally the fertilizers are used, will result in the depreciation of the soil through the using up of the humus and the washing of the bare land in winter. This has been the result in the cotton lands of the South, and will be the result of single continuous cropping anywhere.

The soils of the cotton belt have lost fertility faster through the washing of the bare land in winter than through the summer cultivation. No land that has been in a clean cultivated crop during the summer should be left without a winter growing cover crop during the cold season. This crop will take up the nitrates that form in the soil and they can then be returned by turning under the cover crop in spring.

Fertilizers will always be more efficient on soils abounding in humus or organic decay than in those that are destitute of this, mainly because of the moisture-retaining nature of the humus which causes the solution of the fertilizers applied.

The bulletin of the Ohio Station has the following remarks: "At the prices at which mixed fertilizers are sold in Ohio, the attempt to furnish all the nitrogen, as well as all the phosphoric acid and potash required to produce increase in cereal crops grown in continuous culture has invariably resulted in pecuniary loss, although 
very large increase of crop has been produced. The rotation of cereals with nitrogen-gathering crops, therefore, has been shown to be absolutely essential to the profitable use of commercial fertilizers in any form."

To which we earnestly say Amen. 


\section{USEFUL TABLES FOR CONSTANT REFERENCE}




\section{CHAPTER XXII}

USEFUL TABLES FOR CONSTANT REFERENCE

T TE have compiled the following tables from various reliable sources, and believe that they will be found useful for reference.

The experiments made at the Pennsylvania Agricultural Experiment Station show the total dry matter and plant food in various forage crops: 


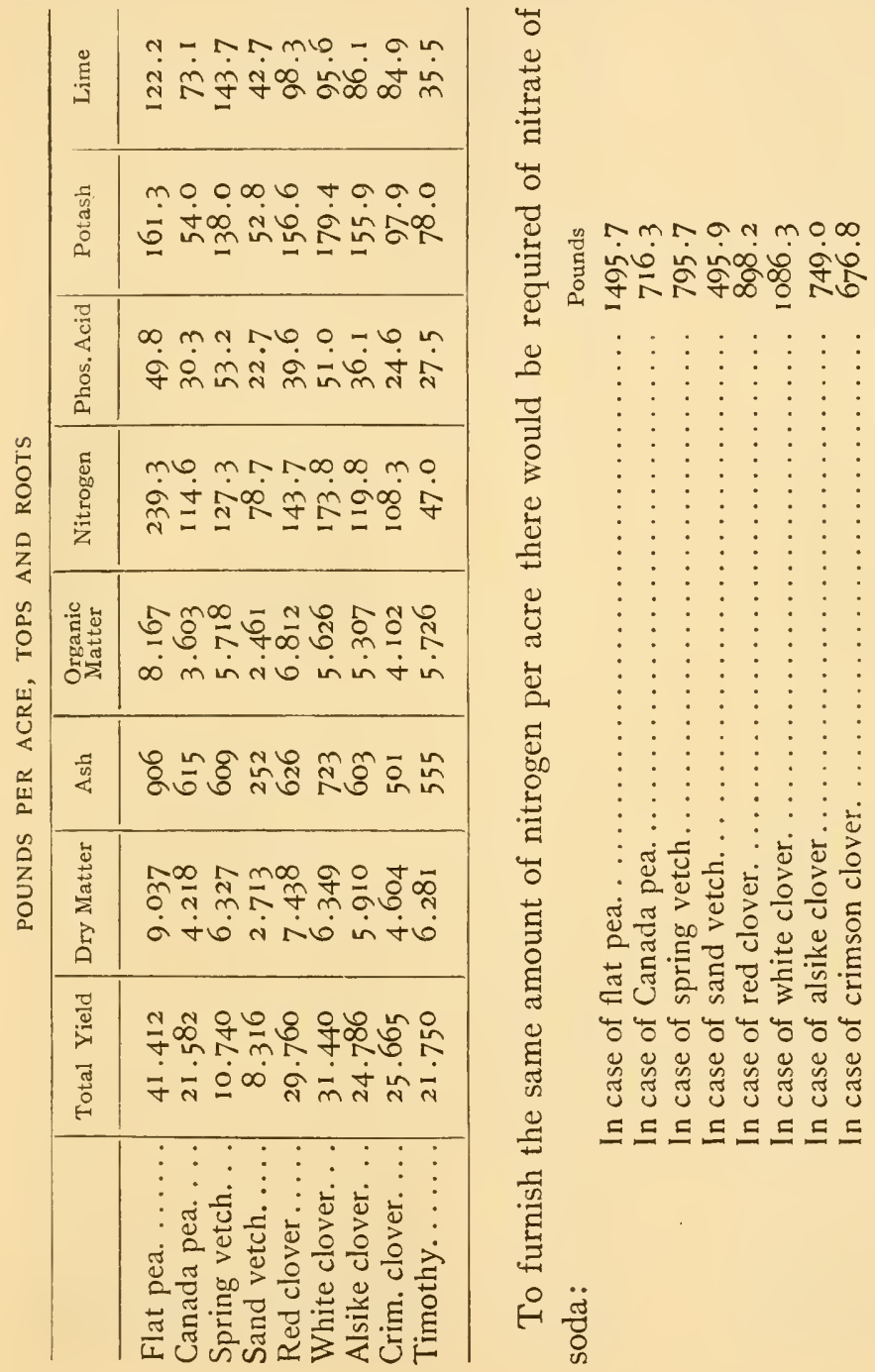




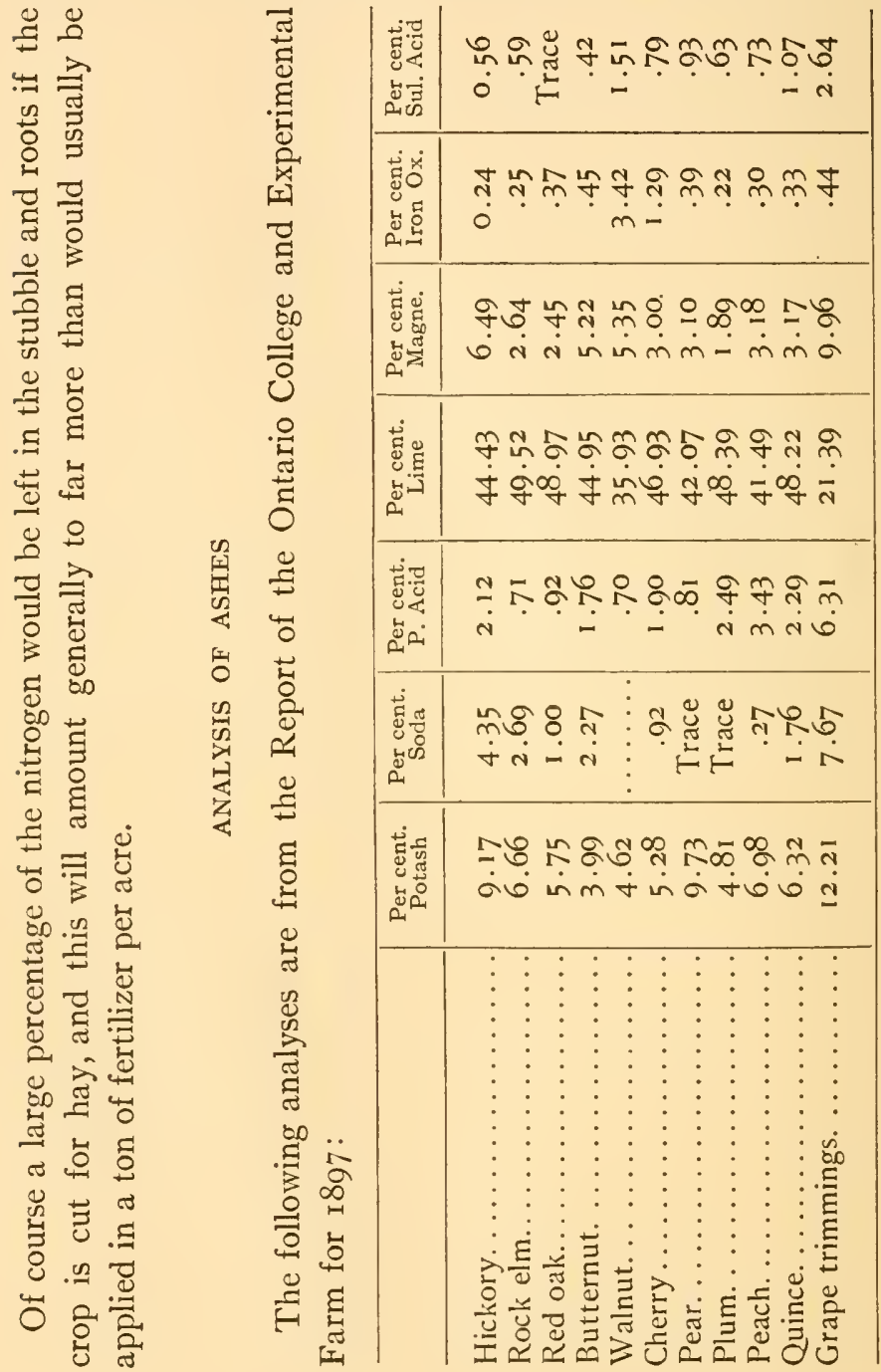




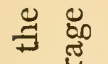
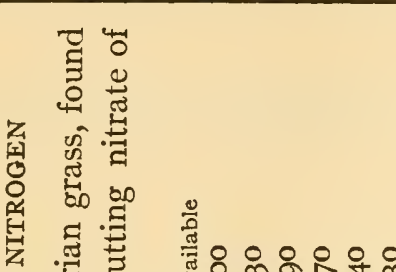

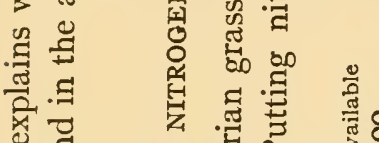

륭

1 0 कू

골

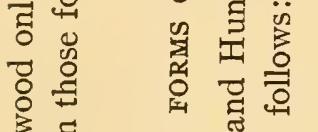

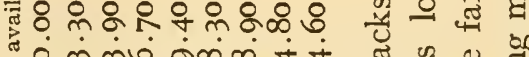

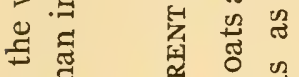

苞

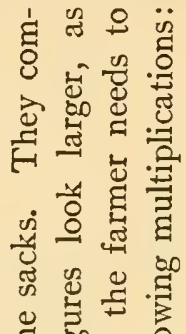

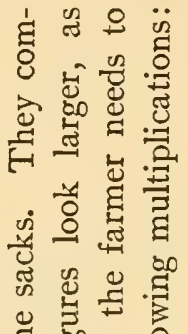

豆

요 है

일 \&

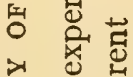

을 获

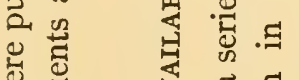

के

造荥

\&

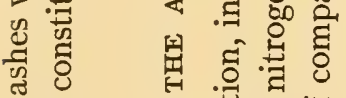

岂 式

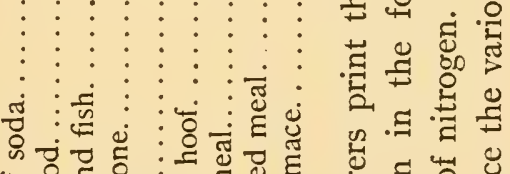

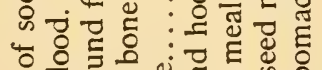

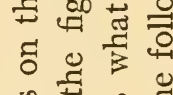

\&

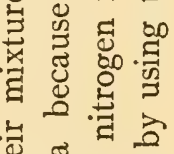

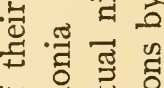

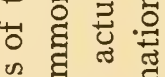

品

范

है

$\frac{\pi}{0}$

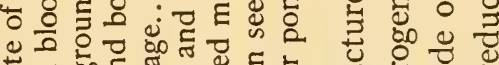

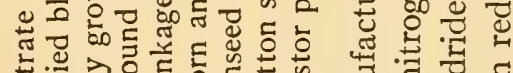

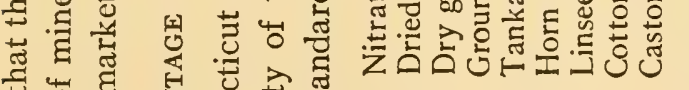

Ð

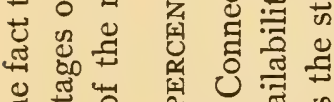

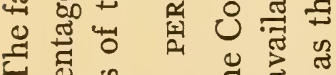

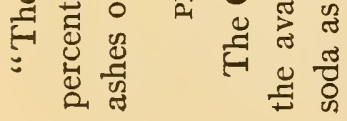

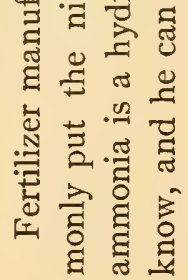


¿্ं

边

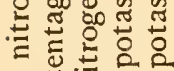

บั

๑

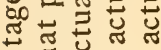

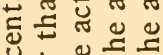

过运至

ญ원

늘

드얄

统

三

$\rightleftarrows \pm$

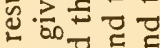

$\equiv$ 을

焉管

च ॠ

ช

m

กิ

- - ป

ก

동 000

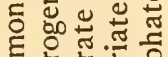

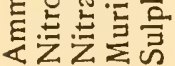

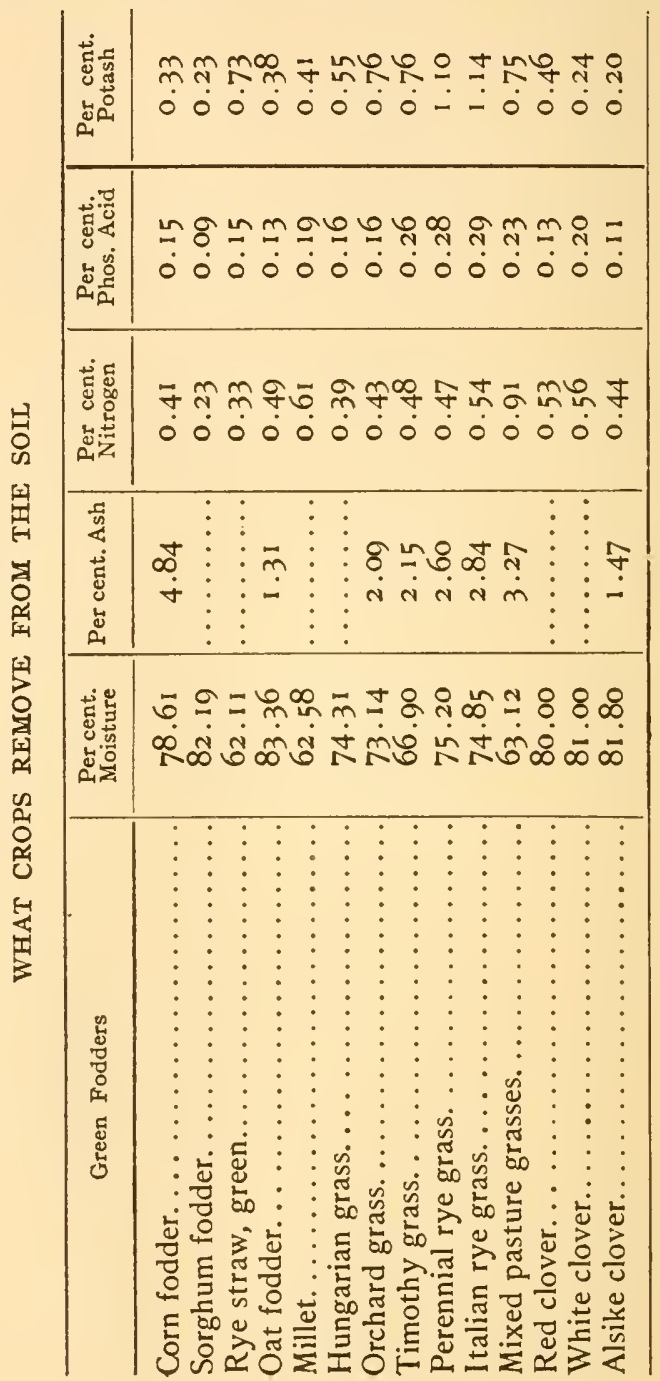


Useful Tables for Constant Reference 309

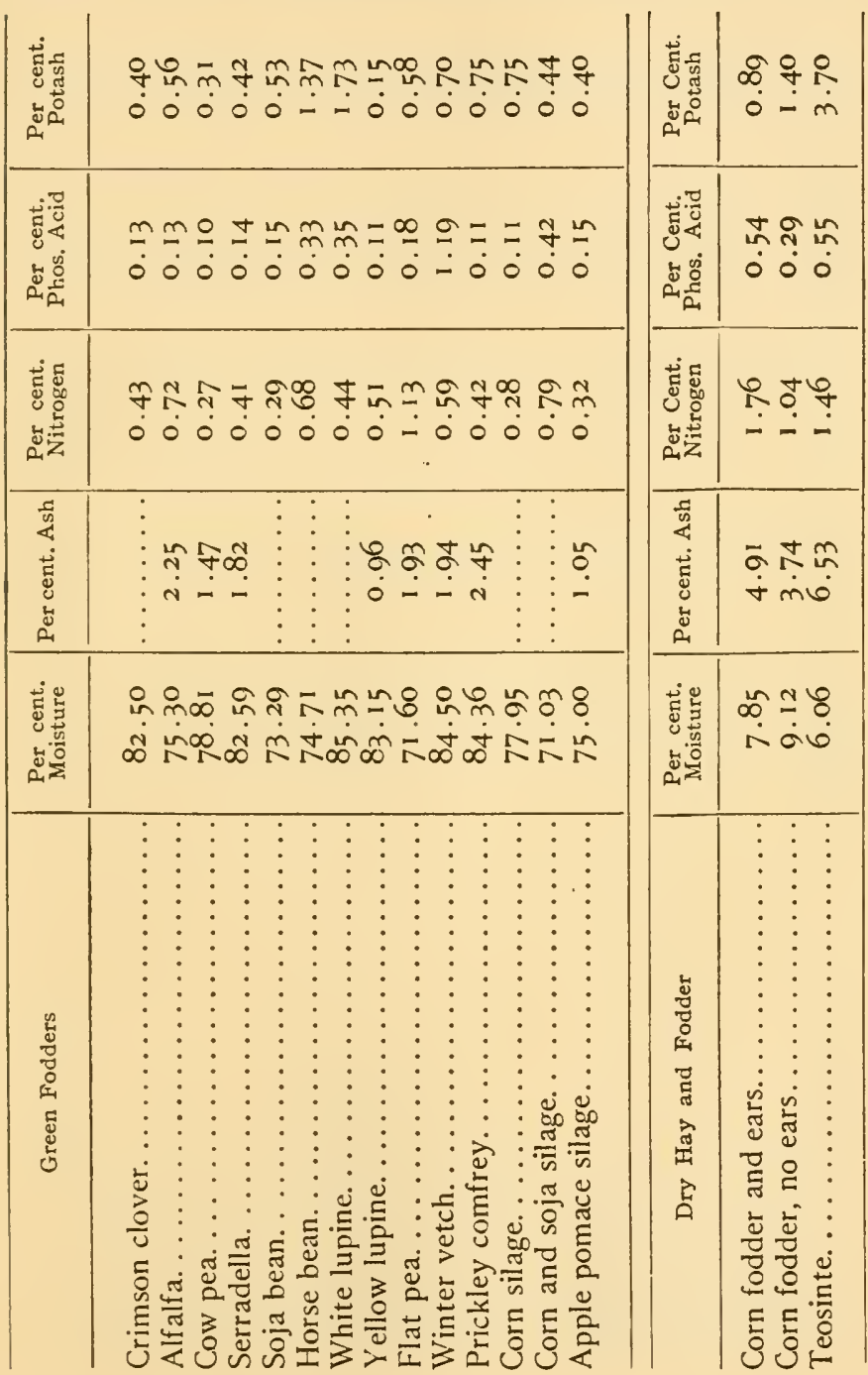




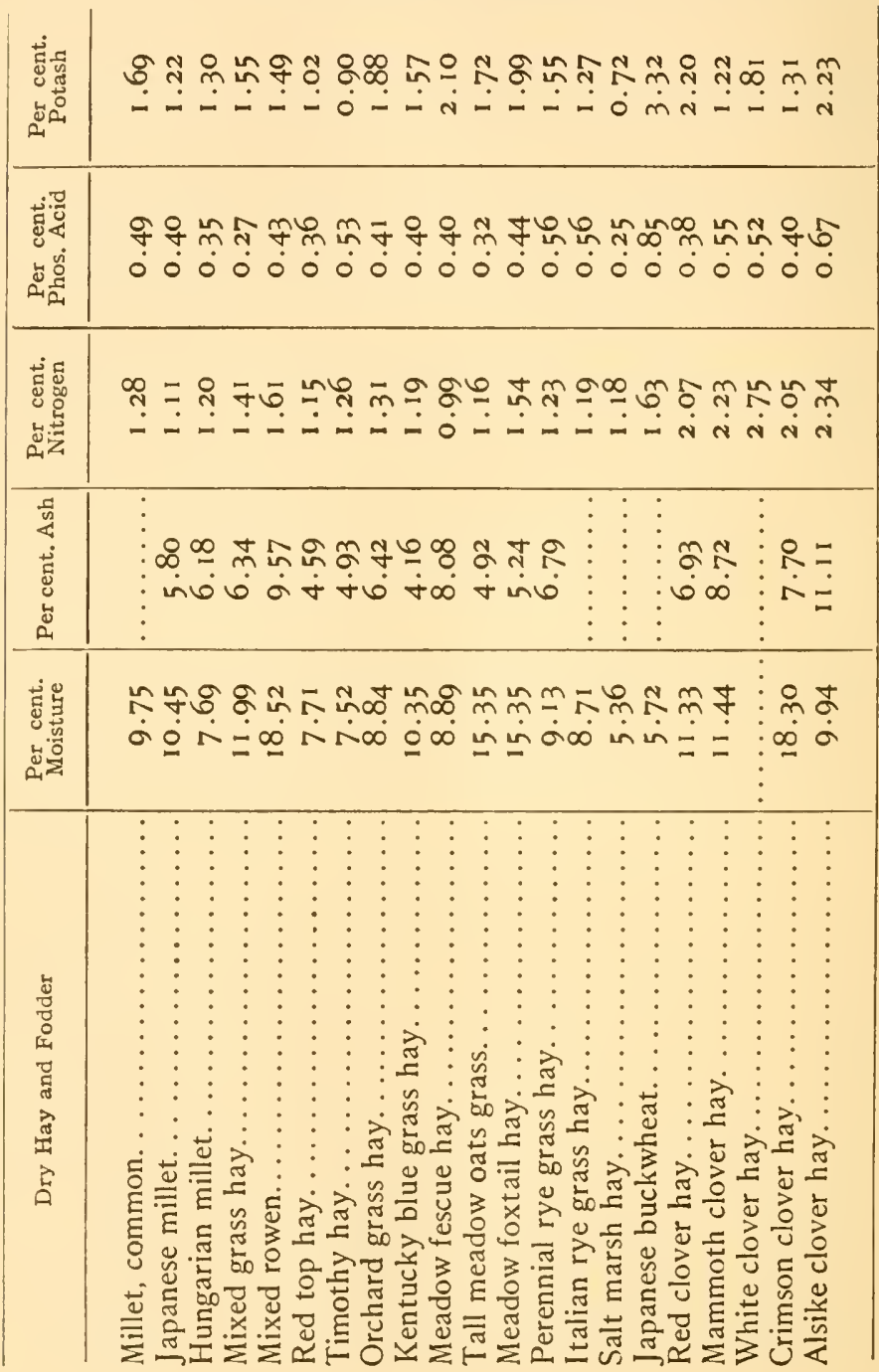




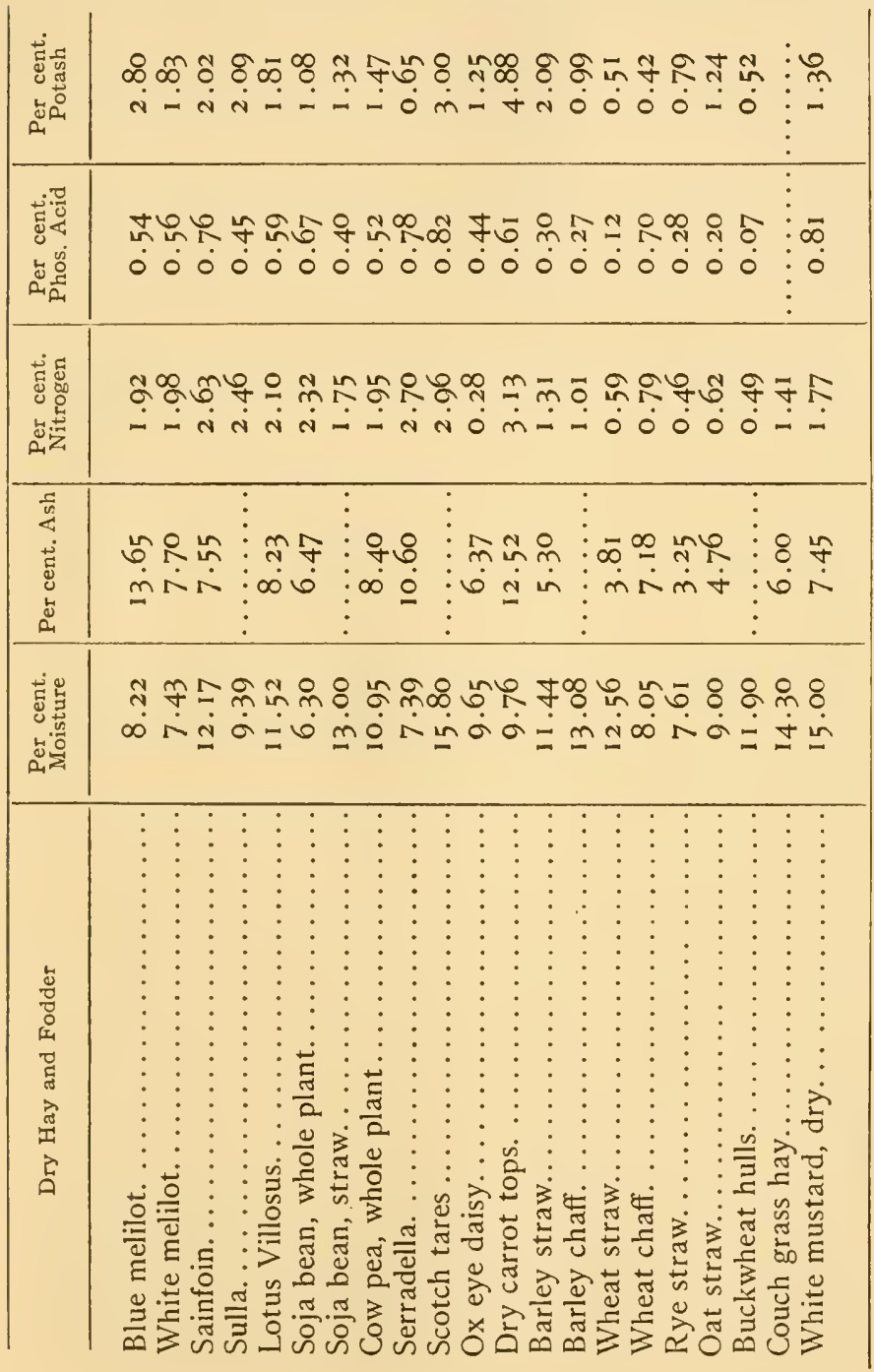




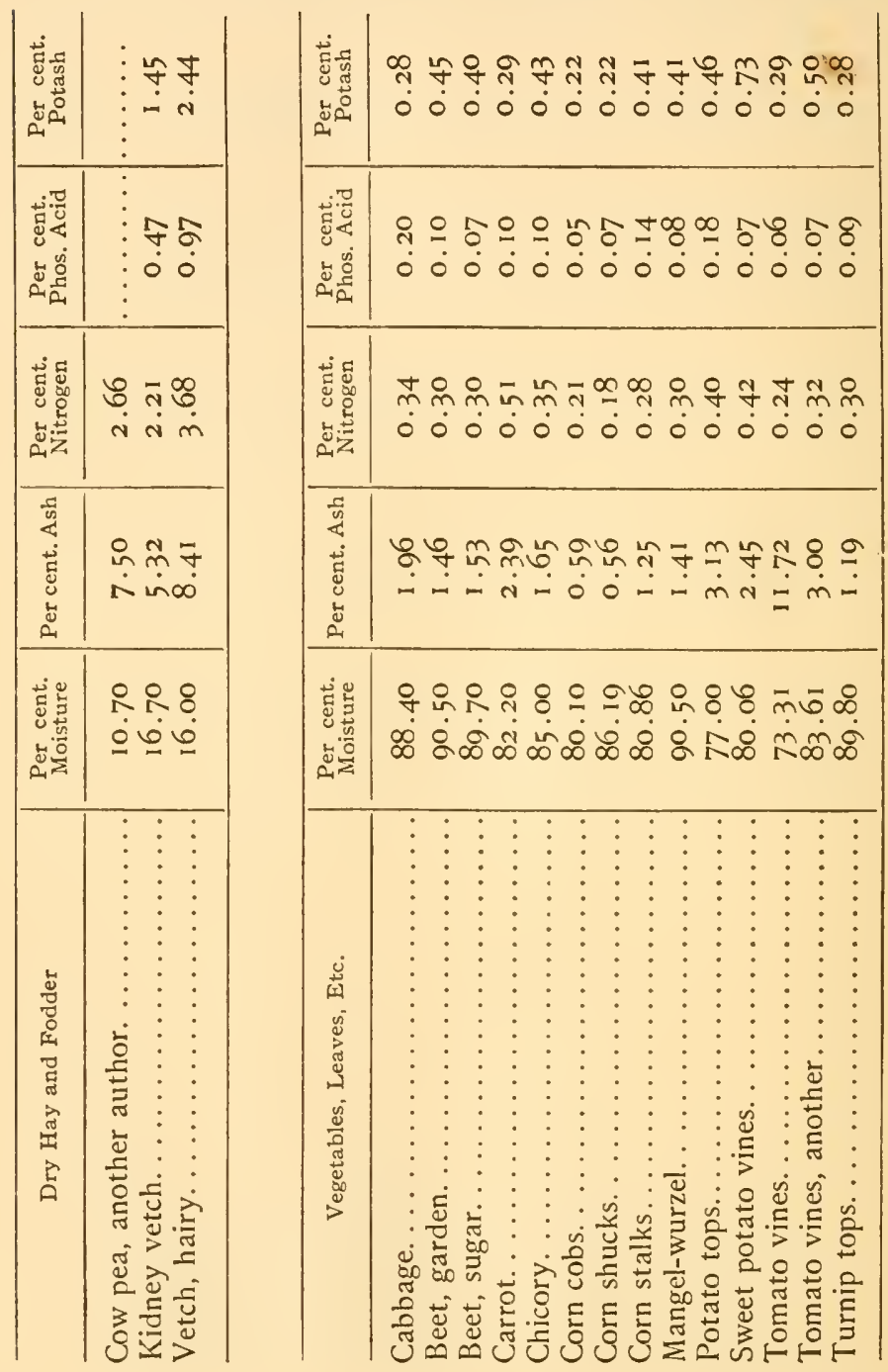




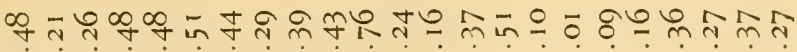

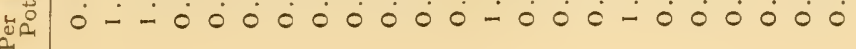

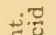

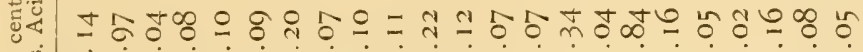

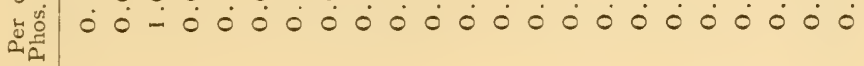

范

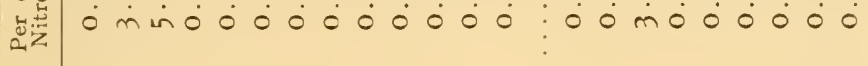
दี 范

片

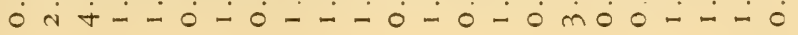
$\stackrel{b}{0}$

8888 온

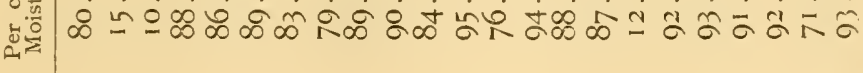




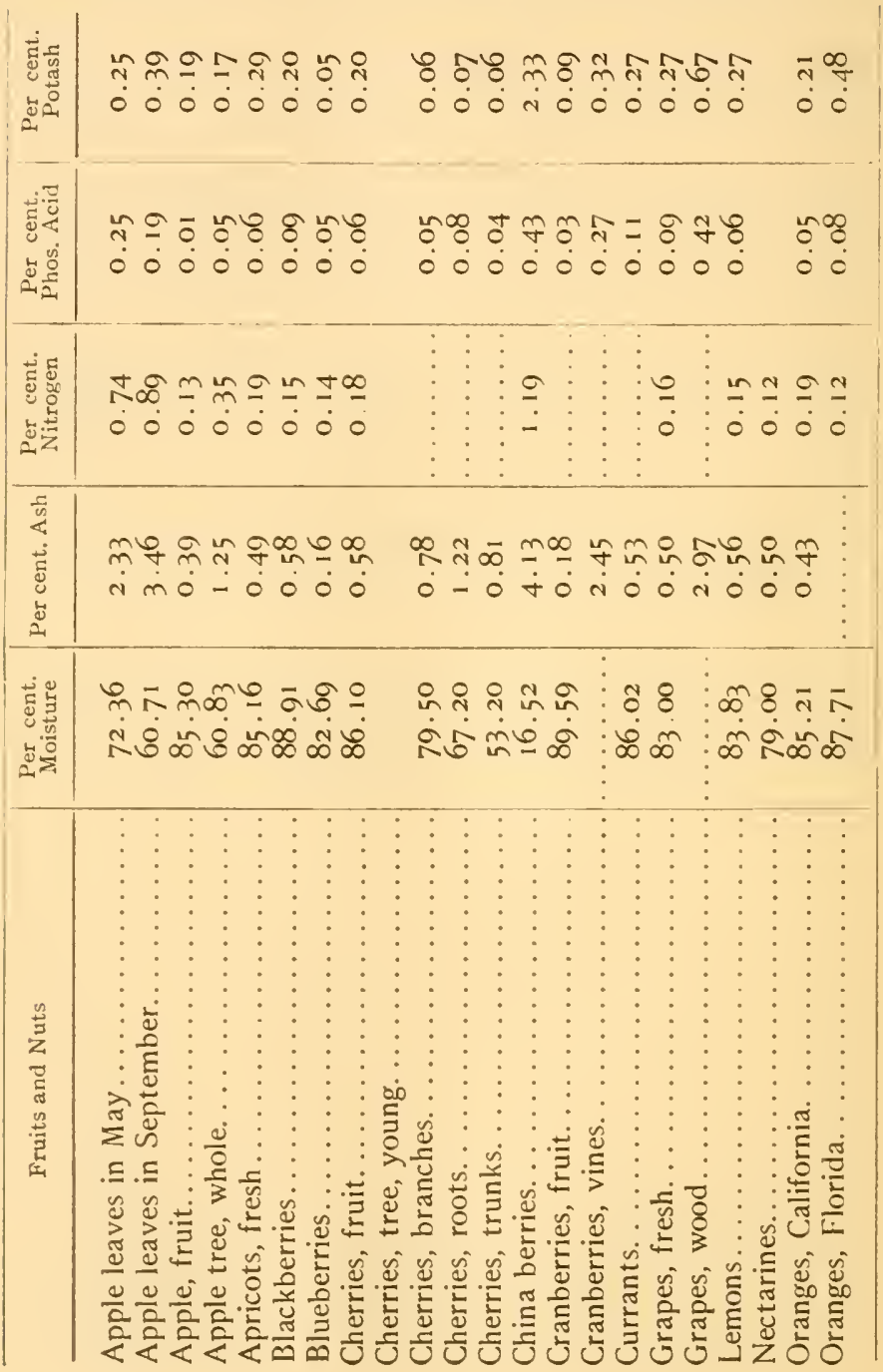




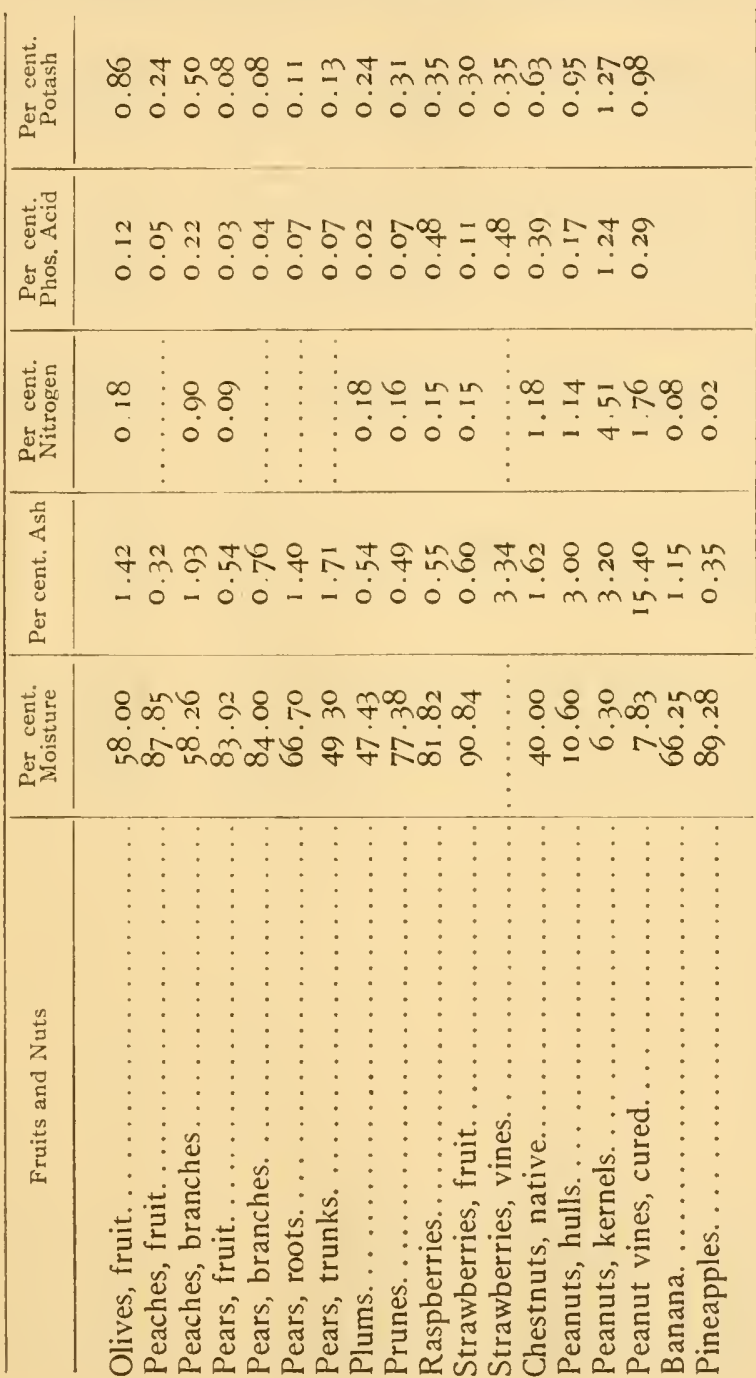




\begin{tabular}{|c|c|c|c|c|c|}
\hline 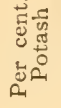 & 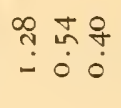 & 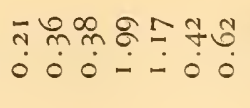 & $\begin{array}{l}\text { mं ज } \\
\dot{0} 0 \\
0\end{array}$ & 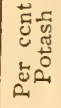 & 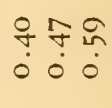 \\
\hline 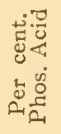 & $\begin{array}{l}\text { mळ } \\
\dot{0} 0 \\
0\end{array}$ & 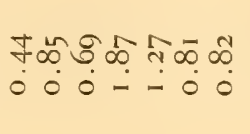 & 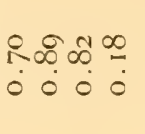 & 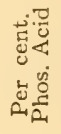 & $\begin{array}{l}\text { min } \\
\dot{0} \dot{0}:\end{array}$ \\
\hline 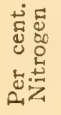 & 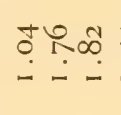 & 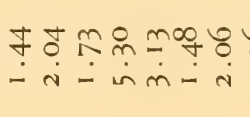 & 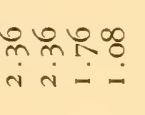 & 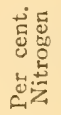 & $\begin{array}{l}\infty=\infty \\
\because=\infty \\
\because--\end{array}$ \\
\hline 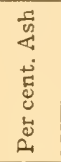 & 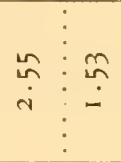 & 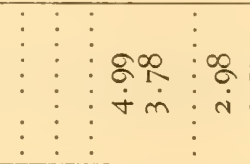 & 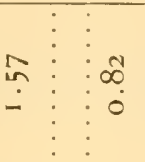 & 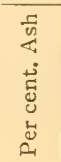 & $\begin{array}{c}: \\
\dot{y}: \\
\dot{m}\end{array}$ \\
\hline 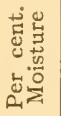 & $\begin{array}{l}8 \infty \\
\text { in }+0\end{array}$ & 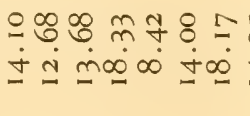 & 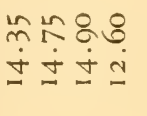 & 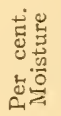 & 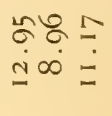 \\
\hline 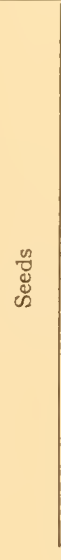 & 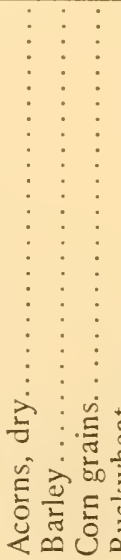 & 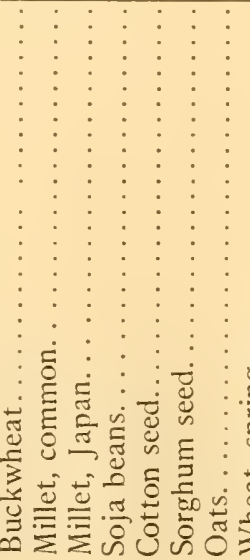 & 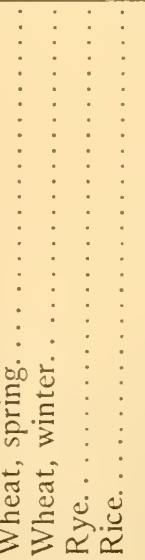 & 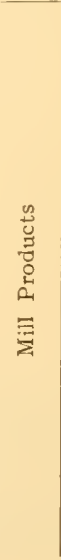 & 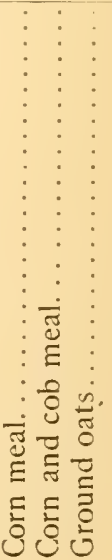 \\
\hline
\end{tabular}




\begin{tabular}{|c|c|c|c|}
\hline 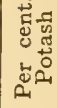 & 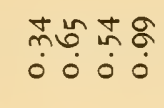 & 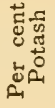 & 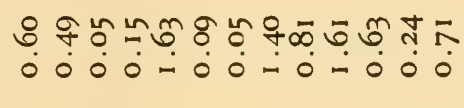 \\
\hline 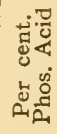 & 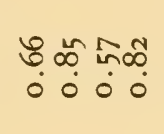 & 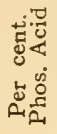 & 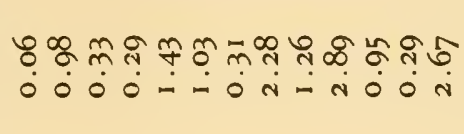 \\
\hline 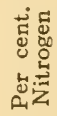 & 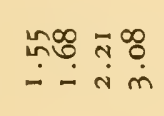 & 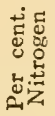 & 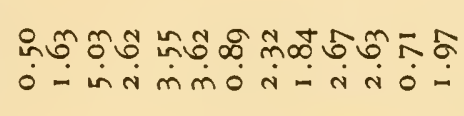 \\
\hline 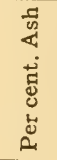 & 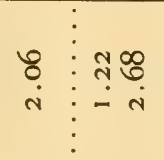 & 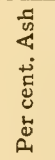 & 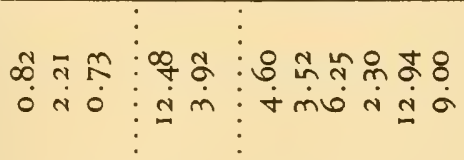 \\
\hline 范总 & 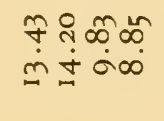 & 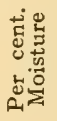 & 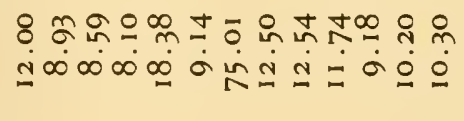 \\
\hline 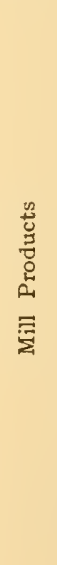 & 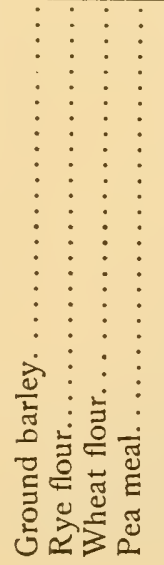 & 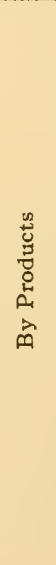 & 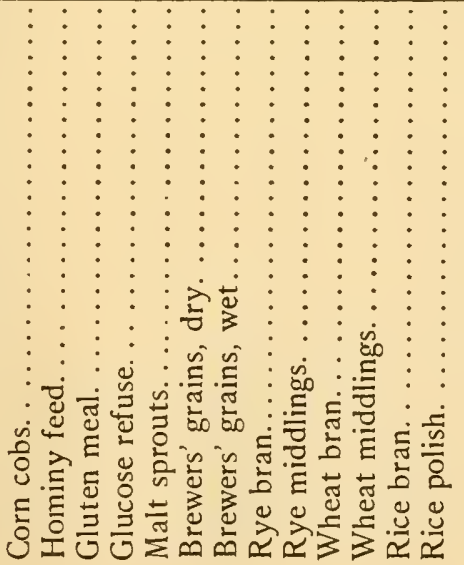 \\
\hline
\end{tabular}




\begin{tabular}{|c|c|}
\hline 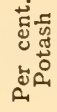 & 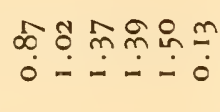 \\
\hline 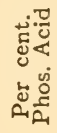 & 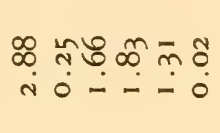 \\
\hline 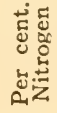 & 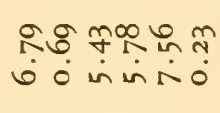 \\
\hline 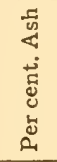 & 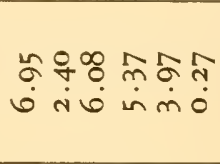 \\
\hline 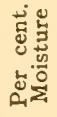 & 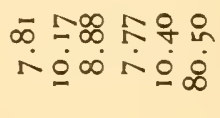 \\
\hline 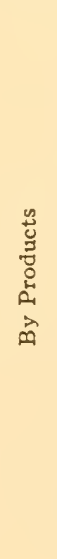 & 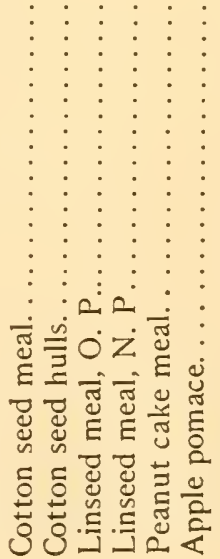 \\
\hline
\end{tabular}

\begin{tabular}{|c|c|c|c|c|}
\hline 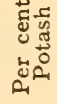 & $\begin{array}{ll}\infty & 0 \\
0 & 0\end{array}$ & $\begin{array}{l}m 0 \\
\dot{0} 0\end{array}$ & $\frac{\infty}{0}$ & $\begin{array}{l}\text { + } \\
0\end{array}$ \\
\hline 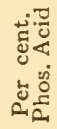 & \begin{tabular}{l}
0 \\
\hdashline \\
0
\end{tabular} & $\stackrel{\operatorname{mn}}{\dddot{0}} \overline{0}$ & \pm & \\
\hline 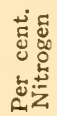 & $\begin{array}{l}\text { mo } \\
\text { in in } \\
\dot{0}\end{array}$ & $\begin{array}{l}\stackrel{0}{+} \stackrel{f}{\square} \\
\dot{0}\end{array}$ & $\frac{1}{0}$ & \\
\hline 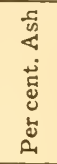 & \begin{tabular}{l} 
mo \\
\hdashline \\
0
\end{tabular} & $\begin{array}{l}0 \\
\text { in } \\
\dot{0}\end{array}$ & & \\
\hline 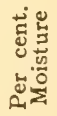 & $\begin{array}{l}\infty \\
8 \\
0\end{array}$ & $\begin{array}{l}\text { un } 0 \\
\dot{0} \\
\dot{1} \\
\dot{8}\end{array}$ & $\begin{array}{l}\text { a } \\
\text { \% }\end{array}$ & $\stackrel{0}{\dot{\sigma}}$ \\
\hline 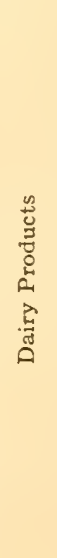 & 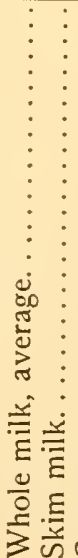 & $\begin{array}{c}\vdots \\
\vdots \\
\vdots \\
\vdots \\
\vdots \\
\vdots \\
\vdots \\
\vdots \\
\vdots \\
\vdots \\
\vdots \\
\vdots \\
\vdots \\
\vdots \\
\vdots \\
\vdots \\
\vdots \\
\vdots \\
\vdots\end{array}$ & $\begin{array}{c} \\
\vdots \\
\vdots \\
\vdots \\
\vdots \\
\vdots \\
\vdots \\
\vdots \\
\vdots \\
\vdots \\
\vdots \\
3 \\
3\end{array}$ & 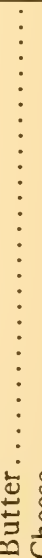 \\
\hline
\end{tabular}




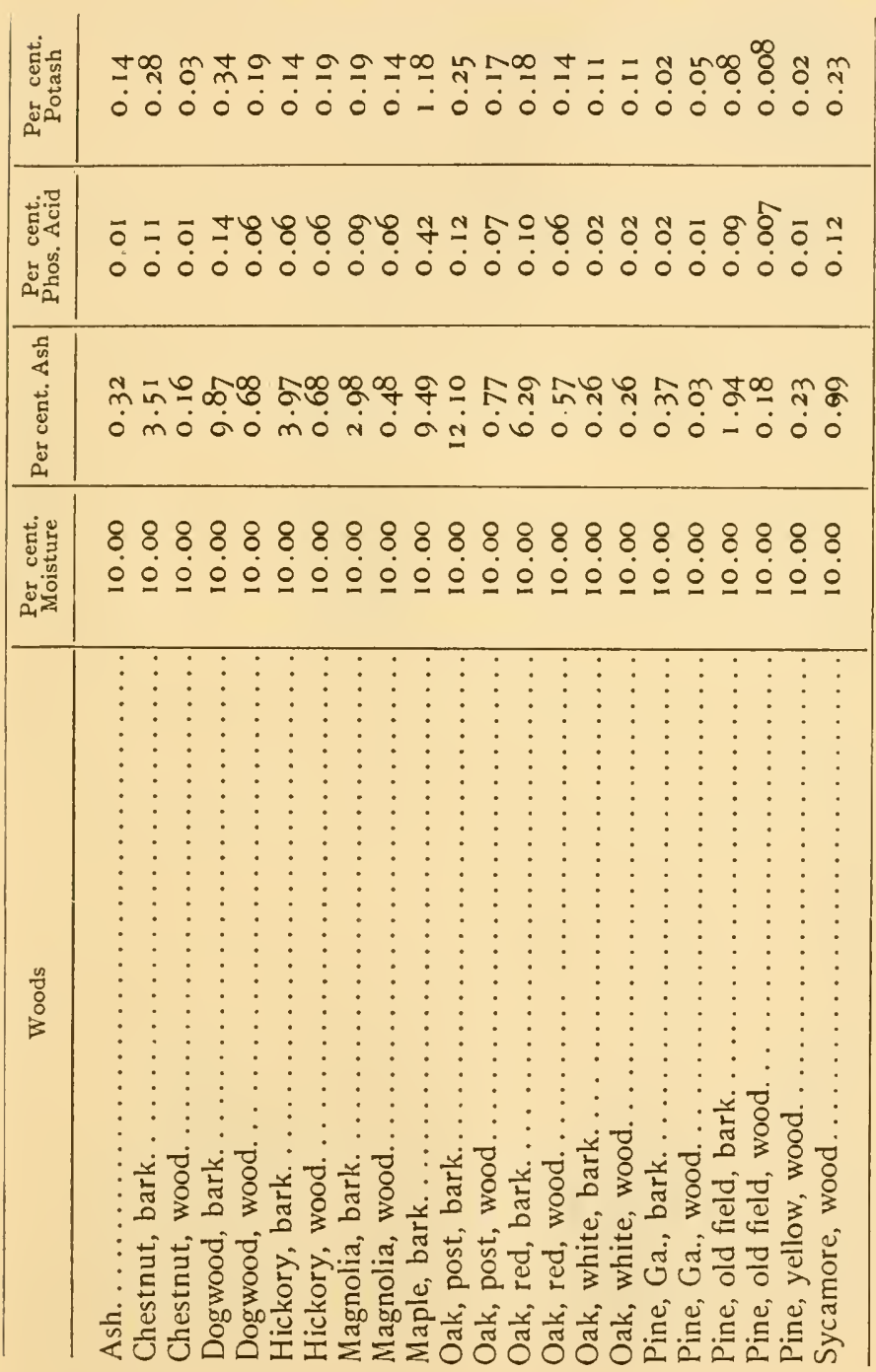




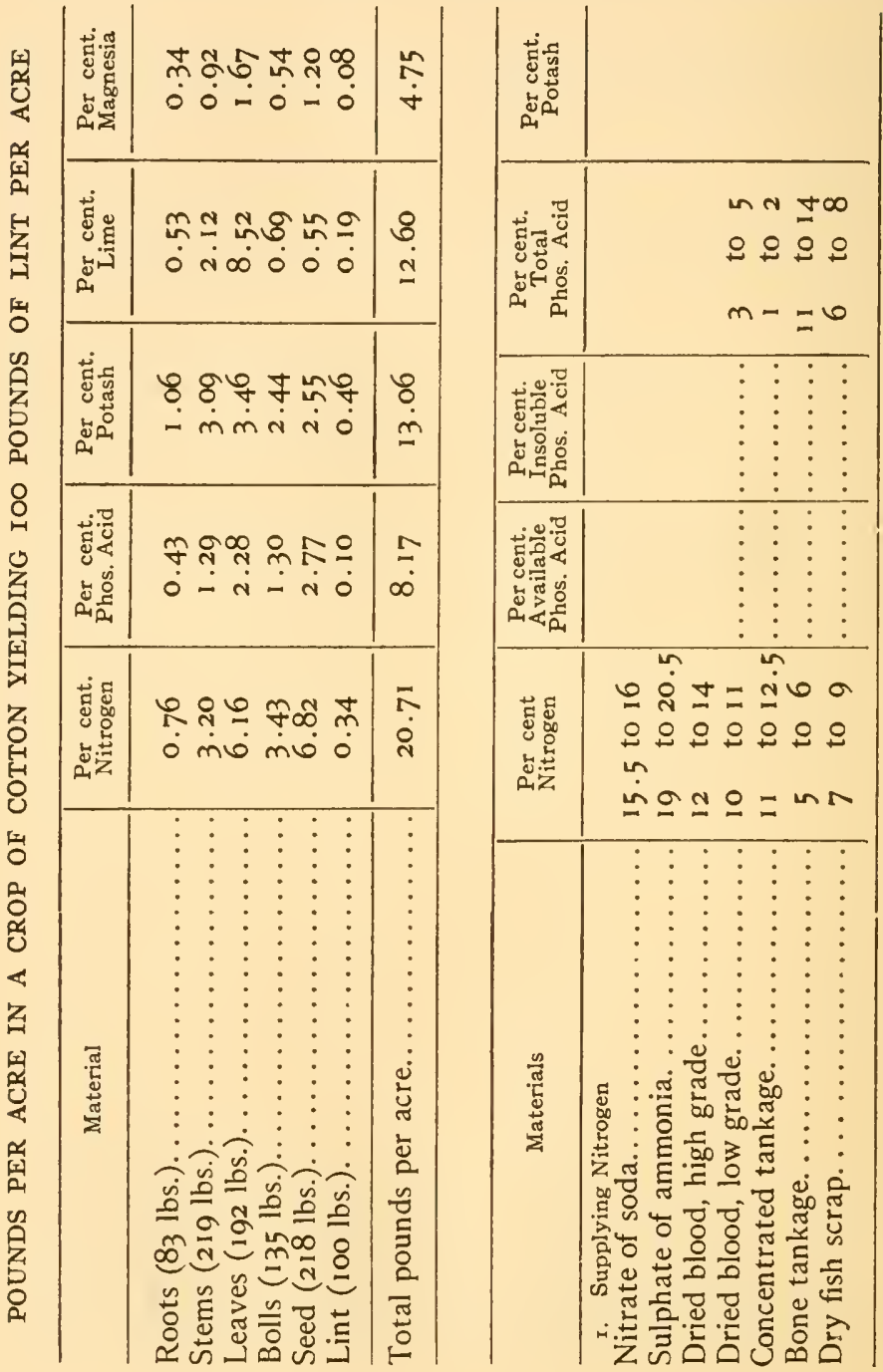




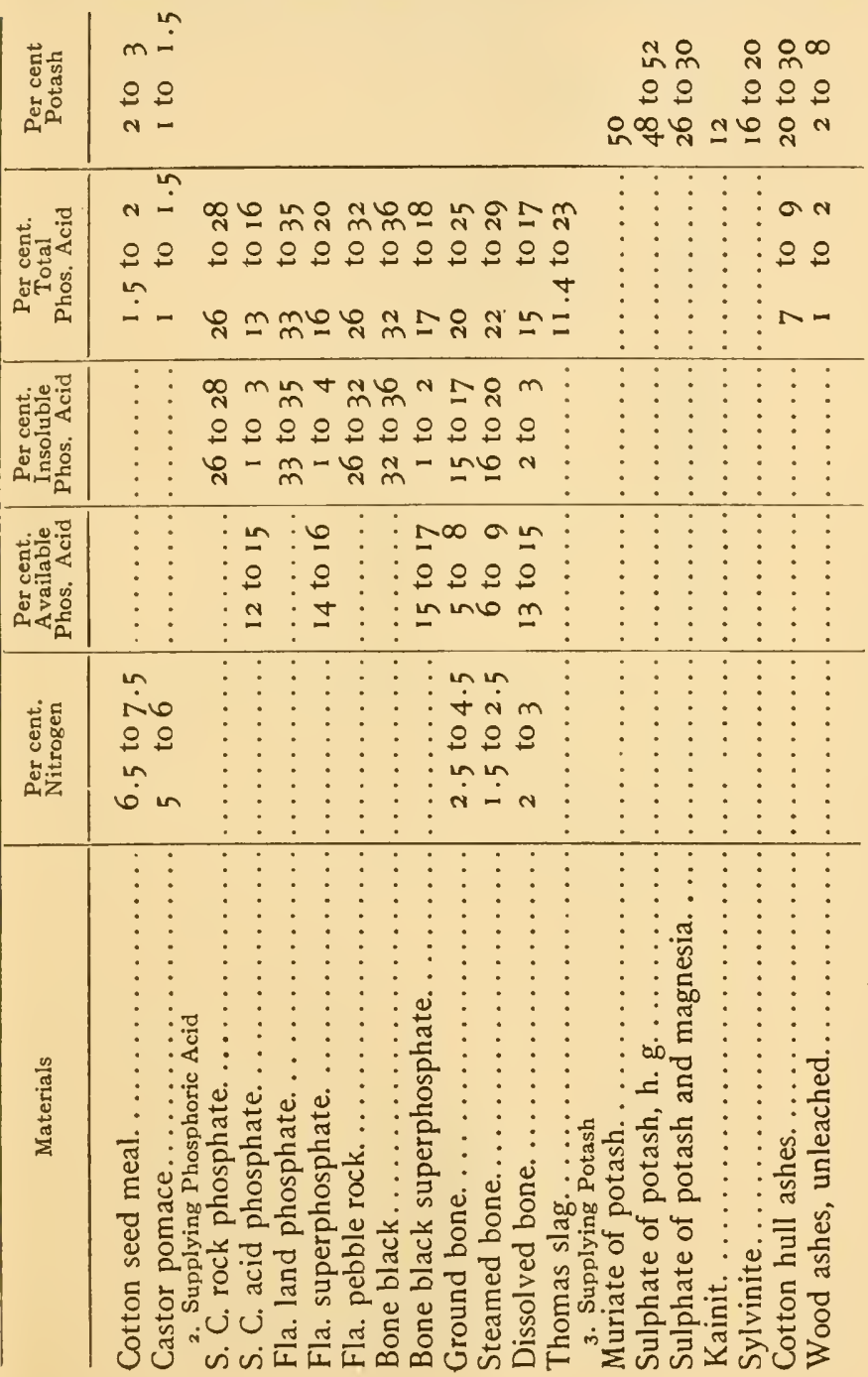




\begin{tabular}{|c|c|c|}
\hline 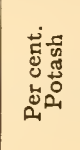 & 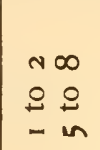 & 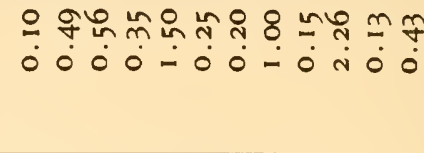 \\
\hline 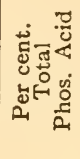 & 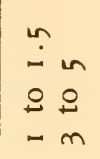 & 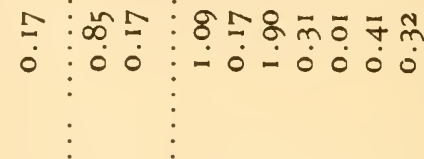 \\
\hline 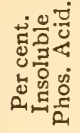 & & 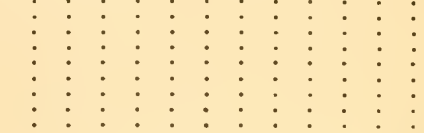 \\
\hline 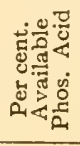 & & 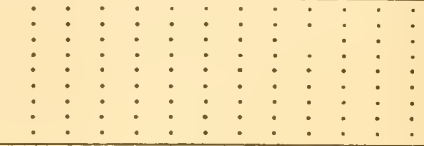 \\
\hline 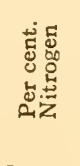 & $\vdots \begin{array}{l}m \\
\vdots \\
\vdots\end{array}$ & 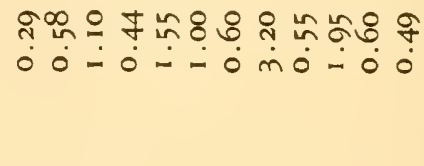 \\
\hline 焉 & 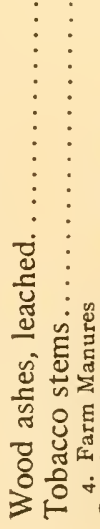 & 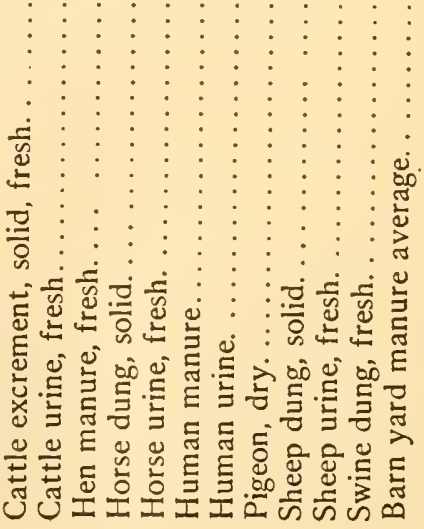 \\
\hline
\end{tabular}




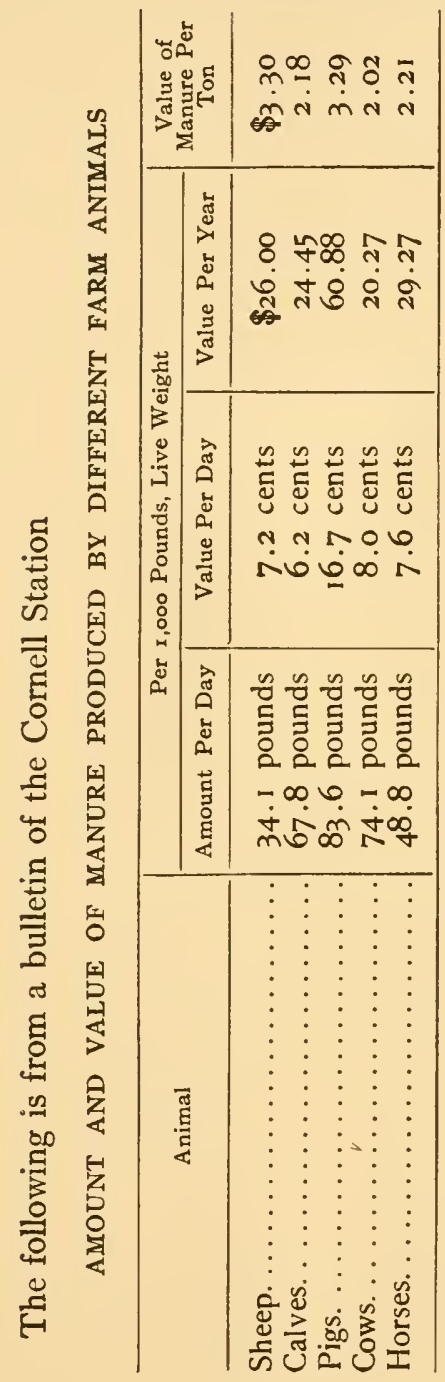




1]5 9 : 



\section{LIBRARY OF CONGRESS}

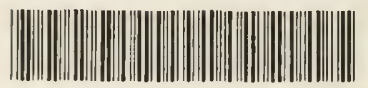

00025862156 